\title{
Decomposition of Tetraphenylborate In Tank 48H
}

by

M. J. Barnes

Westinghouse Savannah River Company

Savannah River Site

Aiken, South Carolina 29808

D. D. Walker

S. D. Fink

C. L. Crawford

R. S. Swingle

R. A. Peterson

M. S. Hay

DOE Contract No. DE-AC09-89SR18035

This paper was prepared in connection with work done under the above contract number with the U.S.

Department of Energy. By acceptance of this paper, the publisher and/or recipient acknowledges the U.S. Government's right to retain a nonexclusive, royalty-free license in and to any copyright covering this paper, along with the right to reproduce and to authorize others to reproduce all or part of the copyrighted paper.

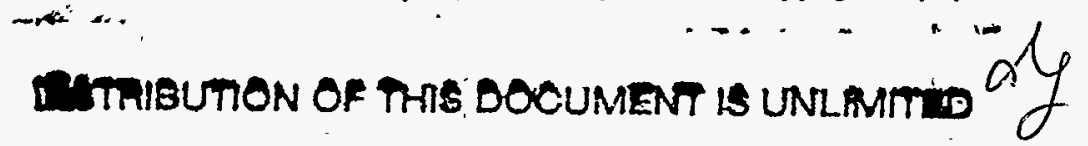




\section{DISCLAIMER}

Portions of this document may be illegible electronic image products. Images are produced from the best available original document. 


\section{DISCLAIMER}

This report was prepared as an account of work sponsored by an agency of the United States Government. Neither the United States Government nor any agency thereof, nor any of their employees, makes any warranty, express or implied, or assumes any legal liability or responsibility for the accuracy, completeness, or usefulness of any information, apparatus, product, or process disclosed, or represents that its use would not infringe privately owned rights. Reference herein to any specific commercial product, process, or service by trade name, trademark, manufacturer, or otherwise does not necessarily constitute or imply its endorsement, recommendation, or favoring by the United States Government or any agency thereof. The views and opinions of authors expressed herein do not necessarily state or reflect those of the United States Government or any agency thereof.

This report has been reproduced directly from the best available copy.

Available to DOE and DOE contractors from the Office of Scientific. and Technical Information, P.O. Box 62, Oak Ridge, TN 37831; prices available from (615) 576-8401.

Available to the public from the National Technical Information Service, U.S. Department of Commerce, 5285 Port Royal Road, Springfield, VA 22161. 
WESTINGHOUSE SAVANNAH RIVER COMPANY SAVANNAH RIVER TECHNOLOGY CENTER
WSRC-TR-96-0113

Rev. 0

Keywords: In-tank precipitation, Tetraphenylborates, Benzene

Retention time: permanent May 10, 1996

TO: W. L. Tamosaitis, 77.3-A

FROM: D. D. Walker, 773-A

M. J. Barnes, 773-A

C. I. Crawford, 773-41A

R. S. Swingle, 773-A

R. A. Peterson, 676-T

M. S. Hay, 773-A

S. D. Fink, 773-A

\section{DECOMPOSITION OF TETRAPHENYLBORATE IN TANR $48 \mathrm{H}$ (U)}

Authors
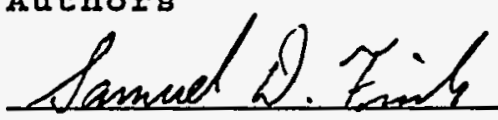

S. D. Fink, Level 4 Manager,

Interim Waste Technology Section

\begin{tabular}{ll} 
Mldsan For DD. Walker & $5 / 10 / 96$ \\
\hline D. W. Walker, Interim Waste Technology Section & bate
\end{tabular}

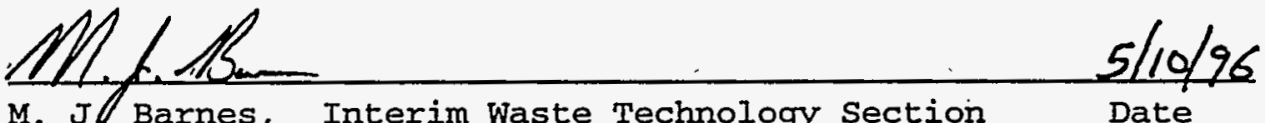

M. J Barnes, Interim Waste Technology Section Date

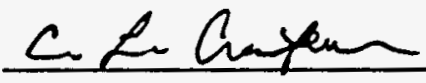

$5 / 10 / 96$

c. L. Crawford, Interim Waste Technology Section Date

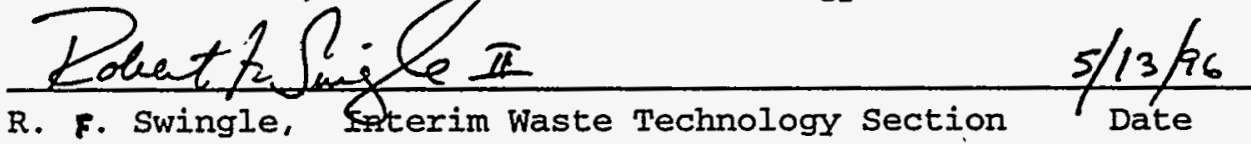

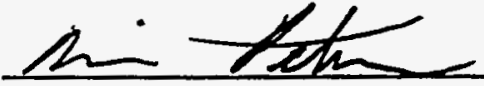

$5 / 10 / 96$

R. A. Potefson, Interim Waste Technology Section Date

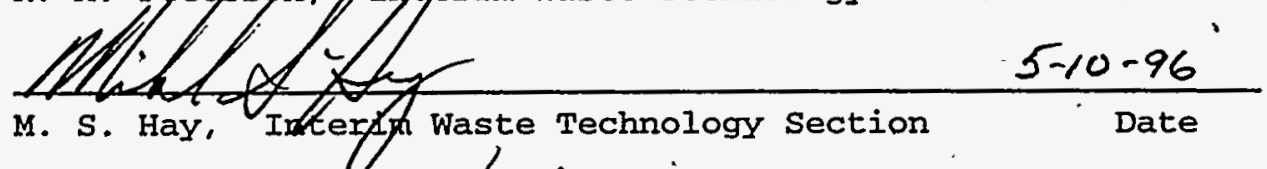

M. S. Hay, Intery waste Technology Section Date

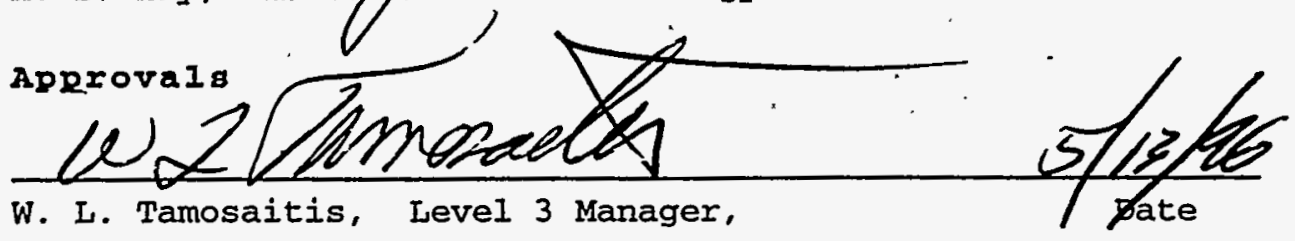

Interim Waste Technology Section 


\section{CONTENTS}

I. Executive Summary

II. Introduction

III. Experimental.

Logic Flowchart

Analysis of Benzene in Tank $48 \mathrm{H}$ Slurry Samples

Hexane Extraction of Tank $48 \mathrm{H}$ slurry samples

NaTPB Decomposition Tests

Isolation of Tanl 48H Insoluble, Inorganic Solids in ITP

slurry samples.

Monosodium Titanate simulant

IV. Results and Discussion

Tank $48 \pi$ Data and Information

Tank $48 \mathrm{H}$ Operation

Excess NaTPB in Tank $48 \mathrm{H}$

Decomposition of NaTPB and Benzene Generation in Tank 48H 12

Tank 48H Sample Results

Tank 48H Material Balance and Reaction Stoichiometry

NaTPB Cold Feeds

Kinetics of Copper-Catalyzed NaTPB Decomposition

NaTPB Decomposition Catalysts

Copper

Potential Catalysts

Non-Radioactive Simulant Slurry Recipe

Characterization of Tank 48H Insoluble Solids

Experimental Tests

Ventilated Radioactive Tests

Summary of Radioactive Tests

Ventilated Non-Radioactive Tests

Non-Ventilated, Non-Radioactive (Bottle) Tests

Series A Test

NaTPB Solution Test

Series 1 Sealed Stainless-Steel Bottle Tests. 51

Follow-up Bottle Test

Series 2 Sealed Stainless-steel Bottle Tests 55

NaTPB Decomposition Reaction Intermediates and Products_ 58

Solubility of Boron-Containing Intermediates

Reaction of Phenylboron Compounds

Benzene Generation in Tank 50H

v. Mechanistic Implications

Mechanistic Reaction Schemes Involving Alkaline

Decomposition of Tetraphenylborate Anion (TPB') in Presence of Soluble and/or solid Catalysis species

VI. Potential High Level Waste System Effects

Tank 50H and Saltstone 
W. L. Tamosaitis

CONTENTS (continued)

VII. Recommendations for Further Testing 69

VIII. Quality Assurance

IX. Acknowledgments

$\mathrm{x}$. References

\begin{tabular}{|c|c|}
\hline 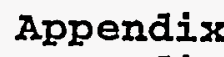 & \\
\hline Appendix & 2 \\
\hline Appendix & \\
\hline Appendix & 2 \\
\hline Appendix & \\
\hline Appendix & \\
\hline Appendix & \\
\hline Appendix & \\
\hline Appendix & \\
\hline Appendix & \\
\hline Appena & \\
\hline Append & \\
\hline Appeno & \\
\hline Appendix & \\
\hline Append & \\
\hline Appen & \\
\hline Appeno & \\
\hline Appen & \\
\hline Append & \\
\hline Append & \\
\hline Append & \\
\hline Append & \\
\hline Appe & \\
\hline & \\
\hline
\end{tabular}




\section{IIST OF FIGURES}

Figure 1. Schematic describing the elements of research program supporting In-Tank Precipitation.

Figure 2. Logic diagram for studies of chemical generation of benzene.

Figure 3. Tank 48H Temperature Profile for August 1995 through April 1996. 11

Figure 4. Tank 48H Oxygen Profile for August 1995 through April 1996.

Figure 5. Estimates of Benzene Generation Rates for Tank 48H 13

Figure 6. Tank 48H soluble boron, potassium, and cesium concentrations.

Figure 7. Molar ratio of potassium and cesium to boron in Tank 48H filtrate.

Figure 8. Tank 48H soluble boron, hydroxide, and organics

Figure 9. Molar ratio (soluble) of hydroxide and organics to boron

Figure 9. Molar ratio (soluble) of hydroxide and organics to boron in Tank $48 \mathrm{H}$.

Figure 10. A kinetics plot of In $\mathrm{K}$ vs $1 / \mathrm{T}$ for the copper-catalyzed decomposition of NaTPB.

dre 11. Copper solubility as a function of hydroxide concentration and waste type. [Ref. 13]

Figure 12. Benzene generation rate as a function of time for Tank $48 \mathrm{H}$ filtrate.

ure 13. Benzene generation rate for Tank 48H filtrate containing

0.2 wt 8 Tank $51 \mathrm{H}$ sludge and oven-dried AFF NaTPB. 26

Figure 14. Benzene generation rate for Tank $48 \mathrm{H}$ filtrate in the. presence of $0.51 \mathrm{wt} \%$ Tank $48 \mathrm{H}$ sludge and MST solids and containing oven-dried AFF NaTPB.

Figure 15. Benzene generation rate for Tank 48H filtrate containing oven-dried AFF NaTPB and simulated MST solids.

Figure 16. Benzene generation rate for Tank 50H filtrate (diluted to simulate Tank $48 \mathrm{H}$ filtrate) containing oven-dried AFF NaTPB. 37

Figure 17. Benzene generation rate for Tank $48 \mathrm{H}$ filtrate containing 0.1 wt o Tank $51 \mathrm{H}$ sludge and oven-dried AFF NaTPB.

Figure 18. Benzene generation rate for Tank 48H filtrate containing
0.2 . wt 8 Tank $51 \mathrm{H}$ sludge and untreated reagent grade NaTPB. 39

Figure 19. Benzene generation rate for Tank $48 \mathrm{H}$ filtrate containing untreated reagent grade NaTPB and 0.25 wt $\%$ Tank $48 \mathrm{H}$ sludge and MST.

Figure 20 . Benzene generation rate for Tank $48 \mathrm{H}$ filtrate containing untreated Boulder Scientific Company NaTPB powder and 0.2 wt 8 Tank $51 \mathrm{H}$ sludge.

Figure 21. Benzene generation rate for the air ventilated nonradioactive test with reagent grade NaTPB solution.

Figure 22. Benzene generation rate for nitrogen ventilated nonradioactive test with reagent grade NaTPB solution.

Figure 23. Boron results for Series A tests.

Figure 24. Phenylboric acid results for Series A tests._- 50

Figure 25. Phenol results for Series A tests.

Figure 26. Concentrations of products from thermal stainless steel bottle tests. 


\section{IIST OF FIGURES (continued)}

Figure 27. Concentrations of products from thermal and irradiated stainless steel bottle tests. 54

Figure 28. Benzene generation from sealed stainless-steel bottle tests using different vendor supplies of NaTPB.

Figure 29. Phenol generation from sealed stainless-steel bottle tests using different vendor supplies of NaTPB.

Figure 30. Phenylboric acid generation from sealed stainless-steel bottle tests using different vendor supplies of NaTPB. 59

Figure 31. Tetraphenylborate consumption in sealed stainless-steel bottle tests using different vendor supplies of NaTPB.

Figure 32. KTPB solubility as a function of sodium concentration. [Ref. 27]

Figure 33. Late Wash allowable storage times (without NaTPB additions).

Figure 34. Late Wash allowable storage times las a function of NaTPB additions).

\section{IIST OF TABLES}

Table 1. Advances in undérstanding causes and implications of unexpected tetraphenylborate decomposition. 6

Table 2. Tank $48 \mathrm{H}$ filtrate analyses. 14

Table 3. Tank 48H Organics Mass Balance. 17

Table 4. Production of Organic Species from Destruction of Tetraphenylborate.

Table 5. Sodium tetraphenylborate solution analyses for those batches of material added to Tank $48 \mathrm{H}$.

Table 6. Organic analyses from prepared solutions of Boulder

Scientific Company NaTPB powder.

Table 7. Potential Tank 48H copper contaminant sources.__ 25

Table 8. Summary Table of Postulated Catalysts._ 27

Table 9. Non-radioactive precipitate slurry simulant.__ 28

Table 10. Composition of insoluble solids in Tank 48H from July 1995 through March 1996.

Table 11. Insoluble solids composition in Tank 48H from July 1995 through March 1996.

Table 12. Characterization of Tank $48 \mathrm{H}$ and Tank $51 \mathrm{H}$ sludge compositions.

Table 13. Summary of Benzene Generation Rates for Radioactive Tests. 42

Table 14. Percent change in the benzene generation rate as a result of changes in temperature and ventilation gas.

Table 15. Analytical data from the air ventilated decomposition of NaTPB solution in the presence on $10 \mathrm{mg} / \mathrm{L}$ copper.

Table 16. Analytical data from the nitrogen ventilated decomposition of NaTPB solution in the presence of $10 \mathrm{mg} / \mathrm{L}$ copper. _ 46

Table 17. Series A Test Matrix.

Table 18. Results of NaTPB Solution Bottle Test. 51

Table 19. Tank 43H batch \#1 Aquafine tetraphenylborate simulant slurry.

Table 20. Results of Follow-up Bottle Test.

Table 21. Composition of AFF and Boulder Scientific Tank 48H simulant slurries. 
W. I. Tamosaitis

WSRC-TR-96-0113, Rev. 0

\section{IIST OF TABLES (continued)}

Table 22. Decomposition of Phenylboron compounds in salt solution at $70{ }^{\circ} \mathrm{C}$. 


\section{Executive Summary}

This report provides a qualitative and semiquantitative description of the chemical reaction that decomposed the excess sodium tetraphenylborate in Tank 48H during November and December 1995. A discussion of potential reaction mechanisms and implications to downstream processes are also included. This data supports development of a global model of the chemical and physical phenomena occurring in both the vapor and condensed phases in Tank 48H. It provides bounding quantities of benzene that can form in Tank $48 \mathrm{H}$ and provides insight into likely reaction rates. Descriptions of the physical phenomena occurring in Tank 48H (mixing, mass transfer, and adsorption) are not included. Further testing is underway to determine quantitative kinetic rate expressions for the significant benzene production mechanisms.

A rapid reaction which decomposed the excess sodium tetraphenylborate (NaTPB) in Tank 48H occurred in November and December 1995. After consuming all of the excess NaTPB, the reaction subsided and appears to have stopped. The current rate of decomposition of the potassium and cesium tetraphenylborate solids is within the expected range from previous tests. Salient points about the reaction follow.

- Benzene is the major product of the decomposition. Phenol and biphenyl are minor products, and phenylboric acid is a semistable intermediate.

- The stoichiometry deperids strongly on the availability of oxygen, the presence of which increases the yields of the minor products. In Tank 48H, $77 \%$ of the phenyl grcups on the decomposed NaTPB formed benzene, 6\% formed phenylboronic acid, $4.5 \%$ formed phenol, $4 \%$ formed biphenyl, and $8.5 \%$ are unaccounted for.

- The average rate of benzene generation in Tank $48 \mathrm{H}$ during the rapid decomposition reaction was between 12,500 and 25,000 $\mu \mathrm{g} / \mathrm{L} / \mathrm{hr}$. This was at least 1000 times faster than the current generation rate in the absence of excess.

- The reaction consumed all of the available sodium tetraphenylborate solids in the tank, but no significant amount of insoluble potassium and cesium tetraphenylborate.

- Laboratory tests with simulated waste have produced rapid decomposition of NaTPB similar to Tank $48 \mathrm{H}$ in stoichiometry, rate, and extent of reaction.

- Laboratory testing has demonstrated that copper ion and sludge solids increase the rate of decomposition of tetraphenylborate slurries. Additional tests in progress continue to examine the influence of other components. 
- The presence or absence of oxygen changes the decomposition mechanism. At $70^{\circ} \mathrm{C}$ in the absence of oxygen, the reaction initiates instantaneously with benzene as the nearly exclusive product. In the presence of oxygen, an induction period is observed, benzene is the predominate decomposition product, and small quantities of phenol and biphenyl are formed.

- Under the limited range of reaction conditions tested to date, little difference in stability is observed between AFF, Boulder Scientific, and reagent grade NaTPB. Spray-drying or similar treatments appear to generate limited amounts $(<1 \%)$ of decomposition impurities that increase initial benzene generation, but this does not appear to be related to the rapid decomposition reaction.

Based on the current understanding of the Tank 48H reaction, the following implications on the downstream processes are presented.

- Tank 50H benzene generation can be higher than previously predicted due to decomposition of soluble, semi-stable products from the Tank 48H reaction. Non-bounding rates as high as 300 $\mu \mathrm{g} / \mathrm{L} / \mathrm{hr}$ have been measured on Tank $48 \mathrm{H}$ Eiltrate.

- Saltstone prepared from a January 1996 sample of Tank 50H salt solution passed TCLP and Constituent Concentration in Waste tests.

- The rapid decomposition reaction in Tank $48 \mathrm{H}$ will not affect transfers to Late Wash once the reaction has subsided and the benzene inventory is reduced to less than $700 \mathrm{mg} / \mathrm{L}$. However, the possibility of the reaction restarting when NaTPB is added in the Late Wash process cycle will limit or reduce allowable storage time.

- The implications of the rapid decomposition reaction for spent washwater storage in Tank $22 \mathrm{H}$ cannot be determined, because the composition of the sludge heel in Tank $22 \mathrm{H}$ has not been evaluated. 


\section{Introduction}

The In-Tank Precipitation (ITP) process at the Savannah River Site (SRS) prepares high level radioactive waste for vitrification in the Defense Waste Processing Facility (DWPF). In Tank 48H of the ITP facility, cesium-137 and strontium-90 are removed from solution using two specialty chemicals, sodium tetraphenylborate (NaTPB) and monosodium titanate (MST). Sodium tetraphenylborate precipitates cesium and potassium. The titanate removes strontium through ion exchange while adsorbing uranium and plutonium. The insoluble species are concentrated and washed using crossflow filters. Decontaminated filtrate is transferred to Tank $50 \mathrm{H}$ for ultimate disposal by the saltstone facility. The concentrated cesium- and strontium-containing waste is transferred to Tank 49H for storage until processed for vitrification by the Late Wash Facility and DWPF.

SRS has purchased NaTPB primarily from two vendors, AFF, Inc. and Boulder Scientific Company. AFF was selected as the primary vendor. They produced and stored NaTPB in solution with a concentration of $0.55 \pm .05 \mathrm{M} \mathrm{NaTPB}$ and $0.10 \mathrm{M} \mathrm{NaOH}$ for stability. Boulder Scientific prepared and stored NaTPB in powder form as a back-up to AFF. During storage, AFF NaTPB solutions were observed to have varying degrees of stability. [Ref. 1,2] Decomposition studies were performed on the NaTPB solution. [Ref. 2,3] In strongly basic solutions, copper was demonstrated to promote the decomposition of dissolved NaTPB. SubsequentIY, AFF material was determined to be contaminated with low levels of copper. Stability studies also indicated that, in conjunction with copper, elevated temperatures ( $40{ }^{\circ} \mathrm{C}$ and above) or decreased hydroxide concentration increased the rate of NaTPB decomposition. Observations obtained from the various NaTPB solution studies are summarized below:

- The rate of NaTPB decomposition is dependent upon the solution temperature.

- The rate of NaTPB decomposition depends on the copper concentration of the solution. Typically, copper concentrations as low as $0.1 \mathrm{mg} / \mathrm{L}$ were capable of catalyzing the decomposition of NaTPB.

- The rate of NaTPB decomposition is proportional to the soluble tetraphenylborate ion concentration.

- Increasing hydroxide ion delays decomposition of NaTPB solutions. An increase in hydroxide concentration from 0.10 molar (typical feed solution hydroxide concentration) to 0.50 molar doubles the shelflife of a decomposing solution.

For economic reasons, the NaTPB produced by AFF was spray-dried by Aquafine, Inc. and stored as a powder. When requested, Aquafine prepared NaTPB solution with the same concentration as that prepared by AFF. Solutions of this material were observed to be unstable when exposed to elevated temperatures during storage. In addition, stability studies on the spray-dried powder indicated that the solid NaTPB was decomposing at a rate of 18 per year. [Ref. 4] During ITP 
startup operations, the contract for storage and solution preparation of NaTPB changed to Holley Oak Chemicals. Sodium tetraphenylborate solutions, prepared by both Aquafine and Holley Oak, were used for ITP. startup.

During September 1995, ITP began radioactive operations by adding 37,300 gallons of NaTPB solution to Tank 48H. Small amounts of benzene were detected in the tank vapor space during the addition of the NaTPB solutions. During October and early November, the slurry was filtered and tests were run to determine how well the vapor space was mixed. During each test, the maximum measured concentration of benzene in the vapor space increased from that observed in the preceding test. In part, the increase was thought to be due to the increased effectiveness of mixing and mass transfer as the liquid level was reduced. On November 13, all pumps in the tank stopped for a test of vapor space mixing with the ventilation system halted. The tank remained stagnant for 18 days. On December 1, 1995, all four slurry pumps were energized for 3.5 hours. There was a rapid increase in the benzene concentration in the tank vapor space, to concentrations that far exceeded previous levels. A few days later, elevated benzene concentrations (near $9 \mathrm{mg} / \mathrm{L}$ ) were also observed in Tank 50H liquid samples. [Ref. 5] (The benzene concentration originally measured in the filtrate hold tank prior to transfer never exceeded $1.0 \mathrm{mg} / \mathrm{L}$.$) This increase suggests that NaTPB or a$ decomposition reaction intermediate in the decontaminated filtrate decomposed after transfer. Tests indicate that saltstone performance was not affected by this material.

The above results were unexpected since the 1983 ITP demonstration did not produce the same effects. The 1983 demonstration differed from the 1995 startup in a number of ways. First, the majority of NaTPB used in 1983 was from Boulder Scientific. [Ref. 6] Second, the 1983 demonstration was performed in a much shorter time period and the tetraphenylborate slurry produced was washed. This washing removed excess NaTPB before decomposition could occur. Third, in 1983 the waste tank was air ventilated and not inerted as was the recent startup. Other differences between the two periods were that the amount of MST added was nearly double in the current operation, the current waste in Tank $48 \mathrm{H}$ had a higher plutonium activity, and there was "aged" precipitate from 1983 present in the current operation. Each of these could have contributed to the differences in behavior between the 1983 demonstration and startup in 1995. 


\section{Experimental}

\section{Logic Flowchart}

Following the unexpected benzene evolution from Tank $48 \mathrm{H}$ on December 1, 1995, researchers from the Savannah River Technology Center (SRTC) met with High Level waste Engineering personnel to consider immediate response actions. During the ensuing month, SRTC structured an integrated research program aimed at understanding the underlying chemistry. Figure 1 provides an overview of that program. (The text section titled "Tank 48H Data and Information" details the significance of the dates cited in Figure 1.) Table 1 documents progress made in understanding the chemistry as a result of the research program.

Figure 2 provides a schematic of the logic used for investigating chemical generation of benzene. This report examines those tests at length. Other reports document the remaining elements of the program. This report makes no attempt to provide a comprehensive examination of the global program.

Figure 1. Schematic describing the elements of research program supporting In-Tank Precipitation.

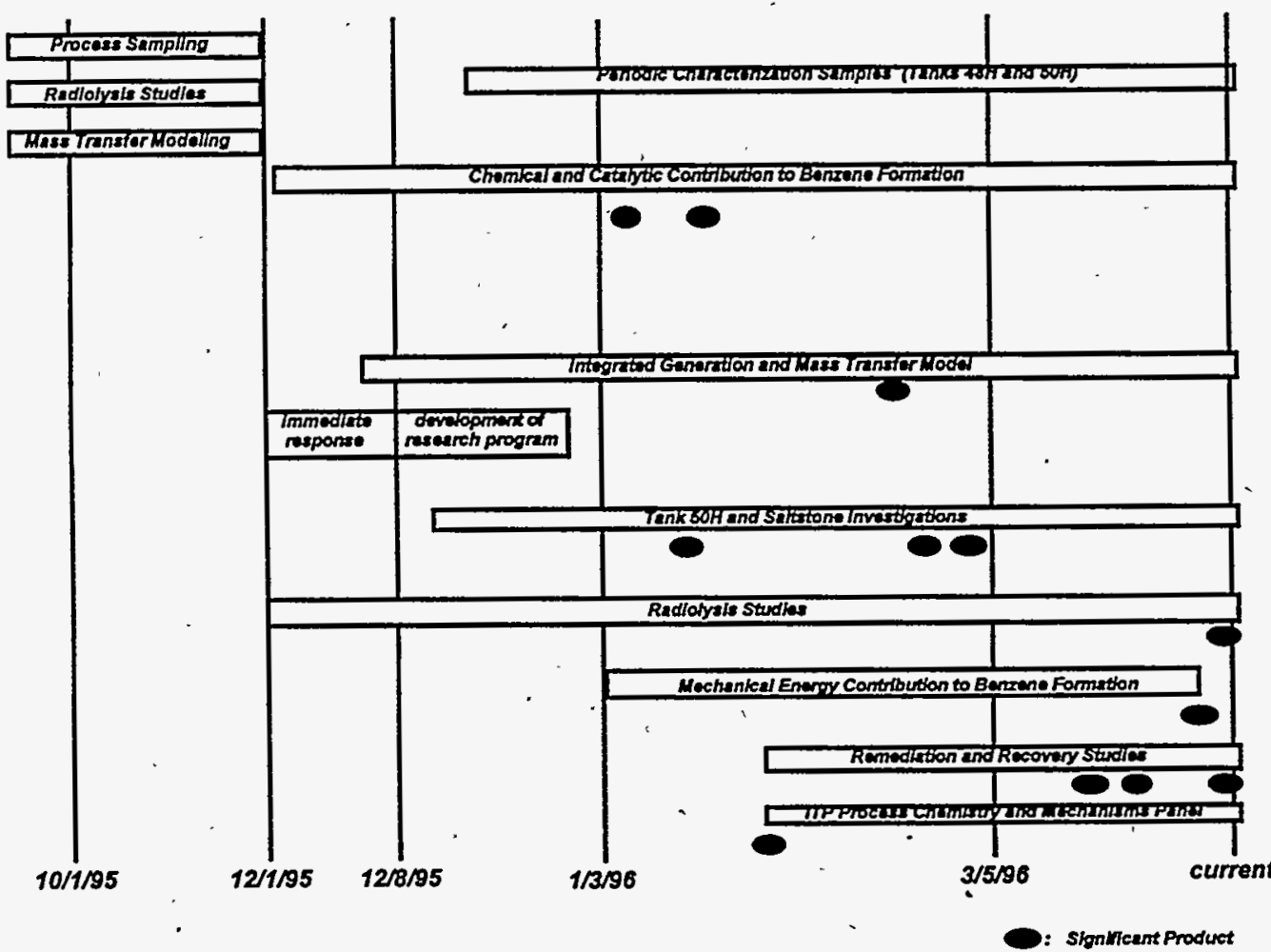


Researchers considered the available data for Tank $48 \mathrm{H}$ for the period of July 1995 through December 1,"1995. They contrasted this data with documented evidence from the 1983 demonstration of the process. This effort produced a list of known differences that may have contributed to the rapid benzene formation in 1995. No single variable was identified initially that would have produced the large amount of benzene. Hence, researchers developed a multivariate exploratory program. The program focused primarily on chemical differences between the two campaigns (e.g., metal hydroxide solids, the source of NaTPB, and the possible presence of soluble metals). Researchers designed the program to allow simultaneous study of potential interaction from perceived 'secondary' variables. These 'secondary' variables included radiation, oxygen level, and presence of organics from the decomposition.

\section{Analysis of Benzene in Tank $48 \mathrm{H}$ slurry samples}

The volume of a 50-mL Erlenmeyer flask was measured by adding distilled, deionized water, of a known temperature and density, and weighing the flask. The flask was equipped with a ground glass stopper and sidearm. A septum was placed over the sidearm. The dried flask was preweighed and $2 \mathrm{~mL}$ of ITP slurry was added. The flask was weighed after replacing the stopper. After stirring for 1 hour the vapor space in the flask was sampled through the septum on the sidearm using a gas tight syringe. The syringe was sealed by closing a valve at the base and removed from the Shielded Cells for analysis by gas chromatography.

Table 1. Advances in understanding causes and implications of unexpected tetraphenylborate decomposition.

Date

Accomplishment

1/19/96 Tank 48H Organic Material Balance Drafted

1/23/96 Tank 50H Generation Rates and Mass Transfer Behavior Documented

2/4/96 Complete Consumption of Excess Sodium

Tetraphenylborate Documented

2/8/96 First Meeting of ITP Process Chemistry and

Mechanisms Panel

2/22/96 Mass Transfer Predictions for Future Pump Operations

2/23/96 Documented Acceptable Saltstone Product

2/28/96 Documented Acceptable Benzene Generation Rates in Saltstone Process

3/25/96 Documented Minor Contribution of Mechanical Energy to Decomposition

4/1/96 Documented Waste-Analyses for Potential Future Feeds

4/9/96 Documented Simulation of Waste Addition to Tank 48H

4/29/96 Documented Accepted Filter Performance for Tank 48H Contents

4/30/96 Documented Hydrogen Radiolysis Data for Authorization Bases Upgrades 
Figure 2. Logic diagram for studies of chemical generation of benzene.

Chemical and Catalytic Contribution to Benzene Formation

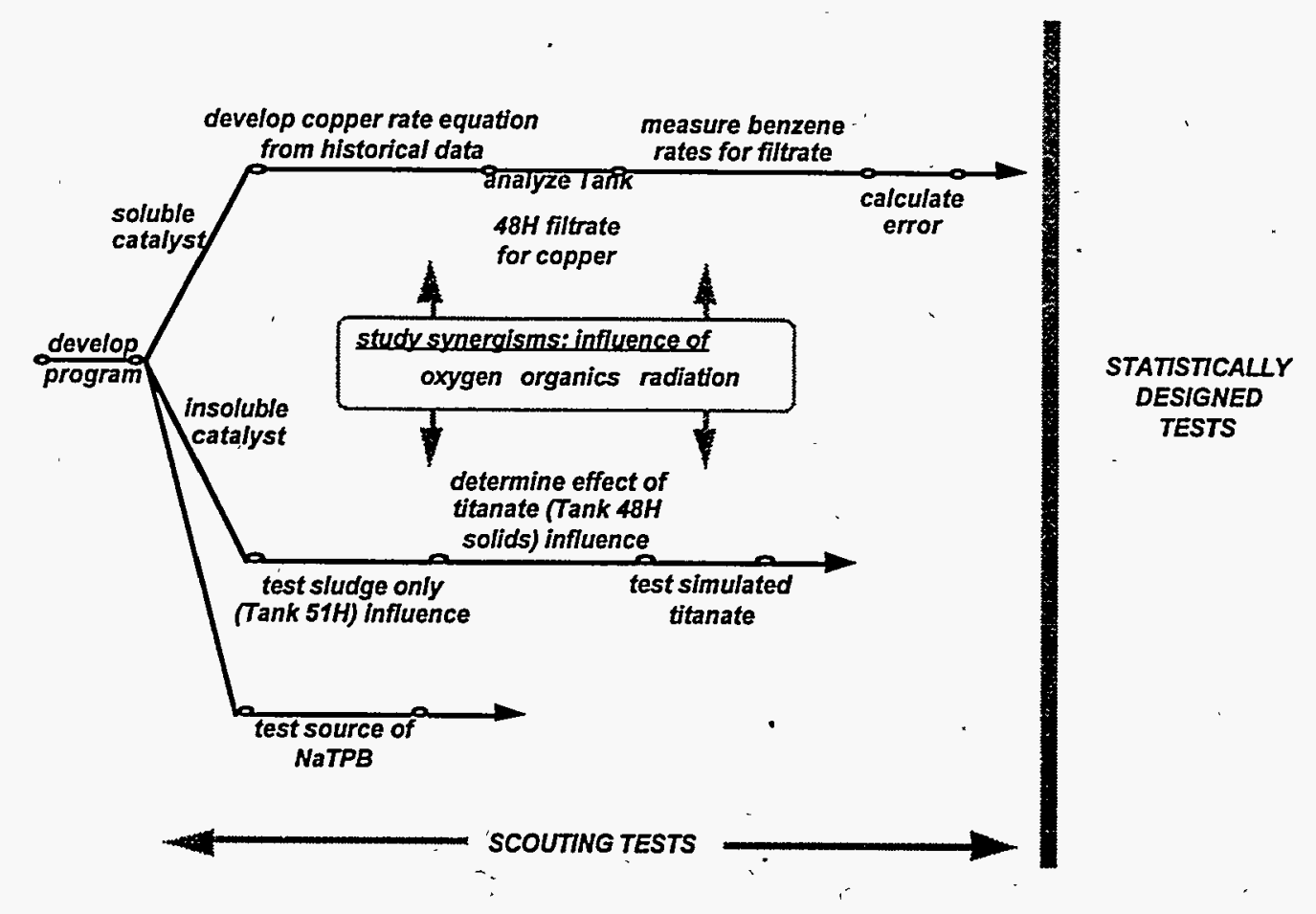

\section{Hexane Extraction of Tank $48 H$ Slurry Samples}

Neutral, aqueous-insoluble organic decomposition products of tetraphenylborate were isolated from the ITP slurry by extraction with hexane. Approximately $10 \mathrm{~mL}$ of ITP slurry were added to a preweighed centrifuge tube. The centrifuge tube was weighed again to accurately determine the amount of slurry added. The slurry was centrifuged for 10 minutes to separate the solids. The aqueous layer was decanted from the centrifuge tube. The solids were washed three times with $10 \mathrm{~mL}$ portions of water using the same centrifugation and decanting technique. The washed solids were then extracted with three $15 \mathrm{~mL}$ portions of hexane. The decanted hexane extracts from the three.extractions were combined and analyzed. A fourth hexane extraction was analyzed separately to determine the effectiveness of the first three extracts:

\section{NaTPB Decomposition Tests}

Laboratory tests of NaTPB decomposition were conducted in reaction vessels that were continuously ventilated and stirred, and also in reaction bottles that were capped, not stirred, and non-ventilated (i.e., static). Both nitrogen and air atmospheres were used during the tests. The continuously ventilated tests were performed by placing $100 \mathrm{~mL}$ of salt solution into a $200 \mathrm{~mL}$ reaction vessel. The 
solution varied from test to test but was in many instances actual Tank 48H filtrate. Sodium tetraphenylborate was added to this solution. Humidified air or nitrogen was passed through the vessel at a flow rate of approximately $10 \mathrm{~mL} / \mathrm{min}$. Samples of the vapor stream were analyzed periodically for benzene by a gas chromatograph fitted with a photoionization detector.

Static bottle tests were conducted by charging either glass, stainless steel, or polyethylene bottles with a salt solution or Tank $48 \mathrm{H}$ simulant. The bottles were capped in the appropriate atmosphere and the gas space sampled periodically. Iiquid samples from both the ventilated and non-ventilated tests were obtained to investigate the potential for forming less volatile soluble aqueous products. In some tests (i.e., static tests conduated in stainless steel vessels), the liquid phase was sampled for benzene.

\section{Isolation of Tank $48 \mathrm{H}$ Insoluble, Inorganic solids in ITP slurry samples}

The insoluble solids entrained in ITP slurry were isolated by filtering approximately $200 \mathrm{~mL}$ of ITP slurry. The solids were washed with three $50-\mathrm{mL}$ portions of water to remove any residual water soluble material. The remaining solids were washed with acetonitrile to remove tetraphenylborate salts. The washing continued until the filtrate was clear. The solids were air dried. The solids were divided into $\sim 0.25 \mathrm{~g}$ aliquots to reduce radiation exposure during removal from the shielded Cells.

\section{Monosodium pitanate simulant}

Actinide-loaded monosodium titanate (MST) was prepared from a sample of the same MST batch that had been added to Tank $48 \mathrm{H}$ in September 1995 (Optima lots \#95QAB391 and \#95QAB393). A solution (2 I) containing the major soluble components in Tank 48 (sodium salts of hydroxide, nitrate, nitrite, sulfate, aluminate, and carbonate) was prepared from reagent grade chemicals. An excess of Pu-239 $10.45 \mathrm{mg}$ of $\mathrm{Pu}$ in acidic nitrate solution) and depleted uranium (30 $\mathrm{mg}$ of $\mathrm{U}$ in acidic nitrate solution) were added to the salt solution and stirred for one week to saturate the solution. Excess solids were removed using a filter with nominal 0.45 micron pore size. MST (2 g) was added to the filtered salt solution and stirred for one week to load the actinides onto the MST solids. The actinide-loaded MST was filtered, rinsed lightly with water, and dried at room temperature. The dried solids contained 0.26 wt $f$ uranium. 


\section{Results and Discussion}

\section{Tank 48F Data and Information}

\section{Tank 48H Operation. .}

Starting on September 2 and continuing through September 29, 1995, 37,300 gallons of sodium tetraphenylborate were pumped to Tank $48 \mathrm{H}$ in eleven separate additions. These solutions contained a total of 14.6 $\mathrm{kg}$ of benzene. Appendix A outlines the timing of these additions and other events described herein. In addition, much of the data and information contained in this section and the remainder of the document were obtained from data reports issued by J. D. 'Menna, M. R. Williams, J. L. Kelly, and D. A. Zupon. These reports are to large to list or include in an appendix. A bibliography is available from the authors of this document.

During this time period, a number of other tarik variables were recorded. Of particular interest for this report are the temperature of the liquid phase in the tank and the oxygen concentration in the vapor space in the tank. Tank temperatures were recorded by two thermocouple poles (small diameter tubes inserted in the D2 and D4 risers that contained thermocouples at different heights). Figure 3 represents the average of the lower two thermocouples from the D2 riser. These temperatures were recorded approximately every 4 hours. Figure 4 contains oxygen concentrations for the vapor space in Tank 48H over the same time period from one of two gas chromatagraphs mounted on Tank 48H. These data were collected at intervals ranging from 3 to 15 minutes. Outlying data points were culled from the data set. Data points were removed when the following criteria were met: the retention time for the GC varied by more than 1 second for the average retention time; the data point varied by more than $50 \%$ from its immediate neighbor data points and when the data point was taken from the port at the top of the tank. Next, data was extracted from the data set at 6 hour intervals and prepared for Figure 4 .

Inspection of Figure 3 and Figure 4 indicate that during the addition of NaTPB, the temperature and oxygen concentration remained relatively constant at values of $33^{\circ} \mathrm{C}$ and between 5 and 6 vol $\%$, respectively. Following addition, the slurry pumps were operated for an extended period to provide mixing for the precipitation. This pump operation produced a measurable increase in the temperature in Tank $48 \mathrm{H}$ as indicated by Figure 3 since cooling coils were unavailable at that time.

On October 9, the first of three pump tests was performed. This test involved the operation of all 4 pumps for an extended period of time followed by operation of one pump for a brief period of time. This test was characterized by a nearly constant benzene release from the Iiquid phase to the vapor space that maintained the tank vapor space at nearly $60 \mathrm{ppm}$ of benzene for a period of greater than 36 hours. Inspection of Figure 3 indicates that a temperature increase was associated with this operation. The oxygen concentration in the vapor space in Tank $48 \mathrm{H}$ remained relatively constant. 
Following completion of the pump test on October 12, the tank remained quiescent. until October 20. At that time, filtration of decontaminated salt solution commenced and continued until. October 25. During filtration, approximately 140,000 gallons of filtrate were removed and the temperature of the liquid in Tank $48 \mathrm{H}$ remained relatively constant at approximately $39^{\circ} \mathrm{C}$.

The first filtration stage was followed by the second pump test starting on October 26 and continuing until October 29. During this operation, the temperature in the tank again increased measurably while the oxygen concentration in the vapor space remained relatively constant. Benzene concentrations were again found to be higher than anticipated; however, a measurable decrease in the benzene release rates was observed during this process after 24 hours of pump operation. A water addition was made during this test, but no change in the release rate for benzene was observed. The second pump test was followed by the second filtration stage From November 2 through November 7 that brought the liquid volume in Tank $48 \mathrm{H}$ to approximately 160,000 gallons. This filtration stage was marked by the same trends as observed during the previous concentration: namely, periods of relatively constant temperature and oxygen concentrations.

On November 9, the third pump test started. Due to the lower liquid level in the tank, the pumps caused a marked increase in the liquid phase temperature to a maximum value of $52{ }^{\circ} \mathrm{C}$. However, the oxygen concentration again remained relatively constant during this time period. For a third time, the peak benzene release rate was higher than anticipated. The rate declined after approximately 24 hours of pump operation. Three water additions were made to Tank $48 \mathrm{H}$ during this time and none resulted in measurable increases in the benzene release rate.

The third pump test was followed by an extended quiescent time period. During this time, the ventilation to Tank $48 \mathrm{H}$ was shut down on three separate occasions. The first of these (from November 15 through November 20) was followed by a short period during which Tank $48 \mathrm{H}$ was ventilated with air. The period of time during which air ventilation was employed is marked by the large spike in the oxygen concentration in Figure 4 . The second ventilation test ran from November 24 through November 26 while the third test ran from November 26 through November 30 . Each of these three tests was marked by an increase in the oxygen concentration in the vapor space of Tank 48H. Upon restoration of nitrogen based ventilation, the oxygen concentration returned to values obtained during previous tests. Because no pumps operated in Tank $48 \mathrm{H}$ during this time period, the tank contents cooled. When pump operations commenced on December 1, the Iiquid phase in Tank $48 \mathrm{H}$ had cooled to approximately $30{ }^{\circ} \mathrm{C}$.

On December 1, all four slurry pumps were operated for approximately 3.5 hours. Pump operation was then halted due to high $(2000 \mathrm{ppm})$ benzene readings in the tank vapor space. This event was followed by periodic pump operation to deplete benzene from the tank between December 8 to January 3. During this time period, the contents of 
the tank cooled further to $25^{\circ} \mathrm{C}$. From January 3 through March 5 the tank was quiescent. On March 5, one slurry pump was restarted at low speed $(600 \mathrm{rpm})$. A large quantity of benzene was seen immediately in the head space, and portions of the tank vapor space reached benzene concentrations in excess of $4000 \mathrm{ppm}$ within 14 minutes. The benzene' concentration varied across the tank vapor space. Pump operation was terminated after 14 minutes.

Starting on March 8, periodic pump operations were resumed in an effort to deplete benzene from the tank. This effort is still in progress. Initial operations employed only one slurry pump. As

\section{Figure 3. Tank 48H Temperature Profile for August 1995} through April 1996.

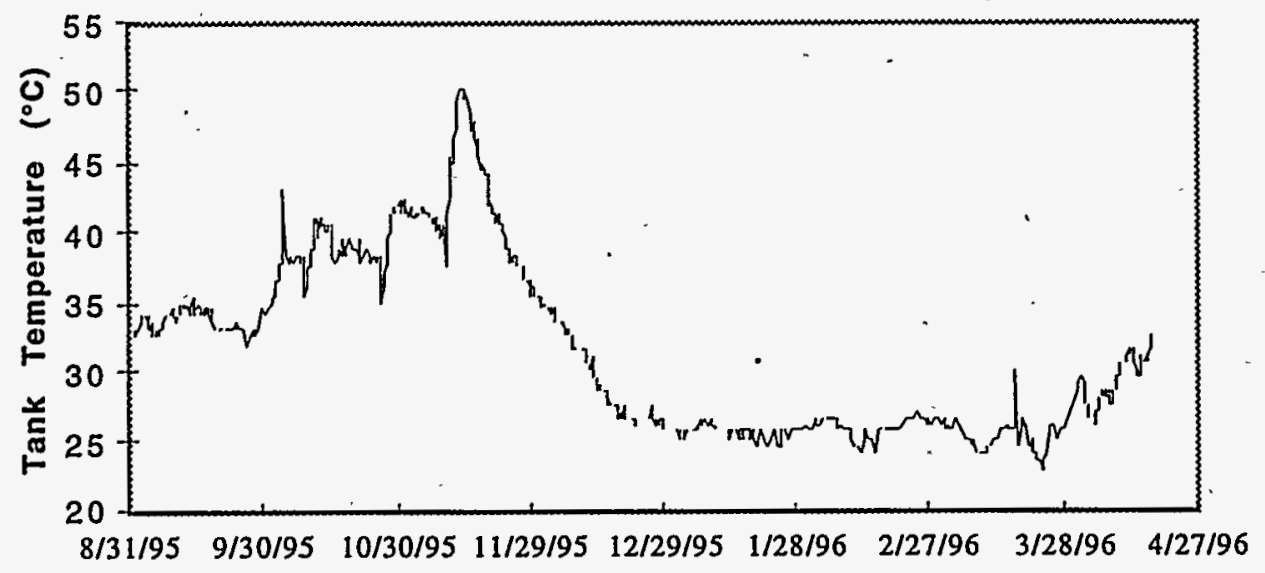

Figure 4. Tank $48 \mathrm{H}$ Oxygen Profile for August 1995 through April 1996.

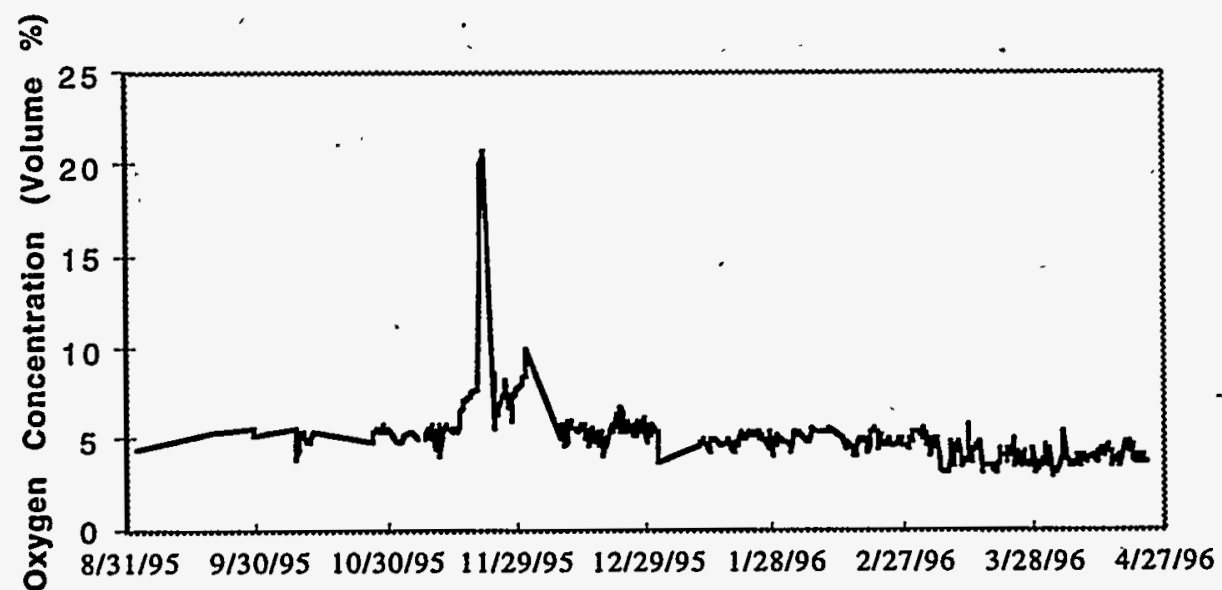


benzene release rates decreased, additional pumps were started sequentially. By April 25, all four pumps were operating at maximum speed of $1180 \mathrm{rpm}$. From November 5 to April 22, $8500 \mathrm{~kg}$ of benzene were removed from Tank $48 \mathrm{H}$.

\section{Excess NaTPB in Tank $48 \mathrm{H}$}

During September 1995, 37,300 gallons of 0.55 molar NaTPB solution were added to Tank $48 \mathrm{H}$. This quantity exceeded that required to precipitate the cesium and potassium in Tank $48 \mathrm{H}$. A small fraction of the excess NaTPB dissolved. The remainder, the quantity present above the solubility limit, precipitated as insoluble NaTPB solids. In addition to the NaTPB added in September, there was a residual amount of potassium tetraphenylborate (KTPB) remaining in Tank 48H from the 1983 demonstration. The amount of this residual KTPB is calculated to be approximately $8400 \mathrm{~kg}$. Since the slurry in Tank $48 \mathrm{H}$ was washed during the 1983 demonstration, no insoluble NaTPB was left from that test, and the amount of soluble tetraphenylborate ion, was not significant.

Analysis of Tank 48H samples from September 1995 through January 1996 indicate that the majority of the excess sodium tetraphenylborate was still present in the tank at the beginning of December. Samples obtained on December 18 and again in January indicated that more than 95\% of the excess NaTPB had decomposed. Subsequent samples have shown an increase in both soluble cesium and potassium ion concentrations, indicating all excess NaTPB in Tank 48H eventually decomposed. [Ref. 7]

Given the fate of the excess NaTPB in Tank 48H, the exact quantity of this excess NaTPB becomes important for analyzing the incident. Calculation of the amount of excess NaTPB is based upon a number of variables. [Ref. 8] These include the total amount of fresh" NaTPB added, the amount of residual NaTPB present, the soluble potassium and cesium ion concentrations, and any minor variations due to other precipitating species such as mercury: The largest source of error in this calculation is the analysis of soluble potassium. Prior to ITP startup, samples were obtained from Tank 48H in July 1995.

[Ref. 9] The reported potassium ion concentrations in these samples ranged from 0.023 molar to 0.033 molar. The 37,300 gallons of NaTPB solution added to Tank $48 \mathrm{H}$ was based upon. a soluble potassium ion concentration of 0.033 molar. This corresponds to a 318 (6600 $\mathrm{kg}$ ) excess of NaTPB. Mass balances performed during removal of the benzene inventory from Tank 48H have shown that 12,200 kg of NaTPB decomposed. This quantity of excess NaTPB would imply that the soluble potassium ion concentration was in fact nearly 0.023 molar and not 0.033 molar.

\section{Decomposition of NaTPB and Benzene Generation in Tank $48 \mathrm{H}$}

From October 1 through November 5, approximately $50 \mathrm{~kg}$ of benzene - were removed from Tank 48H. Based on the benzene vaporization rate at the end of the third pump test, the tank contained less than $20 \mathrm{~kg}$ of benzene on November 14 . 
Approximately $8500 \mathrm{~kg}$ of benzene were removed from Tank 48H between December 1 and April 25. Thus, if one assumes a length of time during which the decomposition occurred, it is possible to estimate the benzene generation rate in Tank 48H. In Figure 5, two values are reported for the benzene generation rate after November 14 . These two rates are based on the assumptions that the reaction reached completion on either December $8(25,000 \mu \mathrm{g} / \mathrm{L} / \mathrm{hr})$, when pump operation was resumed, or December $28(12,500 \mu \mathrm{g} / \mathrm{L} / \mathrm{hr})$, when analysis of the tank sample confirmed the absence of excess NaTPB, respectively. Figure 5 also presents estimates for the benzene generation rate based on previous studies of copper catalyzed decomposition. The rate after December 28 assumes a soluble TPB concentration calculated from a literature solubility correlation. [Ref. 22] Note that the scale for the vertical axis in Figure 5 is logarithmic.

Tank 48H Sample Results

Tank $48 \mathrm{H}$ was initially sampled per a defined sampling plan. [Ref. 10] At the onset of elevated benzene concentrations in the vapor space, samples were obtained more frequently. Surface samples were normally obtained by a dip bottle. Less frequently, samples were obtained using the variable depth sampler (VDS). When sampling, the contents of the tank were agitated prior to obtaining the sample. However, January and February samples were obtained without mixing the tank. Samples were analyzed by inductively coupled plasma emission spectroscopy (ICP-ES), inductively coupled plasma mass spectroscopy (ICP-MS), ion chromatography, high pressure Iiquid chromatography (HPLC), gas chromatography (GC), and titration. The results of the analyses are shown in Table 2. Other components included nitrate, nitrite, fluoride, chloride, phosphate, sulfate, oxalate, and

\section{Figure 5. Estimates of Benzene Generation Rates for Tank} $48 \mathrm{H}$

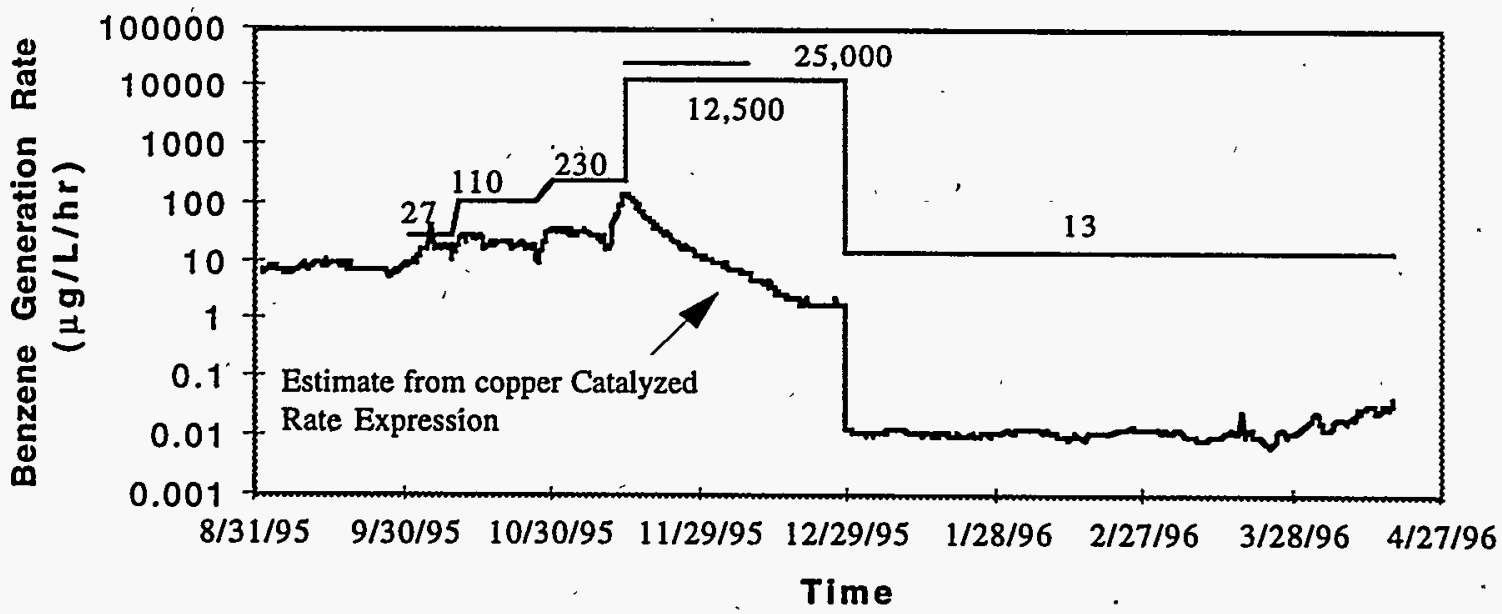


W. I. Tamosaitis

Table 2. Tank $48 \mathrm{H}$ filtrate analyses.

\begin{tabular}{|c|c|c|c|c|c|c|c|c|}
\hline $\begin{array}{c}\therefore \\
\text { Sample } \\
\text { Date }\end{array}$ & $\begin{array}{c}C s-137 \\
(n c 1 / g) \\
\end{array}$ & $\begin{array}{c}K^{+} \\
(m g / L) \\
\end{array}$ & $\begin{array}{c}\text { Benzene } \\
(g / L)^{\circ}\end{array}$ & $\begin{array}{l}\text { Phenol } \\
\text { (mg/L) } \\
\end{array}$ & $\begin{array}{c}P B A \\
(m g / L)\end{array}$ & $\begin{array}{c}\text { Soluble } \\
\text { Boron } \\
\text { (mg/L) }\end{array}$ & $\begin{array}{l}\text { Copper } \\
\text { (mg/L) }\end{array}$ & $\begin{array}{c}\mathrm{OH}^{-} \\
(\operatorname{molar})\end{array}$ \\
\hline $10 / 12$ & 3 & $N D^{b}$ & ND & 189 & $<10$ & 104 & 1.2 & 2.5 \\
\hline $11 / 5$ & $<0.5$ & ND & ND & 220 & $<10$ & 108 & 1.2 & ND \\
\hline $\begin{array}{c}12 / 1 \\
(12 / 8)^{c}\end{array}$ & $<0.5$ & $\mathrm{ND}$ & $\mathrm{ND}$ & 550 & 850 & 392 & $<0.2$ & 2.1 \\
\hline $\begin{array}{c}12 / 18 \\
(12 / 28)\end{array}$ & 27 & $\mathrm{ND}$ & ND & 860 & 1800 & 610 & 1.4 & 2.6 \\
\hline $\begin{array}{c}1 / 5 \\
(1 / 7) \\
\end{array}$ & 50 & $\mathrm{ND}$ & ND & 740 & 1500 & 614 & ND & 2.7 \\
\hline $\begin{array}{c}1 / 12 \\
(1 / 16) \\
\end{array}$ & 71 & $\mathrm{ND}$ & ND & 729 & 1580 & 616 & ND & 2.6 \\
\hline $\begin{array}{c}1 / 21 \\
(1 / 22)\end{array}$ & $78 \pm 15$ & $1.8 \pm .7$ & 6.3 & $740 \pm 180$ & $\begin{array}{c}1730 \pm \\
190\end{array}$ & $561 \pm 10$ & $\dot{\mathrm{ND}}$ & $\begin{array}{c}2.39 \pm \\
.06\end{array}$ \\
\hline $\begin{array}{c}1 / 26 \\
(1 / 29)\end{array}$ & $62 \pm 14$ & $1.6 \pm .4$ & 3.1 & $820 \pm 10$ & $1860 \pm 20$ & $588 \pm 2$ & ND & $\begin{array}{c}2.50 \pm \\
.02\end{array}$ \\
\hline $\begin{array}{c}2 / 10 \\
(2 / 12) \\
\end{array}$ & $78 \pm 15$ & $2.4 \pm 1.0$ & $6.9 \pm 4.0$ & $980 \pm 20$ & $1940 \pm 80$ & $544 \pm 70$ & ND & $\begin{array}{c}2.47 \pm \\
.05\end{array}$ \\
\hline $\begin{array}{c}2 / 23 \\
(2 / 26) \\
\end{array}$ & $114 \pm 30$ & $2.3 \pm .6$ & ND & $1030 \pm 10$ & $1770 \pm 10$ & $504 \pm 33$ & ND & $\begin{array}{c}2.14 \pm \\
.09 \\
\end{array}$ \\
\hline $\begin{array}{c}3 / 22 \\
(3 / 24) \\
\end{array}$ & 164 & 4.7 & $3.6 \pm 1.1$ & 880 & 1710 & 566 & ND & 2.15 \\
\hline $\begin{array}{c}4 / 13 \\
(4 / 15)\end{array}$ & $344 \pm 36$ & $6.0 \pm .8$ & 0.41 & $1190 \pm 47$ & $1565 \pm 38$ & $533 \pm 26$ & ND & $\begin{array}{c}2.08 \pm \\
.08\end{array}$ \\
\hline
\end{tabular}

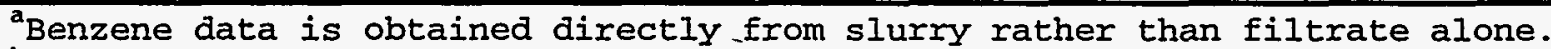

${ }^{\mathrm{B} D}$ indicates analysis was not performed.

'Dates within parentheses indicate that date the sample was filtered.

formate, showed no significant changes and are not included.

Examination of the data with respect to time provides clues to the extent of the decomposition reaction.

With respect to cesium-137, values less than $10 \mathrm{nCi} / \mathrm{g}$ are considered "decontaminated" and within normal process expectations. Examination of the data indicates that prior to December 1, the cesium-137 
concentration was low and within normal process expectations. This indicates that sodium tetraphenylborate was in excess. After December 1 , the concentration begins to increase, coincident with the loss of excess NaTPB. The increase from December 1 through March 22 is linear at a rate of $1.36 \mathrm{nCi} / \mathrm{g} \cdot$ day. This rate is substantially lower than expected during storage in Tank 49H, $8 \mathrm{nCi} / \mathrm{g} \cdot$ day, and observed after the 1983 demonstration, $16 \mathrm{nCi} / \mathrm{g} \cdot$ day. [Ref. 11] The differences in composition (washed vs. unwashed precipitate) and dose rate are the most likely reasons for the different decomposition rate.

Potassium ion concentration was monitored starting January 21 . The presence of very low levels of potassium ion confirm that degradation of KTPB has been minimal. These data, coupled with the cesium-137 data, support the conclusion that insoluble CsTPB and KTPB are not decomposed catalytically as found for the soluble NaTPB. The small increases in concentration of both species can be attributed to the expected small rates of radiolytic and thermal decomposition.

Benzene analysis of the KTPB slurry in Tank $48 \mathrm{H}$ was not attempted until mid-January. Samples obtained while the tank was static between mid-January and into February indicated that as much as $5500 \mathrm{~kg}$ of "free" benzene existed in Tank 48H. Roughly $8500 \mathrm{~kg}$ of benzene have been removed from the tank since the mixing pumps were restarted in early March. The poor agreement obtained from analysis is probably due to sampling variations (i.e., low values resulting from loss of benzene during sampling and transport) and bias in the analysis.

High Pressure Liquid Chromatography (HPLC) analyses were used to measure phenol and phenylboric acid (PBA) in Tank $48 \mathrm{H}$ filtrate samples. The initial phenol concentration (189 mg/L on October 12) is due to phenol in the 37,300 gallons of NaTPB solution (which accounts for $120 \mathrm{mg} / \mathrm{L})$, and the remainder is presumed to be due to the decomposition of KTPB precipitate from 1983. A significant jump in concentration was noticed between November 5 and December 18 . A steady or slight increase in concentration has been observed since mid-December. This may be due to the relatively slow decomposition of PBA, other unidentified decomposition products (e.g., diphenylboric acid, triphenylboron, CsTPB, and KTPB).

Similar behavior to phenol was observed for PBA. One distinct difference between PBA and phenol is that phenol is a stable end product from the decomposition of NaTPB while PBA is an unstable intermediate that undergoes further decomposition.' As with phenol, a significant jump in concentration was observed between November 5 and December 18. Since December 18, PBA has remained within the range of $1500-2000 \mathrm{mg} / \mathrm{L}$. The variations shown in Table 2 are believed to be due to random variations in the sampling and analysis.

The soluble boron concentration was measured by ICP-ES. This method provides a measure of total boron. All soluble boron species (e.g., sodium borate, PBA, diphenylboric acid and $\mathrm{TPB}^{-}$) contribute to this value. Since this analysis is performed upon filtrate, insoluble boron-containing species do not contribute to the total boron value. 
Therefore, the 'soluble boron concentration is a direct measure of the extent of decomposition of all tetraphenylborate species. As observed with phenol, the initial boron concentration is probably due to a combination of residual boron species in the 37,300 gallons of NaTPB solution and decomposition of precipitate remaining from the 1983 demonstration. As noted with previous analyses, a jump in concentration was observed between November and mid-December. . Since mid-December, the concentration of soluble boron has been relatively constant. This evidence supports the theory that only NaTPB was catalytically decomposed and that the catalytic reaction has drastically reduced.

Tank 48H filtrate was analyzed for copper since it had previously been identified as a NaTPB decomposition catalyst. Analysis by both ICP-ES and ICP-MS confirmed the presence of 1.2 to $1.4 \mathrm{mg} / \mathrm{L}$ copper in samples from september through mid-December. The December 1 sample did not contain copper and this result is not currently understood.

The free hydroxide concentration in Tank. 48H varied between 2.1 and 2.7 molar. This wide variance is due largely to analytical/sampling error. Hydroxide concentration is important to tank corrosion control and the concentration must be maintained above 1 molar when the nitrate concentration is less than 1 molar. Nitrate and nitrite concentrations in Tank $48 \mathrm{H}$ have been steady at $0.53 \pm .05$ and $0.64 \pm .05$ molar, respectively.

In addition to benzene, phenol, $\mathrm{PBA}$, and sodium borate, biphenyl is a decomposition product of NaTPB. Samples from January 12 and January 21 were extracted with hexane and analyzed for biphenyl. This method of, isolating the compound was necessary since biphenyl is a solid that is almost completely insoluble in the salt solution. The biphenyl concentration ranged from 1390 to $1690 \mathrm{mg} / \mathrm{L}$. It should be noted that sampling a heterogenous solution such as this can produce unreliable data.

\section{Tank 48H Material Balance and Reaction Stoichiometry}

A mass balance based on Tank $48 \mathrm{H}$ benzene releases through April 22 , 1996 is given in Table 3. The mass balance indicates that after April 22, there was as much as $906 \mathrm{~kg}$ of benzene remaining in Tank $48 \mathrm{H}$; the actual value would be lower if the initial potassium. concentration was somewhat higher than assumed. The following assumptions were made in generating this mass balance.

- Initial Tank $48 \mathrm{H} \mathrm{K}^{+}$concentration was $0.027 \mathrm{M}$. This is the lowest concentration obtained from sample analyses of the tank. [Ref. 9] Though these analyses indicated a range of $\mathrm{K}^{+}$concentration values in Tank $48 \mathrm{H}$ initially, this mass balance assumes the lowest $\mathrm{K}^{+}$ result because benzene releases have already exceeded the available NaTPB for higher concentrations.

- Initial Tank $48 \mathrm{H}$ volume was $1.78 \times 10^{6} \mathrm{I}(470,000 \mathrm{gal})$. 
W. L. Tamosaitis

Table 3. Tank 48H Organics Mass Balance.

\begin{tabular}{|c|c|c|c|c|}
\hline \multirow[b]{2}{*}{ Species } & \multicolumn{2}{|c|}{ Amount } & \multicolumn{2}{|c|}{$\begin{array}{c}\text { Equivalent } \\
\text { Benzene }\end{array}$} \\
\hline & Moles & $\mathrm{kg}$ & Moles & $\mathrm{kg}$ \\
\hline NaTPB Destroyed & 35,500 & 12,200 & 142,000 & 11,100 \\
\hline KTPB Destroyed & 92.7 & 33.2 & 371 & 29.0 \\
\hline CsTPB Destroyed & 0.06 & 0.03 & 0.24 & 0.02 \\
\hline $\begin{array}{l}\text { Benzene Released } \\
\text { (Oct. } 1 \text { - Nov. } 5 \text { ) }\end{array}$ & $641^{\mathrm{a}}$ & 50.0 & 641 & 50.0 \\
\hline $\begin{array}{l}\text { Benzene Released } \\
\text { (Nov. } 5-\text { Apr. 22) }\end{array}$ & $109,000^{\mathrm{a}}$ & 8,500 & 109,000 & 8,500 \\
\hline PBA & 8,100 & 1,000 & 8,100 & 633 \\
\hline $\begin{array}{l}\text { Phenol } \\
\text { (Oct. } 12 \text { - Nov. 5). }\end{array}$ & 633 & 59.6 & 633 & 49.4 \\
\hline $\begin{array}{l}\text { Phenol } \\
\text { (since Nov. 5) }\end{array}$ & 6,680 & 623 & 6680 & 518 \\
\hline Biphenyl & 2,730 & 421 & 5,460 & 427 \\
\hline Terpheny I & 141 & 32.5 & $42 \dot{3}$ & 33.0 \\
\hline Diphenyl Mercury & 81.0 & $3 \dot{8} .7$ & 162 & 12.7 \\
\hline
\end{tabular}

aThese benzene masses used measured GC benzene concentrations, and Tank $48 \mathrm{H}$ ventilation purge rate data in scfm (assumed to be at $0{ }^{\circ} \mathrm{C}$ and $1 \mathrm{~atm}$ ). There was no correction applied for humidity. As this report neared completion, personnel discovered that the purge rate assumed a reference temperature of $70^{\circ} \mathrm{F}$. Additionally, the GC benzene analyses are made on dry air while ventilation flow rate is measured for humid air. The total effect of these combined corrections should reduce the benzene release numbers by 10 to $15 \%$.

- 80,800 moles of NaTPB $(27,600 \mathrm{~kg})$ in $1.41 \times 10^{5}(37,300 \mathrm{gal})$ were added to Tank $48 \mathrm{H}$.

- 40,900 moles $(14,000 \mathrm{~kg})$ of NaTPB precipitated as KTPB and CsTPB.

- 4,320 moles $(1,480 \mathrm{~kg})$ of soluble NaTPB in $1.31 \times 10^{6} \mathrm{~L}$ $(346,000 \mathrm{gal})$ were transferred to Tank 50H. 
- Tank $48 \mathrm{H}$ volume for most of the period between November 9, 1995 and March 31, 1996 averaged $6.11 \times 10^{5} \mathrm{~L}(161,000 \mathrm{gal})$. This increased to $\sim 6.40 \times 10^{5}(169,000 \mathrm{gal})$ on April 12 .

- Phenylboric Acid (PBA) sample analyses indicated no significant change in PBA concentration since December 18. The PBA created is therefore based on the sample analyzed on April 15, 1996.

- Phenol concentrations seem to be trending up slightly; therefore, the phenol created is based on the results of the most recent Tank 48H sample. The concentration on November 5, 1995, prior to NaTPB destruction is subtracted from this. Additionally, since the sample results indicate that some phenol was created prior to November 5. ( 633 moles), this has been added into this number.

- Biphenyl is based on the average of samples taken on January 12 , 1996 and January 21, 1996. The contents of Tank 48H were assumed to be separated into a slurry phase containing solids, and a supernate phase with no solids, it was assumed that the results of the biphenyl analyses were good for the solids containing phase only and that the phase containing no solids also contained no biphenyl. The biphenyl concentration was corrected to an overall concentration for the whole tank. The biphenyl contained in Tank 48H on November 5, 1995 (based on the amount of biphenyl continued in the NaTPB added to Tank 48H) was subtracted.

\section{Table 4. Production of Organic Species from Destruction of} Tetraphenylborate.

\begin{tabular}{|c|c|}
\hline & \multicolumn{2}{c|}{$\begin{array}{c}\text { Moles Produced } \\
\text { Species }\end{array}$} & per mole TPB Destroyed \\
\hline Benzene & 3.08 \\
PBA & 0.23 \\
Phenol & 0.21 \\
Biphenyl & 0.08 \\
Terphenyl & 0.004 \\
Diphenyl Mercury & 0.002 \\
\hline Total & 3.68 \\
\hline
\end{tabular}

Note: Two phenyl groups are needed to produce biphenyl and diphenyl mercury; three are needed to produce terphenyl. One each is needed to produce each of the other species. This missing 0.34 moles of material is the result of the unaccounted for material. It is assumed to be $-906 \mathrm{~kg}$ of entrained benzene in Tank $48 \mathrm{H}$. 
Appendix B shows how the organics mass balance calculations were made. Table 4 gives the stoichiometric yield of the major decomposition products per molecule of NaTPB destroyed. It is based on the mass balance in Table 3 .

As stated above, previous Tank 48H mass balances used different assumptions for the amount of NaTPB destroyed. These assumptions depended primarily on the initial $\mathrm{K}^{+}$concentration assumed in Tank $48 \mathrm{H}$ and the amount of NaTPB added in September. The $\mathrm{K}^{+}$analyses ranged from $0.023 \mathrm{M}$ (implying the destruction of 35,500 moles of TPB or $11,100 \mathrm{~kg}$ of equivalent benzene) to $0.033 \mathrm{M}$ (implying the destruction of 17,700 moles of TPB or $5,530 \mathrm{~kg}$ of equivalent benzene). [Ref. 9]

An alternative method to calculate the mass balance is to assume that the change in soluble boron concentration is an accurate measure of the amount of NaTPB destroyed. Prior to the rapid catalytic reaction, the boron concentration was $104 \mathrm{mg} / \mathrm{L}$ of which $33 \mathrm{mg} / \mathrm{L}$ was due to soluble NaTPB. The average boron concentration since December 18 is $565 \pm 41$. The change attributable to $\mathrm{TPB}^{-}$decomposition is approximately $500 \mathrm{mg} / \mathrm{L}$. This corresponds to a total of 28,200 moles of NaTPB or $8800 \mathrm{~kg}$ of benzene.

The current generation rate of benzene from destruction of CsTPB and KTPB is estimated to be $13 \mu \mathrm{g} / \mathrm{L} / \mathrm{hr}$ or a total of $0.2 \mathrm{~kg} /$ day. This generation rate was obtained by linear regression of soluble $\mathrm{K}^{+}$and Cs-137 data obtained between December 8, 1995 and April 15, 1996 (Figure 6). The data are reasonably linear during that period although the most recent Cs sample shows a larger jump than expected. The fits of the data indicate that soluble $\mathrm{K}^{+}$and $\mathrm{Cs}^{+}$began appearing in Tank $48 \mathrm{H}$ about mid to late December.

Figure 6 also shows the soluble boron concentration. Soluble boron is almost constant since late December, especially when one considers that the volume in the tank has increased from approximately 154,000 gallons to 189,000 gallons since the ITP concentration phase. Since the boron concentration has been virtually constant since late December, it was decided to compare the soluble $\mathrm{K}^{+}$and $\mathrm{Cs}^{+}$. concentrations to the $\mathrm{B}$ concentration. Figure 7 shows that the $\mathrm{Cs}^{+}$ and $\mathrm{K}^{+}$concentrations nearly parallel each other.

Figure 8 gives the boron, hydroxide and organics (PBA and phenol) data for November 5, 1995. through April 15, 1996. The Iines through the data represent linear regression fits of the data. The fits of the boron and organics data are each broken into two parts with a break in mid to late December. This corresponds to the time that all of the NaTPB in Tank 48H was completely destroyed. After this time, the concentrations of boron and the organics are expected to be reasonably constant with a slight decrease due to the addition of water to the tank. The boron and hydroxide concentrations show this decrease, while the organics concentrations still indicate a slightly increasing concentration. 
W. I. Tamosaitis

Figure 6. Tank 48H soluble boron, potassium, and cesium concentrations.

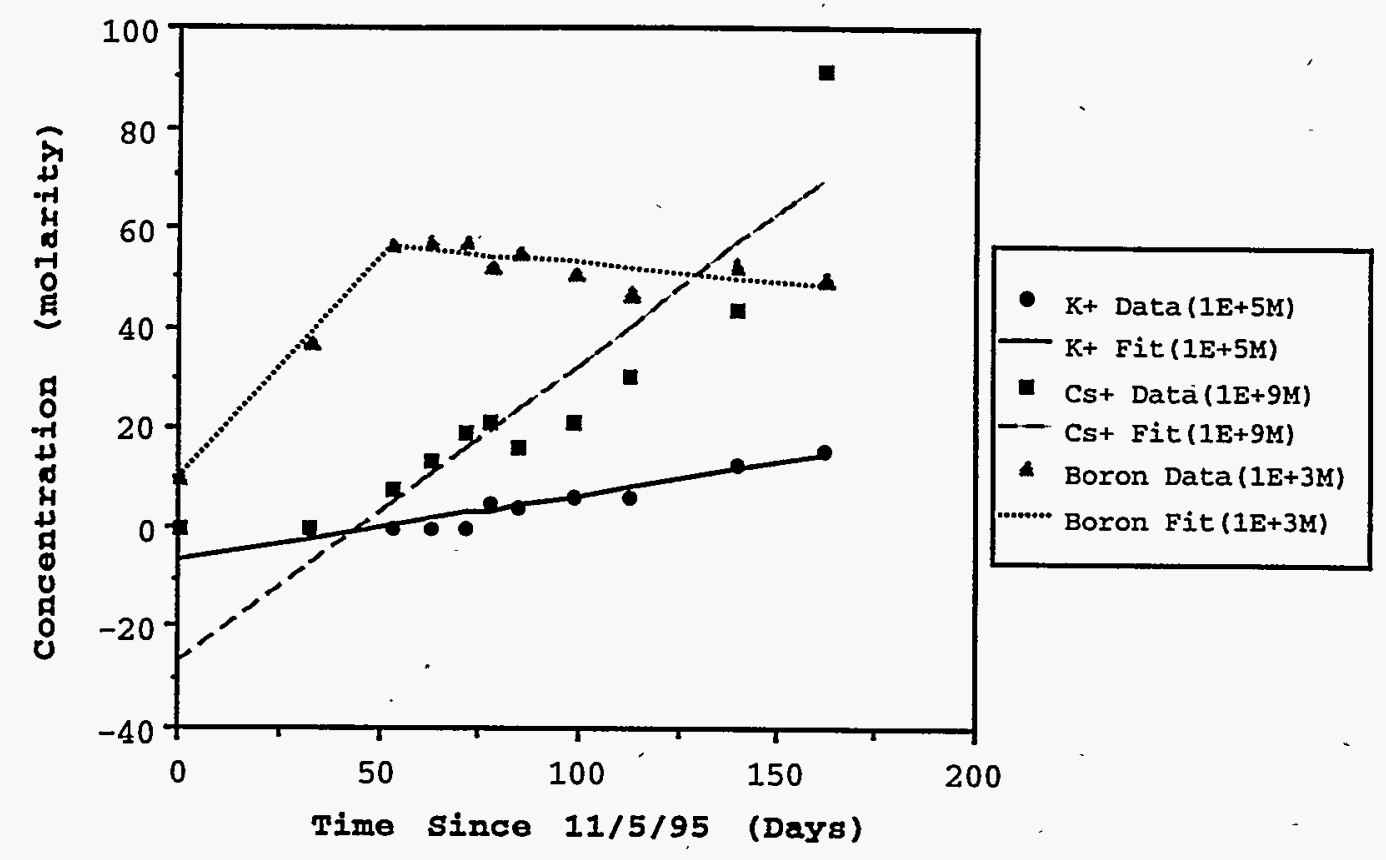

Figure 7. Molar ratio of potassium and cesium to boron in Tank $48 \mathrm{H}$ filtrate.

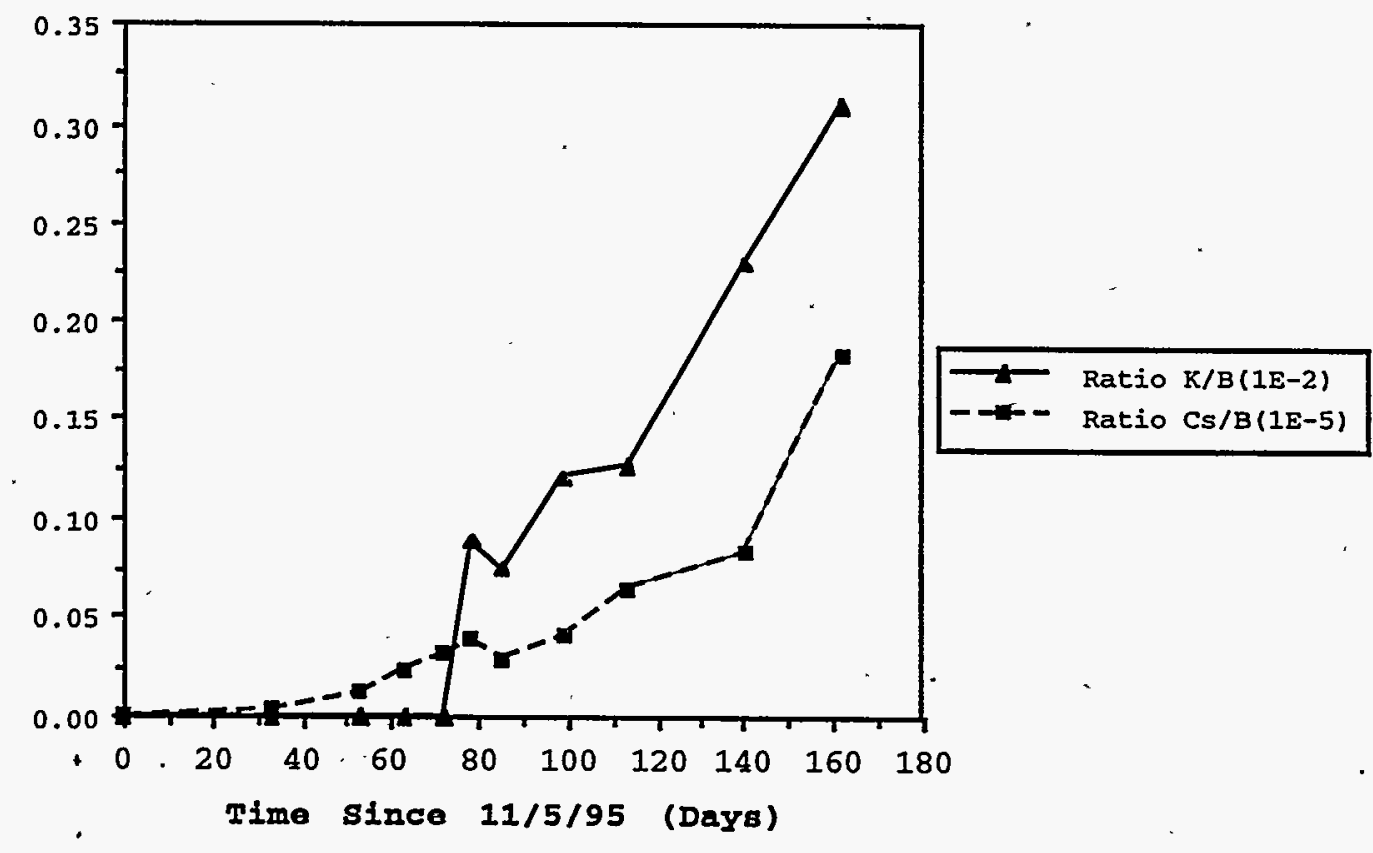


As with the soluble $\mathrm{K}^{+}$and $\mathrm{Cs}^{+}$, a plot of the ratio of the hydroxide and organics concentrations was produced (Figure 9). The hydroxide decreases slightly with respect to boron. The organics, however, still seem to be increasing slightly with respect to boron concentration.

\section{NaTPB Cold Feeds}

Eleven batches of NaTPB solution were added to Tank $48 \mathrm{H}$ during September. The cumulative volume of the batches was 37,300 gallons. Each batch was within specification. [Ref. 12] Benzene analysis was performed by gas chromatography. Phenol, PBA and biphenyl were analyzed by HPLC. Table 5 provides data from the analyses. Addition of the NaTPB solution to the 506,000 gallons of waste present in Tank $48 \mathrm{H}$ in September would have produced a composite waste solution with a PBA concentration of $45 \mathrm{mg} / \mathrm{L}$, a phenol concentration of $111 \mathrm{mg} / \mathrm{L}$, and a biphenyl concentration of $8 \mathrm{mg} / \mathrm{L}$.

Of the eleven batches added to Tank $48 \mathrm{H}$, seven were prepared by Aquafine, Inc. (i.e., batches designated with an AC prefix). The other four were prepared by Holley Oak Chemical Company. All eleven were prepared from the original NaTPB material supplied by AFF Inc.. This material contains significant quantities of NaTPB decomposition products as evidenced by the organics analysis and the brown color of the solution.

Figure 8. Tank 48H soluble boron, hydroxide, and organics concentrations.

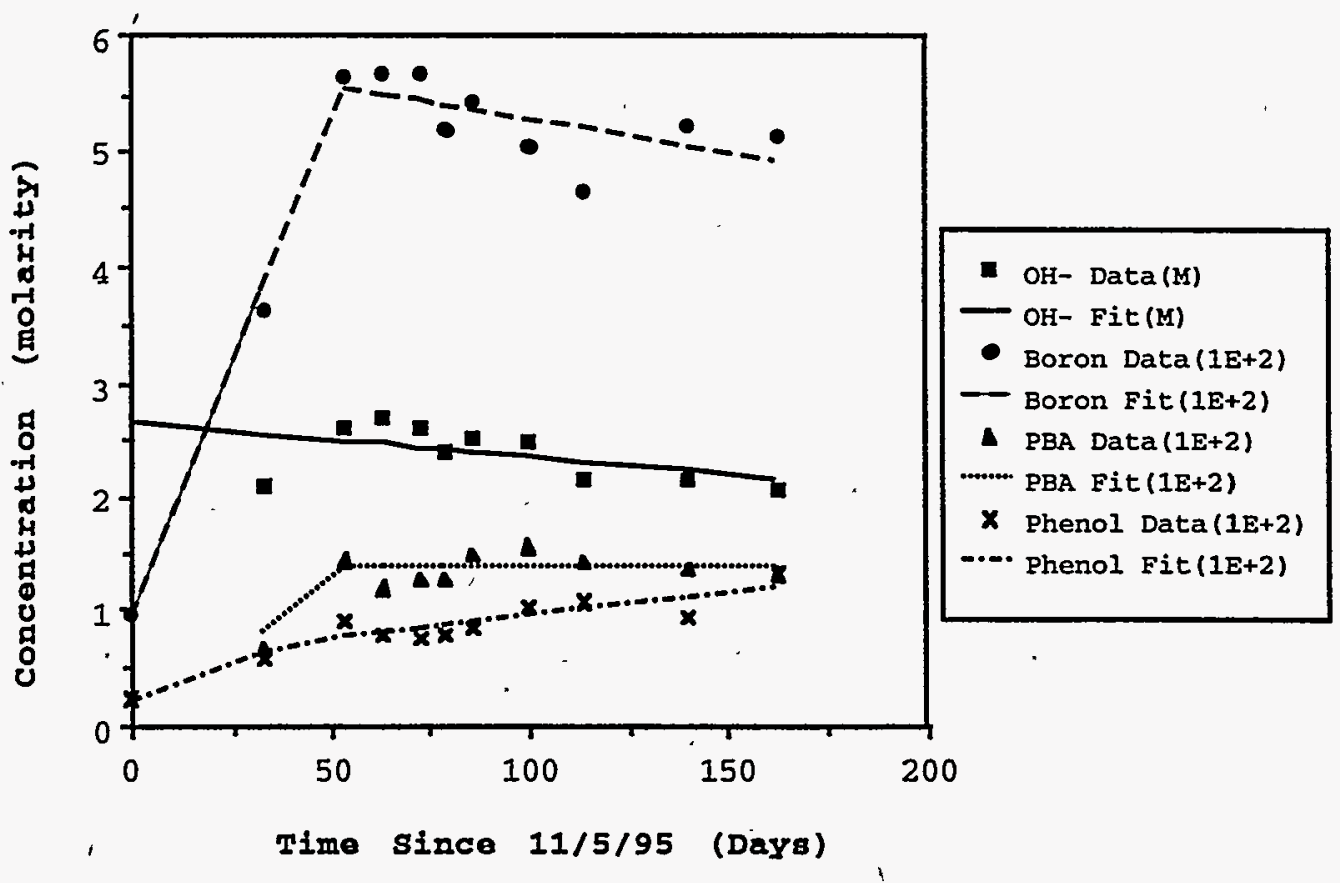


W. L. Tamosaitis

WSRC-TR-96-0113, Rev., 0

Figure 9. Molar ratio (soluble) of hydroxide and organics to boron in Tank $48 \mathrm{H}$.

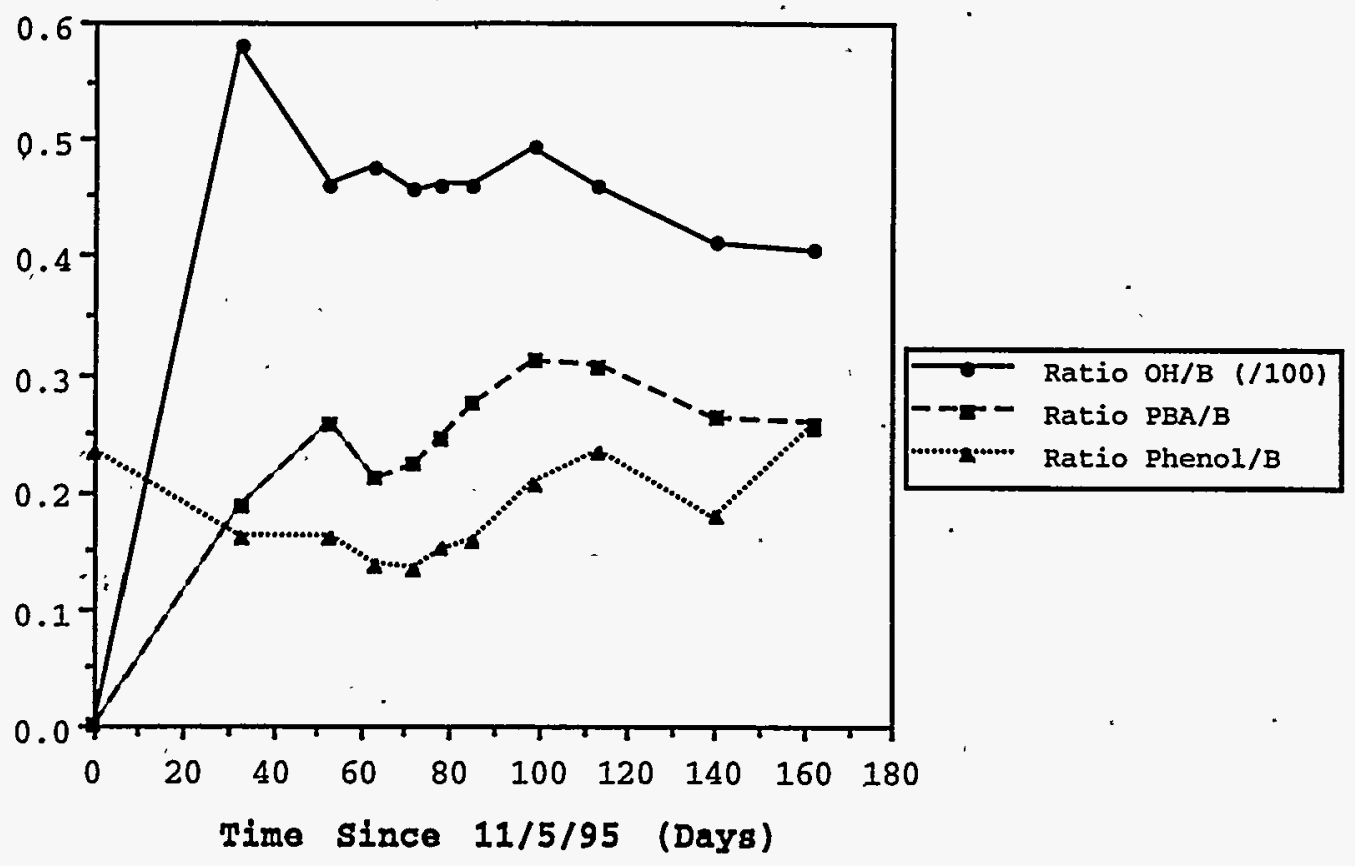

Boulder Scientific Company (BSC) serves as an alternate supplier of NaTPB to SRS and supplied the largest portion of material used in the 1983 demonstration. For comparative study, six batches of BSC NaTPB powder were sampled and analyzed for organic content by gas chromatograph and HPLC. Table 6 lists data from the analyses. Analysis indicates. that all six met specifications. Furthermore, each is significantly more pure than AFF NaTPB, with respect to NaTPB decomposition product impurities. The difference in organic

impurities is probably due to their production methods. AFF obtained the material by extraction while BSC obtained the material by crystallization. Crystallization is a purification technique and, by doing so, BSC purified the material. Toluene was found in small quantities in each BSC sample. It was, most likely the crystallization solvent used. For additional comparison, reagent grade NaTPB powder from Aldrich Chemical Company was analyzed by HPLC and found to contain $<10 \mathrm{mg} / \mathrm{L}$ each of $\mathrm{PBA}$, phenol, and biphenyl.

\section{Kinetics of Copper-Catalyzed NaTPB Decomposition}

Stability data from previous studies of copper-catalyzed NaTPB . decomposition were examined in an effort to derive a rate expression for this reaction. [Ref. 2,3] Previously identified variables demonstrated to affect the rate of reaction included the soluble TPB concentration, copper concentration, and hydroxide concentration. 
W. L. Tamosaitis

Table 5. Sodium tetraphenylborate solution analyses for those batches of material added to rank $48 \mathrm{H}$.

\begin{tabular}{|c|c|c|c|c|c|c|}
\hline Batch & $\begin{array}{c}\text { Volume } \\
\text { (gal) }\end{array}$ & $\begin{array}{c}\text { NaTPB } \\
(\text { molar })\end{array}$ & $\begin{array}{c}\text { Benzene } \\
(\mathrm{mg} / \mathrm{L}\end{array}$ & $\begin{array}{c}\text { PBA } \\
(\mathrm{mg} / \mathrm{L})\end{array}$ & $\begin{array}{c}\text { Phenol } \\
(\mathrm{mg} / \mathrm{L})\end{array}$ & $\begin{array}{c}\text { Bipheny } \\
(\mathrm{mg} / \mathrm{L})\end{array}$ \\
\hline AC-15 & 2735 & 0.53 & 143 & 515 & 1146 & 40 \\
AC-16 & 3650 & 0.57 & 179 & 948 & .1410 & 20 \\
AC-16 & 2342 & 0.56 & 80 & 758 & 1096 & 39 \\
AC-17 & 3200 & 0.55 & 48 & 315 & 2400 & 59 \\
AC-17 & 3907 & 0.59 & 169 & 315 & 2400 & 59 \\
AC-18 & 2006 & 0.59 & 161 & 274 & 1500 & 224 \\
AC-18 & 3301 & 0.63 & 190 & 274 & 1500 & 224 \\
D0528 & 5097 & 0.53 & $<20$ & 809 & 1249 & 32 \\
D0528 & 5103 & 0.54 & 12 & 809 & 1249 & 32 \\
D0528 & 1965 & 0.54 & 24 & 809 & 1249 & 32 \\
D0559 & 4033 & 0.54 & 33 & 632 & 1229 & 56 \\
\hline Average & 3390 & 0.56 & 103 & 609 & 1500 & 105 \\
\hline
\end{tabular}

Table 6. Organic analyses from prepared solutions of Boulder scientific Company NaTpB powder.

\begin{tabular}{|c|c|c|c|c|c|c|}
\hline Batch & $\begin{array}{c}\text { NaTPB } \\
\text { (molar) }\end{array}$ & $\begin{array}{c}\text { Benzene } \\
(\mathrm{mg} / \mathrm{L}\end{array}$ & $\begin{array}{c}\text { PBA } \\
(\mathrm{mg} / \mathrm{L})\end{array}$ & $\begin{array}{c}\text { Phenol } \\
(\mathrm{mg} / \mathrm{L})\end{array}$ & $\begin{array}{c}\text { Biphenyl } \\
(\mathrm{mg} / \mathrm{L})\end{array}$ & $\begin{array}{c}\text { Toluene } \\
(\mathrm{mg} / \mathrm{L})\end{array}$ \\
\hline BSC-142-186A & 0.539 & 13.6 & $<10$ & $<<10$ & 15 & 29.5 \\
BSC-142-250A & 0.540 & 3.3 & $<10$ & $<10$ & 17 & 22.2 \\
BSC-237-165A & 0.533 & 15.1 & 207 & $<10$ & 24 & 8.9 \\
BSC-237-217A & 0.534 & 10.9 & $<10$ & $<10$ & 17 & 0.9 \\
BSC-237-280A & 0.529 & 4.5 & $<10$ & $<10$ & 16 & $<1$ \\
BSC-237-324A & 0.530 & 3.2 & $<10$ & $<<10$ & 15 & $<1$ \\
\hline Average. & 0.534 & 8.4 & $<43$ & $<10$ & 17 & $<11$ \\
\hline
\end{tabular}


A kinetics analysis of the data indicated that tetraphenylborate decomposition most closely fit a first order effect. The rate expression shown in Equation 1 was obtained from the analysis where all concentrations are in molarity and [TPB']

$$
\begin{aligned}
\text { Rate } & =\mathrm{k}[\mathrm{Cu}]\left[\mathrm{TPB}^{-}\right] /\left[\mathrm{OH}^{-}\right] \\
\text {and } \mathrm{k} & =0.078 \mathrm{hr}^{-1} \text { at } 23{ }^{\circ} \mathrm{C}, \\
\mathrm{k} & =3.7 \mathrm{hr}^{-1} \text { at } 40{ }^{\circ} \mathrm{C}, \\
\mathrm{k} & =90 \mathrm{hr}^{-1} \text { at } 65{ }^{\circ} \mathrm{C},
\end{aligned}
$$

represents the concentration of soluble tetraphenylborate ion. A graph of $1 n k$ vs $1 / T$ (where $T$ is in $K$ ) is shown in Figure 10. From the graph, an activation energy, Ea, of $140 \mathrm{~kJ} / \mathrm{mole}$ was obtained.

\section{NaTPB Decomposition Catalysts}

\section{Copper}

Copper was'initially investigated as the cause of catalytic NaTPB decomposition in Tank 48H. As mentioned in the introduction, copper concentrations as low as $0.10 \mathrm{mg} / \mathrm{L}$ are capable of initiating the reaction. Tank $48 \mathrm{H}$ was analyzed and found to contain approximately

Figure 10. A kinetics plot of In $\mathrm{K}$ Vs 1/T for the coppercatalyzed decomposition of NaTPB.

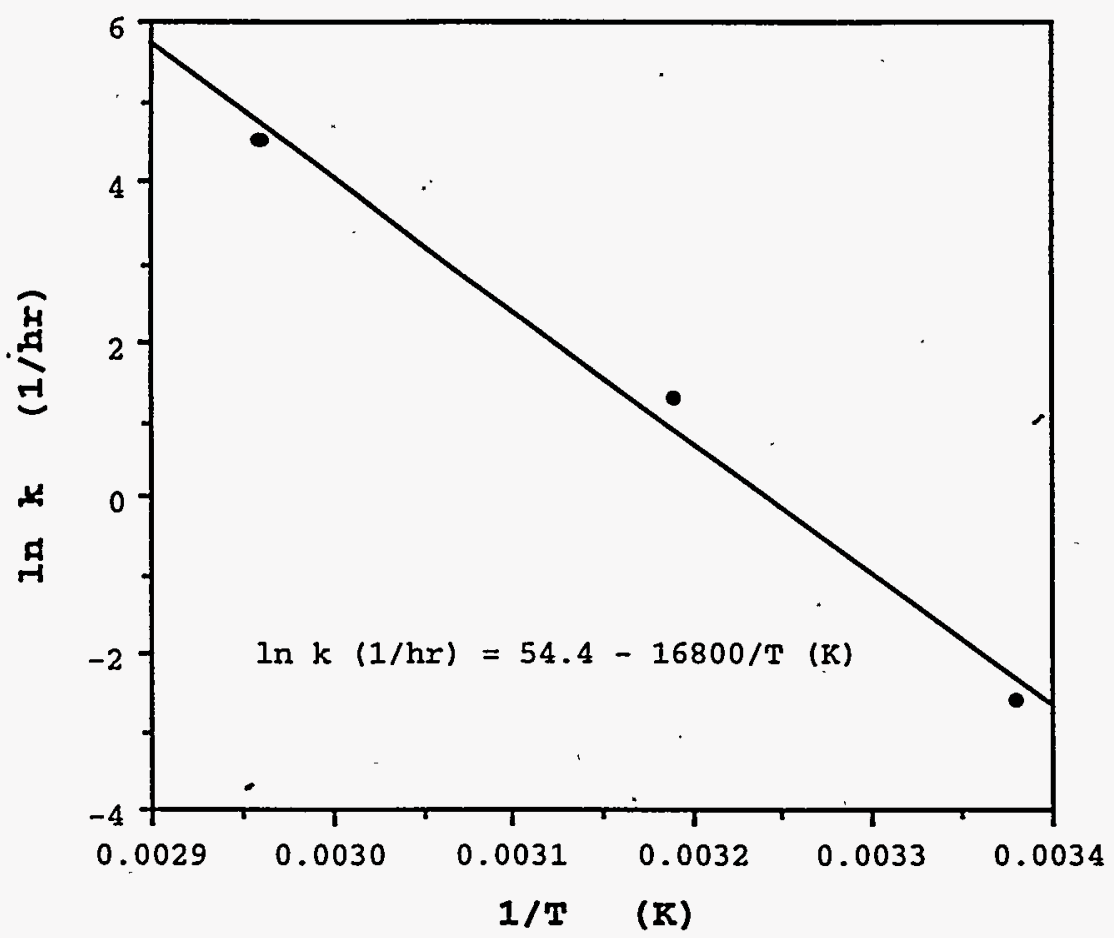


$1.4 \mathrm{mg} / \mathrm{L}$ soluble copper. All sources of material in Tank.48H were examined for copper content to determine the possible contaminant. Table 7 lists the copper concentration and contributing volumes for these potential sources. Based upon the data, the source of copper contamination was the waste itself. A precipitate slurry sample obtained from Tank $48 \mathrm{H}$ in the late $1980^{\prime} \mathrm{s}$ was found to contain 7.5 $\mathrm{mg} / \mathrm{L}$ of insoluble copper. This supports the observation that the salt solution waste itself is contaminated with copper prior to treatment. Data is not available to assess the copper contribution from Taink 38H.

Speculation focused upon the solubility of copper in caustic waste solution. D. T. Hobbs investigated this question and found that the copper solubility profile passes through a minimum at a hydroxide concentration of 0.01 molar. [Ref. 13] At the high hydroxide concentrations found in Tank 48H, the soluble copper concentration is above $1.8 \mathrm{mg} / \mathrm{L}$ and may be an order of magnitude higher. Copper solubility as a function of hydroxide concentration and waste type is shown graphically in Figure 11. Copper was observed to increase significantly in concentration at higher hydroxide concentrations. At $\mathrm{pH} 10$ and $\mathrm{pH} 12$, the concentration of copper in high activity waste (HAW) and low activity waste (LAW) simulants was less than 0.2 $\mathrm{mg} / \mathrm{L}$. In the HAW simulant, the copper concentrations were 32.6 and $342 \mathrm{mg} / \mathrm{I}$, at $1.2 \mathrm{molar}$ and 5.0 molar hydroxide concentrations, respectively. In the LAW simulant, the copper concentrations were 1.78 and $190 \mathrm{mg} / \mathrm{L}$, at 1.2 molar and 5.0 molar hydroxide concentrations, respectively. The lower copper concentrations in the LAW simulant compared to the HAW simulant are attributed to coprecipitation with ferric hydroxide that was also in the simulant. These results in this study are higher than, but consistent with, the trends reported for cupric oxide in aqueous solutions of sodium hyaroxide. [Ref. 14]

Table 7. Potential Tank 48H copper contaminant sources.

\begin{tabular}{|l|c|c|}
\hline \multicolumn{1}{|c|}{ Source } & $\begin{array}{c}\text { Volume } \\
\text { (kgal) }\end{array}$ & $\begin{array}{c}\text { Copper } \\
\text { Concentration } \\
\text { (mg/L) }\end{array}$ \\
\hline $\begin{array}{l}\text { Bearing water and other } \\
\text { miscellaneous additions }\end{array}$ & 10 & 0.003 (soluble) \\
monosodium titanate & 2 & $<0.0001$ (total) \\
NaTPB solution & 37.3 & $<1$ (soluble) \\
Tank 48H (July 199.5) & 420 & $<4$ (soluble) \\
Tank 38H & 130 & undetermined \\
\hline
\end{tabular}


Figure 11. Copper solubility as a function of hydroxide concentration and waste type. [Ref. 13]

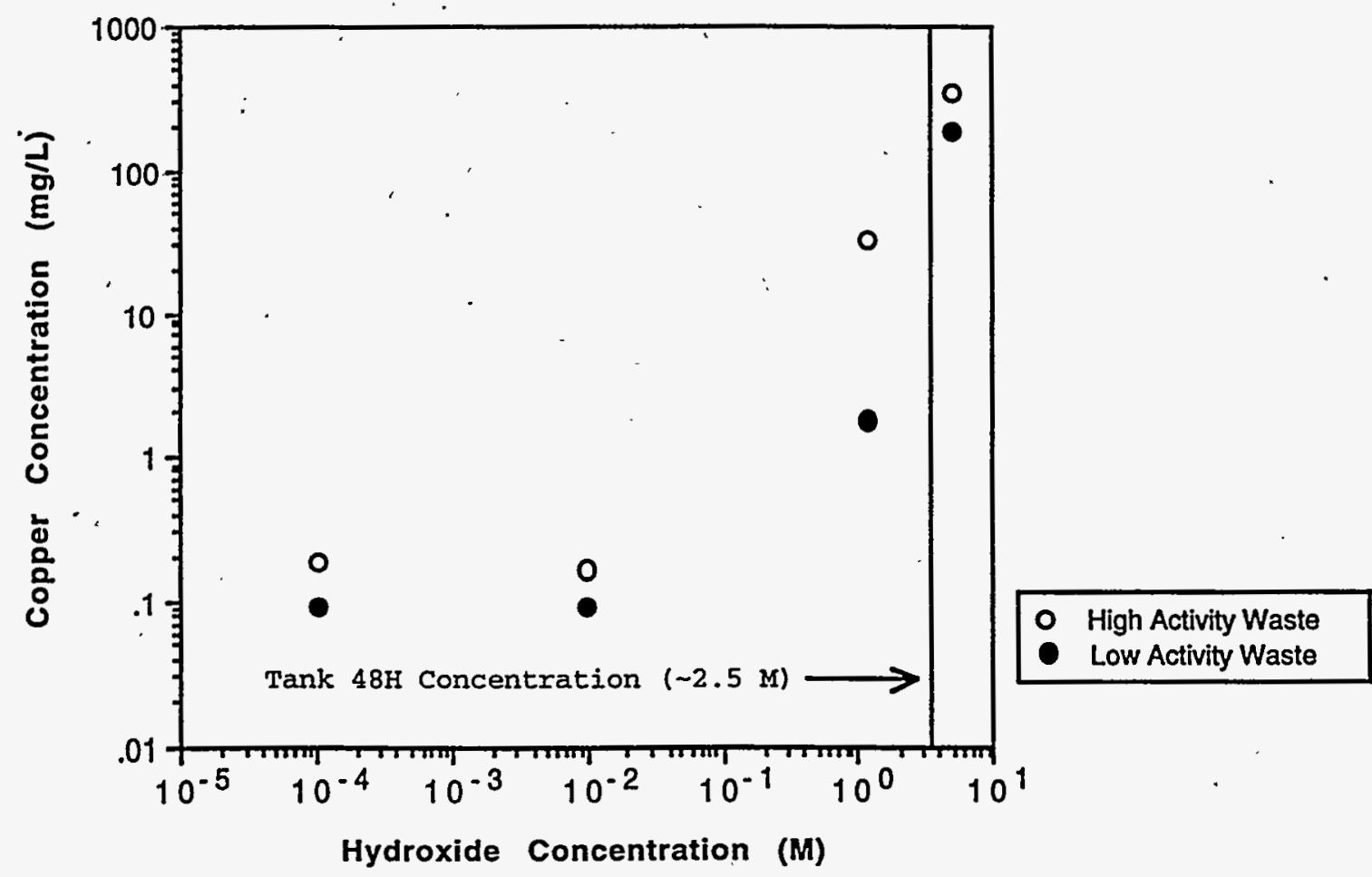

\section{Potential Catalysts}

A literature review was performed on tetraphenylborate chemistry and discussions were held with both internal and external experts in the areas of tetraphenylborate chemistry, catalysis, and radiolysis.

[Ref. 15] The purpose of these investigations was to identify potential TPB decomposition catalysts. "From these reviews, more than twenty-five metals were postulated as potential catalysts.

For comparative purposes, Tank $48 \mathrm{H}$ filtrate was analyzed by ICP-ES and ICP-MS. Table 8 lists the metals observed and their respective concentrations. Less than values are provided for those species which were analyzed for but found to be less than their detection limit. In addition, Tank $48 \mathrm{H}$ sludge (pre-ITP Batch 1) was analyzed. For informational purposes, the availability of solubility data for these metals in alkaline waste simulants is shown. An additional column notes if the postulated catalysts were previously tested for the ability to catalytically decompose sodium tetraphenylborate.

In addition to the listed metals; aluminum (0.6 - 2.9 wt 8$)$, phosphorous $(0.01-0.04$ wt $\%)$, calcium $(0.09-0.21$ wt $\%)$, barium $(0.02-0.03$ wt $\%)$, and magnesium $(0.05-0.08$ wt 8$)$ were detected in the Tank 48H sludge. Silicon (18 ppm) and phosphorous (340 ppm) were identified in the Tank 48H filtrate by ICP-ES. Gallium (1.39 ppm), 
Table 8. Summary Table of Postulated Catalysts.

\begin{tabular}{|c|c|c|c|c|c|}
\hline $\begin{array}{l}\text { Postulated } \\
\text { Catalysts }\end{array}$ & $\begin{array}{c}\text { Concentration } \\
\text { in Tank } 48 \mathrm{H} \\
\text { Filtrate } \\
\text { by ICP-ES } \\
\text { (ppm) (a) }\end{array}$ & $\begin{array}{c}\text { Concentration } \\
\text { in Tank 48H } \\
\text { Filtrate } \\
\text { by ICP-MS } \\
(\mathrm{ppm})(\mathrm{a})\end{array}$ & $\begin{array}{c}\text { Concentration } \\
\text { in Tank } 48 \mathrm{H} \\
\text { Solids } \\
\text { (wt \% of total } \\
\text { insolubles) (b) }\end{array}$ & $\begin{array}{l}\text { Available } \\
\text { Solubility } \\
\text { Data (c) } \\
\end{array}$ & $\begin{array}{l}\text { Catalytic } \\
\text { Activity } \\
\end{array}$ \\
\hline copper & 1.4 (d) & $\mathrm{ND}$ & $0.009-0.05$ & yes & $\operatorname{active}(\mathrm{f}, \mathrm{g})$ \\
\hline manganese & $<0.27$ & ND (e) & $0.07-0.7$ & yes & inactive $(f)$ \\
\hline chromium & 68 & 73 & $0.08-0.15$ & no & inactive(h) \\
\hline ruthenium & $\mathrm{ND}$ & 0.8 & $\mathrm{ND}$ & no & not tested \\
\hline palladium & $\mathrm{ND}$ & 0.4 & $\mathrm{ND}$ & no & not tested \\
\hline rhodium & $\mathrm{ND}$ & 0.2 & $\mathrm{ND}$ & no & not tested \\
\hline uranium & $\mathrm{ND}$ & 1.0 & $0.02-0.03$ & yes & not tested \\
\hline iron & $<1.4$ & $\mathrm{ND}$ & $0.4-0.9$ & yes & inactive( $j$ ) \\
\hline mercury & $\mathrm{ND}$ & $<0.05$ & ND & no & inactive $(\mathrm{g})$ \\
\hline zinc & 7.7 & 4.2 & $0.01-0.04$ & yes & inactive $(\mathrm{g})$ \\
\hline molybdenum & 10.8 & 12 & $\mathrm{ND}$ & yes & not tested \\
\hline silver & $\mathrm{ND}$ & $<0.01$ & ND & yes & not tested \\
\hline nickel & $<2.3$ & $\mathrm{ND}$ & $0.01-0.04$ & yes & inactive $(\mathrm{f})$ \\
\hline platinum & $\mathrm{ND}$ & $<0.01$ & ND & no & not tested \\
\hline antimony & $\mathrm{ND}$ & $<0.05$ & $\mathrm{ND}$ & yes & not tested \\
\hline bismuth & ND & ND & $\mathrm{ND}$ & no & not tested \\
\hline cadmium & $<0.46$ & $<0.05$ & $\mathrm{ND}$ & yes & not tested \\
\hline cerium & $\mathrm{ND}$ & $<0.01$ & $\mathrm{ND}$ & yes & not tested \\
\hline cobalt & $<1.8$ & $\mathrm{ND}$ & ND & yes & not tested \\
\hline lanthanum & $<0.27$ & $\mathrm{ND}$ & $\mathrm{ND}$ & yes & not tested \\
\hline technetium & $\mathrm{ND}$ & 2 & $\mathrm{ND}$ & no & not tested \\
\hline thallium & $\mathrm{ND}$ & $<0.01$ & $\mathrm{ND}$ & no & not tested \\
\hline $\operatorname{tin}$ & 2.3 & 0.9 & ND & yes & not tested \\
\hline titanium & $<0.09$ & $\mathrm{ND}$ & $3.8-6.2$ & yes & not tested \\
\hline zirconium & $<0.46$ & $<0.05$ & $\mathrm{ND}$ & yes & not tested \\
\hline
\end{tabular}

(a) Sample taken on December 1, 1995.

(b) Reference 16 - Sample from July 1995 and represents pre-reaction material. The total insoluble solids concentration in the sample was 0.55 wt 8 .

(c) Unpublished data from D. T. Hobbs.

(d) Result is from a sample taken from Tank 48H on December 18, 1995.

(e) ND indicates data for the specific metal was not obtained.

(f) Reference 17.

(g) Reference 2 .

(h) Reference 2 showed chromium to be inactive while that reported in Reference 17 indicated chromium was an active catalyst.

(i) References 2, 17, and 18 showed iron to be inactive while that reported in Reference 19 indicated iron was an active catalyst.

selenium $(0.8 \mathrm{ppm})$, lead $(1.5 \mathrm{ppm})$, and arsenic $(0.1 \mathrm{ppm})$ were observed in Tank 48H filtrate by ICP-MS. As noted in the table, some species were previously tested for catalytic activity in sodium tetraphenylborate solution. Other species tested, in addition to those in the table, included lead, magnesium, phenol, PBA, borax, and hydrogen peroxide. Each was determined to be inactive. 
Isopropanol and methanol were present in large quantities in the 1983 Demonstration but were present in much smaller quantities in Batch 1. The concentrations of methanol and isopropanol in the 1800 gallons of monosodium titanate added to Batch 1 were $50 \mathrm{mg} / \mathrm{L}$ and $139 \mathrm{mg} / \mathrm{L}$, respectively. It has been speculated that the presence of large quantities of alcohol may have prevented a radical decomposition NaTPB in the 1983 demonstration. Another theory speculates that the presence of organic decomposition products (e.g., triphenylboron, phenol, phenylboric acid, or a radical species) may initiate or be involved in the catalytic decomposition. Previous experiments performed to test this theory did not show that any of these have catalytic activity. [Ref. 2]

\section{Non-Radioactive Simulant Slurry Recipe}

Based upon the list of potential catalysts, a recipe for a representative, non-radioactive precipitate slurry simulant was developed. [Ref. 15] This is shown in Table 9. The recipe represents a hypothetical simulant that contains the primary components of Tank $48 \mathrm{H}$ precipitate slurry. The composition of non-radioactive simulants tested were varied depending upon the objective of the test being performed.

Table 9. Non-radioactive precipitate slurry simulant.

\begin{tabular}{|c|c|}
\hline Component & Concentration \\
\hline $\mathrm{Na}^{+}$ & $4.7 \mathrm{M}$ \\
\hline $\mathrm{OH}^{-}$ & $2.7 \mathrm{M}$ \\
\hline $\mathrm{NO}_{2}^{-}$ & $0.70 \mathrm{M}$ \\
\hline $\mathrm{NO}_{3}^{-}$ & $0.69 \mathrm{M}$ \\
\hline $\mathrm{AlO}_{2}^{-}$ & $0.17 \mathrm{M}$ \\
\hline $\mathrm{SO}_{4}^{2-}$ & $0.010 \mathrm{M}$ \\
\hline $\mathrm{CO}_{3}^{2-}$ & $0.19 \mathrm{M}$ \\
\hline $\mathrm{Cl}^{-}$ & $0.014 \mathrm{M}$ \\
\hline $\mathrm{F}^{-}$ & $0.008 \mathrm{M}$ \\
\hline $\mathrm{PO}_{4}^{3-}$ & $0.006 \mathrm{M}$ \\
\hline $\mathrm{TPB}^{-}$ & $0.0033 \mathrm{M}$ \\
\hline copper (aq) & $1.4 \mathrm{mg} / \mathrm{L}$ \\
\hline chromium (aq) & $73 \mathrm{mg} / \mathrm{L}$ \\
\hline ruthenium (ag) & $0.8 \mathrm{mg} / \mathrm{L}$ \\
\hline palladium (ag) & $0.4 \mathrm{mg} / \mathrm{L}$ \\
\hline rhodium (aq) & $0.2 \mathrm{mg} / \mathrm{L}$ \\
\hline iron (aq) & $1.4 \mathrm{mg} / \mathrm{L}$ \\
\hline $\operatorname{zinc}(a g)$ & $7.7 \mathrm{mg} / \mathrm{L}$ \\
\hline molybdenum (aq) & $12 \mathrm{mg} / \mathrm{L}$ \\
\hline $\operatorname{tin}(a q)$ & $2.3 \mathrm{mg} / \mathrm{L}$ \\
\hline KTPB (s) & $4.0 \mathrm{wt} \%$ \\
\hline NaTPB (s) & $0.6 \mathrm{wt} \%$ \\
\hline $\operatorname{MST}(s)$ & 0.20 wt \% \\
\hline Sludge (s) & 0.20 wt \% \\
\hline
\end{tabular}




\section{Characterization of Tank 48H Insoluble Solids}

Different types of insoluble solids exist in Tank 48H. These include KTPB, NaTPB, MST, sludge, CsTPB, biphenyl, terphenyl, and

diphenylmercury. The distribution of the primary insoluble species as a percentage of the total amount of insoluble solids as a function of time (pre-startup through post-TPB degradation), is shown in Table 10. Table 11 provides the percentage of these four insoluble species in Tank $48 \mathrm{H}$ salt solution over the same time period.

\section{Table 10. Composition of insoluble solids in Tank $48 \mathrm{H}$ from} July 1995 through March 1996.

(July 1995 represents the tank condition prior to startup. October 1995 represents the tank condition after startup but prior to concentration. November 19.95 represents the tank condition after concentration but prior to NaTPB degradation. March 1996 represents the tank condition after NaTPB degradation.)

\begin{tabular}{|c|c|c|c|c|}
\hline Component & $\begin{array}{c}\text { July } \\
1995\end{array}$ & $\begin{array}{c}\text { October } \\
1995\end{array}$ & $\begin{array}{c}\text { November } \\
1995\end{array}$ & $\begin{array}{c}\text { March } \\
1996\end{array}$ \\
\hline KTPB (g/100 g solids) & 76 & 78.4 & 78.4 & 89.3 \\
NaTPB (g/100 g solids) & 0 & 12.2 & 12.2 & 0 \\
MST (g/100 g solids) & 11 & 5.4 & 5.4 & 6.2 \\
Sludge (g/100 g solids) & 13 & 4 & 4 & 4.5 \\
\hline Total Solids (g/100 g soln) & 0.55 & 1.7 & 5.6 & 4.9 \\
\hline
\end{tabular}

Table 11. Insoluble solids composition in Tank 48H from July 1995 through March 1996.

(July 1995 represents the tank condition prior to startup. October 1995 represents the tank condition after startup but prior to concentration. November 1995 represents the tank condition after concentration but prior to NaTPB degradation. March 1996 represents the tank condition after NaTPB degradațion.)

\begin{tabular}{|c|c|c|c|c|}
\hline Component & $\begin{array}{c}\text { July } \\
1995\end{array}$ & $\begin{array}{c}\text { October } \\
1995\end{array}$ & $\begin{array}{c}\text { November } \\
1995\end{array}$ & $\begin{array}{c}\text { March } \\
1996\end{array}$ \\
\hline KTPB (g/100 g soln) & 0.418 & $1.33^{\circ}$ & 4.39 & 4.38 \\
NaTPB (g/100 g soln) & 0 & 0.207 & 0.683 & 0 \\
MST (g/100 g soln) & 0.060 & 0.092 & 0.302 & $0: 304$ \\
Sludge (g/100 g soln) & 0.072 & 0.068 & 0.224 & 0.220 \\
Supernate (g/100 g soln) & 99.45 & 98.3 & 94.4 & 95.1 \\
\hline
\end{tabular}


Investigations into potential catalysts included attention on sludge as a potential heterogeneous catalyst to promote the decomposition of NaTPB. Many of the individual species identified earlier as potential catalysts are present in sludge. For this reason, the sludge composition of Tank $48 \mathrm{H}$ was examined. [Ref. 16] In addition to Tank 48H, the composition of Tank 51H sludge was examined. [Ref. 20] Tank $51 \mathrm{H}$ sludge has been used in tests as a surrogate for Tank $48 \mathrm{H}$ to decouple the influence of monosodium titanate from the sludge proper. The compositions of Tank $48 \mathrm{H}$ and Tank $51 \mathrm{H}$ sludge are shown in Table 12. In addition to sludge, researchers speculated that MST -- with adsorbed plutonium, uranium and other metal species -- may act as an active heterogeneous catalyst.

Table 12. Characterization of Tank $48 \mathrm{H}$ and Tank 51H sludge compositions.

\begin{tabular}{|c|c|c|}
\hline Component & $\begin{array}{c}\text { Tank 48H [Ref. 16] } \\
\text { (g/100 g sludge) }\end{array}$ & $\begin{array}{l}\text { Tank 51H [Ref. 20] } \\
\text { (g/100 g sludge) }\end{array}$ \\
\hline iron & 4.17 & 24.60 \\
\hline sodium & 38.14 & 8.74 \\
\hline aluminum & 11.60 & 6.39 \\
\hline uranium & 0.20 & 3.42 \\
\hline manganese & 0.76 & 2.53 \\
\hline calcium & 1.09 & 2.38 \\
\hline magnesium & 0.48 & 1.16 \\
\hline silicon & $\mathrm{NA}^{\mathrm{a}}$ & 0.63 \\
\hline phosphorous & 0.18 & 0.53 \\
\hline nickel & 0.16 & 0.26 \\
\hline chromium & 0.91 & 0.17 \\
\hline mercury & $\mathrm{NA}$ & 0.15 \\
\hline potassium & $\mathrm{NA}$ & 0.05 \\
\hline copper & 0.16 & 0.03 \\
\hline titanium & $\mathrm{NA}$ & 0.02 \\
\hline plutonium & 0.007 & 0.01 \\
\hline silver & NA & 0.01 \\
\hline ruthenium & $\mathrm{NA}$ & 0.003 \\
\hline rhodium & $\mathrm{NA}$ & 0.001 \\
\hline palladium & NA & 0.001 \\
\hline zinc & 0.16 & $\mathrm{NA}$ \\
\hline barium & 0.18 & $\mathrm{NA}$ \\
\hline oxygen \& water & 41.80 & 48.91 \\
\hline
\end{tabular}




\section{Experimental Tests}

\section{Ventilated Radioactive Tests}

Researchers performed radioactive tests to duplicate the NaTPB reaction in Tank $48 \mathrm{H}$ and to investigate the effect of different variables on NaTPB decomposition. Initial tests focused on the effect of potential soluble catalytic species. Figure 12 shows the rate of benzene generation obtained from Tank $48 \mathrm{H}$ filtrate (Nov. 5 sample): The filtrate was continuously ventilated with $10 \mathrm{~mL} / \mathrm{min}$ air, stirred, and heated at $40^{\circ} \mathrm{C}$. The as-received filtrate generated benzene at a rate of $2 \mu \mathrm{g} / \mathrm{L} / \mathrm{hr}$. Sufficient AFF NaTPB solution (prepared from a composite of the archived samples remaining from the batches added to Tank $48 \mathrm{H}$ in September) was added to the filtrate to produce 1.8 wt of insoluble NaTPB. At that time, the benzene generation rate increased to $74 \mu \mathrm{g} / \mathrm{L} / \mathrm{hr}$. The rate peaked and eventually yielded a rate that varied from 20 to $50 \mu \mathrm{G} / \mathrm{L} / \mathrm{hr}$ :

Addition of excess potassium ion did not affect the rate. This lack of effect is believed largely due to the continued degradation of NaTPB intermediate decomposition products not precipitated by potassium. The cause of the jump in benzene production upon addition of NaTPB solution indicates that there was probably very little TPB remaining in the filtrate. Presumably, most, if not all, of the benzene generation activity is due to the $1.5 \mathrm{mg} / \mathrm{L}$ copper present in the filtrate. Appendix $C$ contains data from this test.

\section{Figure 12. Benzene generation rate as a function of time} for Tank $48 \mathrm{H}$ filtrate.

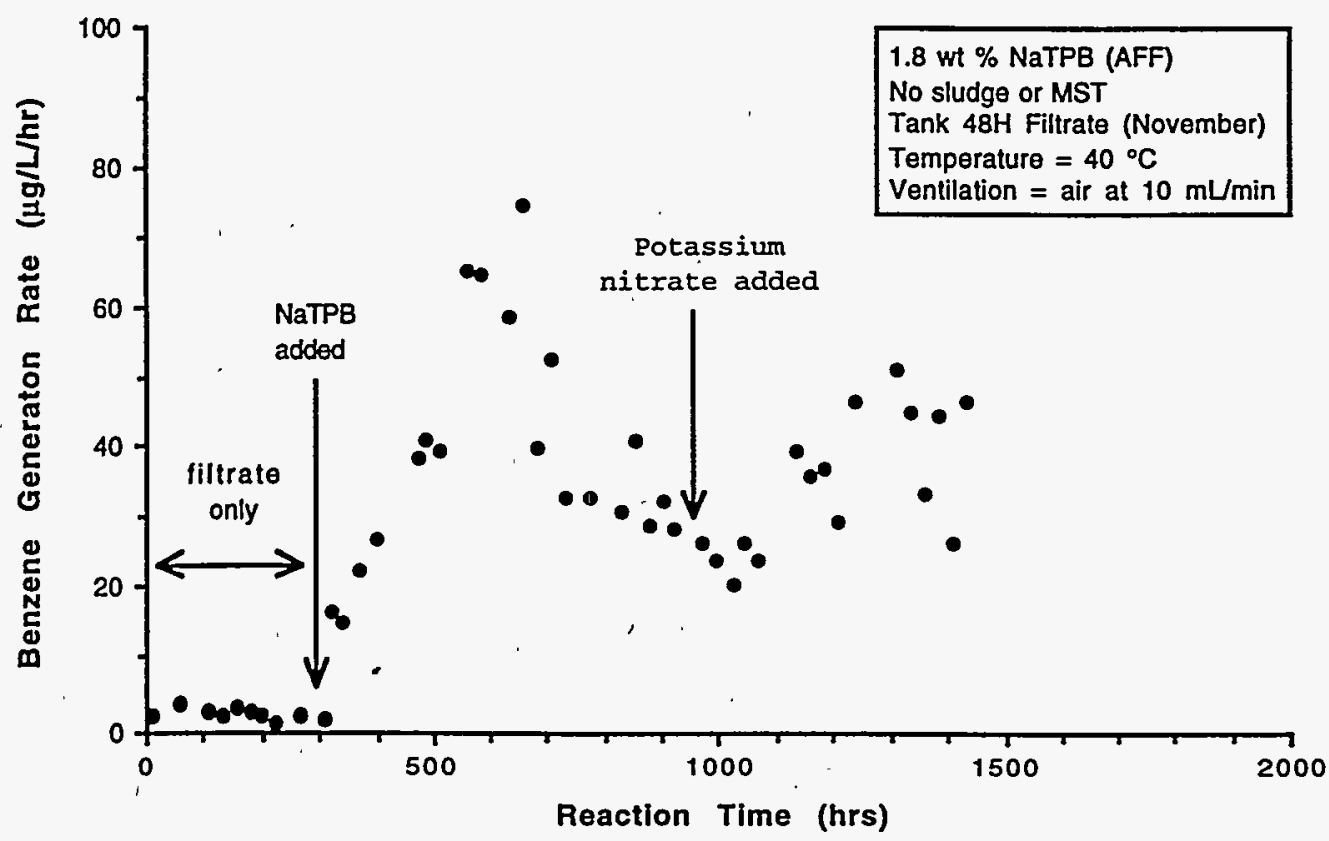


Another radioactive test assessed the impact of sludge on NaTPB decomposition. At the time of the test, Tank $48 \mathrm{H}$ sludge and MST solids were not available. Also, the researchers wanted to determine the influence of the sludge without the presence of MST. Hence, 0.2 wt of Tank $51 \mathrm{H}$ sludge was used. Tank $48 \mathrm{H}$ filtrate (Nov. 5 sample) was used as the solution medium. A 3 wt $\%$ excess of oven-dried AFF NaTPB powder was added to the filtrate. The oven-dried AFF NaTPB powder was prepared for use by overnight low-temperature $\left(40^{\circ} \mathrm{C}\right)$ evaporation of AFF NaTPB solution (prepared from a composite of the archived samples remaining from the batches added to Tank 48H in september). This method of preparation was necessary to prevent dilution of the Tank $48 \mathrm{H}$ filtrate. The solution was continuously ventilated with 10 $\mathrm{mL} / \mathrm{min}$ air, stirred, and heated at $40^{\circ} \mathrm{C}$. Data from the test are shown in Figure 13 and contained in Appendix D.

The solution almost instantaneously began to generate benzene. The rate increased linearly until it reached a maximum of $672 \mu \mathrm{g} / \mathrm{L} / \mathrm{hr}$. The rate of benzene generation then decreased linearly. To study the effect of temperature, the reaction temperature was raised from 40 to $50{ }^{\circ} \mathrm{C}$ to simulate the maximum temperature observed in Tank $48 \mathrm{H} \quad(\sim 52$ $\left.{ }^{\circ} \mathrm{C}\right)$. An immediate increase from 362 to $795 \mu \mathrm{g} / \mathrm{L} / \mathrm{hr}$ in the benzene generation rate was observed. The benzene generation rate peaked at

Figure 13. Benzene generation rate for Tank $48 \mathrm{H}$ filtrate containing 0.2 wt \% Tank $51 \mathrm{H}$ sludge and oven-dried AFF NaTPB.

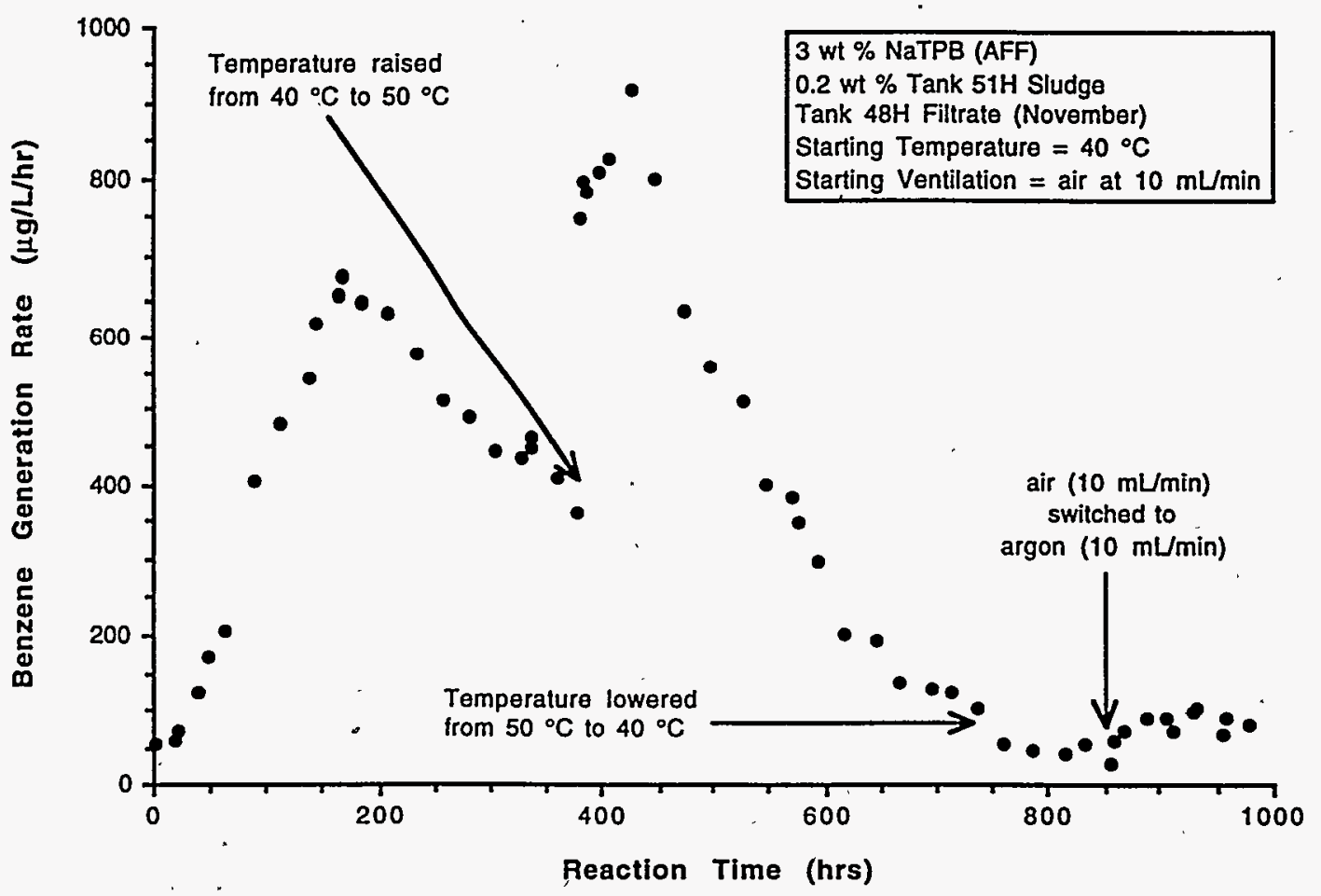


$916 \mu \mathrm{g} / \mathrm{L} / \mathrm{hr}$. After this occurred, the rate of benzene generation began to decrease linearly. Eventually, the benzene generation rate reached steady state at approximately $40 \mu \mathrm{g} / \mathrm{L} / \mathrm{hr}$. Later in the test, the ventilation gas was changed from air to argon. In doing so, the benzene generation rate increased from 40 to $92 \mu \mathrm{g} / \mathrm{L} / \mathrm{hr}$.

Several observations result from this test. First, the method of preparation (i.e., low-temperature evaporation) may affect the stability of NaTPB. Second, the presence of Tank $51 \mathrm{H}$ sludge may promote the decomposition of NaTPB. Third, a $10{ }^{\circ} \mathrm{C}$ increase in temperature results in an increase in the benzene generation rate. Fourth, use of an inert gas for ventilation results in an increase in the benzene generation rate. The latter two observations will be discussed in further detail later in this section.

Tank 48H sludge and MST solids were isolated from a December sample of Tank $48 \mathrm{H}$ precipitate slurry. These solids were added to Tank $48 \mathrm{H}$ filtrate (Nov. 5 sample) to produce a combined sludge and MST solids content of 0.51 wt $\%$. In comparison, Tank $48 \mathrm{H}$ contained 0.52 wt $\%$ sludge and MST solids after concentration (i.e., after November 7). Again, a 3 wt $\%$ excess of oven-dried AFF NaTPB powder was added to the filtrate. The oven-dried AFF NaTPB powder was prepared as described for the previous test. The test solution was continuously ventilated with $10 \mathrm{~mL} / \mathrm{min}$ air, stirred, and heated at $40{ }^{\circ} \mathrm{C}$. Data from the test is shown in Figure 14 and listed in Appendix $\mathrm{E}$.

The initial benzene generation rate was approximately $2035 \mu \mathrm{g} / \mathrm{L} / \mathrm{hr}$ and increased rapidly to a maximum of almost $8600 \mu \mathrm{g} / \mathrm{L} / \mathrm{hr}$.

Afterwards, the rate of benzene generation decreased almost equally as fast. Following $450 \mathrm{hr}$ of testing, the reaction temperature was raised to $50^{\circ} \mathrm{C}$ and the ventilation gas switched from air to nitrogen. An immediate increase in the benzene generation rate from 751 to $6021 \mu \mathrm{g} / \mathrm{L} / \mathrm{hr}$ was observed. After this increase, the rate of benzene generation again decreased. Eventually, the benzene generation rate reached steady state at approximately $900 \mu \mathrm{g} / \mathrm{L} / \mathrm{hr}$ at $50{ }^{\circ} \mathrm{C}$. At that time, the reaction temperature was lowered to $40{ }^{\circ} \mathrm{C}$. As a result, the benzene generation rate decreased from 941 to 362 $\mu \mathrm{g} / \mathrm{L} / \mathrm{hr}$. A few days later, the temperature was again increased to 50 ${ }^{\circ} \mathrm{C}$; the benzene generation rate increased from 326 to $812 \mu \mathrm{g} / \mathrm{L} / \mathrm{hr}$. Soon thereafter, potassium nitrate was added to the test. As observed previously in Figure 12, no significant effect on the benzene generation rate was observed.

Several observations can be drawn from this test. As evidenced in the previous test, the method of preparation (i.e., low-temperature evaporation) may affect the stability of NaTPB. Second, the presence of Tank $48 \mathrm{H}$ sludge and MST solids results in increased benzene generation rates, as compared to Tank $51 \mathrm{H}$ sludge. Once again, the 
Figure 14. Benzene generation rate for Tank $48 \mathrm{H}$ filtrate in the presence of 0.51 wt $\%$ Tank $48 \mathrm{H}$ sludge and MST solids and containing oven-dried AFF NaTPB.

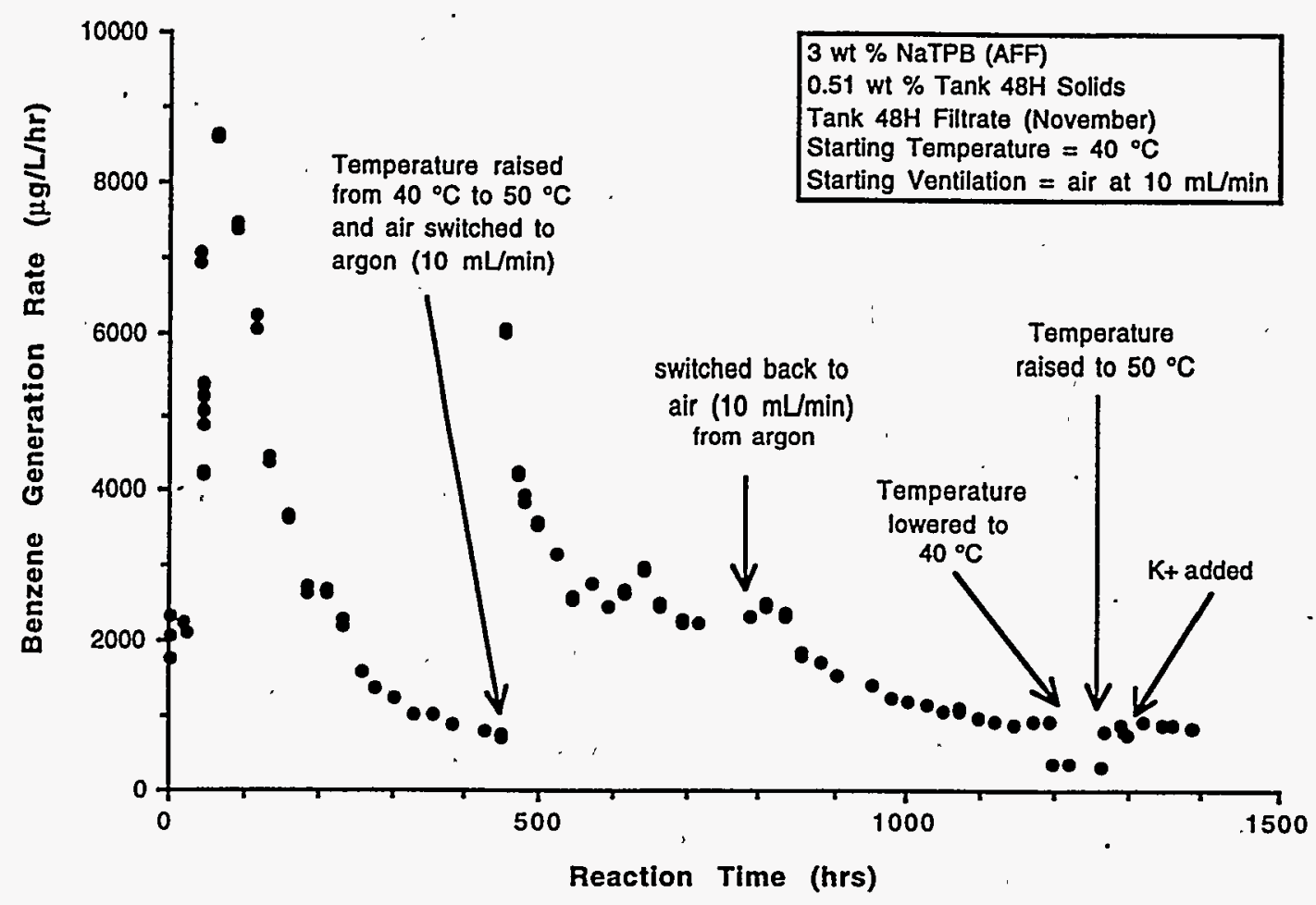

benzene generation rate is affected by both a $10{ }^{\circ} \mathrm{C}$ change in temperature and the use of an inert gas for ventilation. The latter observations will be discussed in further detail later in this section.

The stability of oven-dried NaTPB was investigated to permit differentiation between the effects of sludge, MST, and the method of preparing the NaTPB. In this test, Tank $48 \mathrm{H}$ filtrate (Nov. 5 sample) at a temperature of $40{ }^{\circ} \mathrm{C}$ and with a ventilation of $10 \mathrm{~mL} / \mathrm{min}$ air was stirred and monitored for two days. During this time, the benzene generation rate was observed to be $1 \mu \mathrm{g} / \mathrm{L} / \mathrm{hr}$. At that time, ovendried AFF NaTPB powder (prepared as described in the previous two tests) was added to the filtrate. In less than 100 hours after the addition, the benzene generation rate increased to $1732 \mu \mathrm{g} / \mathrm{L} / \mathrm{hr}$. After the benzene generation rate had decreased and reached a steady state, simulated Tank $48 \mathrm{H}$ MST was added to the test mixture. No increase in the benzene generation rate was observed. This data is shown in Figure 15. and listed in Appendix $F$ at the end of this document.

One observation that can be made from this test is that oven-drying does affect the stability of AFF NaTPB. Recall from Figure 12 that when AFF NaTPB solution is added to Tank $48 \mathrm{H}$ filtrate, a much smaller 
benzene generation rate was achieved. Also, the addition of simulated Tank 48H MST did not result in an increase in the benzene generation rate. This indicates catalysis by uranium-bearing MST is minimal or non-existent. However, this result may not hold true for Tank 48H MST since no plutonium was found when the simulated MST was analyzed (even though it was present in the solution used to prepare the simulated MST). It has been speculated that uranium or plutonium on MST may be a NaTPB decomposition catalyst. Uranium analysis data for the simulated MST was not available at the time this document was prepared.

Further study on oven-dried NaTPB was conducted in an attempt to discern if the instability observed with oven-dried AFF NaTPB would be observed with reagent grade NaTPB (from Aldrich Chemical Company) treated in the same manner. Tank 50H filtrate (sample was obtained in mid-March and diluted with water to simulate Tank $48 \mathrm{H}$ filtrate) was heated to a temperature of $40^{\circ} \mathrm{C}$, stirred, and ventilated with an air flow of $10 \mathrm{mi} / \mathrm{min}$. The benzene generation rate produced from the filtrate alone was measured and found less than $10 \mu \mathrm{g} / \mathrm{L} / \mathrm{hr}$. After 24 hr, oven-dried reagent grade (Aldrich) NaTPB powder (prepared as described in the previous tests) was added to the filtrate. The benzene generation rate increased over the next $350 \mathrm{hr}$ until it reached a maximum at $651 \mu \mathrm{g} / \mathrm{L} / \mathrm{hr}$. . No sludge or MST solids were ever added to this test. The data clearly show that even the best available NaTPB is susceptible to decomposition. However, the extent of decomposition, based upon the benzene generated, is less than that

\section{Figure 15. Benzene generation rate for Tank $48 \mathrm{H}$ filtrate containing oven-dried AFF NaTPB and simulated MST solids.}

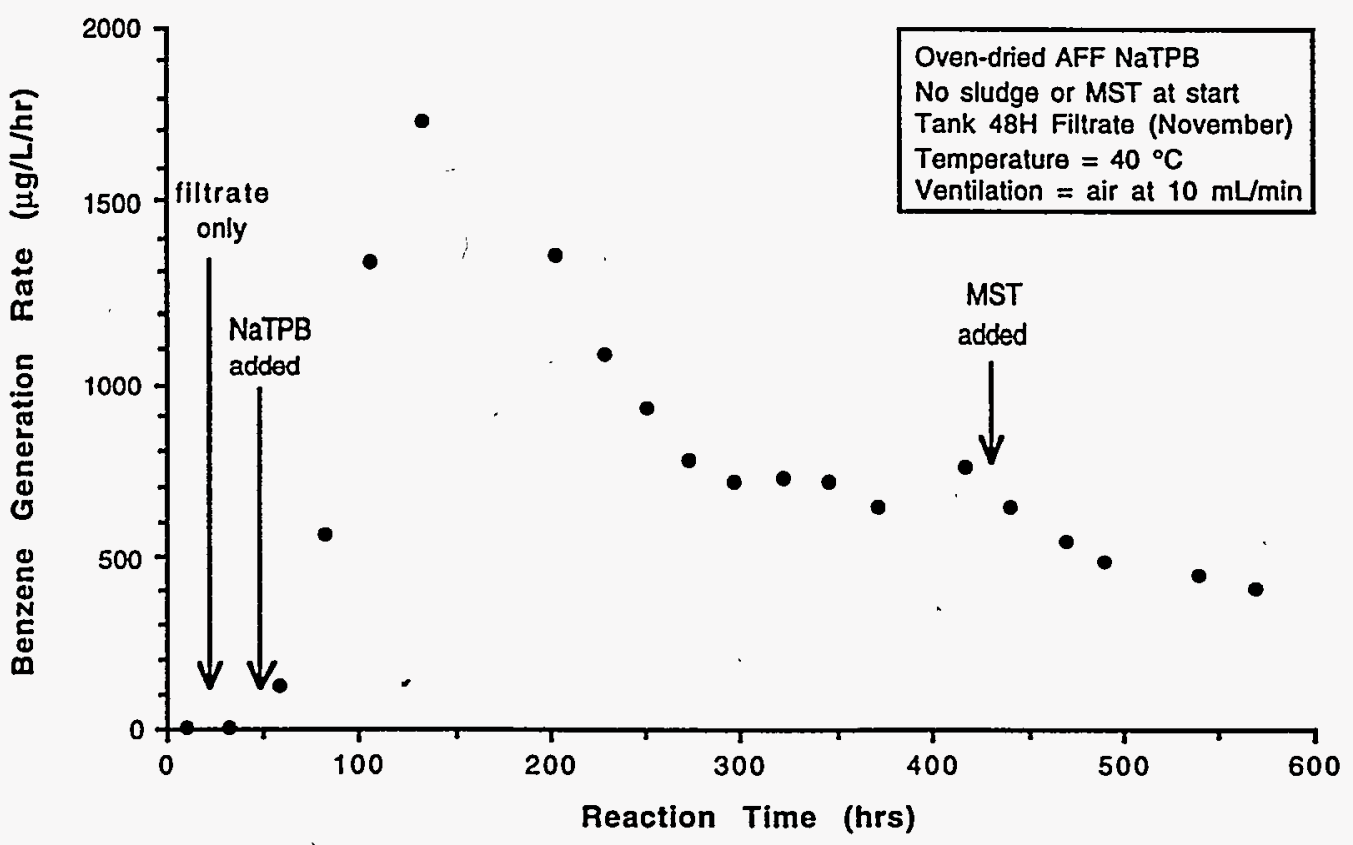


W. L. Iamosaitis

WSRC-IR-96-0113, ReV.

observed with oven-dried AFF NaTPB. This suggests that the AFF NaTPB contains more unstable NaTPB intermediates than does the reagent grade material. This data is shown in Figure 16 and listed in Appendix G.

A test similar to the test depicted by Figure 13 was conducted. The only difference between the tests was that the amount of Tank $51 \mathrm{H}$ sludge added to this test was half of that added in the previous one. A sufficient quantity of Tank $51 \mathrm{H}$ sludge was added to Tank $48 \mathrm{H}$ filtrate (Nov. 5 sample) to result in a concentration of 0.1 wt $\%$. A 3 wt of excess of oven-dried AFF NaTPB powder was added to the filtrate. The oven-dried AFF NaTPB powder was prepared in the same manner as in all other tests. The solution was continuously ventilated with $10 \mathrm{~mL} / \mathrm{min}$ air, stirred, and heated at $40{ }^{\circ} \mathrm{C}$. Benzene generation rate data from the test are shown in Figure 17 and listed in Appendix $\mathrm{H}$.

The solution initially generated benzene at a rate of $45 \mu \mathrm{g} / \mathrm{L} / \mathrm{hr}$. The rate of increase from this test was substantially lower and appeared to level off at approximately $200 \mu \mathrm{g} / \mathrm{L} / \mathrm{hr}$. Subsequently, the ventilation gas was switched from air ( $10 \mathrm{~mL} / \mathrm{min}$ ) to nitrogen $(10 \mathrm{~mL} / \mathrm{min})$. Once again, the benzene generation rate immediately increased from 192 to $415 \mu \mathrm{g} / \mathrm{L} / \mathrm{hr}$. Unlike the temperature increase,

Figure 16. Benzene generation rate for Tank 50F filtrate (diluted to simulate Tank $48 \mathrm{H}$ filtrate) containing ovendried AFF NaTPB.

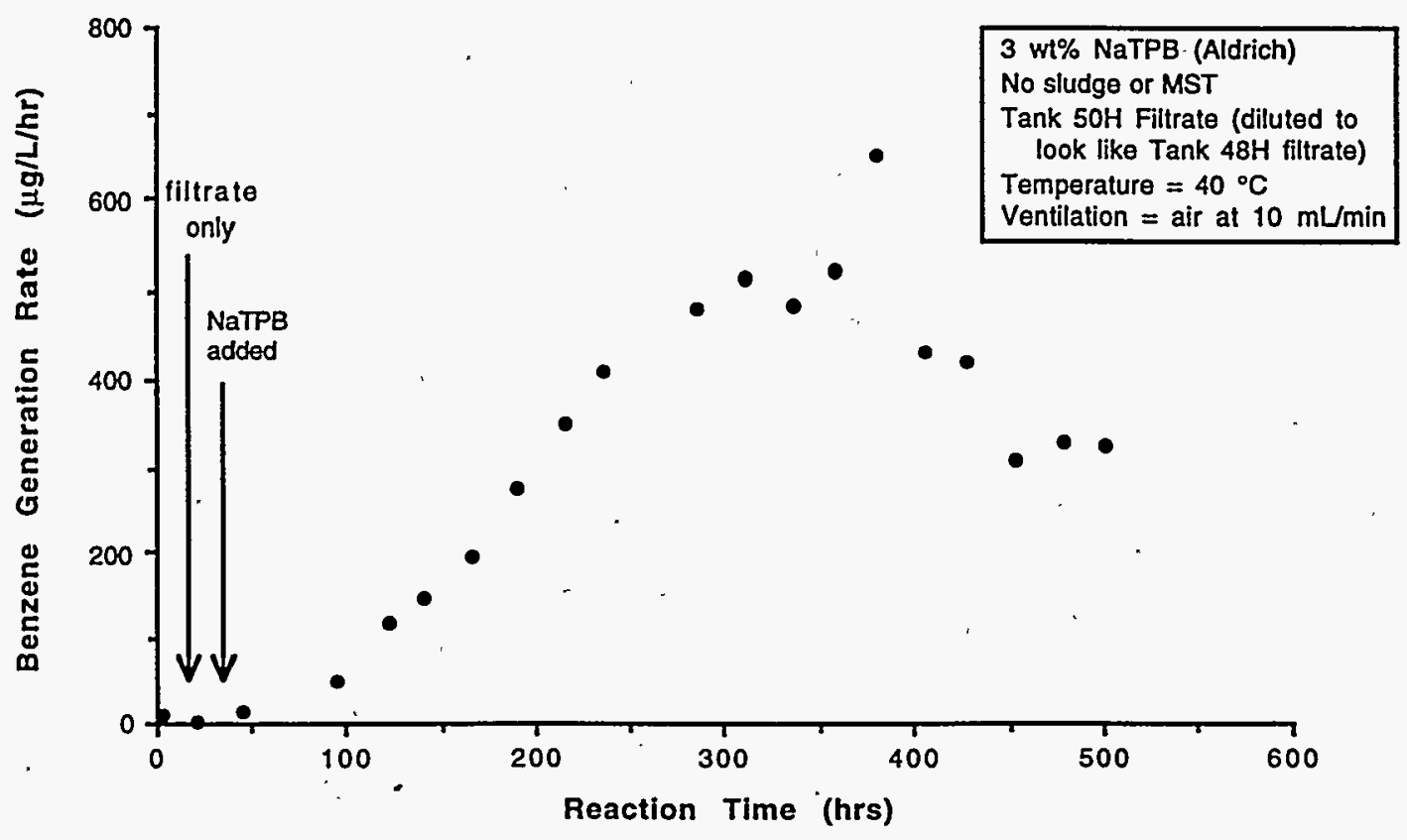




\section{Figure 17. Benzene generation rate for Tank $48 \mathrm{H}$ filtrate containing 0.1 wt \% Tank $51 \mathrm{H}$ sludge and oven-dried AFF NaTPB.}

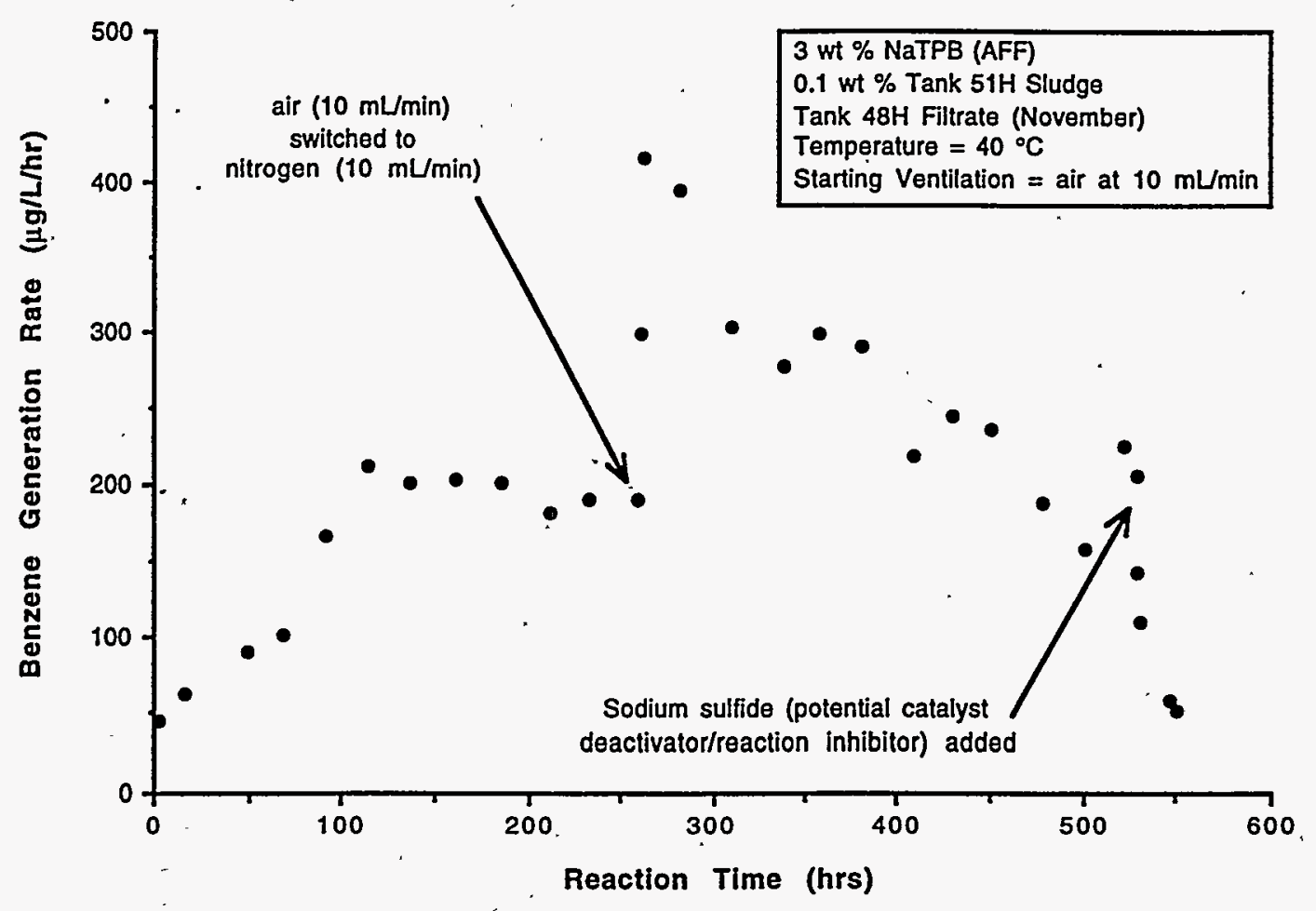

this increase was temporary. At the end of the test, a candidate reaction inhibitor, sodium sulfide, was added to the solution. The benzene generation rate decreased rapidly. The data suggest that the candidate inhibitor was effective. However, due to the scatter within the data, further tests are needed to verify the results.

One observation from this test is that the benzene generation rate is less than half that observed in the first Tank $51 \mathrm{H}$ sludge test. This could result from the decrease in activity due to a decrease in the quantity of catalyst. Another observation is the use of an inert gas for ventilation results in a temporary increase in the benzene generation rate.

Two additional radioactive tests were performed with Tank $48 \mathrm{H}$ filtrate (Nov. 5 sample). The first test was similar to the test represented by Figure 13. The only difference in this test from the original was that 3 wt $\%$ of untreated reagent grade NaTPB powder (from Aldrich) was used. In addition to the untreated reagent grade NaTPB, the Tank $48 \mathrm{H}$ filtrate also contained 0.2 wt 8 Tank $51 \mathrm{H}$ sludge. It was heated at $40^{\circ} \mathrm{C}$, stirred, and ventilated with air at 10 $\mathrm{mL} / \mathrm{min}$. Benzene generation from the mixture was monitored for over 700 hours. Data from the test is shown graphically in Figure 18 and 
Figure 18. Benzene generation rate for Tank $48 \mathrm{H}$ filtrate containing 0.2 wt \% Tank $51 \mathrm{H}$ sludge and untreated reagent grade NaTPB.

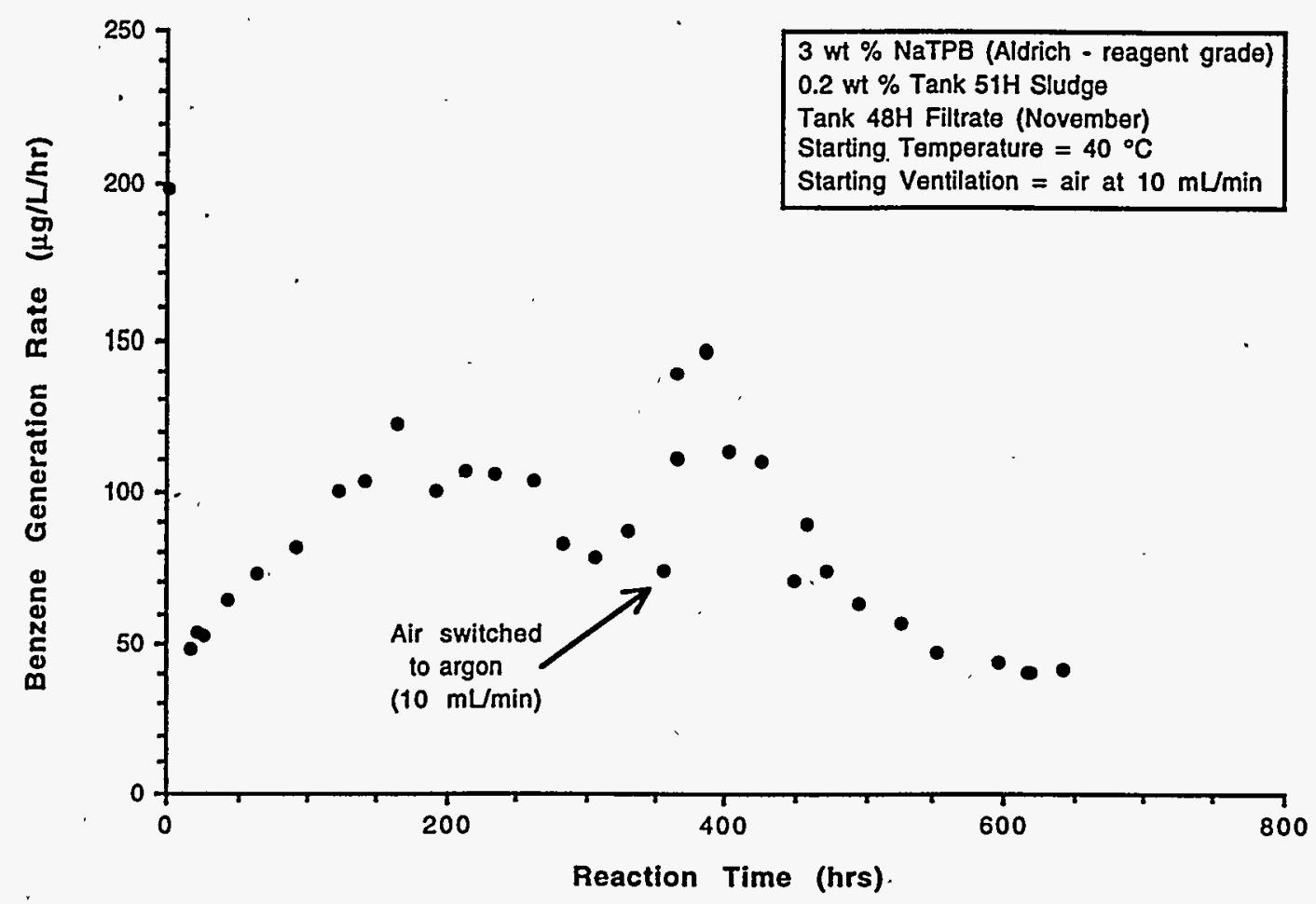

listed in Appendix I. The rate of benzene generation was much lower than observed in the earlier test (see Figure 13) and it appeared to reach a steady state of approximately $100 \mu \mathrm{g} / \mathrm{L} / \mathrm{hr}$. Later in the test, the ventilation gas was switched with the same results as seen in previous tests. A temporary increase in benzene generation was observed. The rate eventually stabilized near $40 \mu \mathrm{g} / \mathrm{L} / \mathrm{hr}$.

The second benzene generation rate test was similar to the test represented by Figure 14. This test, like the difference described in the previous test, used 3 wt 8 of untreated reagent grade NaTPB powder (from Aldrich) in place of oven-dried AFF NaTPB. Also, a smaller amount $(0.25$ wt $\%$ instead of 0.51 wt $q)$ of Tank $48 \mathrm{H}$ sludge and MST was added to the test mixture. The Tank $48 \mathrm{H}$ filtrate was heated at $40{ }^{\circ} \mathrm{C}$, stirred, and ventilated with air at a flow rate of $10 \mathrm{~mL} / \mathrm{min}$. Again, benzene generation was monitored over the next 1000 hours. Benzene generation rate data for this test are shown in Figure 19 and listed in Appendix J.

Like the data from the previous test shown in Figure 18, benzene generation was much lower than observed in Figure 14. A nearly steady state rate of approximately $100 \mu \mathrm{g} / \mathrm{L} / \mathrm{hr}$ was observed.

Subsequently, the reaction temperature was raised to $50{ }^{\circ} \mathrm{C}$ and the ventilation gas switched from air to argon. An immediate increase in 
Figure 19. Benzene generation rate for Tank $48 \mathrm{H}$ filtrate containing untreated reágent grade NaTPB and 0.25 wt \% Tank $48 \mathrm{H}$ sludge and MST.

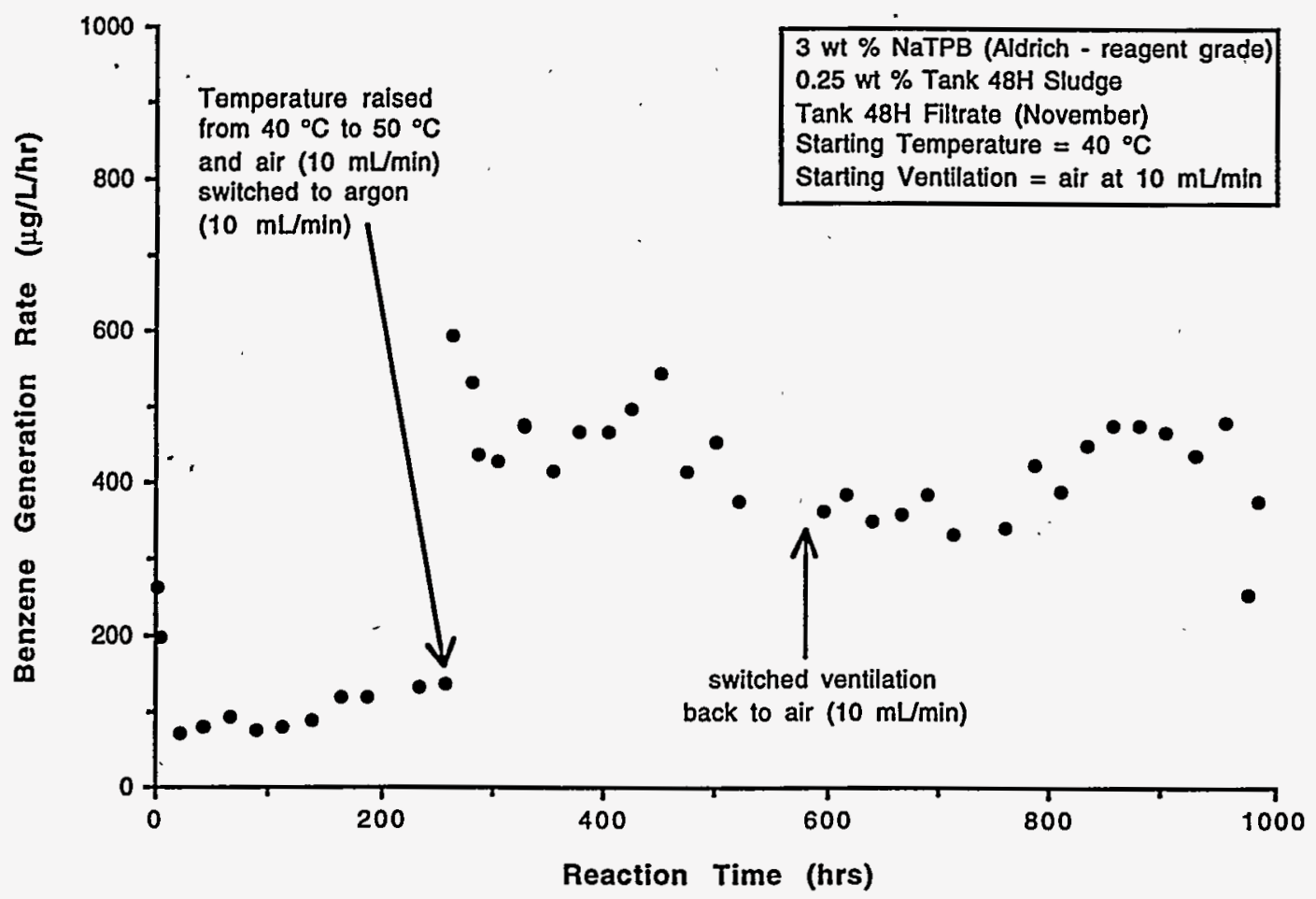

the benzene generation rate from 135 to $593 \mu \mathrm{g} / \mathrm{L} / \mathrm{hr}$ was observed. The benzene generation rate reached steady state at approximately 400 $\mu \mathrm{g} / \mathrm{L} / \mathrm{hr}$ at $50^{\circ} \mathrm{C}$. After approximately $300 \mathrm{hr}$ at this condition, the ventilation gas was switched back to air. No significant change in the benzene generation rate was observed over the next 400 hours.

The data shown in Figure 18 and Figure 19 indicate that untreated reagent grade NaTPB is much less reactive than oven-dried NaTPB. In addition, both tests indicate that switching to an inert gas results in a temporary increase in benzene generation. The data from the first 250 hours of reaction suggest that Tank $51 \mathrm{H}$ sludge and Tank $48 \mathrm{H}$ sludge and MST behave similarly (i.e., they appear equally active as a catalyst) under similar conditions.

The final radioactive test investigated the reactivity of NaTPB from another vendor, Boulder Scientific Company (BSC). The test was similar to the first test of reagent grade NaTPB from Aldrich Chemical Company. A December 18 sample of Tank 48H filtrate was heated at $40^{\circ} \mathrm{C}$, stirred, and ventilated with air at a flow rate of $10 \mathrm{mI} / \mathrm{min}$. The benzene generation rate from the filtrate alone was observed quite high at the start of the test $(294 \mu \mathrm{g} / \mathrm{L} / \mathrm{hr})$ and decreasing with time. Data from this test is shown in Figure 20 and listed in Appendix $\mathrm{K}$. 
More than a month earlier, a sample of Tank $48 \mathrm{H}$ filtrate from December 18 was monitored by D. D. Walker and found to exhibit the same phenomena. Interestingly, both filtrate samples exhibited similar rates of decrease and both samples produced nearly 300 $\mu \mathrm{g} / \mathrm{L} / \mathrm{hr}$ benzene at the start of each test. The December 18 filtrate samples were unlike the previously used November Tank 48H filtrate samples in that the NaTPB present in November was all decomposed by December 18. As a result, December 18 filtrate contains significantly higher quantities of $\mathrm{PBA}$, phenol, and other decomposition products. Therefore, the benzene being generated from the December 18. filtrate samples resulted from the continuing decomposition of NaTPB intermediate products such as PBA and diphenylboric acid. The fact that both samples, which yielded the same result, were tested more than a month apart suggests that the intermediates were stabilized between tests. The most probable explanation of this stabilization was that the storage temperature was sufficiently low to retard the decomposition.

After the high rate of benzene generation from the filtrate had been baselined, the BSC NaTPB was added to the filtrate. An immediate spike in the benzene generation rate was observed. This is not atypical and, in fact, is seen any time that crystallized NaTPB

Figure 20. Benzene generation rate for Tank $48 \mathrm{H}$ filtrate containing untreated Boulder scientific Company NaTPB powder and 0.2 wt \% Tank 51H sludge.

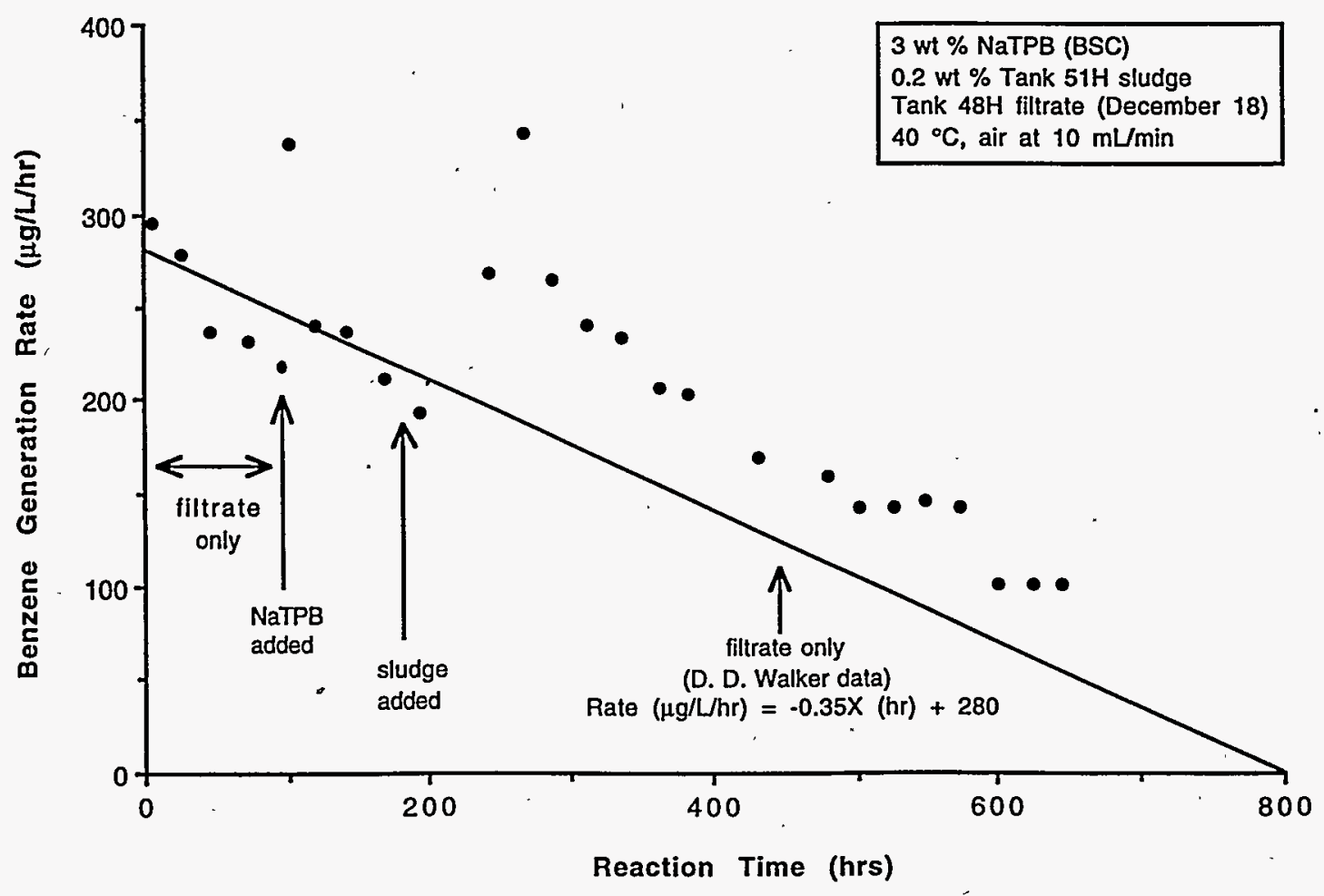


powder is added to a solution (see Figure 18 and Figure 19 for these same spikes at the start of the reactions). The benzene generation rate returned almost immediately to the expected baseline without further increase. Eventually, 0.2 wt 8 Tank $51 \mathrm{H}$ sludge was added to the test mixture. A small increase in the benzene generation rate was observed. However, the benzene generation rate then paralleled the expected Tank $48 \mathrm{H}$ filtrate baseline suggesting that a slow reaction was occurring. The data contained in this test suggest that BSC NaTPB powder is stable (like the reagent grade NaTPB from Aldrich). The data also provides insight into the probable cause of elevated benzene observed in Tank 50H in December 1995. This will be discussed in a later section.

Summary of Radioactive Tests

The ventilated and stirred radioactive tests provided several observations and insights into possible variables in the decomposition of NaTPB. However, none of the tests provided the "smoking guin" evidence of the exact cause of the NaTPB decomposition reaction observed in Tank 48H. Results of the nine tests described in the above section are summarized in Table 13. The highest average benzene generation rate observed in the tests was $2214 \mu \mathrm{g} / \mathrm{L} / \mathrm{hr}$ over a period of nearly two months. However, even this rate is not comparable to the Tank $48 \mathrm{H}$ reaction. The benzene produced in the test represents the decomposition of only 8.3 wt $\%$ of the NaTPB in the test. None of the additives (i.e., Tank $51 \mathrm{H}$ sludge, Tank 48H sludge and MST, soluble catalysts in Tank 48 filtrate, or NaTPB source) tested in these continuously stirred and ventilated systems produced a reaction similar to that in Tank $48 \mathrm{H}$. Recall that one criterion in the search for the cause of the reaction was complete decomposition of the NaTPB. The extent of reaction observed in the tests indicates that the bulk of the NaTPB tested was stable and

\section{Table 13. Summary of Benzene Generation Rates for Radioactive Tests.}

\begin{tabular}{|c|c|c|c|c|c|}
\hline$\cdot$ & $\begin{array}{c}\text { Type } \\
\text { of NaTPB }\end{array}$ & $\begin{array}{l}\text { Sludge/ } \\
\text { Solids. }\end{array}$ & $\begin{array}{c}\text { Reaction } \\
\text { Time } \\
\text { (hr) }\end{array}$ & $\begin{array}{c}\text { Average } \\
\text { Benzene } \\
\text { Generation } \\
\text { Rate } \\
(\mu \mathrm{g} / \mathrm{L} / \mathrm{hr})\end{array}$ & $\begin{array}{c}\text { Benzene } \\
\text { Generated } \\
\text { (wt \& of } \\
\text { NaTPB) }\end{array}$ \\
\hline $\begin{array}{l}\text { Figure } 12 \\
\text { Figure } 13 \\
\text { Figure } 14 \\
\text { Figure } 15 \\
\text { Figure } 16\end{array}$ & $\begin{array}{l}\text { AFF Soln. } \\
\text { AFF Powder } \\
\text { AFF Powder } \\
\text { AFF Powder } \\
\text { Aldrich } \\
\text { AFF Powder }\end{array}$ & $\begin{array}{l}\text { None } \\
0.2 \text { wt } \& \mathrm{Tk} 51 \mathrm{H} \\
0.5 \text { wt } \& \mathrm{Tk} 48 \mathrm{H} \\
\text { Simulated MST } \\
\text { None } \\
0.1 \text { wt \& } \mathrm{Tk} 51 \mathrm{H}\end{array}$ & $\begin{array}{c}1430 \\
979 \\
1384 \\
569 \\
502 \\
572\end{array}$ & $\begin{array}{l}30 \\
341 \\
2214 \\
773 \\
308 \\
204\end{array}$ & $\begin{array}{l}0.203 \\
0.910 \\
8.344 \\
1.196 \\
0.443 \\
0.318\end{array}$ \\
\hline $\begin{array}{l}\text { Figure } 17 \\
\text { Figure } 18 \\
\text { Figure } 19 \\
\text { Figure } 20\end{array}$ & $\begin{array}{l}\text { Aldrich } \\
\text { Aldrich } \\
\text { BSC }\end{array}$ & $\begin{array}{l}0.2 \text { wt } 8 \text { Tk } 51 \mathrm{H} \\
0.2 \text { wt } \& \text { Tk } 48 \mathrm{H} \\
0.2 \text { wt } \& \text { Tk } 51 \mathrm{H}\end{array}$ & $\begin{array}{l}787 \\
984 \\
647\end{array}$ & $\begin{array}{c}76 \\
342 \\
38\end{array}$ & $\begin{array}{l}0.164 \\
0.918 \\
0.068 \\
\end{array}$ \\
\hline
\end{tabular}

arepresents oven-dried NaTPB powder. 
unreactive in the conditions employed and that the small amount of decomposition observed was more likely due to impurities and a small fraction of unstable material.

Two main influences on the NaTPB decomposition reaction that were identified in the radioactive tests were the influence of temperature and ventilation gas. These were briefly mentioned when describing each test. The effect of both temperature changes and ventilation gas switches in each test are summarized in Table 14. In those tests with a $10{ }^{\circ} \mathrm{C}$. temperature change, there was an average change (absolute value) in the benzene generation rate of 254\%. In those tests where there was a switch in ventilation gas from air to, an average change (absolute value) in the benzene generation rate of $193 \%$ was observed. In the two events where there was both a $10^{\circ} \mathrm{C}$ temperature rise and a switch in ventilation gas, an average change (absolute value) in the benzene generation rate of $624 \%$ was observed. Based upon the individual event changes of $254 \%$ and $193 \%$, a dual change would be expected to produce an average change of $490 \%$. While there is much scatter in the data, it is clear that both a $10{ }^{\circ} \mathrm{C}$ increase in temperature and a switch in ventilation gas from air to an inert gas produce drastic increases in the benzene generation rate.

\section{Ventilated Non-Radioactive Tests}

Two ventilated, non-radioactive tests that simulated Tank $48 \mathrm{H}$ were conducted. The tests were similar to each other in that both contained 4.5 wt \% tetraphenylborate solids (prepared from AFF NaTPB solution) in a Tank $48 \mathrm{H}$ salt solution simulant. Each was spiked with $1.4 \mathrm{mg} / \mathrm{L}$ copper as copper nitrate. One contained more NaTPB

Table 14. Percent change in the benzene generation rate as a result of changes in temperature and ventilation gas.

\begin{tabular}{|c|c|c|c|c|c|}
\hline \multirow[b]{2}{*}{ Figure \# } & \multicolumn{2}{|c|}{ Initial } & \multicolumn{2}{|c|}{ Final } & \multirow{2}{*}{$\begin{array}{l}\text { Change in } \\
\text { Benzene } \\
\text { Generation } \\
\text { Rate ( } \%, \\
\text { absolute } \\
\text { value) }\end{array}$} \\
\hline & Condition & $\begin{array}{c}\text { Benzene } \\
\text { Generation } \\
\text { Rate } \\
(\mu \mathrm{g} / \mathrm{L} / \mathrm{hr}) \\
\end{array}$ & Condition & $\begin{array}{c}\text { Benzene } \\
\text { Generation } \\
\text { Rate } \\
(\mu \mathrm{g} / \mathrm{L} / \mathrm{hr}) \\
\end{array}$ & \\
\hline $\begin{array}{l}12 \\
12 \\
12 \\
13 \\
13 \\
13 \\
13 \\
16 \\
17 \\
18 \\
18 \\
\end{array}$ & $\begin{array}{c}40{ }^{\circ} \mathrm{C} \\
50{ }^{\circ} \mathrm{C} \\
\text { air } \\
40{ }^{\circ} \mathrm{C}, \text { air } \\
\mathrm{N}_{2} \cdot \\
50^{\circ}{ }^{\circ} \mathrm{C} \\
40{ }^{\circ} \mathrm{C} \\
\operatorname{air} \\
\operatorname{air} \\
40{ }^{\circ} \mathrm{C}, \text { air } \\
\mathrm{N}_{2}\end{array}$ & $\begin{array}{c}362 \\
104 \\
52 \\
751 \\
2331 \\
941 \\
326 \\
192 \\
74 \\
135 \\
376 \\
\end{array}$ & $\begin{array}{c}50{ }^{\circ} \mathrm{C} \\
40{ }^{\circ} \mathrm{C} \\
50{ }^{\circ} \mathrm{C}, \quad \mathrm{N}_{2} \\
\text { air } \\
40{ }^{\circ} \mathrm{C} \\
50{ }^{\circ} \mathrm{C} \\
\mathrm{N}_{2} \\
\mathrm{~N}_{2} \\
50{ }^{\circ} \mathrm{C}, \mathrm{N}_{2} \\
\text { air } \\
\end{array}$ & $\begin{array}{c}916 \\
53 \\
100 \\
6021 \\
941 \\
326 \\
901 \\
415 \\
147 \\
593 \\
348 \\
\end{array}$ & $\begin{array}{l}253 \\
196 \\
192 \\
802 \\
248 \\
289 \\
276 \\
216 \\
199 \\
439 \\
108 \\
\end{array}$ \\
\hline
\end{tabular}


(relative to potassium) while the other did not have any NaTPB (only KTPB was present). The tests were conducted similarly to all other ventilated tests. The precipitate slurry was heated at $40^{\circ} \mathrm{C}$ while $10 \mathrm{~mL} / \mathrm{min}$ of air was flowed over the surface of the stirred mixture.

The benzene generation rate of the solution containing the excess of NaTPB ranged from $38 \mu \mathrm{g} / \mathrm{L} / \mathrm{hr}$ at the start of the test to $12 \mu \mathrm{g} / \mathrm{L} / \mathrm{hr}$ near the end of the test. The test was run for over 500 hours. The benzene generation rate of the solution containing only KTPB ranged from $39 \mu \mathrm{g} / \mathrm{I} / \mathrm{hr}$ to $14 \mu \mathrm{g} / \mathrm{L} / \mathrm{hr}$ at the end of the test. Again the test duration was more than 500 hours. The data suggest that these nonradioactive simulants reacted similarly to each other but did not simulate the rapid decomposition reaction observed in Tank 48H. Data from these tests are contained in Appendix $I$ (excess NaTPB test) and Appendix M (KTPB only test).

Given the low rates (relative to Tank 48H) observed in the above mentioned two ventilated non-radioactive slurry tests, two additional ventilated; non-radioactive tests were performed using NaTPB

solutions. These tests mimic tests performed in 1990 where rapid decomposition was observed. Each test was identical to the other except for the ventilation gas. The tests were conducted in much the same manner as the ventilated radioactive tests. In these tests, reagent grade NaTPB solution. (0.5 molar NaTPB and 0.1 molar NaOH) was spiked with $10 \mathrm{mg} / \mathrm{L}$ copper nitrate. The solutions were heated at $70{ }^{\circ} \mathrm{C}$ and ventilated at a flow rate of $10 \mathrm{mg} / \mathrm{L}$. The first test was ventilated with air while the second test was ventilated with nitrogen. The benzene generation rate was measured daily. Benzene generation rate data for the air ventilated test is shown in Figure 21 and Iisted in Appendix $N$. Benzene generation rate data for the nitrogen ventilated test is shown in Figure 22 and listed in Appendix 0 . Unlike in the radioactive tests, the solution was sampled periodically and analyzed for PBA, phenol, biphenyl, TPB', and hydroxide. This data along with the cumulative amount of benzene generated are listed in Table 15 for the air ventilated test and Table 16 for the nitrogen ventilated test.

The data show that two distinct reaction mechanisms were responsible for the decomposition process. In air, an induction period of nearly $100 \mathrm{hr}$ was observed during which time hydroxide appears to be slowly consumed. After the reaction initiated, a benzene generation rate in excess of $2,000,000 \mu \mathrm{g} / \mathrm{I} / \mathrm{hr}$ was obtained. The rate of benzene generation decreásed linearly as a result of the decreasing TPBconcentration. Small quantities of the decomposition product phenol was produced as was the intermediate decomposition product PBA. Biphenyl, which is highly insoluble in aqueous salt solutions, was observed in trace amounts. The benzene to phenol mole ratio was 9.42 to 1 after $90.8 \%$ decomposition of the NaTPB had been achieved. In addition, the color of the solution became dark brown-black during the reaction with the largest degree of color change occurring after the induction period was over.

In the nitrogen ventilated test, no induction period was observed. Reaction was almost instantaneous and the benzene generation rate was at least $1,800,000 \mu \mathrm{g} / \mathrm{L} / \mathrm{hr}$. One subtle difference between the two 
Figure 21. Benzene generation rate for the air ventilated non-radioactive test with reagent grade NaTPB solution.

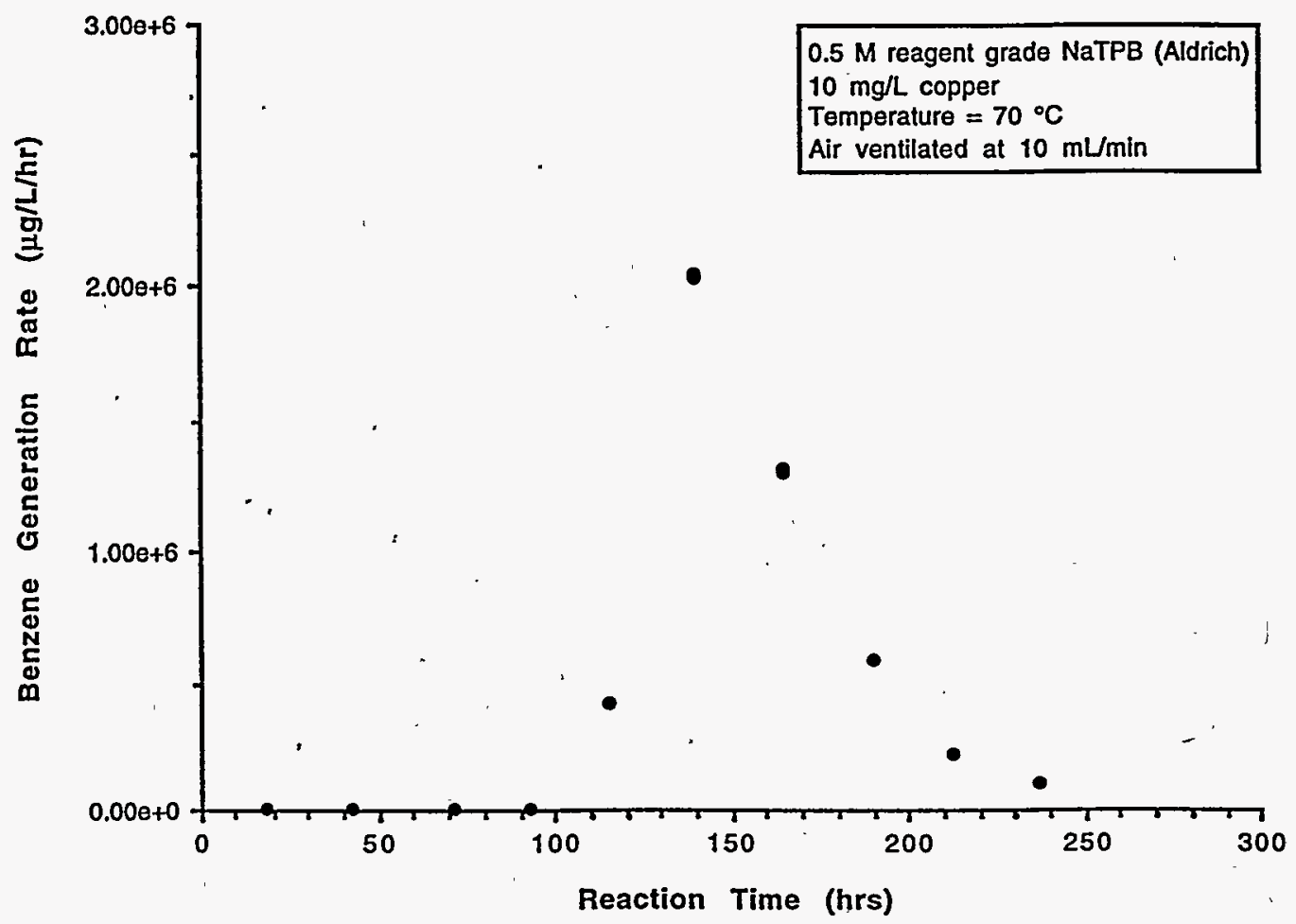

Table 15. Analytical data from the air ventilated decomposition of NaTPB solution in the presence on $10 \mathrm{mg} / \mathrm{I}$ copper.

\begin{tabular}{|c|c|c|c|c|c|c|}
\hline $\begin{array}{l}\text { Reaction } \\
\text { Time } \\
\text { (hr) }\end{array}$ & $\begin{array}{c}\text { NaTPB } \\
\text { Remaining } \\
\text { (moles) } \\
\end{array}$ & $\begin{array}{c}\text { Cumulative } \\
\text { Benzene } \\
\text { Generated } \\
\text { (moles) }\end{array}$ & $\begin{array}{c}\text { PBA } \\
\text { (moles) }\end{array}$ & $\begin{array}{l}\text { Phenol } \\
\text { (moles) }\end{array}$ & $\begin{array}{c}\text { Biphenyl } \\
\text { (moles) }\end{array}$ & $\begin{array}{c}\text { Free } \\
\text { Hydroxide } \\
\text { (molarity) }\end{array}$ \\
\hline $\begin{array}{c}0 \\
181\end{array}$ & 0.0500 & $\begin{array}{l}0.0000 \\
0.0000\end{array}$ & 0.0000 & 0.0000 & 0.0000 & 0.0963 \\
\hline $\begin{array}{l}42.9 \\
72.0\end{array}$ & 0.0494 & $\begin{array}{l}0.0001 \\
0.0003\end{array}$ & 0.00039 & 0.00048 & $<0.00004$ & 0.0938 \\
\hline $\begin{array}{c}92.7 \\
115.8 \\
139.4\end{array}$ & 0.0465 & $\begin{array}{l}0.0006 \\
0.0076 \\
0.0459\end{array}$ & 0.00010 & 0.0022 & $<0.00004$ & 0.0819 \\
\hline $\begin{array}{l}165.0 \\
190.2\end{array}$ & 0.0114 & $\begin{array}{l}0.1017 \\
0.1311\end{array}$ & 0.0133 & 0.0107 & 0.000045 & 0.4144 \\
\hline $\begin{array}{l}212.4 \\
236.2 \\
\end{array}$ & 0.0046 . & $\begin{array}{r}0.1433 \\
-0.1466 \\
\end{array}$ & 0.0007 & 0.0152 & $<0.00007$ & 0.5125 \\
\hline
\end{tabular}


Table 16. Analytical data from the nitrogen ventilated decomposition of NaTPB solution in the presence of $10 \mathrm{mg} / \mathrm{L}$ copper.

\begin{tabular}{|c|c|c|c|c|c|c|}
\hline $\begin{array}{l}\text { Reaction } \\
\text { Time } \\
\text { (hr) }\end{array}$ & $\begin{array}{c}\text { NaTPB } \\
\text { Remaining } \\
\text { (moles) }\end{array}$ & $\begin{array}{l}\text { Cumulative } \\
\text { Benzene } \\
\text { Generated } \\
\text { (moles) }\end{array}$ & $\begin{array}{c}\text { PBA } \\
\text { (moles) }\end{array}$ & $\begin{array}{l}\text { Phenol } \\
\text { (moles) }\end{array}$ & $\begin{array}{r}\text { Biphenyl } \\
\text { (moles) }\end{array}$ & $\begin{array}{c}\text { Free } \\
\text { Hydroxide } \\
\text { (molarity) }\end{array}$ \\
\hline $\begin{array}{c}0 \\
19.5\end{array}$ & 0.0500 & $\begin{array}{l}0.0000 \\
0.0527\end{array}$ & 0.0000 & .0 .0000 & 0.0000 & 0.0963 \\
\hline $\begin{array}{l}43.1 \\
68.6\end{array}$ & 0.0181 & $\begin{array}{l}0.0975 \\
0.1261\end{array}$ & 0.0257 & 0.0005 & $<0.00004$ & 0.3625 \\
\hline $\begin{array}{c}93.4 \\
116.3 \\
139.5\end{array}$ & 0.0079 & $\begin{array}{l}0.1435 \\
0.1542 \\
0.1651\end{array}$ & 0.0220 & 0.0021 & $<0.00004$ & 0.5106 \\
\hline $\begin{array}{l}164.8 \\
190.0\end{array}$ & 0.0033 & $\begin{array}{l}0.1748 \\
0.1808\end{array}$ & 0.0155 & 0.00071 & $<0.00004$ & 0.4388 \\
\hline $\begin{array}{l}212.7 \\
237.0\end{array}$ & $\cdot 0.0047$ & $\begin{array}{l}0.1882 \\
0.1925\end{array}$ & 0.0089 & 0.00042 & $<0.00007$ & 0.4419 \\
\hline
\end{tabular}

Figure 22. Benzene generation rate for nitrogen ventilated non-radioactive test with reagent grade NaTPB solution.

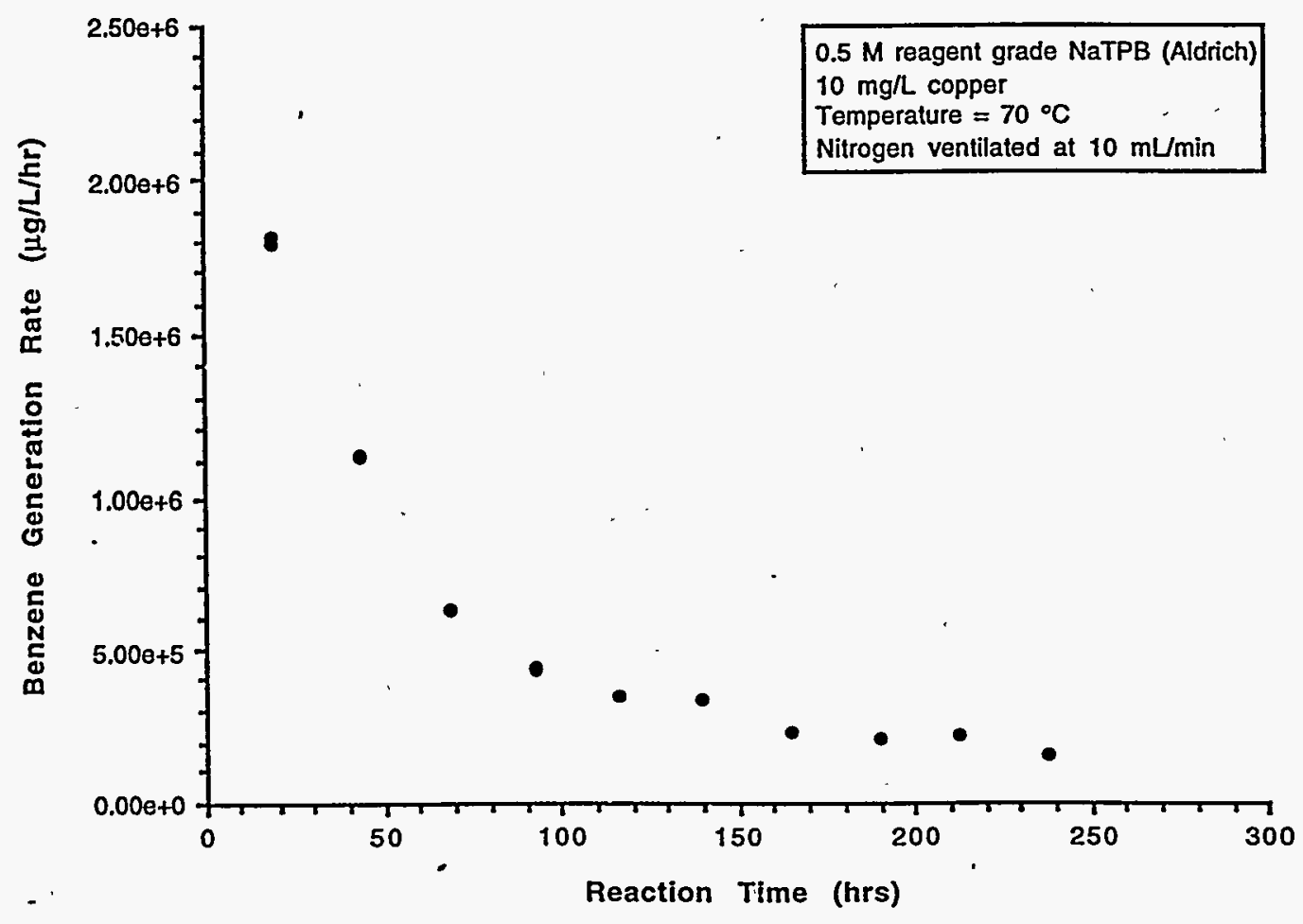

tests was that the rate of benzene generation in nitrogen did not decrease linearly but rather appeared to decrease exponentially with decreasing $\mathrm{TPB}^{-}$concentration. Another difference observed in this 
test was the reaction stoichiometry. Only trace amounts of phenol were formed. Biphenyl was not observed in the HPLC chromatograms. Biphenyl is highly insoluble in aqueous salt solutions and would not be expected to be seen in HPLC chromatograms of filtrate samples. However, an insoluble organic, presumably biphenyl, was observed floating in small beads on the surface of the solution. This contrasts the air ventilated test in which no insoluble biphenyl beads were observed in the test solution. The benzene to phenol mole ratio was 448 to 1 after 90.6 . \% decomposition of the NaTPB had been achieved. In this test, the color of the solution remained clear throughout the entire test.

Non-Ventilated, Non-Radioactive (Bottle) Tests

\section{Series A Test}

These tests represent an initial attempt to determine the effect of various chemical species on the rate of decomposition of simulated Tank 48 slúrries. Portions of simulated Tank $48 \mathrm{H}$ slurry (100 mL) were prepared and placed in polyethylene bottles with screw caps. A different combination of minor components was added to each bottle. The bottles were incubated in ovens at either 40 or $70^{\circ} \mathrm{C}$. Samples were taken each week and analyzed for soluble boron, phenol, and phenylboric acid. No effort was made to exclude air. The slurries were calculated to contain 0.7 wt $\%$ excess NaTPB solids. The pretest expectations of large increases in the decomposition products were never observed during the seven weeks of testing. Post-test evaluation of several slurries showed no excess NaTPB present. It is probable that a combination of potassium impurities in the sludge and low tetraphenylborate in the AFF/Aquafine solutions combined to significantly reduce the actual excess NaTPB relative to the calculated amount. Despite the low total amount of decomposition measured, the results do suggest potential effects due to minor components. The test matrix is shown in Table 17. The test variables are listed below.

Variable

NaTPB source

Temperature

Soluble $\mathrm{Cu}$

Soluble minor salt components

\section{Components}

reagent grade (Aldrich)

or

AFF / Aquafine.

$70{ }^{\circ} \mathrm{C}$ or $40{ }^{\circ} \mathrm{C}$

$1.5 \mathrm{mg} / \mathrm{L}$, added as $\mathrm{Cu}$ (II) salt

Mo (VI) $\quad .12 \cdot \mathrm{mg} / \mathrm{L}$

- $\operatorname{Cr}(V I)$

$\mathrm{Si}(I V)$

$\mathrm{Se}$ (VI)

As (IV)

$\mathrm{Zn}(I I)$
$73 \cdot \mathrm{mg} / \mathrm{L}$

$18 \mathrm{mg} / \mathrm{L}$

$0.8 \cdot \mathrm{mg} / \mathrm{L}$

$0.1 \mathrm{mg} / \mathrm{L}$

$7.7 \mathrm{mg} / \mathrm{L}$

(Continued on the next page) 


$\begin{array}{lll}\text { Soluble minor } & \mathrm{Pb}(\mathrm{II}) & 1.5 \mathrm{mg} / \mathrm{L} \\ \text { salt components } & \mathrm{Fe}(\mathrm{III}) & 1.4 \mathrm{mg} / \mathrm{L} \\ \text { (continued) } & \mathrm{Sn}(\mathrm{II}) & 2.3 \mathrm{mg} / \mathrm{L} \\ & \mathrm{Ru}(\mathrm{III}) & 0.8 \mathrm{mg} / \mathrm{L}\end{array}$

Sludge

$2.4 \mathrm{~g} / \mathrm{L}$.

The sludge was predried and

contained the following components:

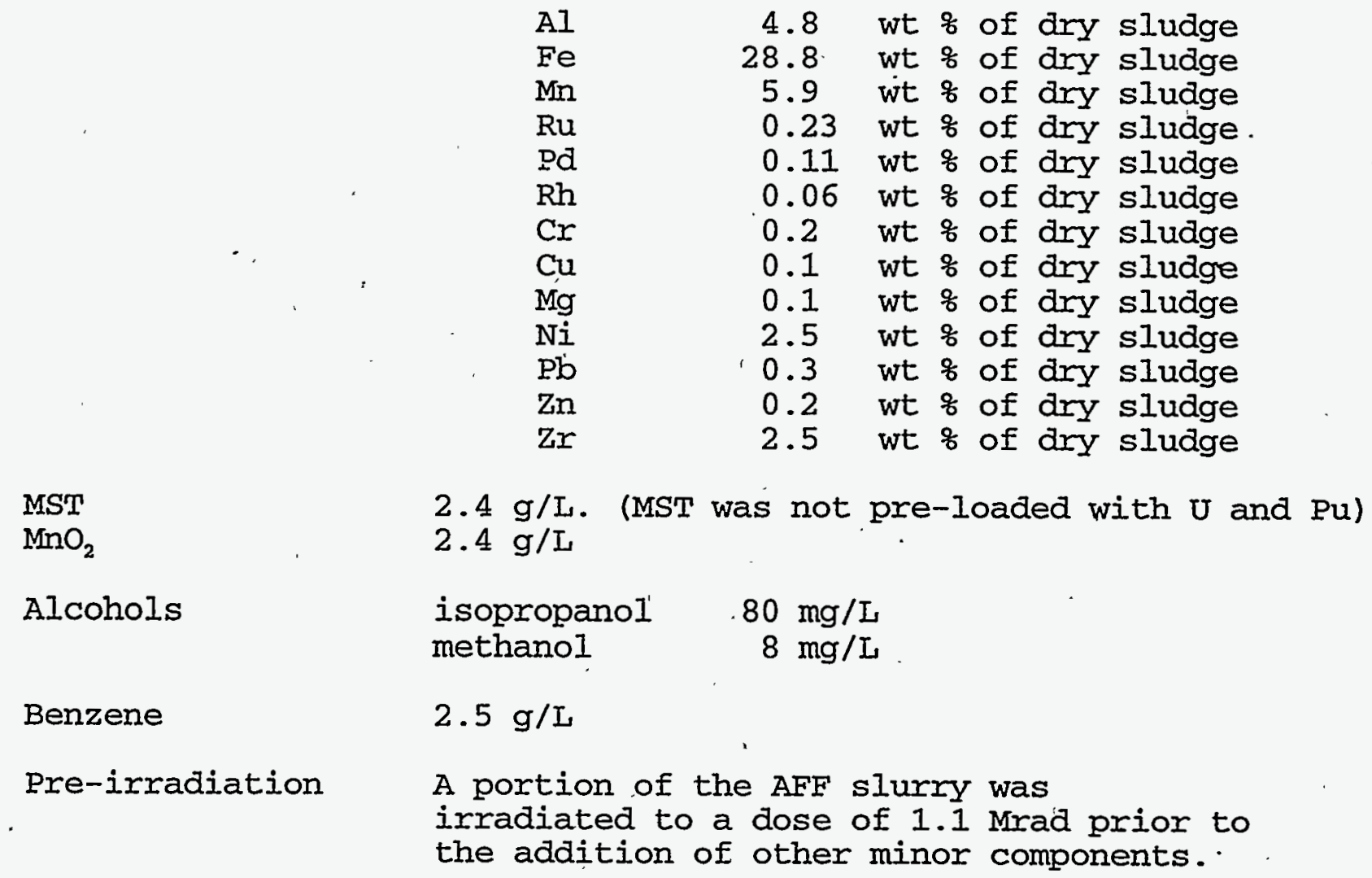

The results are shown in Figure 23 through Figure 25. The results near the latter half of the test (27-49 days) have been corrected for bias in the analysis based on a standard submitted with each batch of samples. The standard was not included during the first half of the test. Soluble boron (Figure 23) appears to have increased significantly in several bottles at fourteen days. The only bottles that did not show this jump were the ones at $40^{\circ} \mathrm{C}$. The subsequent decrease in soluble boron in many of these bottles is unexplained since none of the major soluble decomposition products containing boron (sodium borate, phenylboric acid, or diphenylboric acid) approached their saturation limits. These results suggest that the available NaTPB excess decomposed between 7 and 14 days following the start of the test. The phenylboric acid result's (Figure 24) also suggest that decomposition occurred at about the same time as indicated by the soluble boron results. The subsequent disappearance of this compound is expected since it is know to hydrolyze to benzene and sodium borate at a slow rate without catalyst present. The 
Figure 23. Boron results for series A tests.

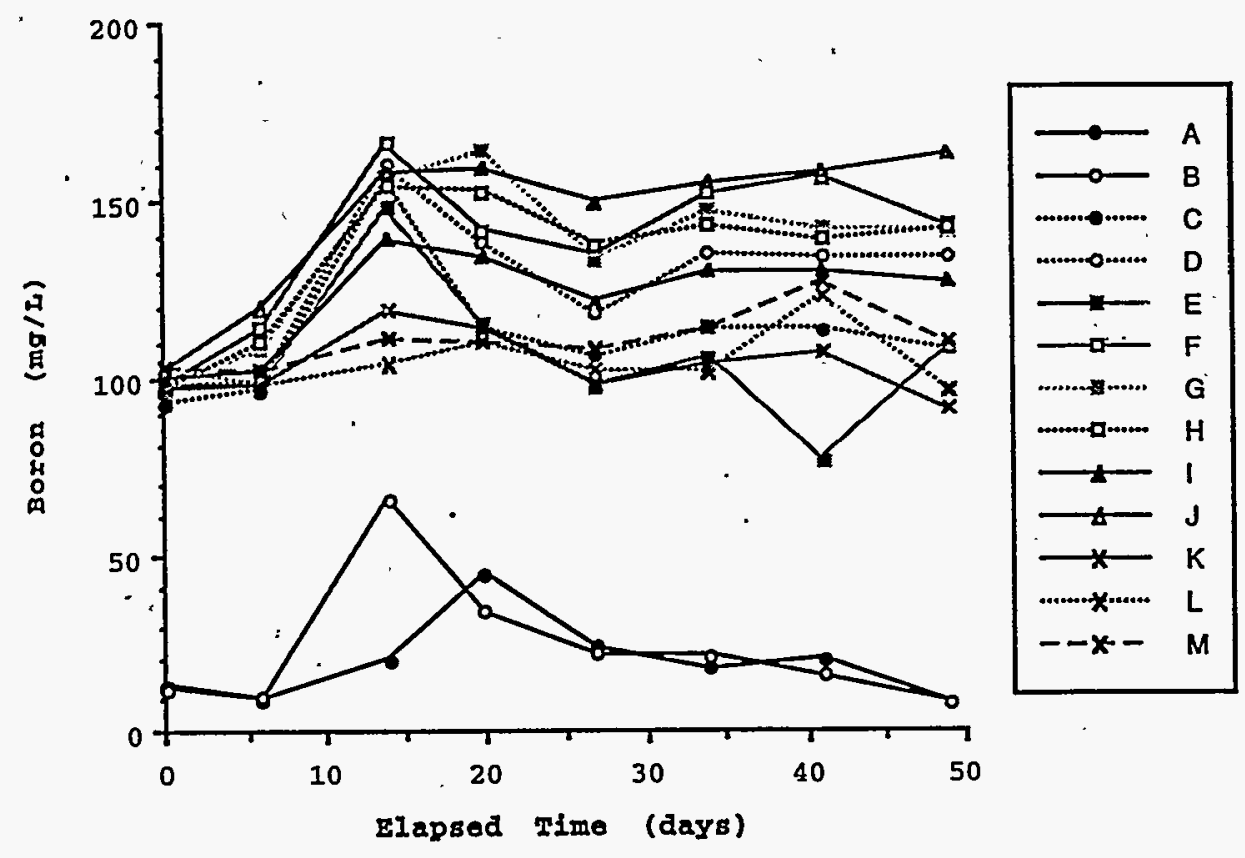

phenol results (Figure 25) showed three patterns in different samples: (1) no change, (2) gradual increase during the entire test, and (3) rapid initial increase followed by a leveling off.

Considering the results for all three products and emphasizing the later data points, the results suggest the following generalizations:

- Temperature increases significantly promote decomposition,

- Neither reagent grade (test A) nor AFF/Aquafine NaTPB (test C) decompose if none of the minor components are present,

- AFF/Aquafine NaTPB (test D) appears more susceptible to degradation in the presence of (only) soluble $\mathrm{Cu}$ than reagent grade NaTPB (test $B$ ),

- $\mathrm{MnO}_{2}$ has no effect alone (test $\mathrm{E}$ ),

- Preirradiation increases decomposition (test $J$ versus test G),

- Sludge and soluble copper promote decomposition,

- Other components (minor soluble compounds, MST, alcohols, or benzene) do not increase decomposition over the effect of the sludge or soluble copper.

These generalizations are not conclusively proven by these Series $A$ tests and further work is suggested. 
Figure 24. Phenylboric acid results for series A tests.

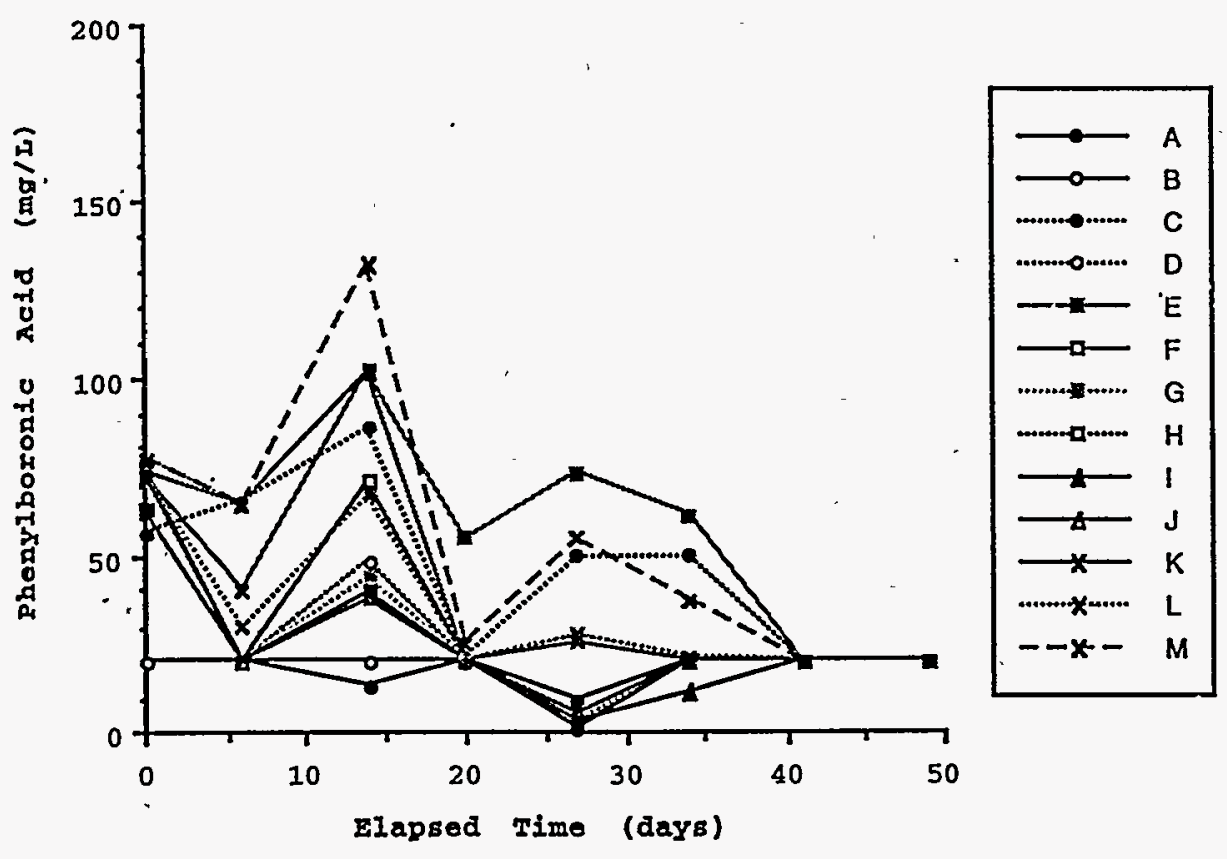

Figure 25. Phenol results for series A tests.

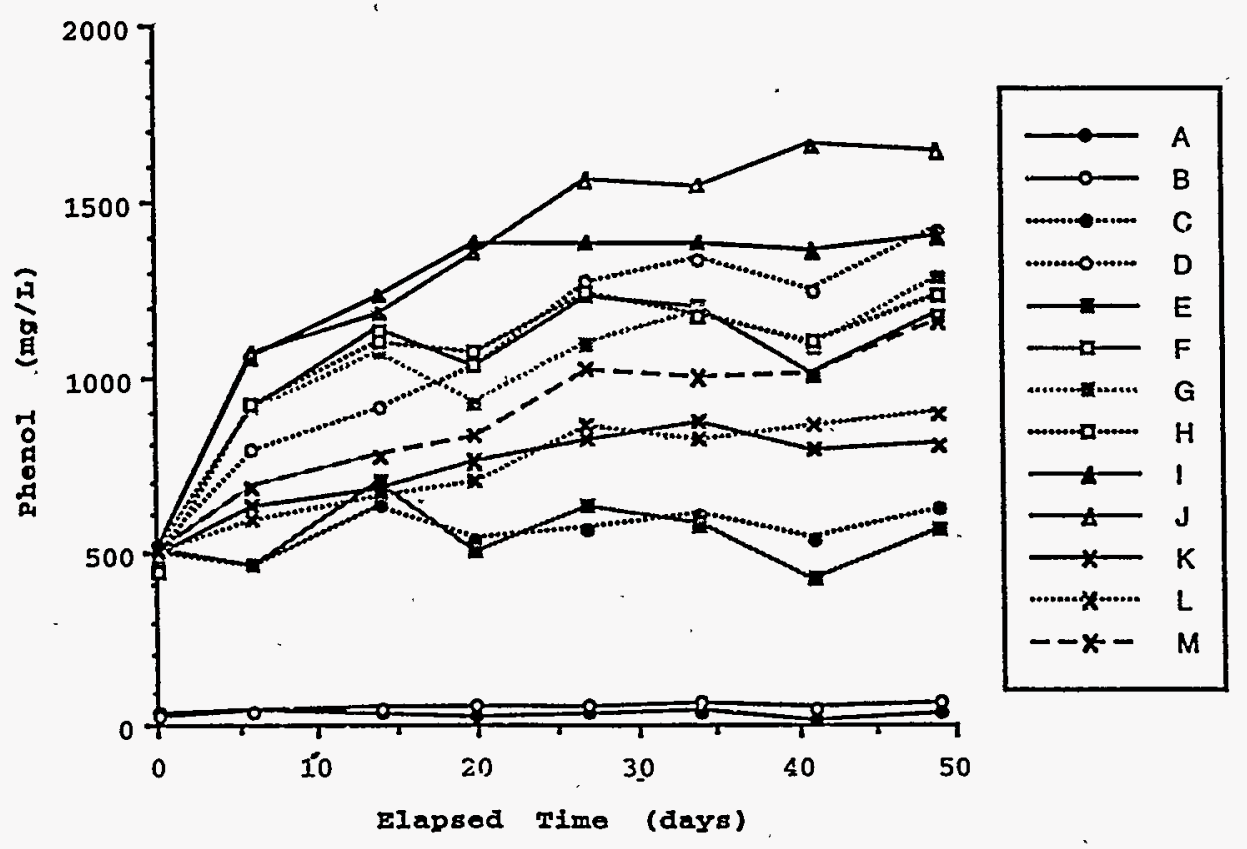


Table 17. Series A Test Matrix.

\begin{tabular}{|c|c|c|c|c|c|c|c|c|c|c|}
\hline \multirow[b]{2}{*}{$\begin{array}{c}\text { Test } \\
\text { ID } \\
\end{array}$} & \multirow[b]{2}{*}{$\begin{array}{c}\text { Temp. } \\
\left({ }^{\circ} \mathrm{C}\right)\end{array}$} & \multirow[b]{2}{*}{$\begin{array}{l}\text { NATPB } \\
\text { Source }\end{array}$} & \multicolumn{8}{|c|}{ Additives } \\
\hline & & & Copper & $\begin{array}{c}\text { Soluble } \\
\text { Minor }\end{array}$ & Sludge & MST & $\mathrm{MnO}_{2}$ & Alcohol & Benzene & $\begin{array}{l}\text { Pre- } \\
\text { Irrad. }\end{array}$ \\
\hline A & 70 & Aldrich & & & & & - & & v & \\
\hline $\mathrm{B}$ & 70 & Aldrich & $t^{a}$ & & & & & & & \\
\hline C & 70 & $\mathrm{AFF}$ & & & & & & & & \\
\hline D & 70 & $\mathrm{AFF}$ & + & : & & & & & & \\
\hline $\mathrm{E}$ & 70 & AFF & & & & & + & 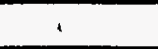 & & \\
\hline$F$ & 70 & AFF & & & + & & & & & \\
\hline $\mathbf{G}$ & 70 & $\mathrm{AFF}$ & + & + & + & + & & & & \\
\hline $\mathrm{H}$ & .70 & $\mathrm{AFF}$ & + & + & + & + & & + & & \\
\hline$I$ & 70 & AFF & + & + & + & + & & & + & \\
\hline$J$ & 70 & $\mathrm{AFF}$ & + & + & + & + & & & & + \\
\hline$K$ & 40 & $\mathrm{AFF}$ & + & + & + & + & & & & \\
\hline L & 40 & $\mathrm{AFF}$ & + & + & + & + & & & + & \\
\hline$M$ & 40 & AFF & + & + & + & + & & & . & + \\
\hline
\end{tabular}

${ }^{\mathrm{a}}+$ indicates the additive was present in the test sample.

Table 18. Results of NaTPB Solution Bottle Test.

\begin{tabular}{|c|c|c|c|}
\hline \multirow{2}{*}{$\begin{array}{c}\text { Elapsed Time } \\
\text { (days) }\end{array}$} & \multicolumn{3}{|c|}{ Benzene (g/L) } \\
\cline { 2 - 4 } & Bottle A & Bottle B & Bottle C \\
\hline & (air, $\left.0.1 \mathrm{M} \mathrm{OH}^{-}\right)$ & $\left(\right.$air, $\left.0.4 \mathrm{M} \mathrm{OH}^{-}\right)$ & $\left.0.1 \mathrm{MH}^{-}\right)$ \\
\hline 0 & 0.010 & 0.0009 & 0.019 \\
2 & 45 & 34 & 57 \\
4 & 64 & 48. & 61 \\
7 & 64 & 48 & 61 \\
\hline
\end{tabular}

\section{NaTPB Solution Test}

The purpose of these experiments was to determine the effect of benzene and sodium hydroxide on the decomposition rate. It had been postulated that a layer of benzene might provide a nonaqueous phase which would promote the decomposition reaction. Hydroxide had been postulated as a potential inhibitor of the reaction. Portions of the same solution described above for the non-radioactive ventilated tests (See Figure 21 and Figure 22) were placed in $125^{\circ}-\mathrm{mL}$ glass bottles and closed with septa-lined caps. In this test, the solutions were not stirred. The first bottle was sealed under air. The second bottle was sealed under air after additional sodium hydroxide was added to increase the concentration to 0.40 molar. The third bottle was sealed and then purged with nitrogen. The bottles were placed in an oven at 
$70{ }^{\circ} \mathrm{C}$ for 15 minutes, then removed and sampled. After 24 hours, a visible layer of benzene was observed in all three bottles. After 48 hours, the benzene layer was removed by syringe and the volume measured. In addition, a portion of the aqueous phase was removed and analyzed for phenol and phenylboric acid by HPLC. The removal of benzene and sampling for analysis was repeated after 4 and 7 days, at which time the experiment terminated. Table 18 shows the results of the analyses for benzene. Large amounts of phenol, phenylboric acid, and unidentified products (possibly triphenylboron and diphenylboric acid) were found in the aqueous phase while biphenyl was found in the benzene phase. The potential yield of benzene is $156 \mathrm{~g} / \mathrm{L}$. It is uncertain why the reaction appears to have stopped without going to completion.

\section{Series 1 sealed stainiess-steel Bottle Tests.}

Researchers studied the decomposition of tetraphenylborate slurries using sealed $\sim 150 \mathrm{~mL}$ stainless steel vessels stored unstirred at a temperature of $70{ }^{\circ} \mathrm{C}$. A black polymeric material, possibly either neoprene or viton, was used as the sealing gasket material. Three vessels were prepared with $120 \mathrm{~mL}$ slurries with various additives present. All of the slurry came from the same $\sim 0.5 \mathrm{I}$ batch. The composition of the slurry and the various additives are shown in Table 19. The slurry was prepared to be $\sim 4.7 \mathrm{M} \mathrm{Na}$. and to have a Tank $48 \mathrm{H}$ simulated salt solution content with theoretically 4 wt $\%$ KTPB and 0.6 wt \% NaTPB. Slurry was prepared using solid powder-like Aquafine NaTPB.. These tests investigated the combined effects of radiation and temperature compared to temperature effects only. Another purpose for conducting these tests was to investigate the effects of nine additional soluble metal ion additives and some trace levels of various organic' species. Previous initial series A tests in sealed polyethylene bottles at $70^{\circ} \mathrm{C}$ did not contain these nine soluble metal components nor the trace organics. The organic components were added to approximately the known levels of organics present in Tank $48 \mathrm{H}$ slurries prior to the excessive benzene production. One vessel was exposed to $70{ }^{\circ} \mathrm{C}$ and received no irradiation. The other two vessels were intermittently irradiated to approximate a 24,000 rad/day dose rate ( 15 minutes every other day at a dose rate of $\sim 2 \times 10^{5} \mathrm{rad} / \mathrm{hr}$ ) and exposed to $70{ }^{\circ} \mathrm{C}$ when not being irradiated. The dose of $\sim 24,000$ rad/day approximates the daily dose received by the radioactive slurry in Tank $48 \mathrm{H}$. This dose was based on a measured $\mathrm{Cs}-137$ specific activity of $\sim 400,000 \mathrm{Ci} / 160,000$ gallons of radioactive slurry in Tank $48 \mathrm{H}$. This amount of radioactive $\mathrm{C}-137$, which is the predominant radionuclide contributing to the radioactivity of the slurry, was determined from an acid. digestion of an actual slurry sample followed by gamma spectroscopy.

Figure 26 and Figure 27 show the amounts of decomposition products produced as a function of time over $\sim 1,000$ hours of testing. Figure 26 shows the results for the $70^{\circ} \mathrm{C}$ exposed slurry with additives and no radiation exposure. Figure 27 shows one of the duplicate irradiated and $70^{\circ} \mathrm{C}$ exposed slurries with additives. Benzene yields were measured by sealing $0.25-0.5 \mathrm{~mL}$ of the slurry in sealed $1.0 \mathrm{I}$ glass bulbs. After evaporation, benzene in the vapor space of the bulbs was measured by gas chromatography. All other products were 
Table 19. Tank $48 \mathrm{H}$ batch \#1 Aquafine tetraphenylborate simulant slurry.a

\begin{tabular}{|c|c|c|c|c|}
\hline Salt Content & \multicolumn{3}{|c|}{ Soluble Additives ${ }^{\mathrm{b}}$ (mg/L) } & Solid Additives \\
\hline $4.7 \mathrm{M} \mathrm{Na}^{+}$ & $1.7 \mathrm{Cu}(\mathrm{II})$ & 0.3 & $\mathrm{Ru}(I I I)$ & 0.17 wt $\%$ Sludge \\
\hline $2.7 \mathrm{M} \mathrm{OH}^{-}$ & $12 \mathrm{Mo}(\mathrm{VI})$ & 0.6 & $\mathrm{Ag}(I)$ & 0.17 wt \& MST \\
\hline $0.7 \mathrm{M} \mathrm{NO}_{2}^{-}$ & $60 \mathrm{Cr}(\mathrm{VI})$ & 2.2 & $\mathrm{Hg}(I I)$ & 0.11 wt $\% \mathrm{SiO} 2$ \\
\hline $0.69 \mathrm{M} \mathrm{NO}_{3}^{-}$ & $16 \mathrm{Si}(\mathrm{IV})$ & 12 & $\mathrm{Ca}$ (II) & \\
\hline $0.01 \mathrm{M} \mathrm{SO}_{4}^{2-}$ & $1 \mathrm{Se}(\mathrm{VI})$ & $0 . i$ & $\mathrm{Sr}(I I)$ & - \\
\hline $0.19 \mathrm{M} \mathrm{CO}_{3}^{2-}$ & $0.04 \mathrm{As}$ (IV) & 0.0 & $\mathrm{La}$ (III) & \\
\hline $0.014 \mathrm{M} \mathrm{Cl}^{-}$ & $\mathrm{Zn}) \mathrm{II}$ ) & 0.3 & $\mathrm{Ce}(I V)$ & \\
\hline $0.008 \mathrm{M} \mathrm{F}^{-}$ & $\mathrm{Pb}(I I)$ & 0.4 & $\mathrm{Cd}(I I)$ & , \\
\hline $0.006 \mathrm{M} \mathrm{PO}_{4}^{3-}$ & $\mathrm{Fe}$ (III) & 0.0 & $\operatorname{Co}(I I)$ & - \\
\hline $0.003 \mathrm{M} \mathrm{TPB}^{-}$ & $2.1 \mathrm{Sn}(I I)$ & & & \\
\hline
\end{tabular}

"Tetraphenylborate slurry prepared to be 4.6 wt $\%$ total solids with 4.0 wt $\&$ KTPB and 0.6 wt $\&$ NaTPB.

Trace levels $(0.1$ to $0.2 \mathrm{~g} / \mathrm{L}$ ) of organics (benzene, diphenylmercury, triphenylborane, diphenylboric acid, PBA, phenol and biphenyl) were also added.

Figure 26. Concentrations of products from thermal stainless steel bottle tests.

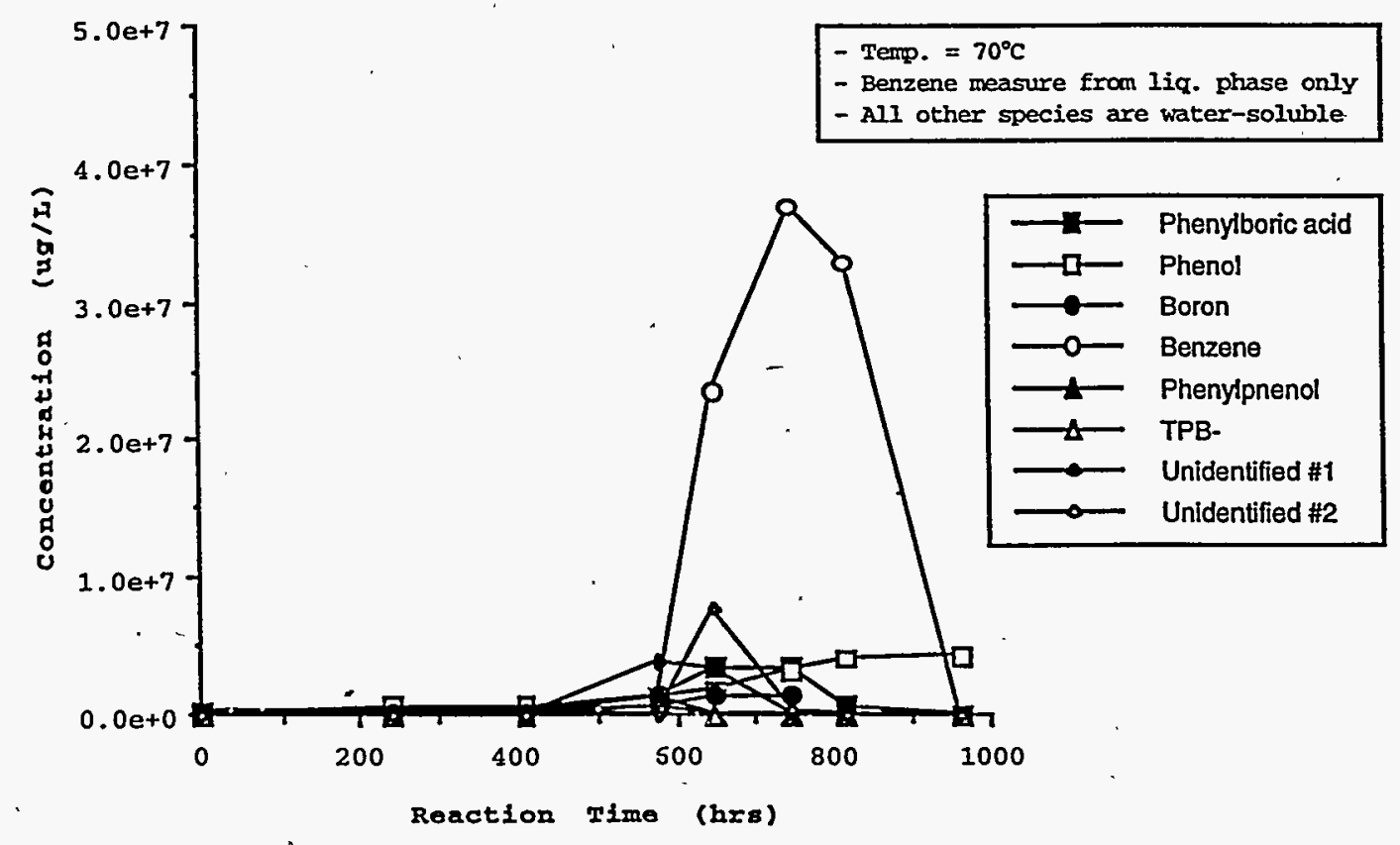


Figure 27. Concentrations of products from thermal and irradiated stainless steel bottle tests.

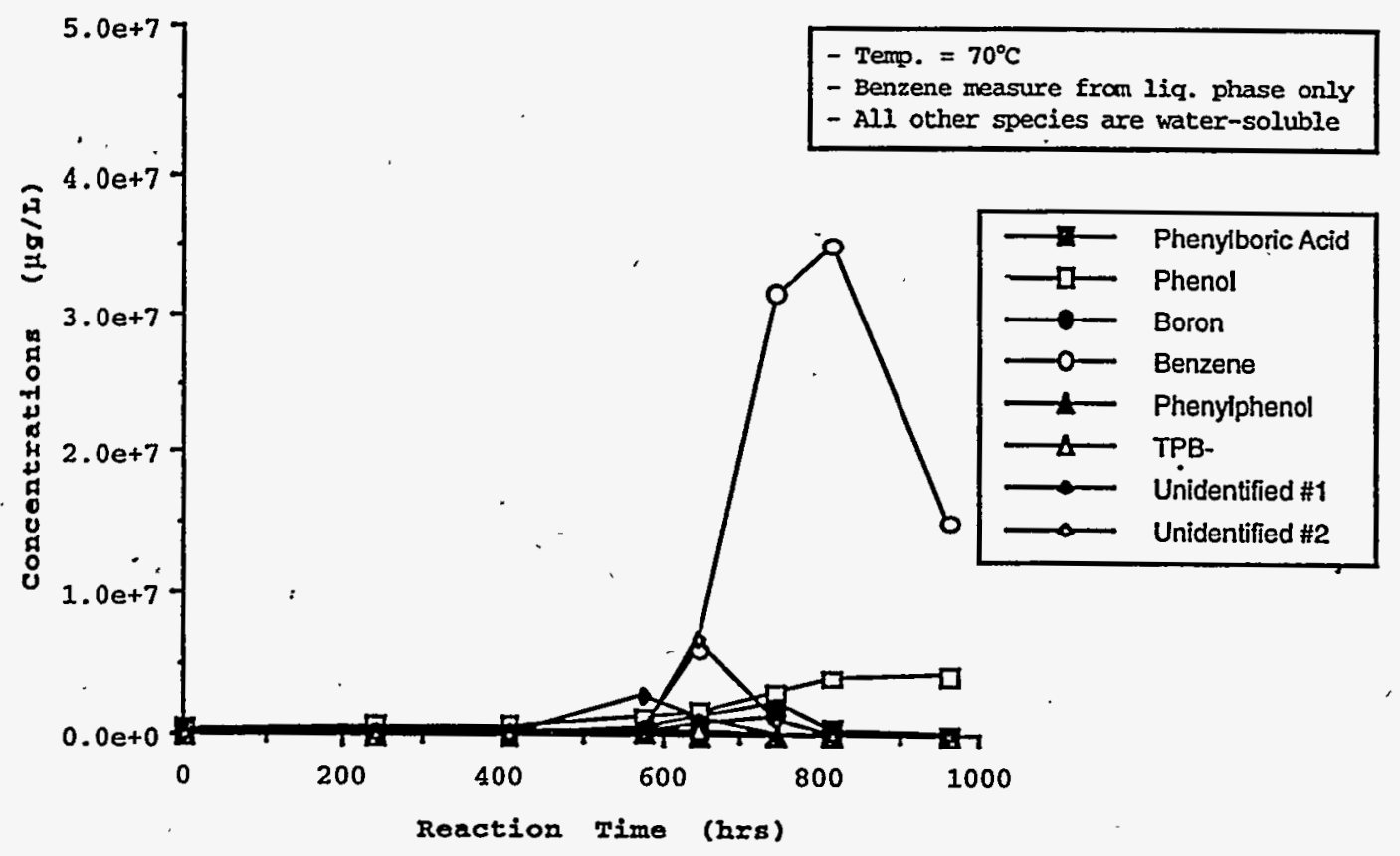

measured as soluble species in the aqueous filtrate of the slurry after filtering with a 0.45 um filter. Each time the slurry was sampled the vessels were removed from the oven, allowed to cool, and the tops removed. After brief stirring to thoroughly mix the slurries, a total of $\sim 10 \mathrm{~mL}$ of the slurry was removed by pipette for the benzene and filtrate analyses. The slurries were then resealed and put back in the oven at $70^{\circ} \mathrm{C}$.

There appears to be no difference in the irradiated and unirradiated systems. Both of the duplicate irradiated slurries showed nearly identical results. Initially, for $\sim 3$ weeks, no decomposition was observed. Liquid-chromatographic measurements on the filtrate from the slurries indicated no soluble TPB' was present for this 3 week period. It was later realized (after the slurries had been prepared and the tests started) that the original solid Aquafine NaTPB was only $\sim 87$ \& pure. Therefore, at the $\sim 480$ hour test time period, researchers added solid reagent grade Aldrich NaTPB material to the slurries. Three grams of the solid NaTPB was added to each vessel which at 480 hour contained $-90 \mathrm{~mL}$ of slurry. This $\sim 33 \mathrm{~g} / \mathrm{L}$ addition of reagent grade NaTPB was calculated to equal the amount that was deficient in the starting slurries due to the use of only $\sim 87$ \% pure solid Aquafine NaTFB. As. Shown in Figure 26 and Figure 27, four days after adding the NaTPB, rapid increases in decomposition products occurred for an additional $~ 8$ days, then leveled off. The low amounts of benzene in the final analyses are suspected to be due to evaporative losses. At the time of this final sampling, only 20-30 mL of the 
original $120 \mathrm{~mL}$ of slurry remained in the vessels. Follow-up bottle tests in steel vessels with Teflon gasket seals, described below, will investigate these effects further.

Product yields can be summarized as follows. Approximately $35 \mathrm{~g} / \mathrm{L}$ of benzene formed. A maximum rate of production is calculated in the range of 150,000 to $200,000 \mathrm{ug} / \mathrm{L} / \mathrm{hr}$, i.e. $\sim 30 \mathrm{~g} / \mathrm{L}$ benzene formed in 150 to 200 hours. Phenol reached about $4 \mathrm{~g} / \mathrm{I}$ and phenylboric acid reached about $3 \mathrm{~g} / \mathrm{L}$. The phenylboric acid then rapidly decreased to near zero again. Soluble boron reached $1 \mathrm{~g} / \mathrm{L}$, roughly equal to the theoretical yield from decomposition of the $33 \mathrm{~g} / \mathrm{L}$ of reagent grade NaTPB added at the 480 hour time. Two other decomposition products detected.in the aqueous filtrates showed transient behavior over a 150-200 hour time period consisting of rapid increases followed by rapid decreases to near zero. These two species are most likely triphenylboron and diphenylboric acid. This identification is based on comparison to standard solutions prepared and submitted during the several weeks of testing. The triphenylboron and diphenylboric acid standards were prepared from reagent-grade compounds described below (see Reaction of Phenylboron Compounds Section). It is assumed that these two aqueous species were destroyed by alkaline hydrolysis processes.

These experiments appear to approximate the behavior in Tank $48 \mathrm{H}$ better than previous tests involving stirred and gas purged slurries. Several factors may contribute to the decomposition such as sealed non-stirred containers, a long. induction period with no excess NaTPB present, and the presence of nine additional minor sludge ingredients and organics (relative to similar previous series A tests in sealed polyethylene bottles) added as soluble components (see Table 19).

\section{Follow-up Bottle Test}

Following the results described above for the series 1 sealed Stainless steel Bottle Test, similar experiments were repeated in glass vessels. The same slurry composition and all of the same minor components except the organic decomposition products (other than benzene) were used. These vessels were sealed using ground glass stopcocks to provide better isolation from air than obtained with polyethylene bottles. The ground glass stopcocks became frozen in place after extended heating in the presence of the alkaline salt solution, and the reaction could only be sampled once after the start of the experiment. However, the results (Table 20) show that significant decomposition of the excess NaTPB occurred within 9 days at $70{ }^{\circ} \mathrm{C}$. This result indicates that the materials of construction used for the container were not important, and that one or more of the minor components is instrumental in promóting the decomposition. The results are consistent with the postulate that limiting the amount of air available may be important in promoting the reaction. Other features of the decomposition are similar to Tank 48H: the reaction occurred rapidly over a short period of time, consumed the bulk of the excess NaTPB, and the major product was benzene. The average benzene generation rate over the 9. day period was $270,000 \mu \mathrm{g} / \mathrm{L} / \mathrm{hr}$. 
Table 20. Results of Follow-up Bottle Test.

\begin{tabular}{|c|c|c|c|}
\hline \multirow{2}{*}{ Component } & \multirow{2}{*}{ Time (days) } & \multicolumn{2}{|c|}{ Minor Component Concentrations } \\
\cline { 2 - 4 } & Tenzene & $\begin{array}{c}\text { None } \\
(\mathrm{g} / \mathrm{L})\end{array}$ & $\begin{array}{c}\text { AlI } \\
(\mathrm{g} / \mathrm{L})\end{array}$ \\
\hline \multirow{2}{*}{ Phenol } & 0 & .0036 & $0.39^{\mathrm{a}}$ \\
& 9 & .0036 & 6.7 \\
\hline \multirow{2}{*}{ PBA } & 0 & $<.1$ & $<.1$ \\
& 9 & $<.1$ & 0.66 \\
\hline \multirow{2}{*}{ TPB } & 0 & $<.1$ & $<.1$ \\
& 9 & .1 & 2.2 \\
\hline & 0 & 15 & 16 \\
\hline
\end{tabular}

aThe initial, benzene concentration is due to liquid benzene added as a minor component to the slurry.

\section{Series 2 sealed stainless-steel Bottle Tests}

The dual purposes of these tests were to investigate the differences between Aquafine slurry decomposition with and without additives at 70 ${ }^{\circ} \mathrm{C}$, and to compare the decomposition behavior of the Aquafine tetraphenylborate slurry versus the BSC tetraphenylborate slurry, both with candidate catalyst additives at $70^{\circ} \mathrm{C}$. None of the slurries in these tests were irradiated. Tests were initiated in the $150 \mathrm{~mL}$ steel vessels stored at $70^{\circ} \mathrm{C}$. The vessel lids had been modified to allow vapor-space sampling and slurry sampling through a $3 / 8$ inch gas chromatographic septum. Sampling the vessels in this manner allowed vapor space gas analyses and slurry analyses without opening and exposing the sysiems to air during sampling. Teflon ${ }^{\mathrm{TM}}$ gaskets were used as sealing material in place of the previous black polymeric materials.

A stirring bar was added to each sealed vessel to allow for brief stirring immediately before each slurry sampling. One vessel was prepared with $125 \mathrm{~mL}$ of Aquafine NaTPB slurry with various potential catalyst additives present. Another vessel contained only the Aquafine NaTPB slurry with no soluble or solid potential catalysts present. A vessel contained Boulder Scientific Company NaTPB slurry with various potential catalyst additives present. Both of the vessels containing Aquafine tetraphenylborate slurries were prepared from the same $\sim 0.5 \mathrm{I}$ batch of tetraphenylborate slurry. The composition of the tetraphenylborate slurries and the various additives, which were identical to the additives used in the Series 1 Sealed Stainless-steel Bottle Tests, are shown in Table 21. Both tetraphenylborate slurries were prepared to have a sodium ion concentration of $\sim 4.7$ molar and to have a Tank $48 \mathrm{H}$ simulated salt solution content with theoretically 4 wt $\%$ KTPB and 1.5 wto NaTPB. The amount of solid NaTPB was purposely increased for these slurries 
(Na'TPB $=1.5$ wt $\%$ ) relative to the Series 1 Sealed Stainless steel Bottle Tests (NaTPB $=0.6 \mathrm{wt} \%$ ). This was done to assure an adequate excess of NaTPB initially present in the slurries. Based on results of the previous Series I Sealed Stainless Steel Bottle Tests, it was expected that perhaps all of this 1.5 wt 8 NaTPB would decompose to benzene, PBA and phenol. Both the Aquafine and Boulder. tetraphenylborate slurries were prepared using $\sim 0.55 \mathrm{M} \mathrm{TPB}^{-}$aqueous solutions as the Aquafine and Boulder NaTPB source, respectively. Each test was sampled periodically over 300 hours and analyzed for benzene (in both the vapor and liquid), phenol, PBA, and TPB'.

Figure 28 through Figure 31 show the amounts of decomposition products produced as a function of time over $\sim 300$ hours of testing. At the time of this writing, these tests are ongoing and are planned to continue for $\sim 700$ hours. Examination of the benzene data (Figure 28) from the BSC and AFF tests that contained the potential catalysts indicate little difference in reactivity between the two sources of NaTPB. The amounts of benzene measured to date in these two slurries, $1.6 \times 10^{7}$ to $1.8 \times 10^{7} \mathrm{ug} / \mathrm{L}$, is in the range expected from complete decomposition of the original 1.5 wt $\%$ of solid NaTPB present and the $\sim 0.001$ molar soluble tetraphenylborate present in the initial slurries. Further comparison of the two AFF NaTPB tests indicate that in the absence of the potential catalysts, AFF NaTPB is relatively stable at $70^{\circ} \mathrm{C}$ over the ten day test period.

\section{Table 21. Composition of $\mathrm{AFF}$ and Boulder Scientific Tank 48\% simulant slurries.a}

\begin{tabular}{|c|c|c|c|c|}
\hline Salt Content & \multicolumn{3}{|c|}{ Soluble Additives ${ }^{b, c}$ (mg/L) } & $\begin{array}{c}\text { Solid } \\
\text { Additives }^{c}\end{array}$ \\
\hline $4.7 \mathrm{M} \mathrm{Na}^{+}$ & $1.7 \mathrm{Cu}(I I)$ & 0.3 & $\mathrm{Ru}(I I I)$ & 0.17 wt $\%$ siudge \\
\hline $2.7 \mathrm{M} \mathrm{OH}^{-}$ & $12 \operatorname{Mo}(\mathrm{VI})$ & 0.6 & $\mathrm{Ag}(I)$ & 0.17 wt 8 MST. \\
\hline $0.7 \mathrm{M} \mathrm{NO}_{2}^{-}$ & $60 \mathrm{Cr}(\mathrm{VI})$ & 2.2 & $\mathrm{Hg}(I I)$ & 0.11 wt \% SiO2 \\
\hline $0.69 \mathrm{M} \mathrm{NO}_{3}^{-}$ & $16 \mathrm{Si}(\mathrm{IV})$ & 12.2 & $\mathrm{Ca}(\mathrm{II})$ & \\
\hline $0.01 \mathrm{M} \mathrm{SO}_{4}^{2-}$ & $1 S \operatorname{Se}(V I)$ & 0.1 & $\operatorname{Sr}(I I)$ & \\
\hline $0.19 \mathrm{M} \mathrm{CO}_{3}^{2-}$ & $0.04 \mathrm{As}(\mathrm{IV})$ & 0.05 & $\mathrm{La}(I I I)$ & \\
\hline $0.014 \mathrm{M} \mathrm{Cl}^{-}$ & $8.8 \mathrm{Zn}) \mathrm{II})$ & 0.3 & $\mathrm{Ce}(I V)$ & \\
\hline $0.008 \mathrm{M} \mathrm{F}^{-}$ & $\mathrm{Pb}(I I)$ & 0.4 & $\mathrm{Cd}(I I)$ & \\
\hline $0.006 \mathrm{M} \mathrm{PO}_{4}^{3-}$ & $2.6 \mathrm{Fe}$ (III) & 0.04 & $\operatorname{Co}(I I)$ & \\
\hline $0.003 \mathrm{M} \mathrm{TPB}$ & $2.1 \operatorname{Sn}(I I)$ & & & \\
\hline
\end{tabular}

"Both Aquafine and Boulder TPB slurry prepared to be 5.5 wt $\%$ total solids with 4.0 wt $\mathrm{KTPB}$ and 1.5 wt of NaTPB.

Trace levels $(0.1$ to $0.2 \mathrm{~g} / \mathrm{L})$ of organics (benzene, diphenylmercury, triphenylborane, diphenylboric acid, PBA, phenol and biphenyl) were also added. 'One of the Aquafine TPB slurry systems contained no soluble nor solid additives. 
Figure 28. Benzene generation from sealed stainless-steel bottle tests using different vendor supplies of NaTPB.

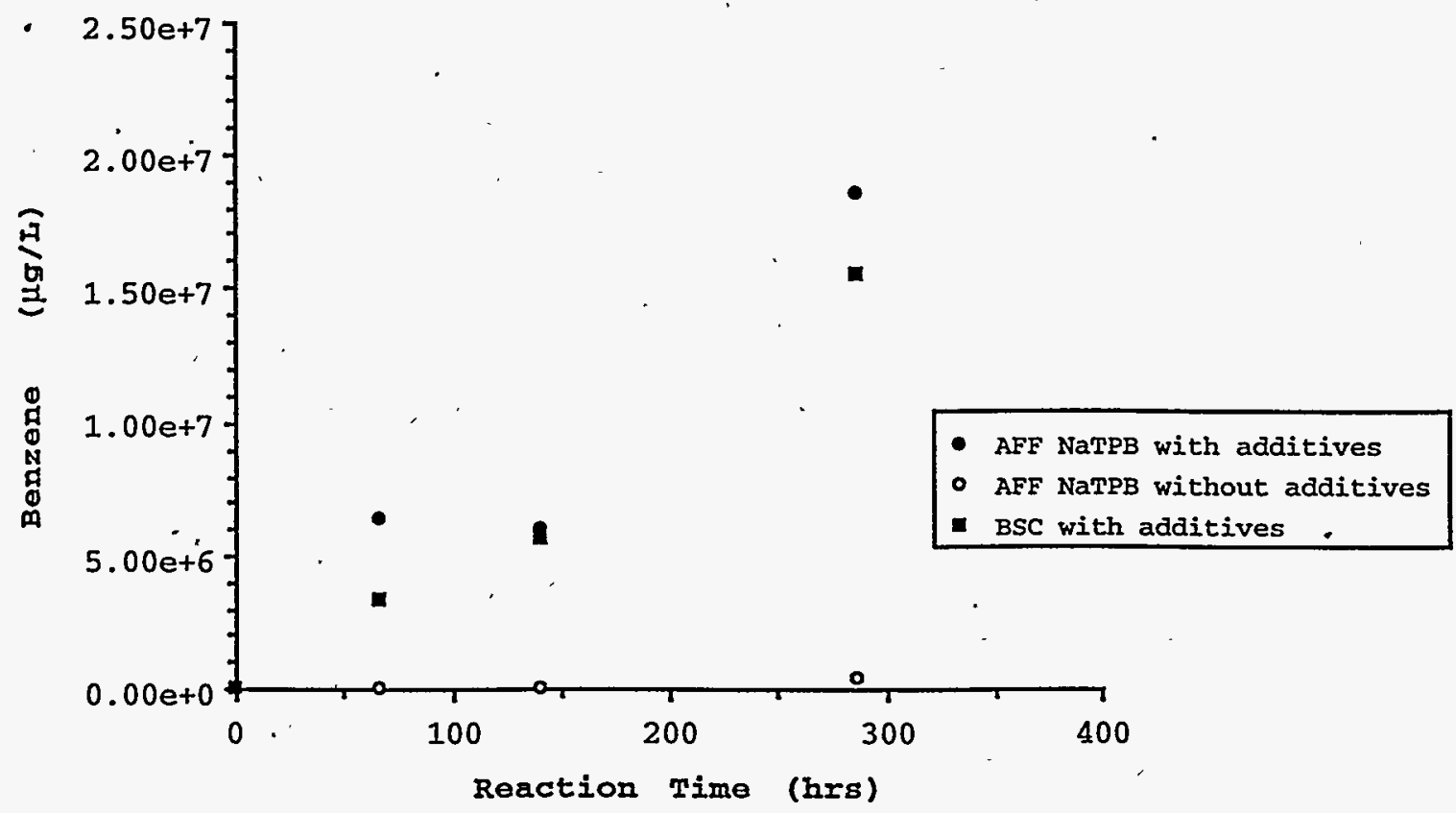

Figure 29. Phenol generation from sealed stainless-steel bottle tests using different vendor supplies of NaTPB.

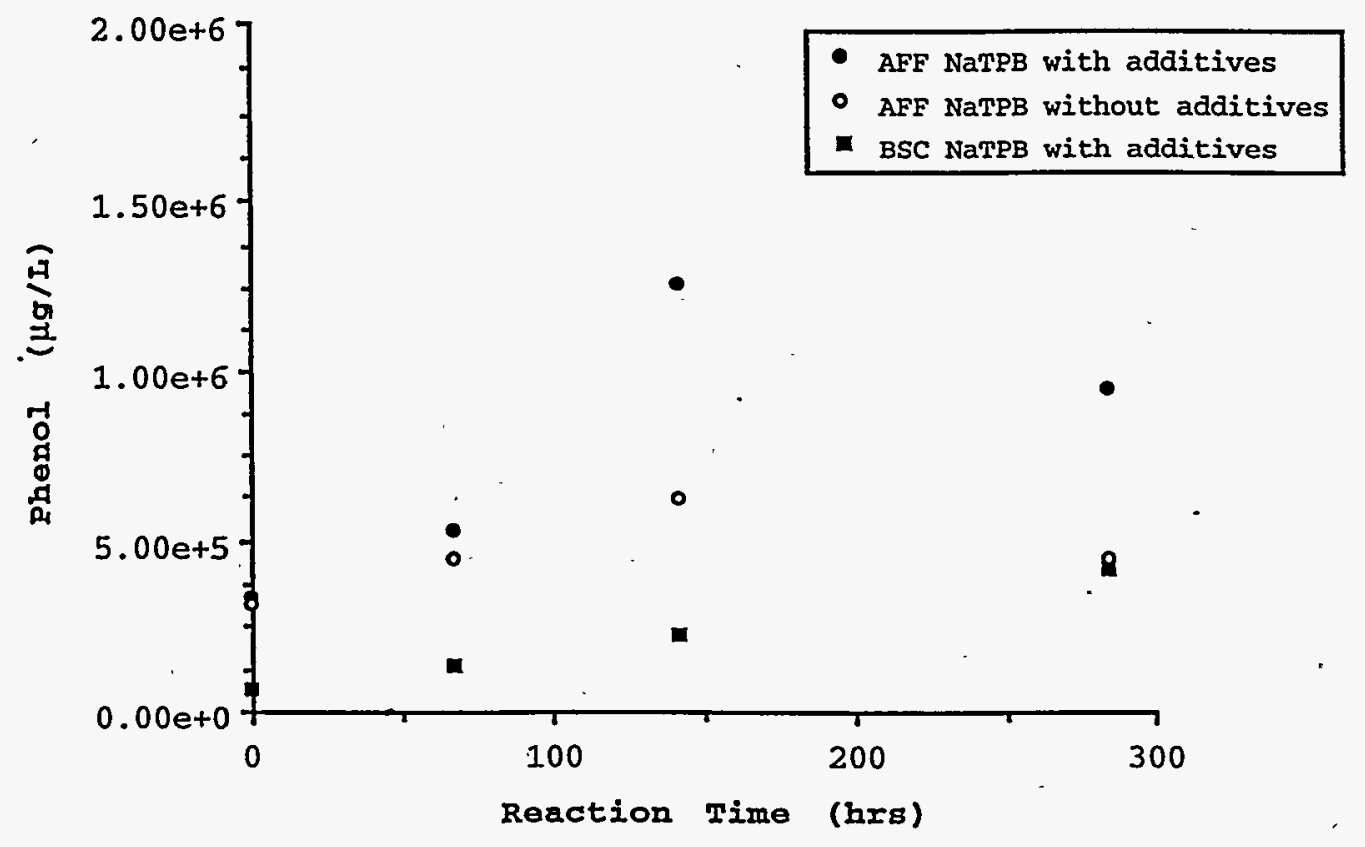


Similar conclusions can be made from the phenol (Figure 29) and PBA (Figure 30) data. We note that the benzene concentrations shown are an order of magnitude greater than either phenol or PBA. Figure 31 shows the soluble tetraphenylborate data. The soluble tetraphenylborate (see Table 20) appears to be decreasing as the reaction proceeds in both the AFF and BSC slurries with additives, relative to its apparent stability in the AFF. NaTPB slurry with no additives present.

\section{NaTPB Decomposition Reaction Intermediates and Products}

The behavior of NaTPB decomposition products and intermediates in Tank $48 \mathrm{H}$ is only partially understood. Much information concerning potential intermediates, their solubility, and their reactivities remain unknown. For example, current HPLC methodologies cannot quantify triphenylboron or diphenylboric acid (DPBA). Hence, the behavior of these intermediates in the decomposition reaction scheme are only speculative. Work is in progress to address these inadequacies.

\section{Solubility of Boron-Containing Intermediates}

One previously unknown parameter was the solubility of boron in these alkaline solutions. Boron concentration in Tank 48H filtrate has provided a means of determining the extent of reaction. To this end, the solubilities of several boron compounds in 4.7 molar sodium salt

Figure 30. Phenylboric acid generation from sealed stainless-steel bottle tests using different vendor supplies of NaTPB.

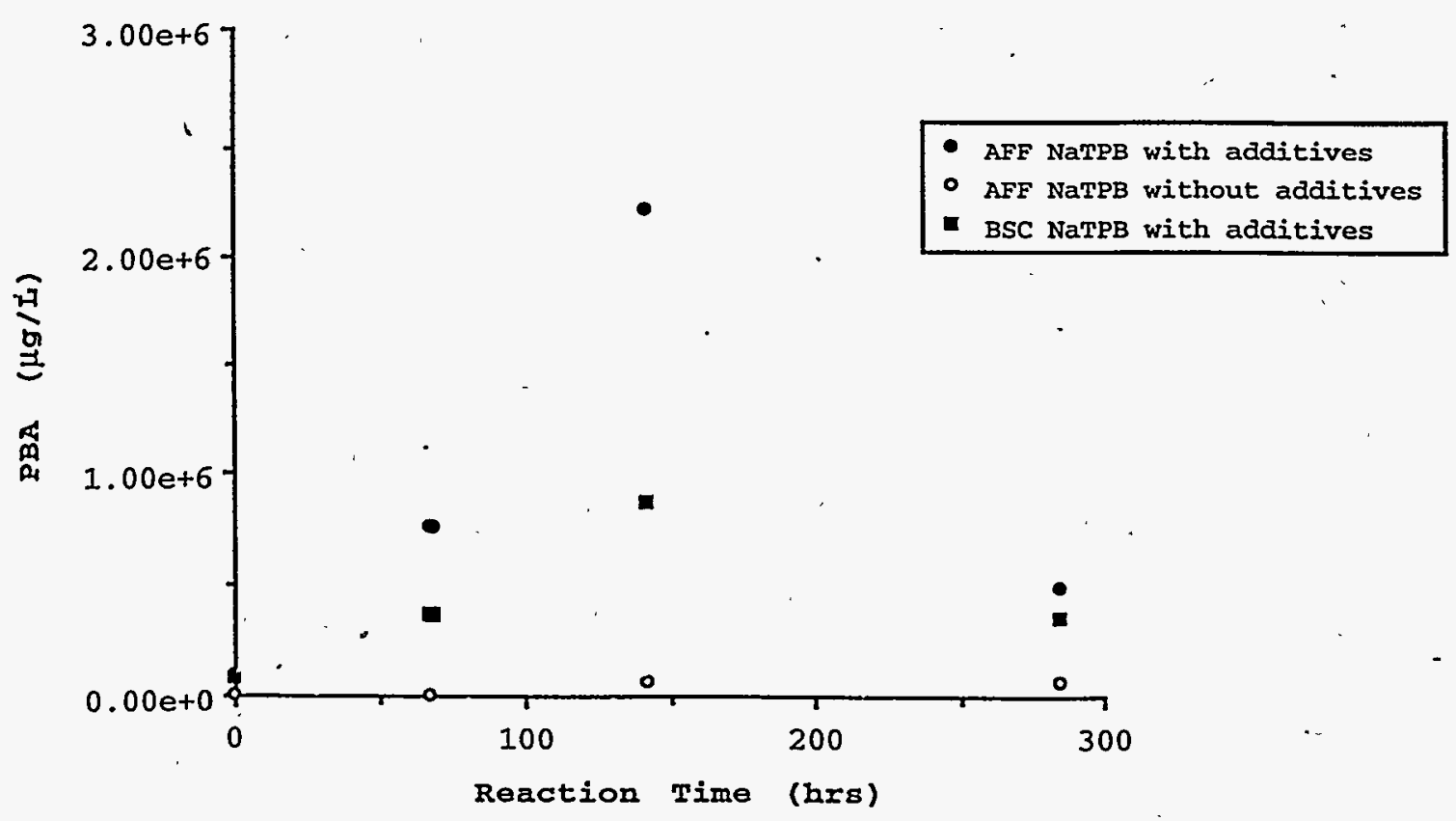


solution ( 2 molar $\left.\mathrm{OH}^{-}\right)$were measured. The solubility of boric acid, $\mathrm{B}(\mathrm{OH})_{3}$, was greater than $120 \mathrm{~g} / \mathrm{L}$. This equates to a boron solubility greater than $21 \mathrm{~g} / \mathrm{L}$. The solubility of borax, $\mathrm{Na}_{2} \mathrm{~B}_{4} \mathrm{O}_{7} \cdot 10 \mathrm{H}_{2} \mathrm{O}$, was greater than $80.4 \mathrm{~g} / \mathrm{L}$ realizing a boron solubility greater than $9 \mathrm{~g} / \mathrm{L}$. The solubility of $\mathrm{PBA}$ was determined as greater than $15 \mathrm{~g} / \mathrm{L}$ but less than $30 \mathrm{~g} / \mathrm{L}$. The solubility of tetraphenylborate has been well studied. Its solubility is approximately 0.003 molar for these solutions, resulting in a boron solubility of $32 \mathrm{mg} / \mathrm{L}$. The conclusion that can be drawn from this is that Tank $48 \mathrm{H}$ and the small scale experiments have not approached the solubility limit for boron or PBA.

Reaction of Phenylboron Compounds

Also unknown were the rates and product distribution from the continued reaction of NaTPB decomposition product intermediates. Simple tests were conducted with an air atmosphere at $70 .{ }^{\circ} \mathrm{C}$ in which weighed portions of NaTPB, triphenylboron hydroxy complex, DPBA ethanolamine complex, anhydrous $\mathrm{DPBA}$, and $\mathrm{PBA}$ were placed in a 2.0 molar sodium salt solution $\left(0.6 \mathrm{M} \mathrm{OH}^{-}\right)$for seven days. Aliquots of each test were taken at the start of test and again after 3 days and 7 days. These were analyzed by HPLC. Table 22 provides results from the tests.

Figure 31. Tetraphenylborate stainless-steel bottle tests. of NaTPB.

consumption in sealed. using different vendor supplies

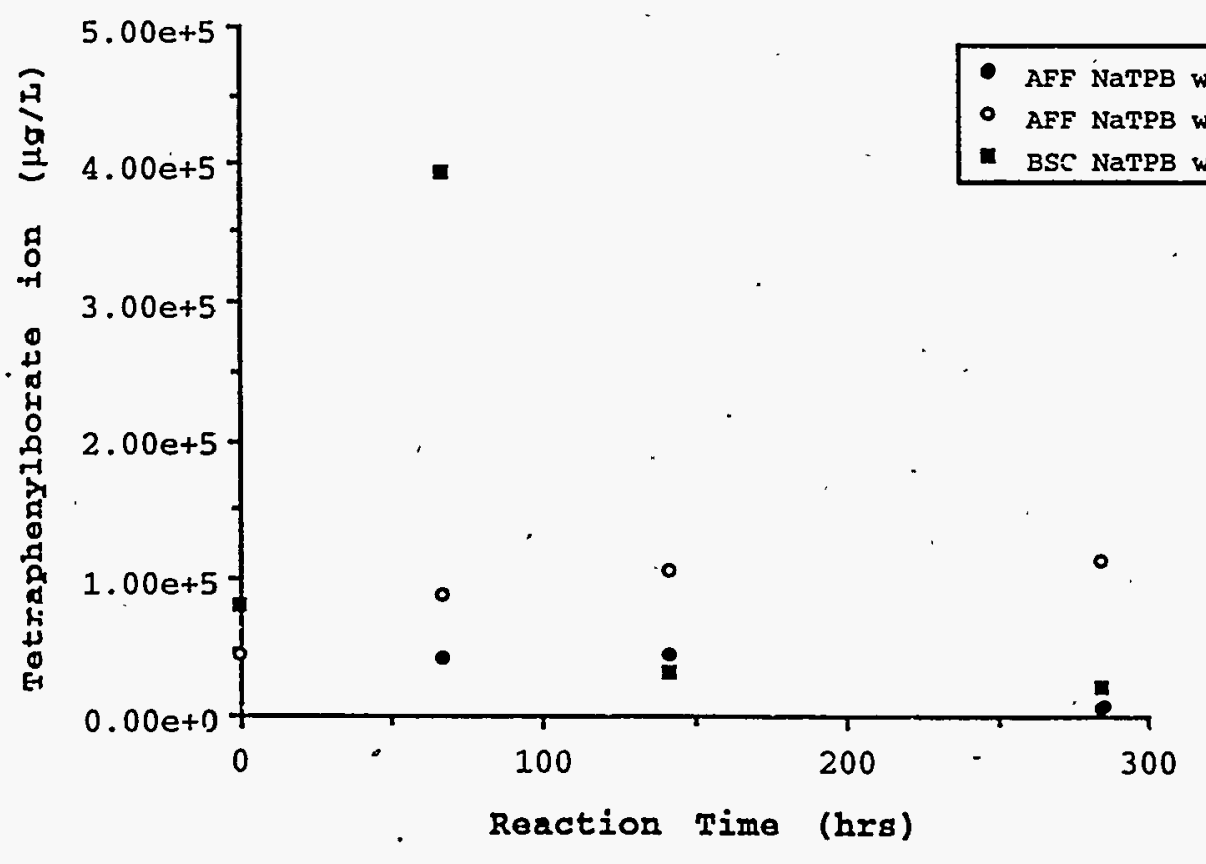


The results show that NaTPB is relatively stable under these conditions. The triphenylboron hydroxy complex is undetectable by HPLC, however, phenol is formed from the material. . The data suggest the triphenylboron hydroxy complex was entirely decomposed in the first 3 days. The DPBA ethanolamine complex is observed by HPLC but it is not quantifiable. Area counts from the HPLC were used to measure its relative concentration. The data suggest that it is more stable than the triphenylboron hydroxy adduct and comparable to PBA in terms of stability. "Note that the DPBA ethanolamine complex contained an insignificant amount of PBA impurity at the start of the test. Anhydrous DPBA appears to be slightly less stable than the ethanolamine complex. Note that the anhydrous DPBA contained little or no PBA impurity at the start of the test. The data indicate that PBA and phenol are the only decomposition products. Phenylboric acid is more stable than any of the other compounds except NaTPB itself. The decomposition of PBA in air produces approximately $50 \%$ phenol and $50 \%$ unknown (most likely benzene).

\section{Benzene Generation in Tank 5OH}

During the time in which rapid decomposition of NaTPB and large benzene generation rates were observed in Tank 48H, elevated levels of benzene $(9.0 \mathrm{mg} / \mathrm{L}$, Ref. 5) were observed in Tank $50 \mathrm{H}$ salt solution. This level was both a flammability and regulatory concern to the downstream Saltstone facility. Initially, personnel thought soluble tetraphenylborate, in the decontaminated filtrate transferred from Tank $48 \mathrm{H}$ to $50 \mathrm{H}$ during concentration, was decomposing and producing the elevated benzene. However, given the more moderate Tank $50 \mathrm{H}$ temperatures $\left(25-30^{\circ} \mathrm{C}\right)$, it seems more probable that an intermediate product (e.g., diphenylboric acid or triphenylboron hydroxy complex) from the early stages of NaTPB decomposition in Tank $48 \mathrm{H}$ was transferred into Tank $50 \mathrm{H}$ during the final concentration phase in Tank 48H. Examination of the Tank 48H filtrate analyses in Table 2 indicates that the NaTPB decomposition reaction was beginning at that time. The potassium concentration in Tank $50 \mathrm{H}$ also supports the theory that something other than NaTPB was decomposing to produce benzene. A Tank 50H sample from late December was found to contain $265 \mathrm{mg} / \mathrm{L}$ of soluble potassium. This suggests that an excess of potassium (relative to NaTPB) existed in Tank $50 \mathrm{H}$ during November and that any soluble TPB $^{-}$would have precipitated as KTPB.

No benzene concentration data exists between the first week of November and the first week of December. It is during this time that the highest benzene generation rate most likely occurred. Therefore, it is difficult to determine the highest rate directly from Tank $50 \mathrm{H}$ data. Instead, the initial benzene generation rates, described earlier and shown in Figure 20, observed from the December 18 Tank $48 \mathrm{H}$ filtrate sample is the best data available to predict the highest rate observed in Tank $50 \mathrm{H}$. In two different samples measured more than a month apart; an initial benzene generation rate of $300 \mu \mathrm{g} / \mathrm{\tau} / \mathrm{hr}$ was observed from the continued decomposition of NaTPB intermediates. The concentration of these intermediates were unknown. As such, it is impossible to determine if $300 \mu \mathrm{g} / \mathrm{L} / \mathrm{hr}$ is conservative. 
W. L. Tamosaitis

Table 22. Decomposition of Phenylboron compounds in salt solution at $70^{\circ} \mathrm{C}$.

\begin{tabular}{|c|c|c|c|}
\hline \multicolumn{4}{|l|}{ A. NaTPB } \\
\hline \multicolumn{4}{|c|}{\begin{tabular}{|c|c|c|c}
$\begin{array}{c}\text { Time } \\
\text { (days) }\end{array}$ & $\begin{array}{c}\text { PBA } \\
\text { (mg/L) }\end{array}$ & $\begin{array}{c}\text { Phenol } \\
\text { (mg/L) }\end{array}$ & $\begin{array}{c}\text { NaTPB } \\
\text { (mg/L) }\end{array}$ \\
\end{tabular}} \\
\hline 0 & $<20$ & $<20$ & 140 \\
\hline 3 & $<20$ & $<20$ & 135 \\
\hline 7 & $<20$ & $<20$ & 121 \\
\hline
\end{tabular}

B. Triphenylboron hyaroxy complex

\begin{tabular}{|c|c|c|c|}
\hline $\begin{array}{c}\text { Time } \\
\text { days) }\end{array}$ & $\begin{array}{c}\text { PBA } \\
(\mathrm{mg} / \mathrm{L})\end{array}$ & $\begin{array}{c}\text { Phenol } \\
(\mathrm{mg} / \mathrm{L})\end{array}$ & $\begin{array}{c}\text { Triphenylboron } \\
\text { hydroxy } \\
\text { complex }\end{array}$ \\
\hline 0 & $<20$ & 33 & not observed \\
\hline 3 & 27 & 100 & not observed \\
\hline 7 & 20 & 100. & not observed \\
\hline
\end{tabular}

C. DPBA (ethanolamine complex)

\begin{tabular}{|c|c|c|c|}
\hline $\begin{array}{l}\text { Time } \\
\text { (days) }\end{array}$ & $\begin{array}{c}\mathrm{PBA} \\
(\mathrm{mg} / \mathrm{I})\end{array}$ & $\begin{array}{l}\text { Phenol } \\
\text { (mg/L) }\end{array}$ & $\begin{array}{c}\text { DPBA } \\
\text { (HPLC area } \\
\text { units) }\end{array}$ \\
\hline 0 & 30 & $<20$ & 11.2 \\
\hline 3 & 380 & 210 & 9.55 \\
\hline 7 & 720 & 420 & 7.92 \\
\hline \multicolumn{4}{|c|}{ D. DPBA (anhyarous) } \\
\hline $\begin{array}{c}\text { Time } \\
\text { (days) }\end{array}$ & $\begin{array}{c}\mathrm{PBA} \\
(\mathrm{mg} / \mathrm{L})\end{array}$ & $\begin{array}{l}\text { Phenol } \\
\text { (mg/L) }\end{array}$ & $\begin{array}{c}\text { DPBA } \\
\text { (HPLC area } \\
\text { units) }\end{array}$ \\
\hline 0 & 320 & $<20$ & 13.5 \\
\hline 3 & 720 & 260 & 11.3 \\
\hline 7 & 1380 & 770 & 9.83 \\
\hline \multicolumn{4}{|l|}{ E. $\mathrm{PBA}$} \\
\hline $\begin{array}{c}\text { Time } \\
\text { (days) }\end{array}$ & $\begin{array}{c}\mathrm{PBA} \\
-(\mathrm{mg} / \mathrm{L}) \\
\end{array}$ & $\begin{array}{l}\text { Phenol } \\
\text { (mg/L) }\end{array}$ & \\
\hline 0 & 5080 & $\leq 20$ & \\
\hline 3 & 4370 & 460 & \\
\hline 7 & 3580 & 820 & \\
\hline
\end{tabular}


phenyl radical and biphenylboron radical products of reactions 3 and 4 could undergo further reactions involving dimerization, oxidation, and alkaline-adduct hydrolysis. The products of which would be various dimers, phenol, phenylboric acid, benzene, and biphenyl (see Appendix P) .

A separate postulated scheme involves phenyl transfer to a copper ion, forming a metal-phenyl adduct and triphenylboron. Reactions 7 12 show this scheme with copper, a metal known to exhibit the proposed chemistry.

7) $\mathrm{Cu}^{2+}+2\left(\mathrm{C}_{6} \mathrm{H}_{5}\right)_{3} \mathrm{~B}\left(\mathrm{C}_{6} \mathrm{H}_{5}\right)^{-} \rightarrow \mathrm{Cu}(\mathrm{I}) \mathrm{B}\left(\mathrm{C}_{6} \mathrm{H}_{5}\right)_{4}+\left(\mathrm{C}_{6} \mathrm{H}_{5}\right)_{4} \mathrm{~B}$.

8) $\mathrm{Cu}(\mathrm{I}) \mathrm{B}\left(\mathrm{C}_{6} \mathrm{H}_{5}\right)_{4} \Leftrightarrow \mathrm{Cu}(\mathrm{I})\left(\mathrm{C}_{6} \mathrm{H}_{5}\right)+\left(\mathrm{C}_{6} \mathrm{H}_{5}\right)_{3 \mathrm{~B}}$

9) $\mathrm{Cu}(\mathrm{I})\left(\mathrm{C}_{6} \mathrm{H}_{5}\right)+\mathrm{OH}^{-} \Leftrightarrow\left(\mathrm{C}_{6} \mathrm{H}_{5}\right) \mathrm{Cu}(\mathrm{I}) \mathrm{OH}^{-}$

10) $\left(\mathrm{C}_{6} \mathrm{H}_{5}\right) \mathrm{Cu}(I) \mathrm{OH}^{-} \rightarrow \mathrm{C}_{6} \mathrm{H}_{6}+\mathrm{Cu}(I) \mathrm{O}^{-}$

11) $\mathrm{Cu}(\mathrm{I}) \mathrm{O}^{-}+\mathrm{H}_{2} \mathrm{O} \rightarrow->\mathrm{Cu}^{+}+2 \mathrm{OH}^{-}$

12) $\mathrm{Cu}^{+}+.\left(\mathrm{C}_{6} \mathrm{H}_{5}\right)_{3} \mathrm{~B}\left(\mathrm{C}_{6} \mathrm{H}_{5}\right)^{-} \rightarrow \mathrm{Cu}(\mathrm{I}) \mathrm{B}\left(\mathrm{C}_{6} \mathrm{H}_{5}\right)_{4}$

The above scheme would involve a catalytic cycle (reactions 8-12) without redox reactions of the $\mathrm{Cu}$ (II) species after reduction as in reaction 7. The copper-phenyl adduct. shown in reaction 9 could alternatively undergo hydrolysis by water, or:

$$
\mathrm{Cu}(I)\left(\mathrm{C}_{6} \mathrm{H}_{5}\right)+\mathrm{H}_{2} \mathrm{O} \Leftrightarrow \mathrm{C}_{6} \mathrm{H}_{6}+\mathrm{Cu}(I) \mathrm{OH}
$$

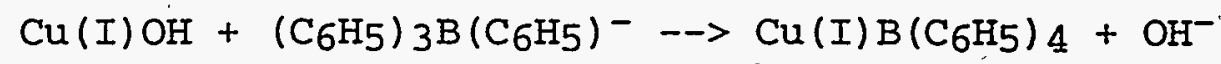

This reaction pathway might also lead to a catalytic cycle, involving reaction 8 and reactions $13-14$.

Both of the two generalized schemes postulated above, reactions 1-6 or reactions 7-14, could be facilitated or accelerated by the presence of a separate benzene layer within the slurry or by a separate solid phase acting as a heterogeneous catalysis site. The formation of a benzene layer or localized regions of benzene liquid within the aqueous tetraphenylborate slurry could effect the solubility of an otherwise insoluble catalyst, (e.g., a metal species present as their solid metal hydroxide or metal oxide forms, in a caustic aqueous media). The existence of solid particles within a tetraphenylborate slurry, such as. sludge comprised of iron, manganese, nickel and aluminum oxides and hydroxides, or titanate existing as monosodium titanate solids could serve to provide an active site for heterogeneous catalysis. In the case of a heterogeneous catalysis site, the solid could serve to provide an appropriate site for adsorption of a catalytically active soluble metal cation and the soluble tetraphenyiborate anion, which would otherwise not react in solids-free solutions (i.e., in tetraphenylborate slurries not containing such heterogeneous solid catalysts).

In radioactive tetraphenylborate slurries, radiation effects could also play a role in the catalytic processes. Various strong reducing agents such as the hydrated electron and hydrogen atom, as well as 


\section{Mechanistic Implications}

Portions of the following section are derived from information and suggestions provided by the ITP Process and Mechanisms Panel. A more detailed discussion of the mechanistic implications, with emphasis on possible oxygen effects, and references pertaining thereto are contained in Appendix $P$.

\section{Mechanistic Reaction Schemes Involving Alkaline} Decomposition of Tetraphenylborate Anion (TPB-) in Presence of soluble and/or solid Catalysis species

The proposed mechanism for tetraphenylborate decomposition involves dephenylation of tetraphenylborate. The first scheme shown below represents a homogeneous catalytic homolysis of the $\mathrm{C}-\mathrm{B}$ bond of tetraphenylborate. Removal of the first phenyl group involves a free radical process. Reaction 1 shows an oxidizing agent (M), acting as a catalytic species, undergoing reduction in an electron transfer step involving the original tetraphenylborate anion. Reaction 2 involves oxidizing the catalyst to complete the redox couple. Examples of the catalytic oxidant in reaction 1 include soluble copper or other soluble multivalent.cations. The oxidant in reaction 2 could be molecular oxygen or possibly an oxygen-containing organic species. For ITP slurries, this oxidant shown in reaction 2 could also be a separate dissolved cation species different from the original $\mathrm{M}^{+\mathrm{X}}$ shown in reaction 1 . In the case of a completely anoxic system a catalytic decomposition of tetraphenylborate can also be postulated involving only $\mathrm{Cu}(\mathrm{I})$ cation (see reactions 7-12 presented and discussed below).

1) $\left(\mathrm{C}_{6} \mathrm{H}_{5}\right)_{3 \mathrm{~B}}\left(\mathrm{C}_{6} \mathrm{H}_{5}\right)-+\mathrm{M}^{+\mathrm{X}} \rightarrow\left(\mathrm{C}_{6} \mathrm{H}_{5}\right)_{3 \mathrm{~B}}\left(\mathrm{C}_{6} \mathrm{H}_{5}\right) \cdot+\mathrm{M}^{+}(\mathrm{X}-1)$

2) $\mathrm{M}^{+(\mathrm{X}-1)}+$ oxidant $\rightarrow \mathrm{M}^{+\mathrm{X}}+$ Reduced Oxidant

3) $\left(\mathrm{C}_{6} \mathrm{H}_{5}\right) 3 \mathrm{~B}\left(\mathrm{C}_{6} \mathrm{H}_{5}\right) \cdot-\rightarrow\left(\mathrm{C}_{6} \mathrm{H}_{5}\right) 3 \mathrm{~B}+\left(\mathrm{C}_{6} \mathrm{H}_{5}\right) \cdot$

4) $\left(\mathrm{C}_{6} \mathrm{H}_{5}\right)_{3} \mathrm{~B}\left(\mathrm{C}_{6} \mathrm{H}_{5}\right) \cdot-\rightarrow\left(\mathrm{C}_{6} \mathrm{H}_{5}\right)_{2} \mathrm{~B} \cdot+\left(\mathrm{C}_{6} \mathrm{H}_{5}\right)_{2}$

5) $\left(\mathrm{C}_{6} \mathrm{H}_{5}\right)_{3 \mathrm{~B}}+\mathrm{OH}^{-}\left(+3 \mathrm{H}_{2} \mathrm{O}\right)-\rightarrow \mathrm{B}(\mathrm{OH})_{4}^{-}+3 \mathrm{C}_{6} \mathrm{H}_{6}$

$$
\begin{array}{r}
\left(\mathrm{C}_{6} \mathrm{H}_{5}\right) 3 \mathrm{~B}\left(\mathrm{C}_{6} \mathrm{H}_{5}\right)^{-}+\mathrm{B}(\mathrm{OH})_{4}^{-}+3 \mathrm{H}_{2} \mathrm{O}-\rightarrow \\
\quad \mathrm{B}(\mathrm{OH}) 4^{-}+ \\
\quad\left(\mathrm{C}_{6} \mathrm{H}_{5}\right) \mathrm{B}(\mathrm{OH})_{3}^{-}+3 \mathrm{C}_{6} \mathrm{H}_{6}
\end{array}
$$

Subsequent reactions of the tetraphenylboron radical, $\left(\mathrm{C}_{6} \mathrm{H}_{5}\right) 3 \mathrm{~B}\left(\mathrm{C}_{6} \mathrm{H}_{5}\right) \cdot$, are shown in reactions 3 and 4 . Reactions of the resulting triphenylboron, $\left(\mathrm{C}_{6} \mathrm{H}_{5}\right)_{3 \mathrm{~B}}$, are shown in reaction 5 . This reaction would presumably occur in several successive steps involving initial hydroxide adduct formation and subsequent hydrolysis (see Appendix P). Reaction 6 gives an example of a phenyl transfer to boron (the $\mathrm{B}(\mathrm{OH})_{4}{ }^{-}$species resulting from reaction 5) by the parent tetraphenylborate, followed by hydrolysis. The product species $\mathrm{B}(\mathrm{OH}) 4^{-}$in reaction 6 could then undergo continuous cyclic reactions with the parent tetraphenylborate. We note that the product species of reactions 5 and 6 involve predominately benzene formation. The 
strong oxidizing agents such as the hydroxyl radical (or $\mathrm{O}^{-}$in strongly alkaline solutions), and $\mathrm{H}_{2} \mathrm{O}_{2}$ are all well-established primary products of radiolytic water decomposition. Additionally the reactions of these primary radiolytic products with both nitrate and nitrite in the tetraphenylborate slurry would form the potentially redox-active $\mathrm{NO}_{2}$ and $\mathrm{NO}$ radicals. These two radical species could participate in redox chemistry associated with an active catalyst. Preliminary high temperature experiments designed to test the effects of radiolysis on slurries with various potential catalysts added (see Series 1 Sealed stainless steel Bottle Tests) indicated no significant differences in tetraphenylborate decomposition at $70{ }^{\circ} \mathrm{C}$ with and without radiation exposure. However, similar planned tests at lower temperatures (i.e., in the more applicable temperature range of $\left.25-50{ }^{\circ} \mathrm{C}\right)$ might indicate that radiolysis effects do significantly contribute to the overall tetraphenylborate decomposition in the presence of catalysts at these lower temperatures.

Further decomposition schemes, as they apply to relatively simple two-component alkaline $\mathrm{TPB}^{-} /$copper(II) solutions, are discussed in Appendix $\mathrm{P}$. 


\section{Potential High Level Waste system Effects}

\section{Tank 50H and Saltstone}

As discussed in an earlier section, elevated levels of benzene $(9.0 \mathrm{mg} / \mathrm{L}$, Ref. 5) were observed in Tank $50 \mathrm{H}$ salt solution at the same time as the rapid decomposition of NaTPB was occurring in Tank 48H. This level was both a flammability and regulatory concern to the downstream saltstone facility. The formation of benzene in Tank $50 \mathrm{H}$ was likely due to the continued decomposition of an intermediate product (e.g., diphenylboric acid or triphenylboron hydroxy complex) produced in the early stages of the rapid NaTPB decomposition in Tank 48H. This intermediate was likely transferred into Tank 50H during the final concentration phase in Tank 48H. In separate laboratory tests, benzene generation rates of $300 \mu \mathrm{g} / \mathrm{L}$ were observed from the continued decomposition of NaTPB intermediates in Tank 48H filtrate. This value represents the best information available in regards to determining the benzene generation rate that occurred in Tank $50 \mathrm{H}$. Since the concentration of the intermediates in Tank $50 \mathrm{H}$ at the time of the reaction were unknown, it is impossible to determine if 300 $\mu \mathrm{g} / \mathrm{L} / \mathrm{hr}$ is conservative.

SRTC prepared Saltstone with a sample of Tank $50 \mathrm{H}$ salt solution collected in January 1996. Benzene evolution rates measured over 48 days were between 0.02 and $0.2 \mu \mathrm{g} / \mathrm{L} / \mathrm{hr}$ [Ref.21-23] which are below the rates measured in comparable 1985 tests [Ref. 24]. TCLP and Constituent Concentration in waste ("Totals") tests were performed for benzene in Saltstone samples cured for 7, 14, and 28 days at ambient temperature and $60^{\circ} \mathrm{C}$. [Ref. 23,25] In these tests, the measured benzene concentrations remained below the regulatory limits.

\section{Late Wash}

The Late Wash Technical Bases requires the slurry feed to Late Wash from ITP to contain less than $700 \mathrm{ppm}$ of benzene. [Ref. 26] Analysis of the data from Tank $48 \mathrm{H}$ indicates that the current benzene concentration in Tank $48 \mathrm{H}$ is approximately $550 \mathrm{ppm}$. Thus, it would appear that ITP will be able to supply material that meets this criteria. Additional data indicates that the benzene generation rate in Tank $48 \mathrm{H}$ as of April 25 is $13.2 \mu \mathrm{g} / \mathrm{L} / \mathrm{hr}$. At this reaction rate, in excess of 600 days without pump operation would be required to return the benzene concentration in Tank $48 \mathrm{H}$ to $700 \mathrm{ppm}$. This reaction appears governed by the solubility of potassium tetraphenylborate and temperature. During most of the time over which the low $(13.2 \mathrm{mg} / \mathrm{L} / \mathrm{hr})$ benzene generation rate was observed, the temperature in Tank $48 \mathrm{H}$ was less than $30^{\circ} \mathrm{C}$.

The sodium ion concentration in Tank $48 \mathrm{H}$ for the first batch is approximately 4.7 molar. Decreasing the sodium ion concentration in Tank $48 \mathrm{H}$ to less than 1 molar by washing would produce an order of magnitude increase in the KTPB solubility (see Figure 32). [Ref. 27] Since the reaction to produce benzene appears first order in $\mathrm{TPB}^{-}$ ion, washing would produce an order of magnitude increase in reaction rate. Thus, a significant quantity of benzene could build into a 
washed slurry at a faster rate than for an unwashed slurry. However, this analysis does not reflect any benefit be obtained by removing soluble catalyst from the slurry.

While the limit for feed to the Late Wash Facility has been specified as $700 \mathrm{ppm}$, it may prove impractical to maintain this material at a concentration below $700 \mathrm{ppm}$. A less restrictive limit has been proposed that the material in the Late Wash Facility should not exceed $1200 \mathrm{ppm}$ in benzene. This limits maintains the benzene concentration in the slurry below the solubility limit for the associated salt solution $(\sim 1260 \mathrm{ppm})$. Researchers now realize that crediting mass transfer considerations in analyses will allow a larger benzene inventory while maintaining the same effective safety margin. However, future studies are needed to establish the acceptance of the proposed limit although preliminary data indicate this approximate value.

If all of the NaTPB is consumed prior to transfer to Late Wash such that the reaction rate depends on KTPB solubility, one may es.timate allowable storage times in the Late Wash Facility based on a

13.2 $\mathrm{g} / \mathrm{L} / \mathrm{hr}$ generation rate. Such a prediction is provided in

Figure 33. Inspection of this figure indicates that storage times in excess of 100 days would be required to increase the benzene concentration in the facility from 700 to $1200 \mathrm{ppm}$. However, this calculation assumes the temperature in the facility is maintained at $25{ }^{\circ} \mathrm{C}$, no insoluble NaTPB is transferred to Late wash, the KTPB solubility employed in this calculation is correct, and no additional NaTPB is added in the Late Wash Facility.

An increase in the storage temperature would produce an increase in the reaction rate and thus a proportional decrease in the allowable storage time. If insoluble NaTPB is transferred to the Late wash Facility, the reaction rate can be expected to be quite large and allowable storage times would decrease to less than 4 days. Adaition of NaTPB in the iate Wash Facility would increase the free TPB ion concentration, but not necessarily produce insoluble NaTPB. A fraction of this TPB $^{-}$ion would be consumed through precipitation of potassium and cesium. It is possible to estimate the allowable storage time based on the quantity of excess NaTPB. Such estimates are shown in Figure 34. Inspection of this figure indicates that even small (25 gallons) additions of excess NaTPB to the Late Wash Precipitate Tank will require significantly shorter storage times.

The above analysis is limited by a number of constraints. Use of this analysis should be made with these limitations in mind. Primarily, the temperature is assumed as $25^{\circ} \mathrm{C}$. Increases in temperature will increase reaction rates. No credit has been taken for the removal of soluble catalysts. The removal of soluble catalysts would likely produce measurable decreases in ganeration rates. The existing solubility data for KTPB was assumed accurate for both high and low sodium ion concentrations. The benzene generation rate was assumed to be $13.2 \mu \mathrm{g} / \mathrm{L} / \mathrm{hr}$ for a 4.7 molar slurry with no insoluble NaTPB present. This analysis has ignored the operational case wherein insoluble NaTPB is present in the feed to 
Late Wash. The presence of such material would result in significantly higher reaction rates and lower allowable storage times.

Figure 32. KTPB solubility as a function of sodium concentration. [Ref. 27]
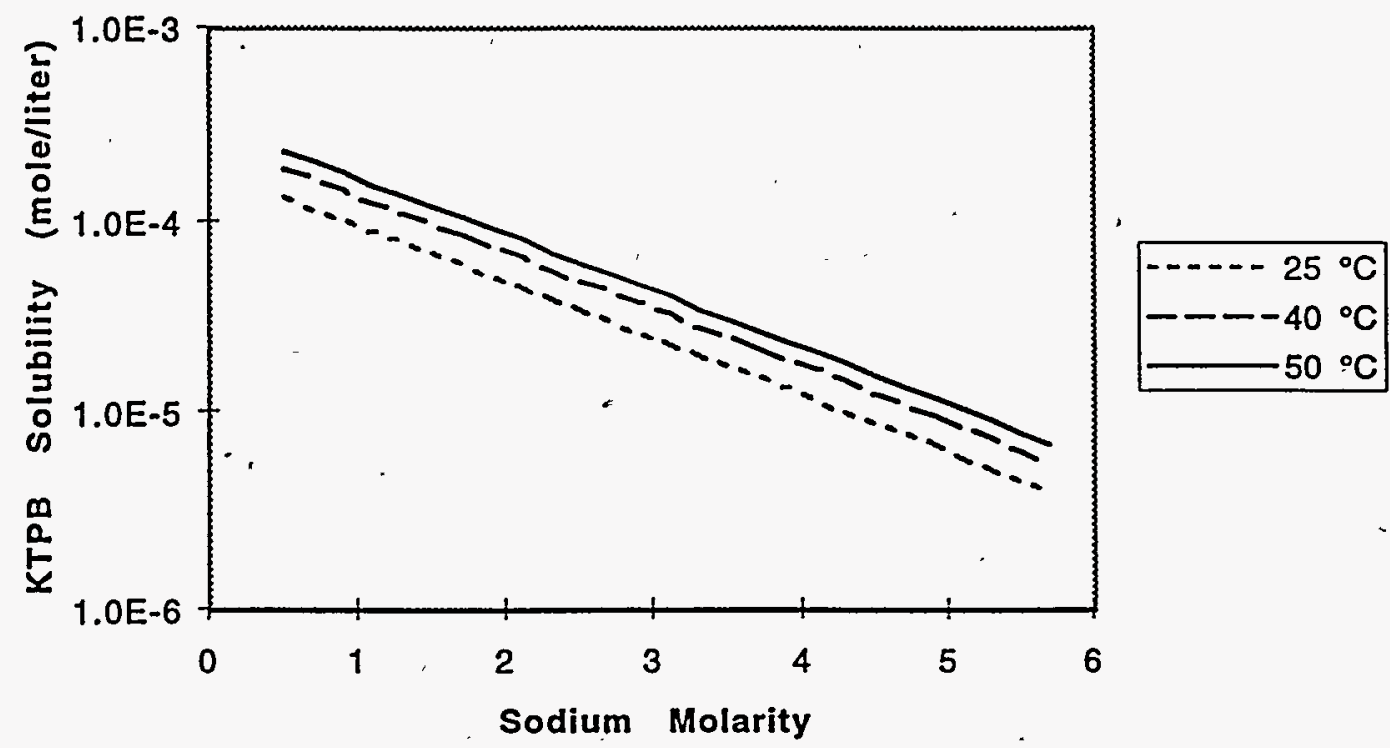

Figure 33. Late Wash allowable storage times (without NaTPB additions).

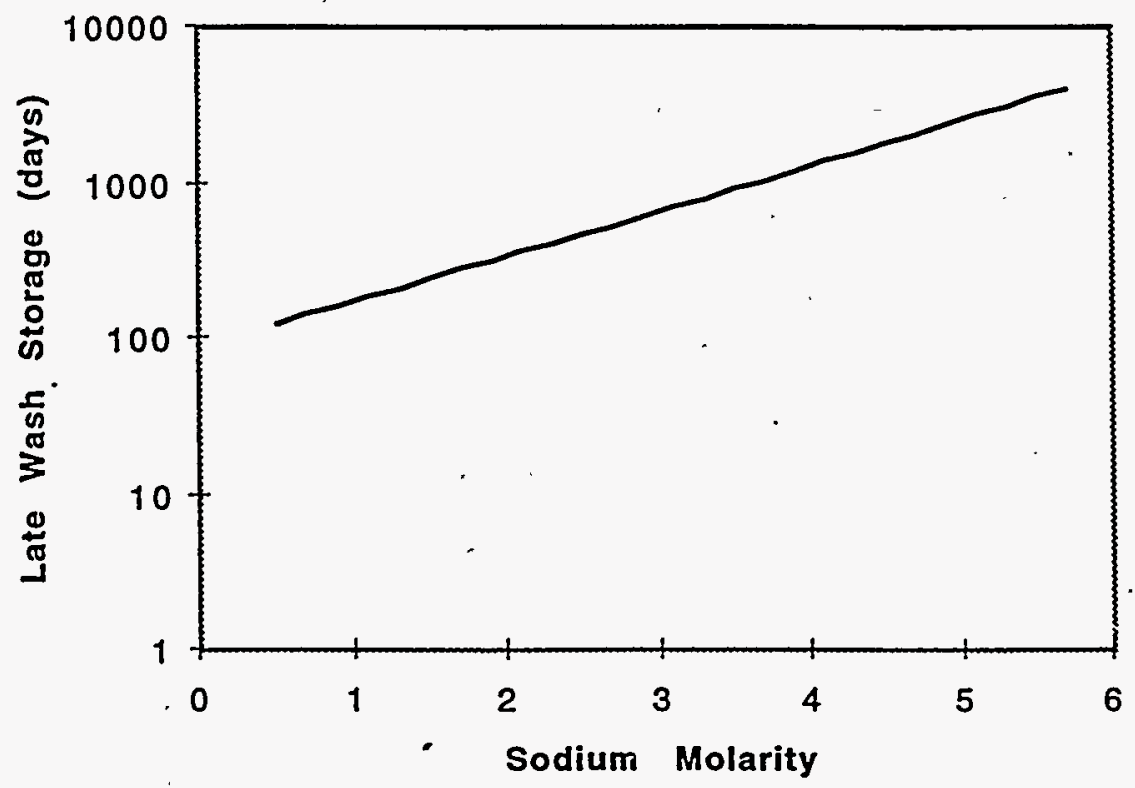


Figure 34. Late Wash allowable storage times (as a function of NaTPB additions).

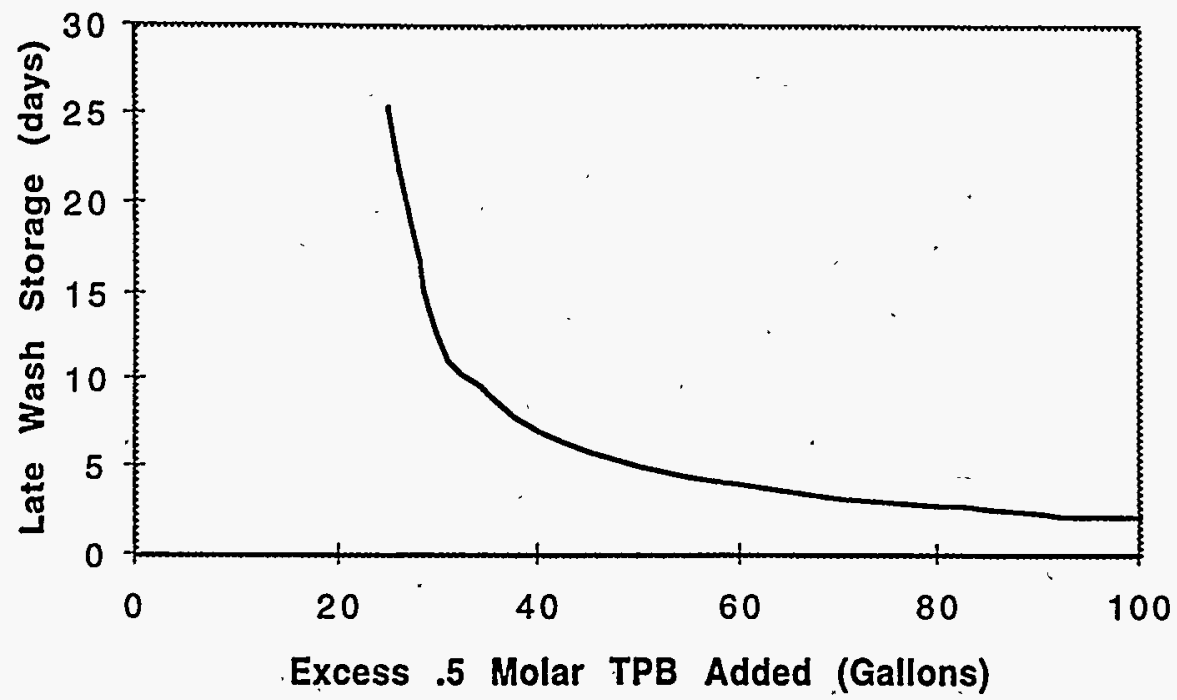

The above analysis suggests the possible need for additional restraints on the Late Wash operating envelope. Such restraints might include limiting the feed to the late wash Facility to below $700 \mathrm{ppm}$, limiting the allowable addition of NaTPB to less than 25 gallons of $0.5 \mathrm{M}$ NaTPB, or requiring the ability to provide mixing to the Late Wash Precipitate Tank in less than 4 days.' Additional calculations will determine which, if any, of these restraints provide the needed safety margin. The calculations will require information including specification of the feed composition for late Wash and, in particular, the degree of washing achieved in Tank 48H. A second requirement for.specification of restraints involves identification of the required excess for the NaTPB addition in Late Wash. To determine the quantity required for this addition requires information regarding the concentration of soluble $\mathrm{K}^{+}$and $\mathrm{Cs}^{+}$present in the feed to Late Wash.

\section{Tank $22 \mathrm{E}$}

Tank $22 \mathrm{H}$ is the receipt tank for ITP washwater and Late wash filtrate.' This tank contains a small quantity of sludge. This sludge has not been adequately characterized to assess the ability of the solids to catalyze the decomposition of NaTPB. Because of this. concern, the use of Tank $22 \mathrm{H}$ as a receipt tank has been suspended until such time that concerns surrounding this issue can be resolved. [Ref. 28] 


\section{Recommendations for Further Testing}

Future tests are required to integrate the ventilated, non-radioactive NaTPB solution tests with the conditions of Tank 48H during the rapid decomposition of NaTPB. Specific variables that need to be studied in greater detail are TPB concentration, hydroxide concentration, oxygen concentration, copper concentration, and other additives used in the non-radioactive bottle tests. In addition, the use of inhibitors to prevent future NaTPB decomposition should be pursued. Other tasks being pursued include the use of boron NMR to study the NaTPB decomposition reactions and initiating Tank 48H and Batch \#2 simulations in the SRTC Shielded Cells. The ultimate goal of this program is to develop a well characterized kinetic expression of NaTPB decomposition.

\section{Quality Assurance}

All work was conducted in accordance with the DWP\&HT Quality Assurance Procedures Manual, 1Q43. This experimental program was conducted at the request of High Level Waste Engineering. Data collected during this project are contained in the authors' notebooks and files.

\section{Acknowledgments}

The authors wish to express their gratitude to.all of the individuals who have contributed to this work. We would specifically like to thank the ITP Process and Mechanisms Panel: E. J. Lahoda, G. W. Parshall, R. A. Smiley, R. J. Hanrahan, and R. B. King for their wisdom and input. C. P. Coffey, B. H. Croy, S. W. McCollum, and $\mathrm{K}$. I. Wyszynski provided untiring experimental support. This research was supported in part by appointment of $C$. I. Crawford to . the USDOE Post-graduate Research Training Program administered by Oak Ridge Associated Universities. 
X. References

1. M. J. Barnes, "Technical Investigation of The Aquafine Incident (U) ", WSRC-RP-94-149, February 1, 1994.

2. M. J. Barnes, "Decomposition of Sodium Tetraphenylborate (U)", WSRC-RP-90-465, May 10, 1990.

3. M. J. Barnes, "Sodium Tetraphenylborate Solution Stability - A Long Term Study (U)", WSRC-RP-92-786, June 11, 1992.

4. M. J. Barnes, "Stability of Spray-Dried Sodium Tetraphenylborate (U) ", WSRC-RP-94-774, August 5, 1994.

5. J. E. Young, "ITP Tank H50 Saltstone Feed - Benzene Analysis Data (U) ", SRT-ADS-95-0294, December 21, 1995, see Appendix W.

6. M. A. Schmitz, "NaTPB Analysis" (U), Inter-office memorandum, January 14, 1996, see Appendix X.

7. D. D. Walker and A. A. Ekechukwu, "Analysis of Excess Sodium Tetraphenylborate in Tank 48H (U)," WSRC-TR-96-0034, February 4, 1996.

8. D. D. Walker, "Excess NaTPB in Tank 48 Batch \#1 (U)", March 28, 1996, see Appendix Q.

9. C. J. Coleman, T. B. Edwards, and C. A. Nash, "Statistical Analysis of Sample Data from Tank 48H (U), " WSRC-TR-95-0325,

Rev. 0, September 29, 1995.

10. K. Andringa and C. J. Coleman, "Technical Assistance Plan for ITP Process Support Analyses by ADS (U) ", WSRC-RP-95-987,

November $20,1995$.

11. D. D. Walker, "Răte of Decomposition in Tank 48H (U)", April 3; 1996, see Appendix R.

12. D. D. Walker and M. A. Schmitz, "Purity Specifications for Sodium Tetraphenylborate" (U), DPST-84-582, June 21, 1984.

13. D. T. Hobbs, "Concentration of Metals and Non-Metal in Alkaline Waste Slurry (U)," WSRC-TR-96-0058, Febrụary 28, 1996.

14. W. F. Linke, Solubilities of Inorganic and Metal-Organic Compounds, 4th Edition., Volumes I and II, D. Van Nostrand Co., Inc., Princeton NJ, 1965.

15. M. J. Barnes and D. D. Walker, "Potential Tetraphenylborate Decomposition Catalysts (U) ", SRT-IWP-96-006, January 17, 1996.

16. D. T. Hobbs, C. J. Coleman, and M. S. Hay, "Characterization of Tank 48H Samples for Alpha Activity and Actinide Isotopics (U)", WSRC-TR-95-0421, Rev. 0, December 4, 1995. 
References (continued)

17. L. Earnhart, "STPB Stability Studies", Memorandum from AFF, Inc., March 31, 1987.

18. D. T. Hobbs, "Long Term Storage of Sodium Tetraphenylborate Solutions" (U), DPST-88-1044, December 30, 1988:

19. J. C. Marek, "Status Report: Precipitate Layup Stability Assessment (U)", WSRC-RP-93-1508, December 3， 1993.

20. M. S. Hay and N. E. Bibler, "The Characterization of Tank $51 \mathrm{H}$ Sludge Feed for DWPF and Comparison to ESP Process Requirements (U)" ", WSRC-RP-95-1048, December 19, 1995.

21. M. R. Poirier, "Preliminary Benzene Evolution Rates During Saltstone Curing " (U), SRT-WHM-96-0014, February 28, 1996, see Appendix S.

22. M. R. Poirier, "Benzene Generation Rates During Curing of Saltstone Prepared with Tank 50 Salt Solution", SRT-WHM-96-0029, see Appendix T.

23. M. R. Poirier, "TCLP Benzene Results and Preliminary Benzene Generation Rates from Saltstone Prepared with the January 1996 Tank 50H Sample", SRT-WHM-96-0013; February 22, 1996, see Appendix U.

24. S. B. Oblath, "Benzene Evolution During the Curing of Saltstone", DPST-86-645, September 2, 1986.

25. C. A. Langton, "Saltstone TCLP Results Versus Curing Time and Initial Benzene Concentration (U)", SRTC-WED-96-0163, February 27, 1996, See Appendix V.

26. S. D. Fink, "Technical Bases - DWPF Late Washing Facility (U)", WSRC-RP-92-793, Rev. 4, July 1, 1994.

27. E. Siska, "The Solubility of Difficulty Soluble Tetraphenylborate Compounds - The Solubility of Potassium, Cesium, and Ammonium Tetraphenylborate", Magyar Kemiai Folyoirat, 82, No. 6, 275 (1976).

28. H. D. Harmon, et al., "ITP Chemical Process and Safety Issue Resolution Program Plan (U), " HLW-ENG-960009, April 19, 1996. 

Appendix A. Tank 48H Event Log for September, 1995, through
April, 1996.

Date Time Event

$9 / 21418$ Addition of 3200 gallons of STPB containing $48 \mathrm{mg} / \mathrm{L}$ of benzene. SIurry pumps operated for period of 2 hours 47 minutes.

$9 / 7 \quad 415$ Addition of 3900 gallons of STPB containing $169 \mathrm{mg} / \mathrm{L}$ of benzene. Slurry pumps operated for period of 15 hours 34 minutes.

9/8 541 Addition of 2006 gallons of STPB containing $169 \mathrm{mg} / \mathrm{L}$ of benzene. Slurry pumps operated for period of 8 hours 44 minutes.

9/10 440 Addition of 3300 gallons of STPB containing $190 \mathrm{mg} / \mathrm{L}$ of benzene. Slurry pumps operated for period of 11 hours 16 minutes.

9/11 1320 Addition of 3650 gallons of STPB containing $179 \mathrm{mg} / \mathrm{L}$ of benzene. Slurry pumps operated for period of 14 hours 12 minutes.

9/19 1320 Addition of 2342 gallons of STPB containing $80 \mathrm{mg} / \mathrm{L}$ of benzene. Slurry pumps operated for period of 12 hours 53 minutes.

9/26 1125 Addition of 2735 gallons of STPB containing $143.7 \mathrm{mg} / \mathrm{L}$ of benzene. Slurry pumps operated for period of 13 hours 40 minutes.

9/27 2357 Addition of 5097 gallons of STPB containing $<20 \mathrm{mg} / \mathrm{L}$ of benzene. and 5103 gallons of STPB containing 112 $\mathrm{mg} / \mathrm{L}$ of benzene. Slurry pumps operated for period of 16 hours 36 minutes.

$9 / 29141$ Slurry pumps-operated for period of 10 hours and 39 minutes.

$9 / 29 \quad 1541$

Addition of 4033 gallons of STPB containing $33 \mathrm{mg} / \mathrm{L}$ of benzene and 1965 gallons of STPB containing $24 \mathrm{mg} / \mathrm{L}$ of benzene. Slurry pumps operated for period of 27 hours 47. minutes.

9/30. $1306 \quad 2100$ gallons of sodium titanate added. .

9/30 $1947 \quad$ Slurry pumps operated, at $885 \mathrm{Ipm}$ for period of 21 hours and 37 minutes. Rate increase to 1180 rpm for 20 hours and 26 minutes. 
10/9 $1100 \quad$ Started 4 slurry pumps at $1180 \mathrm{rpm}$ with ventilation rate of $\sim 600$ scfm. Pumps allowed to run for 48 hours and 14 minutes.

10/12 $128 \quad$ Started 1 slurry pump at $1180 \mathrm{rpm}$ for 2 hours and 3 minutes.

$10 / 20$

$10 / 25$

Filtration commenced to tank volume of 361,000 galions.

10/26 $1420 \quad$ Started one slurry pump at $1180 \mathrm{rpm}$ for 12 hours and 50 minutes. All four slurry pumps operated for 42 hours and 50 minutes at $1180 \mathrm{rpm}$. During this time, 1300 gallons of water was added to Tank 48H. Pump

$11 / 2$ speed reduced to $885 \mathrm{rpm}$ for 10 hours.

Filtration commenced to tank volume of $\sim 160,000$ gallons.

11/7 Filtration completed.

$11 / 9 \quad 1715 \quad$ B1 slurry pump started.

$11 / 10930 \quad$ Remaining slurry pumps started.

$11 / 11 \quad 1147$ Exhaust alarm trip.

1202 Slurry pumps trip.

1247 Exhaust restarted.

1330 Slurry pumps restarted.

1514 Slurry pumps shut down.

2240 Slurry pumps restarted.

11/12 1630 Water addition.

2101 Water addition.

$11 / 13018$ Water addition.

142 GCs lost.

851 B4 and V1 slurry pumps shut down.

1329 Exhaust trip.

1420

1519

Slurry pumps shutdown.

1954

B1 and V2 slurry pumps restarted.

Slurry pumps shut down.

11/15 055 Ventilation shut down.

$11 / 20 \quad 048$ Air based ventilation started.

11/24 1041 Ventilation shut down.

$11 / 26 \quad 433$ Ventilation started.

11/26 1617 Ventilation shut down. 
$11 / 301650$. Ventilation started.

$12 / 1 \quad 1220 \quad$ Started slurry pumps for VDS sample.

1553 Slurry pump operation halted due to high benzene concentrations in the vapor space.

12/8 2238 Benzene Depletion Pump Runs initiated. Intermittent slurry pump operation continued until 1/3/96.

1/3/96 734 Slurry pump operation halted. Tank remained quiesceint until 3/5/96.

$3 / 5.1336$ Operated slurry pump V-1 at 600 rpm for 14 minutes.

$3 / 8 \quad 1311$ Operated slurry pump B-4 for 20 hours and 19 minutes. During subsequent pump operation, pump speed was incrementally increased. Following this slurry pump B-1. and V-2 operated individually.

$3 / 24 \quad 725$. Operated sIurry pumps $V-1$ and $V-2$ for 25 hours 1 minute. Periodic operations with two pumps continued until $4 / 9$.

4/3 1430 Reduced purge exhaust flow to $490 \mathrm{scfm}$ (variable ventilation test).

1845 Increased purge exhaust flow to $550 \mathrm{scfm}$.

4/4 255 Restored purge exhaust flow to $850 \mathrm{scfm}$.

4/9 $1554 \quad$ Started third pump. Continued periodic three pump operation unti1 $4 / 16$.

4/16 $1050 \quad$ started fourth pump. 


\section{Appendix B. Benzene Mass Balance Calculations.}

\section{Excëss NaTPB Calculations}

Results of samples taken prior to the addition of NaTPB to Tank $48 \mathrm{H}$. indicated that the soluble potassium concentration in Tank $48 \mathrm{H}$ at that time was between $0.023 \mathrm{M}$ and $0.033 \mathrm{M}$. [Ref. A] Additionally, some cesium (both radioactive and non-radioactive) was contained in Tank 48H. For the purposes of this calculation, cesium was ignored because the concentration was much less than that of soluble potassium $\left(\mathrm{K}^{+}\right)$. The volume of the contents of Tank $48 \mathrm{H}$ was approximately $1.78 \times 10^{6} \mathrm{~L}$. Multiplying this volume by a concentration of $0.23 \mathrm{M}$ gives a total of 40,940 moles of soluble $\mathrm{K}^{+}$. A total of 80800 moles $\left(1.41 \times 10^{5} \mathrm{~L}\right)$ of NaTPB was added to Tank $48 \mathrm{H}$. Of this, 40,940 moles precipitated as insoluble KTPB and CsTPB, leaving 39,860 moles of NaTPB in Tank 48H. Some of this was in the form of dissolved NaTPB and some was in the form of solid NaTPB. During the concentration phase of the ITP process, some of the soluble NaTPB was transferred to Tank 50H. The amount was calculated by first calculating the solubility of NaTPB in Tank 48H using the following equation. [Ref. B]

$$
\begin{aligned}
& {[N a T P B]=\left\{\frac{0.684+0.00324(T)}{1-0.00324(T)}\right\}\left\{1.08 e^{-1.22(X)}\right\}} \\
& \text { where [NaTPB] }= \\
& T \begin{aligned}
\text { the solubility of NaTPB in the } \\
\text { salt solution in molarity, }
\end{aligned} \\
& =\begin{aligned}
& \text { the solution temperature in }{ }^{\circ} \mathrm{C} \text { and } \\
&=\text { the total sodium ion (Na } \left.{ }^{+}\right) \\
& \text {concentration in molarity }
\end{aligned}
\end{aligned}
$$

Using the Tank $48 \mathrm{H} \mathrm{Na}^{+}$concentration in November of $4.7 \mathrm{M}$ and a tank temperature of $40 .{ }^{\circ} \mathrm{C}$, gives a NaTPB solubility of $0.0033 \mathrm{M}$. With $1.31 \times 10^{6} \mathrm{~L}$ of salt solution pumped to Tank $50 \mathrm{H}$ (in October and early November), this gives $4,320 \mathrm{M}$ of soluble NaTPB transferred from Tank 48H.. This left 35,540 M of NaTPB in Tank $48 \mathrm{H}$ after concentration. If this NaTPB degrades completely. to benzene, four moles of benzene may be formed by each mole of NaTPB, giving 142,160 M of potential benzene.

\section{Benzene Release Calculations}

Benzene releases have been calculated using the data collected from Tank 48H. These data have been stored on the WG020 fileserver. Tank $48 \mathrm{H}$ vent rate data were obtained directly from files in the dcs_data directory. The gas chromatography data and tank temperatures were obtained from files in the gc_data directory. The GC \#1 and tank ceiling temperature data were used. Tank $48 \mathrm{H}$ data were given in scfm and were corrected for temperature. The GC data were given in volume 
percent benzene. The ideal gas equation was used to calculate the amount of benzene. Data were supplied every half hour. The following equation was used to calculate the benzene released during every half hour.

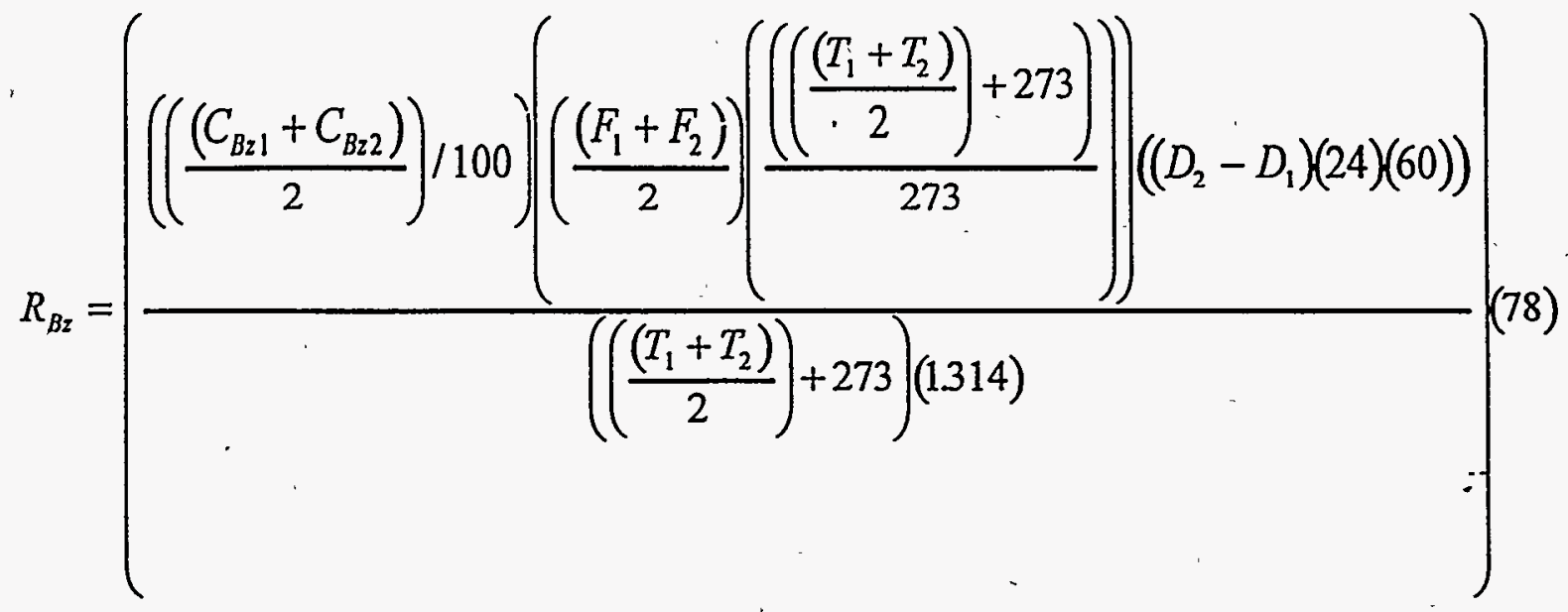

where $R_{b z}$. = benzene release, in $1 \mathrm{~b}$ during the time

$C_{B z}=$ period in question,

$F \quad=$ Tánk $48 \mathrm{H}^{\circ}$ vent flow in scfm,

- $T=$ Tank $48 \mathrm{H}$ ceiling temperature in ${ }^{\circ} \mathrm{C}$,

$D=$ time at which data is taken (one day = 1),

$78=$ molecular weight of benzene in $1 \mathrm{~b} / 1 \mathrm{~b}-$ mole and

$1.314=$ ideal gas constant $(R)$ in $\left(\mathrm{ft}^{3}\right)(\mathrm{atm}) /(\mathrm{Ib}$-mole) $(\mathrm{K})$.

For the purposes of this calculation the pressure is assumed to be constant as 1 atmosphere and is therefore left out of the equation. The subscripts 1 and 2 refer to data at the start and end of the half hour. To calculate the total release over a period of time, the data are summed over that period of time.

\section{Calculation of Tank 48H PBA, Phenol and Biphenyl Content}

Results of Tank 48H samples analyzed between December 28, 1995 and Apri1 15, 1996 indicate that the PBA concentration has remained constant over that period. Since sample analyses indicated no PBA in Tank 48H after the slurry concentration phase in early November, there was :no need to subtract out the initial Tank $48 \mathrm{H}$ content. FBA is completely solubie at the concentrations in question. 'Therefore, there is no need to account for settling of the solids in the tank. Therefore, the sample results obtained between December 28; 1995 and 
April 15, 1996 were averaged to give the concentration used in the mass balance. For PBA, the average of nine sample results between December 28, 1995 and April 15, 1996 was $1717 \mathrm{mg} / \mathrm{L}$. This gives a total of $1050 \mathrm{~kg}$.

The phenol in Tank 48H was calculated in much the same way, using the April 15, 1996 sample result ( 8100 moles). Additionally, because there was initially some phenol in the tank prior to degradation of the NaTPB, the initial amount (November 5 sample, 162,000 gal., result - 1420 moles) was subtracted out. Sample results also indicated that some phenol appeared between October 12 and November 5. This amount $(633$ moles) was also shown in the mass balance.

Iimited data is available for the calculation biphenyl, terphenyl and diphenyl mercury contents of Tank $48 \mathrm{H}$. Data are only available for samples taken on January 12 and 21, 1996. Additionally, there is data on the biphenyl contained in the NaTPB added to Tank 48 H during precipitation. To obtain the contents used in the mass balance, the January 12 and 21 data were averaged; it is assumed that by that time, biphenyl, terphenyl and diphenyl mercury concentrations were essentially constant. The average results were $1541 \mathrm{mg} / \mathrm{L}$ for biphenyl, $102 \mathrm{mg} / \mathrm{I}$ for diphenyl mercury and $114 \mathrm{mg} / \mathrm{L}$ for terphenyl. ${ }^{3}$ These three materials are all insoluble. At the time the samples were taken in January, the slurry phase had begun to separate from the clear supernate phase. The samples taken were representative of the slurry phase only and not the whole tank. The sample results had to be corrected to a tank average concentration. The average solids content of Tank $48 \mathrm{H}$ dip samples taken between January 21 and. February 10, 1996 is 8.2 wt $\%$. If the tank had been well mixed the solids content was calculated to have been 3.8 wt $\% .{ }^{4}$ Concentrations representative of the entire tank contents may be obtained by multiplying the actual sample results by the ratio between the wellmixed solids content and the unmixed solids content. This gives concentrations of $714 \mathrm{mg} / \mathrm{L}, 53 \mathrm{mg} / \mathrm{L}$ and $47 \mathrm{mg} / \mathrm{L}$ of biphenyl. terphenyl and diphenyl mercury, respectively. These concentrations were converted to total amounts of the respective materials. Because there was an initial amount of biphenyl present (96 moles) that number was subtracted from the total to give the amount of biphenyl created in Table 1.

\section{References}

A). C. J. Coleman, T. B. Edwards, and C. A. Nash, "Statistical Analysis of Sample Data from Tank 48H (U)," WSRC-TR-95-0325, Rev. 0, September 29, 1995.

B) M. J. Barnes, et al., "Sodium Tetraphenylborate Solubility and Dissolution Rates (U)", WSRC-TR-95-0092, Rev. 0, March 7, 1995. 
W. I. Tamosaitis - $-1-$

WSRC-TR-96-0113

Appendix C. Benzene generation rate data obtained from Tank 48H filtrate and AFF NaTPB solution.

\begin{tabular}{|c|c|}
\hline $\begin{array}{c}\text { Reaction } \\
\text { Time } \\
\text { (hrs) } \\
\end{array}$ & $\begin{array}{c}\text { Benzene } \\
\text { Generation } \\
\text { Rate } \\
(\mu \mathrm{g} / \mathrm{L} / \mathrm{hr}) \\
\end{array}$ \\
\hline 8.8 & 2.6 \\
\hline 58.5 & 3.6 \\
\hline 106.6 & 2.8 \\
\hline 131.3 & 2.3 \\
\hline 154.4 & 3.2 \\
\hline 178.6 & 2.9 \\
\hline 201.2 & 1.8 \\
\hline 225.4 & 1.4 \\
\hline 271.2 & 1.8 \\
\hline 307.4 & 1.7 \\
\hline 321.0 & 16.2 \\
\hline 344.7 & 15.0 \\
\hline 371.7 & 22.0 \\
\hline 400.2 & 26.9 \\
\hline 472.0 & 38.7 \\
\hline 491.2 & 41.0 \\
\hline 513.8 & 39.5 \\
\hline 562.6 & 64.9 \\
\hline 586.8 & 64.8 \\
\hline 631.8 & 58.1 \\
\hline 655.2 & 74.2 \\
\hline 681.8 & 39.9 \\
\hline 704.4 & 52.1 \\
\hline 729.2 & 32.8 \\
\hline 774.9 & 33.0 \\
\hline 826.2 & 30.8 \\
\hline 850.4 & 40.8 \\
\hline 873.0 & 28.8 \\
\hline 904.1 & 32.7 \\
\hline 921.0 & 28.6 \\
\hline 970.5 & 25.9 \\
\hline 993.0 & 23.6 \\
\hline 1021.6 & 20.6 \\
\hline 1039.5 & 26.2 \\
\hline 1063.9 & 23.8 \\
\hline 1136.2 & 39.2 \\
\hline 1160.2 & 35.6 \\
\hline 1184.2 & 37.1 \\
\hline 1206.9 & 29.2 \\
\hline 1239.1 & 46.1 \\
\hline 1309.6 & 50.8 \\
\hline
\end{tabular}

\begin{tabular}{|c|c|}
\hline $\begin{array}{c}\text { Reaction Time } \\
\text { (hrs) }\end{array}$ & $\begin{array}{c}\text { Benzene } \\
\text { Generation } \\
\text { Rate } \\
(\mu \mathrm{g} / \mathrm{L} / \mathrm{hr})\end{array}$ \\
\hline 1337.0 & 44.9 \\
\hline 1361.5 & 33.5 \\
\hline $1381: 4$ & 44.7 \\
\hline 1407.7 & 26.0 \\
\hline 1430.5 & 46.6 \\
\hline
\end{tabular}


Appendix D. Benzene generation rate data obtained from Tank 48H filtrate, oven-dried AFF NaTPB powder, and 0.2 wt \% Tank 51H sludge.

\begin{tabular}{|c|c|}
\hline $\begin{array}{c}\text { Reaction } \\
\text { Time } \\
\text { (hrs) }\end{array}$ & $\begin{array}{c}\text { Benzene } \\
\text { Generation } \\
\text { Rate } \\
(\mu \mathrm{g} / \mathrm{L} / \mathrm{hr})\end{array}$ \\
\hline 2.8 & 50.6 \\
\hline 19.2 & 60.0 \\
\hline 24.3 & 70.2 \\
\hline 40.6 & 121.7 \\
\hline 49.0 & 170.1 \\
\hline 64.0 & 205.0 \\
\hline 87.8 & 405.6 \\
\hline 111.9 & 477.9 \\
\hline 138.0 & 540.0 \\
\hline 144.6 & 618.0 \\
\hline 162.4 & 652.4 \\
\hline 168.0 & 672.1 \\
\hline 184.8 & 647.4 \\
\hline 208.8 & 630.8 \\
\hline 234.2 & 575.7 \\
\hline 256.2 & 509.2 \\
\hline 281.2 & 487.1 \\
\hline 305.5 & 443.3 \\
\hline 328.5 & 437.7 \\
\hline 336.0 & 461.4 \\
\hline 337.5 & 447.6 \\
\hline 359.0 & 411.4 \\
\hline 378.5 & 362.4 \\
\hline 381.8 & 751.6 \\
\hline 383.8 & 795.0 \\
\hline 386.0 & 785.0 \\
\hline 400.6 & 810.0 \\
\hline 407.0 & 827.6 \\
\hline 426.5 & 916.0 \\
\hline 449.3 & 802.1 \\
\hline 475.0 & 636.2 \\
\hline 496.8 & 558.6 \\
\hline 527.8 & 510.0 \\
\hline 547.8 & 402.1 \\
\hline 571.0 & 385.1 \\
\hline 577.7 & 347.1 \\
\hline 592.5 & 296.8 \\
\hline 616.0 & 205.1 \\
\hline 648.2 & 201.8 \\
\hline 666.0 & 142.2 \\
\hline 697.2 & 132.9 \\
\hline
\end{tabular}

\begin{tabular}{|c|c|}
\hline $\begin{array}{c}\text { Reaction Time } \\
\text { (hrs) }\end{array}$ & $\begin{array}{c}\text { Benzene } \\
\text { Generation } \\
\text { Rate } \\
(\mu \mathrm{g} / \mathrm{L} / \mathrm{hr})\end{array}$ \\
\hline 711.8 & 124.0 \\
\hline 737.8 & 103.7 \\
\hline 760.5 & 52.8 \\
\hline 787.8 & 47.0 \\
\hline 816.0 & 43.9 \\
\hline 835.1 & 52.5 \\
\hline 857.8 & 26.8 \\
\hline 860.1 & 66.4 \\
\hline 867.8 & 70.7 \\
\hline 887.3 & 92.0 \\
\hline 907.1 & 87.3 \\
\hline 910.4 & 73.6 \\
\hline 929.4 & 98.6 \\
\hline 931.7 & 100.3 \\
\hline 956.4 & 65.9 \\
\hline 958.2 & 86.6 \\
\hline 959.1 & 87.3 \\
\hline 979.4 & 78.0 \\
\hline
\end{tabular}


Appendix E. Benzene generation rate data obtained from Tank 48I filtrate, oven-dried AFF NaTPB powder, and 0.51 wt \% Tank $48 \mathrm{H}$ sludge and MST.

\begin{tabular}{|c|c|}
\hline $\begin{array}{c}\text { Reaction } \\
\text { Time } \\
\text { (hrs) }\end{array}$ & $\begin{array}{c}\text { Benzene } \\
\text { Generation } \\
\text { Rate } \\
(\mu \mathrm{g} / \mathrm{L} / \mathrm{hr})\end{array}$ \\
\hline 3.0 & 2035 \\
\hline 22.7 & 2224 \\
\hline 25.0 & 2093 \\
\hline 42.5 & 6984 \\
\hline 45.6 & 4209 \\
\hline 47.8 & 4958 \\
\hline 48.9 & 5302 \\
\hline 66.5 & 8596 \\
\hline 91.7 & 7397 \\
\hline 115.2 & 6142 \\
\hline 138.1 & 4388 \\
\hline 161.7 & 3661 \\
\hline 187.1 & 2668 \\
\hline 213.2 & 2639 \\
\hline 234.2 & 2236 \\
\hline 259.4 & 1566 \\
\hline 281.5 & 1356 \\
\hline 305.5 & 1254 \\
\hline 329.4 & 1010 \\
\hline 356.8 & 992 \\
\hline 381.7 & 867 \\
\hline 426.8 & 794 \\
\hline 449.5 & 751 \\
\hline 457.1 & 6021 \\
\hline 472.1 & 4218 \\
\hline 479.2 & 3883 \\
\hline 498.2 & 3556 \\
\hline 522.3 & 3130 \\
\hline 546.2 & 2555 \\
\hline 570.0 & 2742 \\
\hline 593.9 & 2460 \\
\hline 618.3 & 2637 \\
\hline 642.2 & 2922 \\
\hline 667.2 & 2484 \\
\hline 692.5 & 2244 \\
\hline 714.0 & 2228 \\
\hline 78.9 .6 & 2331 \\
\hline 808.9 & 2482 \\
\hline 833.2 & 2342 \\
\hline 857.7 & 1818 \\
\hline 884.5 & 1691 \\
\hline
\end{tabular}

\begin{tabular}{|c|c|}
\hline $\begin{array}{c}\text { Reaction Time } \\
\text { (hrs) }\end{array}$ & $\begin{array}{c}\text { Benzene } \\
\text { Generation } \\
\text { Rate } \\
(\mu \mathrm{g} / \mathrm{L} / \mathrm{hr})\end{array}$ \\
\hline 904.8 & 1526 \\
\hline 953.9 & 1383 \\
\hline 979.2 & 1231 \\
\hline 1003.2 & 1188 \\
\hline . 1025.8 & 1158 \\
\hline 1050.1 & 1061 \\
\hline 1073.7 & 1096 \\
\hline 1095.8 & 978 \\
\hline 1121.9 & 952 \\
\hline 1147.1 & 886 \\
\hline 1169.5 & 941 \\
\hline 1193.8 & 941 \\
\hline 1198.1 & 362 \\
\hline 1220.0 & 354 \\
\hline 1266.4 & 326 \\
\hline 1268.5 & 812 \\
\hline 1288.0 & 901 \\
\hline 1291.8 & 806 \\
\hline 1293.9 & 813 \\
\hline 1296.2 & 770 \\
\hline 1320.2 & 934 \\
\hline 1344.2 & 887 \\
\hline 1359.4 & 856 \\
\hline 1384.5 & 819 \\
\hline
\end{tabular}


Appendix F. Benzene generation rate data obtained from Tank 48H filtrate, oven-dried AFF NaTPB powder, and simulated Tank $48 \mathrm{H}$ MST.

\begin{tabular}{|c|c|}
\hline $\begin{array}{c}\text { Reaction } \\
\text { Time } \\
\text { (hrs) }\end{array}$ & $\begin{array}{c}\text { Benzene } \\
\text { Generation } \\
\text { Rate } \\
(\mu \mathrm{g} / \mathrm{L} / \mathrm{hr})\end{array}$ \\
\hline 10.1 & 1.0 \\
\hline 31.8 & 0.9 \\
\hline 57.3 & 117.2 \\
\hline 82.8 & 572.2 \\
\hline 106.1 & 1329.0 \\
\hline 133.1 & 1731.5 \\
\hline 203.0 & 1350.1 \\
\hline 228.2 & 1082.5 \\
\hline 251.0 & 924.0 \\
\hline 272.8 & 778.1 \\
\hline 296.7 & 711.8 \\
\hline 320.9 & 734.8 \\
\hline 345.8 & 714.1 \\
\hline 371.6 & 649.5 \\
\hline 416.7 & 756.1 \\
\hline 442.0 & 640.0 \\
\hline 471.0 & 547.0 \\
\hline 489.8 & 484.2 \\
\hline 539.5 & 451.2 \\
\hline 568.7 & 406.5 \\
\hline
\end{tabular}


Appendix G. Benzene generation rate data obtained from Tank 48H filtrate and oven-dried reagent grade NaTPB powder from Aldrich Chemical Company.

\begin{tabular}{|c|c|}
\hline $\begin{array}{c}\text { Reaction } \\
\text { Time } \\
\text { (hrs) }\end{array}$ & $\begin{array}{c}\text { Benzene } \\
\text { Generation } \\
\text { Rate } \\
(\mu \mathrm{g} / \mathrm{L} / \mathrm{hr})\end{array}$ \\
\hline 3.2 & 9.1 \\
\hline 20.2 & 4.3 \\
\hline 45.7 & 13.9 \\
\hline 96.0 & 51.8 \\
\hline 121.2 & 119.3 \\
\hline 140.9 & 148.5 \\
\hline 165.2 & 192.7 \\
\hline 189.8 & 276.9 \\
\hline 216.2 & 345.4 \\
\hline 236.8 & 409.6 \\
\hline 286.1 & 485.5 \\
\hline 311.4 & 516.2 \\
\hline 335.4 & 488.1 \\
\hline 357.9 & 525.0 \\
\hline 382.1 & 651.0 \\
\hline 405.9 & 431.6 \\
\hline 427.8 & 417.0 \\
\hline 454.0 & 307.1 \\
\hline 479.1 & 327.8 \\
\hline 501.7 & 325.4 \\
\hline
\end{tabular}


Appendix H. Benzene generation rate data obtained from Tank 48H filtrate, oven-dried AFF NaTPB powder, and 0.1 wt \% Tank 51H sludge.

\begin{tabular}{|c|c|}
\hline $\begin{array}{c}\text { Reaction } \\
\text { Time } \\
\text { (hrs) }\end{array}$ & $\begin{array}{c}\text { Benzene } \\
\text { Generation } \\
\text { Rate } \\
(\mu \mathrm{g} / \mathrm{L} / \mathrm{hr})\end{array}$ \\
\hline 3.0 & 45.1 \\
\hline 17.5 & 62.9 \\
\hline 48.5 & 93.2 \\
\hline 68.5 & 105.3 \\
\hline 90.5 & 173.3 \\
\hline 113.5 & 211.3 \\
\hline 137.0 & 205.7 \\
\hline 161.1 & 206.2 \\
\hline 186.7 & 204.8 \\
\hline 212.8 & 186.6 \\
\hline 233.0 & 191.7 \\
\hline 259.0 & 191.6 \\
\hline 260.5 & $298^{\circ} .4$ \\
\hline 263.5 & 414.9 \\
\hline 281.7 & 394.8 \\
\hline 309.6 & 304.2 \\
\hline 337.5 & 277.2 \\
\hline 357.0 & 298.7 \\
\hline 381.7 & 290.1 \\
\hline 408.0 & 216.9 \\
\hline 428.7 & 244.0 \\
\hline 450.9 & 234.7 \\
\hline 477.5 & 186.7 \\
\hline 500.8 & 155.0 \\
\hline 523.4 & 223.4 \\
\hline 528.6 & 203.8 \\
\hline 530.5 & 139.9 \\
\hline 531.4 & 108.4 \\
\hline 546.1 & 56.9 \\
\hline 551.1 & 50.6 \\
\hline 572.5 & 38.2 \\
\hline
\end{tabular}


W. I. Tamosaitis

Appendix I. Benzene generation rate data obtained from Tank $48 \mathrm{H}$ filtrate, untreated reagent grade NaTPB powder (from Aldrich), and 0.2 wt \% Tank $51 \mathrm{H}$ sludge.

\begin{tabular}{|c|c|}
\hline $\begin{array}{c}\text { Reaction } \\
\text { Time } \\
\text { (hrs) }\end{array}$ & $\begin{array}{c}\text { Benzene } \\
\text { Generation } \\
\text { Rate } \\
(\mu \mathrm{g} / \mathrm{L} / \mathrm{hr})\end{array}$ \\
\hline 2.4 & 198.2 \\
\hline 16.9 & 47.9 \\
\hline 21.6 & 54.1 \\
\hline 25.6 & 52.4 \\
\hline 42.1 & 64.6 \\
\hline 65.1 & 72.7 \\
\hline 93.3 & 81.2 \\
\hline 121.5 & 100.3 \\
\hline 140.5 & 103.0 \\
\hline 165.2 & 121.6 \\
\hline 191.8 & 101.0 \\
\hline 212.3 & 106.8 \\
\hline 234.8 & 106.2 \\
\hline 261.0 & 103.0 \\
\hline 284.2 & 83.2 \\
\hline 306.9 & 79.1 \\
\hline 331.1 & 87.6 \\
\hline 356.2 & 74.1 \\
\hline 364.4 & 110.8 \\
\hline 366.6 & 139.8 \\
\hline 386.7 & 147.0 \\
\hline 404.2 & 112.6 \\
\hline 426.5 & 110.0 \\
\hline 450.3 & 71.2 \\
\hline 458.7 & 89.2 \\
\hline 473.4 & 74.3 \\
\hline 497.9 & 63.4 \\
\hline 526.2 & 57.4 \\
\hline 551.1 & 47.0 \\
\hline 596.2 & 44.7 \\
\hline 618.2 & 41.0 \\
\hline 643.8 & 41.8 \\
\hline 667.1 & 37.6 \\
\hline 693.5 & 39.2 \\
\hline 715.3 & 38.4 \\
\hline 738.3 & 37.3 \\
\hline 764.7 & 38.8 \\
\hline 787.3 & 39.0 \\
\hline
\end{tabular}


W. L. Tamosaitis - J-1 -

Appendix $J$. Benzene generation rate data obtained from

Tank 48H filtrate, untreated reagent grade NaTPB

powder (from Aldrich), and 0.25 wt \% Tank $48 \mathrm{H}$

sludge and MST.

\begin{tabular}{|c|c|}
\hline $\begin{array}{c}\text { Reaction } \\
\text { Time } \\
\text { (hrs) }\end{array}$ & $\begin{array}{c}\text { Benzene } \\
\text { Generation } \\
\text { Rate } \\
(\mu \mathrm{g} / \mathrm{L} / \mathrm{hr})\end{array}$ \\
\hline 2.7 & 264.2 \\
\hline 4.7 & 197.4 \\
\hline 21.5 & 72.4 \\
\hline 42.2 & 78.7 \\
\hline 64.4 & 93.3 \\
\hline 89.4 & 77.5 \\
\hline 113.2 & 78.7 \\
\hline 137.2 & 87.4 \\
\hline 164.7 & 117.0 \\
\hline 189.6 & 117.8 \\
\hline 234.7 & 133.1 \\
\hline 257.1 & 134.6 \\
\hline 264.7 & 593.2 \\
\hline 279.9 & 531.4 \\
\hline 287.1 & 435.6 \\
\hline 305.7 & 428.6 \\
\hline 329.8 & 475.5 \\
\hline 354.0 & 412.1 \\
\hline 377.4 & 463.8 \\
\hline 404.7 & 464.6 \\
\hline 426.1 & 498.1 \\
\hline 449.8 & 544.6 \\
\hline 475.0 & 414.8 \\
\hline 500.2 & 452.6 \\
\hline 521.6 & 376.0 \\
\hline 597.4 & 360.9 \\
\hline 616.7 & 380.3 \\
\hline 641.1 & 347.6 \\
\hline 665.5 & 356.7 \\
\hline 692.4 & 384.0 \\
\hline 712.4 & 331.6 \\
\hline 761.8 & 339.6 \\
\hline 786.8 & 422.0 \\
\hline 810.7 & 387.3 \\
\hline 833.2 & 449.2 \\
\hline 857.4 & 477.4 \\
\hline 880.9 & 474.9 \\
\hline 904.1 & 466.1 \\
\hline 929.7 & 438.0 \\
\hline 954.8 & 480.4 \\
\hline 977.2 & 254.6 \\
\hline 984.3 & 376.1 \\
\hline
\end{tabular}


Appendix K. Benzene generation rate data obtained from Tank 48H filtrate, untreated Boulder scientific Company NaTPB powder, and 0.2 wt \% Tank $51 \mathrm{H}$ sluagge.

\begin{tabular}{|c|c|}
\hline $\begin{array}{c}\text { Reaction } \\
\text { Time } \\
\text { (hrs) }\end{array}$ & $\begin{array}{c}\text { Benzene } \\
\text { Generation } \\
\text { Rate } \\
(\mu \mathrm{g} / \mathrm{L} / \mathrm{hr})\end{array}$ \\
\hline 5.6 & 294.4 \\
\hline 24.1 & 278.2 \\
\hline 47.1 & 236.2 \\
\hline 73.5 & 231.2 \\
\hline 96.2 & 217.4 \\
\hline 101.7 & 336.6 \\
\hline 119.5 & 240.6 \\
\hline 142.9 & 236.1 \\
\hline 170.1 & 210.9 \\
\hline 191.8 & 191.2 \\
\hline 241.9 & 267.0 \\
\hline 267.2 & 341.0 \\
\hline 286.8 & 263.7 \\
\hline 311.2 & 240.0 \\
\hline 335.7 & 232.6 \\
\hline 361.8 & 205.6 \\
\hline 382.4 & 202.3 \\
\hline 431.7 & 169.2 \\
\hline 480.8 & 158.6 \\
\hline 503.3 & 141.2 \\
\hline 527.5 & 142.1 \\
\hline 551.1 & 145.1 \\
\hline 573.2 & 141.5 \\
\hline 599.6 & 100.6 \\
\hline 624.7 & 100.9 \\
\hline 647.2 & 100.8 \\
\hline
\end{tabular}


Appendix I. Benzene generation rate data from ventilated, non-radioactive tests with Tank $48 \mathrm{H}$ simulant containing 4.5 wt \% NaTPB and KTPB solids and spiked with $1.4 \mathrm{mg} / \mathrm{L}$ copper.

\begin{tabular}{|c|c|}
\hline $\begin{array}{c}\text { Reaction } \\
\text { Time } \\
\text { (hrs) }\end{array}$ & $\begin{array}{c}\text { Benzene } \\
\text { Generation } \\
\text { Rate } \\
(\mu \mathrm{g} / \mathrm{L} / \mathrm{h} r)\end{array}$ \\
\hline 55.1 & 37.7 \\
\hline 105.9 & 35.2 \\
\hline 130.8 & 30.5 \\
\hline 158.3 & 29.6 \\
\hline 177.8 & 26.7 \\
\hline 201.2 & 22.6 \\
\hline 227.3 & 22.1 \\
\hline 250.3 & 24.7 \\
\hline 273.2 & 18.3 \\
\hline 301.8 & 18.5 \\
\hline 319.8 & 16.3 \\
\hline 344.1 & 16.0 \\
\hline 370.7 & 16.0 \\
\hline 416.8 & 13.3 \\
\hline 441.0 & 12.4 \\
\hline 464.6 & 15.1 \\
\hline 486.6 & 12.1 \\
\hline 518.5 & 14.9 \\
\hline
\end{tabular}


Appendix M. Benzene generation rate data from air ventilated, non-radioactive tests with Tank $48 \mathrm{H}$ simulant containing 4.5 wt \% KTPB solids (no excess NaTPB) and spiked with $1.4 \mathrm{mg} / \mathrm{L}$ copper.

\begin{tabular}{|c|c|}
\hline $\begin{array}{c}\text { Reaction } \\
\text { Time } \\
\text { (hrs) }\end{array}$ & $\begin{array}{c}\text { Benzene } \\
\text { Generation } \\
\text { Rate } \\
(\mu \mathrm{g} / \mathrm{L} / \mathrm{hr})\end{array}$ \\
\hline 55.1 & 38.9 \\
\hline 130.8 & 37.8 \\
\hline 158.3 & 31.7 \\
\hline 177.8 & 28.6 \\
\hline 201.2 & 27.6 \\
\hline 227.3 & 25.3 \\
\hline 250.3 & 24.3 \\
\hline 273.2 & 22.1 \\
\hline 301.8 & 21.6 \\
\hline 319.8 & 19.2 \\
\hline 344.1 & 15.0 \\
\hline 370.7 & 17.2 \\
\hline 441.0 & 15.4 \\
\hline 464.6 & 14.1 \\
\hline 486.6 & 14.4 \\
\hline 518.5 & 21.7 \\
\hline
\end{tabular}


w. I. Tamosaitis

Appendix N. Benzene generation rate data for the air ventilated non-radioactive test with reagent grade NaTPB solution.

\begin{tabular}{|c|c|}
\hline $\begin{array}{c}\text { Reaction } \\
\text { Time } \\
\text { (hrs) }\end{array}$ & $\begin{array}{c}\text { Benzene } \\
\text { Generation } \\
\text { Rate } \\
(\mu \mathrm{g} / \mathrm{L} / \mathrm{hr})\end{array}$ \\
\hline 18.1 & $1.688 \mathrm{e}+3$ \\
\hline 42.9 & $2.861 \mathrm{e}+3$ \\
\hline 72.0 & $7.888 \mathrm{e}+3$ \\
\hline 92.7 & $1.366 \mathrm{e}+4$ \\
\hline 115.8 & $4.222 \mathrm{e}+5$ \\
\hline 139.4 & $2.030 \mathrm{e}+6$ \\
\hline 165.0 & $1.315 \mathrm{e}+6$ \\
\hline 190.2 & $5.880 \mathrm{e}+5$ \\
\hline 212.4 & $2.247 \mathrm{e}+5$ \\
\hline 236.2 & $1.073 \mathrm{e}+5$ \\
\hline
\end{tabular}


Appendix 0. Benzene generation rate data for the nitrogen ventilated non-radioactive test with reagent grade NaTPB solution.

\begin{tabular}{|c|c|}
\hline $\begin{array}{c}\text { Reaction } \\
\text { Time } \\
\text { (hrs) } \\
\end{array}$ & $\begin{array}{c}\text { Benzene } \\
\text { Generation } \\
\text { Rate } \\
(\mu \mathrm{g} / \mathrm{L} / \mathrm{hr})\end{array}$ \\
\hline 19.5 & $1.810 \mathrm{e}+6$ \\
\hline 43.1 & $1.118 \mathrm{e}+6$ \\
\hline 68.6 & $6.276 e+5$ \\
\hline 93.4 & $4.356 e+5$ \\
\hline 116.3 & $3.491 e+5$ \\
\hline 139.5 & $3.337 e+5$ \\
\hline 164.8 & $2.312 e+5$ \\
\hline 190.0 & $2.083 e+5$ \\
\hline 212.7 & $2.210 e+5$ \\
\hline 237.0 & $1.561 e+5$ \\
\hline
\end{tabular}


Appendix P. Reactions Involving Alkaline Solution

Decomposition of Tetraphenylborate Anion (TPB-) in Presence of Trace Copper.

\section{Catalytic Reaction Mechanisms Involving Metal-Redox Couple}

The decomposition of aqueous tetraphenylborate in the presence of copper has been previously investigated in alkaline solutions. [Ref.

A] The tests were prompted by concerns about aqueous TPBdecomposition during interim storage, prior to batch additions as cold feed material in the ITP process. These previous experiments have recently received much attention as relatively simple, prototypical experiments for investigating the reactivity of soluble $\mathrm{TPB}^{-}$in the presence of copper. Current tests involving $\mathrm{TPB}^{-} / \mathrm{Cu}$ (II) solutions are indicating that trace levels of copper(II) ion can possibly completely decompose the TPB- (see Ventilated NonRadioactive Solution Tests in text). The solutions in the present tests are $0.1 \mathrm{M} \mathrm{OH}^{-}$and $0.5 \mathrm{M} \mathrm{TPB}^{-}$and contain $10 \mathrm{ppm} \mathrm{Cu}$ (II) $\left(\sim 1.6 \times 10^{-4} \mathrm{M}\right)$. Present tests were suggested and designed specifically, to investigate the effects of aerated and inert atmospheres on TPB decomposition. The original-tests were carried out in sealed plastic bottles whereas the current tests involve flowing a gas (air or nitrogen) over constantly-stirred 100-mL solutions. Pertinent questions to be addressed by the current investigations are:

1) Is copper catalytically involved to the same extent with and without air present, $i . e$. does one system indicate catalytic reactions while another only reacts stoichiometrically?

2) Are the TPB- decomposition product yields significantly different with and without air present, i.e. is either benzene or phenol formed at the exclusion of the other?

Catalytic properties of copper are suspected to be dependent on the redox reactions of the $\mathrm{Cu}(\mathrm{II}) / \mathrm{Cu}(\mathrm{I})$ couple. One possibility is that copper could be catalytic in aerated systems but inactive in similar anoxic systems with both gaseous and dissolved $\mathrm{O}_{2}$ removed. Several industrial copper catalyzed chemical processes are reported to be sustained in the presence of air. [Ref. B,C] In a continuously aerated solution the dissolved oxygen in solutions could be replenished to provide an unlimited source of oxidant.

Table P-1 shows the molar amounts of dissolved species present in a 100-mL solution of $0.1 \mathrm{M} \mathrm{OH}^{-}, 0.5 \mathrm{M} \mathrm{TPB}^{-}$, and $10 \mathrm{ppm} \mathrm{Cu(II),} \mathrm{with}$ dissolved air from the atmosphere initially present. Comparing the relative amounts of copper and TPB $^{-}$in Table 1 suggests that a catalytic reaction scheme would be necessary for the complete - destruction of the original $\mathrm{TPB}^{-}$. A stoichiometric reaction between copper and $\mathrm{TPB}^{-}$would only decompose $-0.06 \%$ of the original 0.5 molar TPB present. Also note from the data in Table P-1 that only 0.28 of 
Table P-1. Amounts of dissolved species present in the 100-mL aerated $\mathrm{OH}^{-} / \mathrm{TPB}^{-} / \mathrm{Cu}$ (II) system.

\begin{tabular}{|c|c|c|c|}
\hline Species & $\begin{array}{c}\text { Concentration } \\
\text { (molar) }\end{array}$ & $\begin{array}{c}\text { Quantity } \\
\text { (moles) }\end{array}$ & $\begin{array}{c}\text { Maximum Percent } \\
\text { TPB }^{-} \text {Decomposed } \\
\text { (\%) }\end{array}$ \\
\hline $\mathrm{TPB}^{-}$ & 0.5 & 0.050 & not applicable \\
$\mathrm{Cu}(\mathrm{II})$ & 0.00016 & $0.000016^{\mathrm{a}}$ & $0.06^{\mathrm{b}}$ \\
$\mathrm{O}_{2}$ & $0.00025^{\mathrm{c}}$ & 0.000025 & $0.2^{\mathrm{d}}$ \\
\hline
\end{tabular}

Actual dissolved $\mathrm{Cu}$ (II) could be lower due to its solubility equilibrium with solid hydrated copper hydroxide $\mathrm{Cu}\left(\mathrm{H}_{2} \mathrm{O}\right)_{4}(\mathrm{OH})_{2}$ in alkaline solution (see text).

'Assume stoichiometric reaction between original $\mathrm{Cu}(\mathrm{II})$ present and TPB ${ }^{-}$i.e. 2 $\mathrm{TPB}^{-}+\mathrm{Cu}(\mathrm{II}) \rightarrow 2 \mathrm{TPB} \cdot+\mathrm{Cu}^{\circ}$.

Aqueous concentration of $\mathrm{O}_{2}$ from dissolved air in equilibrium with the atmosphere at standard conditions.

Assume stoichiometric reaction between $\mathrm{Cu}$ (II) and TPB ${ }^{-}$with subsequent oxidation of $4 \mathrm{Cu}(\mathrm{I})$ by $\mathrm{O}_{2}$ (see reaction 2 in text) until original amount of dissolved $\mathrm{O}_{2}$ in solution is depleted. This would likely apply for a solution that was prepared in an open vessel, sealed and continuously purged with a nitrogen-flow over the gas-space in the vessel.

the $\mathrm{Cu}$ (I) generated in reaction 1 (see below) could be re-oxidized from reaction with the initial amount of dissolved $\mathrm{O}_{2}$ present in the 100-mL of solution.

Generalized equations describing TPB- decomposition involving copper catalysis can be written as:

1) $\mathrm{TPB}^{-}+\mathrm{Cu}(\mathrm{II}) \rightarrow\left(\mathrm{TPB}^{-}\right.$decomposition products) + $\mathrm{Cu}(\mathrm{I})$

2) $\mathrm{CU}(\mathrm{I})+\mathrm{O}_{2} \rightarrow \mathrm{Cu}(\mathrm{II})+\mathrm{O}_{2}^{-}$

where TPB- decomposition products are any of the various observed end-products such as benzene, phenol, biphenyl, and phenylboric acid.

Aerated Alkaline Solutions with $\ddot{C u}(I I) / C u(I)-R e d o x$ Couple

Suggested reactions describing TPB- decomposition in the aerated $\mathrm{TPB}^{-}$ /Cu(II) alkaline solutions can be generalized as follows:

\section{Primary Reactions}

1) $\quad\left(\mathrm{C}_{6} \mathrm{H}_{5}\right)_{3} \mathrm{~B}\left(\mathrm{C}_{6} \mathrm{H}_{5}\right)^{-}+\mathrm{Cu}^{2+} \rightarrow\left(\mathrm{C}_{6} \mathrm{H}_{5}\right)_{3}{ }_{3}\left(\mathrm{C}_{6} \mathrm{H}_{5}\right) \cdot+\mathrm{Cu}^{+}$

2) $4 \mathrm{Cu}^{+}+\mathrm{O}_{2} \rightarrow 4 \mathrm{Cu}^{2+}+2 \mathrm{O}^{2-}\left(2 \mathrm{O}^{2-}+2 \mathrm{H}_{2} \mathrm{O} \rightarrow 4 \mathrm{OH}^{-}\right)$

3) $\quad\left(\mathrm{C}_{6} \mathrm{H}_{5}\right)_{3} \mathrm{~B}\left(\mathrm{C}_{6} \mathrm{H}_{5}\right)^{-}+\mathrm{Cu}^{+}-->\left(\mathrm{C}_{6} \mathrm{H}_{5}\right)_{3} \mathrm{~B}\left(\mathrm{C}_{6} \mathrm{H}_{5}\right) \cdot \mathrm{Cu}(\mathrm{s})$

4) $\left(\mathrm{C}_{6} \mathrm{H}_{5}\right)_{3 \mathrm{~B}}\left(\mathrm{C}_{6} \mathrm{H}_{5}\right)+\mathrm{Cu}^{2+}+\mathrm{OH}^{-}-\rightarrow\left(\mathrm{C}_{6} \mathrm{H}_{5}\right)_{3} \mathrm{~B}+\left(\mathrm{C}_{6} \mathrm{H}_{5}\right) \mathrm{OH}+\mathrm{Cu}^{+}$

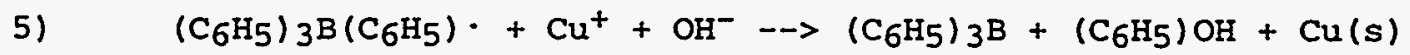


6) $\left(\mathrm{C}_{6} \mathrm{H}_{5}\right)_{3} \mathrm{~B}\left(\mathrm{C}_{6} \mathrm{H}_{5}\right) \cdot-\rightarrow\left(\mathrm{C}_{6} \mathrm{H}_{5}\right)_{3} \mathrm{~B}+\left(\mathrm{C}_{6} \mathrm{H}_{5}\right) \cdot$

7) $\quad\left(\mathrm{C}_{6} \mathrm{H}_{5}\right)_{3} \mathrm{~B}\left(\mathrm{C}_{6} \mathrm{H}_{5}\right) \cdot->\left(\mathrm{C}_{6} \mathrm{H}_{5}\right)_{2} \mathrm{~B} \cdot+\left(\mathrm{C}_{6} \mathrm{H}_{5}\right)_{2}$

For simplicity copper ion is shown in the above equations as $\mathrm{Cu}$ (II) or $\mathrm{Cu}(\mathrm{I})$ ion. In alkaline solution the $\mathrm{Cu}$ (II) ion would exist as the cuprate ion $\mathrm{Cu}\left(\mathrm{H}_{2} \mathrm{O}\right)_{2}(\mathrm{OH})_{4}^{2-}$ and $\mathrm{Cu}(\mathrm{I})$ as $\mathrm{Cu}(\mathrm{OH})_{2}^{-}$. Cuprate concentrations would be limited by its equilibrium with hydrated copper hydroxide solid via:

$\mathrm{Cu}\left(\mathrm{H}_{2} \mathrm{O}\right)_{2}(\mathrm{OH})_{4}^{2-}+2 \mathrm{H}_{2} \mathrm{O} \Leftrightarrow=>\mathrm{Cu}\left(\mathrm{H}_{2} \mathrm{O}\right)_{4}(\mathrm{OH})_{2}+2 \mathrm{OH}^{-}$

Reactions 1 and 3 as shown above could possibly be fast electron transfer, perhaps diffusion-limited reactions with rate constants possibly on the order of $1 \times 10^{8}$ to $1 \times 10^{10} \mathrm{M}^{-1} \mathrm{~s}^{-1}$. Another possibility for reactions 1 and 3 , instead of electron transfer, would be formation of a copper-coordinated boron complex. Such a reaction sequence will be discussed later in this report discussion.:-

Radiation chemistry studies have shown that both $\mathrm{Cu}$ (II) and $\mathrm{Cu}$ (I) rapidly react with the hydrated electron, $e_{a q^{-}}$, in aqueous, neutral $\mathrm{pH}$ 4-7, solution with $\mathrm{k}\left(\mathrm{Cu}(\mathrm{II})+\mathrm{eaq}^{-} \rightarrow \mathrm{Cu}(\mathrm{I})\right)=3.5 \times 10^{10} \mathrm{M}^{-1} \mathrm{~s}^{-1}$ and $\mathrm{k}\left(\mathrm{Cu}(\mathrm{I})+\mathrm{eaq}^{-} \rightarrow \mathrm{Cu}(0)\right)=2.7 \times 10^{10} \mathrm{M}^{-1} \mathrm{~s}^{-1}$, respectively, [Ref. D] Reaction 2 shows oxygen, an obvious oxidant available in the aerated system, reacting to oxidize the $\mathrm{Cu}(\mathrm{I})$ to $\mathrm{Cu}$ (II). This reaction as written shows that one oxygen molecule could potentially oxidize four $\mathrm{Cu}$ (I) to $\mathrm{Cu}$ (II). The oxidation of $\mathrm{Cu}$ (I) by $\mathrm{O}_{2}$ could be in competition with the other reactions involving $\mathrm{TPB}^{-}$and TPB. reductions of $\mathrm{Cu}(I)$ to metallic copper, reactions 3 and 5 respectively. If a solution were continuously supplied with $\mathrm{O}_{2}$, it would seem that the necessary conditions for the copper-catalyzed decomposition of $\mathrm{TPB}^{-}$via reactions $1-7$ shown above could exist.

Reactions 6 and 7 describe the decomposition of the tetraphenylboron radical species formed in reactions 1 and 3. Reaction 6 is speculative while reaction 7 has been postulated in connection with experimental studies involving pulse radiolysis of aqueous tetraphenylborate. [Ref. E]

Further possible secondary reactions involving the products of reactions 6 and 7 above are listed in the schemes below. Several of the reaction sequences shown below have been previously proposed in experimental studies pertaining to the radiolysis of tetraphenylborate [Ref. F-H], the acid protolysis of tetraphenylborate [Ref. I], the radiolysis of benzene [Ref. J-M], and the radiolysis of phenol. [Ref. N] The initial sequence below indicates triphenylboron in equilibrium with hydroxytriphenylborate. While the hydroxide adduct is reported to be fairly stable in organic solvents, a published account indicates that it will hydrolyze moderately rapidly in cold water and rapidly in dilute sodium hyḋroxide solutions. [Ref. O] Other published studies have discussed the possible role of oxygen in the hydrolysis of triphenylboron. [Ref: H and Ref. I] studies on the aqueous stability of 
triphenylboron conducted in the present study (see Reaction of Phenylboron Compounds in the text) indicate that triphenylboron (obtained as the $\sim 9$ wt $8 \mathrm{NaOH}$ adduct solution in water, $\left(\mathrm{C}_{6} \mathrm{H}_{5}\right) 3 \mathrm{~B} \cdot \mathrm{NaOH}$, from Aldrich. Chemical Co.) is likely to be completely decomposed in aerated 2.0 molar salt solutions at $70^{\circ} \mathrm{C}$ within $\sim 3$ days.

\section{Secondary Reactions}

Reactions of Triphenylboron $\left(\mathrm{C}_{6} \mathrm{H}_{5}\right)_{3} \mathrm{~B}$ :

-Alkaline-adduct/Hydrolysis

8)

9)

$$
\begin{aligned}
& \left(\mathrm{C}_{6} \mathrm{H}_{5}\right)_{3} \mathrm{~B}+\mathrm{OH}^{-} \quad \Leftrightarrow\left(\mathrm{C}_{6} \mathrm{H}_{5}\right)_{3} \mathrm{BOH}^{-} \\
& \left(\mathrm{C}_{6} \mathrm{H}_{5}\right)_{3} \mathrm{BOH}^{-}+\mathrm{H}_{2} \mathrm{O} \rightarrow\left(\mathrm{C}_{6} \mathrm{H}_{5}\right)_{2} \mathrm{~B}\left(\mathrm{OH}_{2}\right)^{-}+\mathrm{C}_{6} \mathrm{H}_{6} \\
& \left(\mathrm{C}_{6} \mathrm{H}_{5}\right)_{2} \mathrm{~B}(\mathrm{OH})_{2}^{-}+\mathrm{H}_{2} \mathrm{O} \rightarrow\left(\mathrm{C}_{6} \mathrm{H}_{5}\right) \mathrm{B}\left(\mathrm{OH}_{3}\right)^{-}+\mathrm{C}_{6} \mathrm{H}_{6}
\end{aligned}
$$

SUM: $\quad\left(\mathrm{C}_{6} \mathrm{H}_{5}\right)_{3} \mathrm{~B}+\mathrm{OH}^{-}\left(+3 \mathrm{H}_{2} \mathrm{O}\right) \rightarrow \mathrm{B}(\mathrm{OH})_{4}^{-}+3 \mathrm{C}_{6} \mathrm{H}_{6}$

Note: It can be postulated that a phenyl radical transfer could occur between the original parent $\mathrm{TPB}^{-}$and the $\mathrm{B}(\mathrm{OH}) 4^{-}$endproduct formed in reaction 11 above. Indirect evidence exists in the literature to support such a phenyl radical transfer. [Ref. P] This reaction would suggest a chain-propagation sequence as follows :

12) $\left(\mathrm{C}_{6} \mathrm{H}_{5}\right)_{3} \mathrm{~B}\left(\mathrm{C}_{6} \mathrm{H}_{5}\right)^{-}+\mathrm{B}\left(\mathrm{OH}_{4} 4^{-} \rightarrow\left(\mathrm{C}_{6} \mathrm{H}_{5}\right)_{3} \mathrm{~B}(\mathrm{OH})^{-}+\left(\mathrm{C}_{6} \mathrm{H}_{5}\right) \mathrm{B}(\mathrm{OH})_{3}^{-}\right.$

9) $\left(\mathrm{C}_{6} \mathrm{H}_{5}\right)_{3} \mathrm{BOH}^{-}+\mathrm{H}_{2} \mathrm{O} \rightarrow\left(\mathrm{C}_{6} \mathrm{H}_{5}\right)_{2} \mathrm{~B}(\mathrm{OH})_{2}^{-}+\mathrm{C}_{6} \mathrm{H}_{6}$

10) $\left(\mathrm{C}_{6} \mathrm{H}_{5}\right)_{2} \mathrm{~B}(\mathrm{OH})_{2}+\mathrm{H}_{2} \mathrm{O}-\rightarrow\left(\mathrm{C}_{6} \mathrm{H}_{5}\right) \mathrm{B}(\mathrm{OH})_{3}^{-}+\mathrm{C}_{6} \mathrm{H}_{6}$

11) $\left(\mathrm{C}_{6} \mathrm{H}_{5}\right) \mathrm{B}(\mathrm{OH})_{3}^{-}+\mathrm{H}_{2} \mathrm{O} \rightarrow \mathrm{B}(\mathrm{OH})_{4}^{-}+\mathrm{C}_{6} \mathrm{H}_{6}$

- Oxidation/Hydrolysis

13) $2\left(\mathrm{C}_{6} \mathrm{H}_{5}\right)_{3} \mathrm{~B}+\mathrm{O}_{2} \quad \rightarrow 2 \cdot\left(\mathrm{C}_{6} \mathrm{H}_{5}\right)_{2} \mathrm{BO}\left(\mathrm{C}_{6} \mathrm{H}_{5}\right)$

14) $\left(\mathrm{C}_{6} \mathrm{H}_{5}\right)_{2} \mathrm{BO}\left(\mathrm{C}_{6} \mathrm{H}_{5}\right)+\mathrm{H}_{2} \mathrm{O} \rightarrow\left(\mathrm{C}_{6} \mathrm{H}_{5}\right)_{2} \mathrm{BOH}+\left(\mathrm{C}_{6} \mathrm{H}_{5}\right) \mathrm{OH}$

15) $\left(\mathrm{C}_{6} \mathrm{H}_{5}\right)_{2} \mathrm{BOH}+\mathrm{H}_{2} \mathrm{O} \rightarrow\left(\mathrm{C}_{6} \mathrm{H}_{5}\right) \mathrm{B}(\mathrm{OH})_{2}+\mathrm{C}_{6} \mathrm{H}_{6}$,

SUM: $\quad 2\left(\mathrm{C}_{6} \mathrm{H}_{5}\right)_{3} \mathrm{~B}+\mathrm{O}_{2}+\left(4 \mathrm{H}_{2} \mathrm{O}\right)-\dot{\mathrm{O}}_{2}\left(\mathrm{C}_{6} \mathrm{H}_{5}\right) \mathrm{OH}+2\left(\mathrm{C}_{6} \mathrm{H}_{5}\right) \mathrm{B}(\mathrm{OH})_{2}+2 \mathrm{C}_{6} \mathrm{H}_{6}$

-Alkaline-adduct/Oxidation/Hydrolysis - Scheme A

16) $2\left(\mathrm{C}_{6} \mathrm{H}_{5}\right)_{3} \mathrm{BOH}^{-}+\mathrm{O}_{2} \rightarrow 2\left(\mathrm{C}_{6} \mathrm{H}_{5}\right)_{2} \mathrm{BO}\left(\mathrm{C}_{6} \mathrm{H}_{5}\right) \mathrm{OH}^{-}$

17) $\quad\left(\mathrm{C}_{6} \mathrm{H}_{5}\right)_{2} \mathrm{BO}\left(\mathrm{C}_{6} \mathrm{H}_{5}\right) \mathrm{OH}^{-}+\mathrm{H}_{2} \mathrm{O} \rightarrow\left(\mathrm{C}_{6} \mathrm{H}_{5}\right)_{2} \mathrm{~B}(\mathrm{OH})_{2}^{-}+\left(\mathrm{C}_{6} \mathrm{H}_{5}\right) \mathrm{OH}$

18) $\quad\left(\mathrm{C}_{6} \mathrm{H}_{5}\right)_{2} \mathrm{~B}(\mathrm{OH})_{2}+\mathrm{H}_{2} \mathrm{O} \rightarrow\left(\mathrm{C}_{6} \mathrm{H}_{5}\right) \mathrm{B}(\mathrm{OH})_{3}+\mathrm{C}_{6} \mathrm{H}_{6}$

19) $\left(\mathrm{C}_{6} \mathrm{H}_{5}\right) \mathrm{B}(\mathrm{OH})_{3}^{-}+\mathrm{H}_{2} \mathrm{O} \rightarrow \mathrm{B}(\mathrm{OH})_{4}^{-}+\mathrm{C}_{6} \mathrm{H}_{6}+\left(\mathrm{C}_{6} \mathrm{H}_{5}\right) \mathrm{OH}$

SUM: $\quad 2\left(\mathrm{C}_{6} \mathrm{H}_{5}\right)_{3} \mathrm{~B}+2 \mathrm{OH}^{-}+\mathrm{O}_{2}\left(+6 \mathrm{H}_{2} \mathrm{O}\right)--2.2 \mathrm{~B}\left(\mathrm{OH}_{4}\right)^{-}+4 \mathrm{C}_{6} \mathrm{H}_{6}+2\left(\mathrm{C}_{6} \mathrm{H}_{5}\right)_{\mathrm{OH}}$ 
-Alkaline-adduct/oxidation/Hydrolysis - Scheme B

20) $2\left(\mathrm{C}_{6} \mathrm{H}_{5}\right)_{3} \mathrm{BOH}^{-}+\mathrm{O}_{2} \rightarrow 2\left(\mathrm{C}_{6} \mathrm{H}_{5}\right)_{2} \mathrm{BO}\left(\mathrm{C}_{6} \mathrm{H}_{5}\right) \mathrm{OH}^{-}$

21) $\left(\mathrm{C}_{6} \mathrm{H}_{5}\right)_{2} \mathrm{BO}\left(\mathrm{C}_{6} \mathrm{H}_{5}\right) \mathrm{OH}^{-} \rightarrow\left(\mathrm{C}_{6} \mathrm{H}_{5}\right)_{2} \mathrm{BOH}+\left(\mathrm{C}_{6} \mathrm{H}_{5}\right) \mathrm{O}^{-}$.

22) $\left(\mathrm{C}_{6} \mathrm{H}_{5}\right)_{2} \mathrm{BOH}+\mathrm{H}_{2} \mathrm{O} \rightarrow\left(\mathrm{C}_{6} \mathrm{H}_{5}\right) \mathrm{B}(\mathrm{OH})_{2}+\mathrm{C}_{6} \mathrm{H}_{6}$

23) $\left(\mathrm{C}_{6} \mathrm{H}_{5}\right) \mathrm{O}^{-}+\mathrm{H}_{2} \mathrm{O} \quad \rightarrow\left(\mathrm{C}_{6} \mathrm{H}_{5}\right) \mathrm{OH}+\mathrm{OH}^{-}$

SUM: $\quad 2\left(\mathrm{C}_{6} \mathrm{H}_{5}\right)_{3} \mathrm{~B}+2 \mathrm{OH}^{-}+\mathrm{O}_{2}\left(+4 \mathrm{H}_{2} \mathrm{O}\right) \rightarrow 2\left(\mathrm{C}_{6} \mathrm{H}_{5}\right) \mathrm{B}(\mathrm{OH})_{2}+$

$2 \mathrm{C}_{6} \mathrm{H}_{6}+2\left(\mathrm{C}_{6} \mathrm{H}_{5}\right) \mathrm{OH}+2 \mathrm{OH}^{-}$

In the reaction sequences $13-15,16-19$, and 20-23 shown above, involving oxidation reactions of molecular oxygen, the initiating reactions 13,16 , and 20 as written would involve a two step process. Using $\left(\mathrm{C}_{6} \mathrm{H}_{5}\right)_{3} \mathrm{~B}$ as an example, these steps would involve the following two reactions:

$$
\begin{aligned}
& \left(\mathrm{C}_{6} \mathrm{H}_{5}\right)_{3} \mathrm{~B}+\mathrm{O}_{2} \rightarrow\left(\mathrm{C}_{6} \mathrm{H}_{5}\right)_{3} \mathrm{BO}_{2} \\
& \left(\mathrm{C}_{6} \mathrm{H}_{5}\right)_{3} \mathrm{BO}_{2}+\left(\mathrm{C}_{6} \mathrm{H}_{5}\right)_{3} \mathrm{~B} \rightarrow->2\left(\mathrm{C}_{6} \mathrm{H}_{5}\right)_{2} \mathrm{~B}-\mathrm{O}-\left(\mathrm{C}_{6} \mathrm{H}_{5}\right)
\end{aligned}
$$

These reaction sequences 13-15, 16-19, and 20-23 are thus postulated to occur via molecular oxygen attack as opposed to a less likely oxygen atom oxidation of the B-C species. Alternative molecular oxidation of the $\mathrm{B}-\mathrm{C}$ species could involve insertion of $\mathrm{O}_{2}$ itself (essentially a di-radical species) into the boron-phenyl bond, followed by subsequent homolytic or heterolytic 0-0 bond rupture as shown below:

$$
\begin{aligned}
& \left(\mathrm{C}_{6} \mathrm{H}_{5}\right)_{3} \mathrm{~B}+\mathrm{O}_{2} \rightarrow\left(\mathrm{C}_{6} \mathrm{H}_{5}\right)_{2} \mathrm{~B}-\mathrm{O}-\mathrm{O}-\left(\mathrm{C}_{6} \mathrm{H}_{5}\right) \\
& \left(\mathrm{C}_{6} \mathrm{H}_{5}\right)_{2} \mathrm{~B}-\mathrm{O}-\mathrm{O}-\left(\mathrm{C}_{6} \mathrm{H}_{5}\right) \rightarrow\left(\mathrm{C}_{6} \mathrm{H}_{5}\right)_{2} \mathrm{~B}-\mathrm{O}^{-}+\mathrm{O}-\left(\mathrm{C}_{6} \mathrm{H}_{5}\right) \\
& \left(\mathrm{C}_{6} \mathrm{H}_{5}\right)_{2} \mathrm{~B}-\mathrm{O}-\mathrm{O}-\left(\mathrm{C}_{6} \mathrm{H}_{5}\right) \rightarrow\left(\mathrm{C}_{6} \mathrm{H}_{5}\right)_{2} \mathrm{~B}-\mathrm{O}^{-}+{ }^{+} \mathrm{O}-\left(\mathrm{C}_{6} \mathrm{H}_{5}\right) \text { or }\left(\mathrm{C}_{6} \mathrm{H}_{5}\right)_{2} \mathrm{~B}-\mathrm{O}^{+}+{ }^{-} \mathrm{O}-\left(\mathrm{C}_{6} \mathrm{H}_{5}\right)
\end{aligned}
$$

Reactions of Phenyl Radical $\left(\mathrm{C}_{6} \mathrm{H}_{5}\right)$ :

$$
\begin{array}{ll}
24) & \left(\mathrm{C}_{6} \mathrm{H}_{5}\right)+\left(\mathrm{C}_{6} \mathrm{H}_{5}\right) \cdot \rightarrow\left(\mathrm{C}_{6} \mathrm{H}_{5}\right)-\left(\mathrm{C}_{6} \mathrm{H}_{5}\right) \\
25) & \left(\mathrm{C}_{6} \mathrm{H}_{5}\right)+\mathrm{O}_{2}\left(+\mathrm{H}_{2} \mathrm{O}\right) \rightarrow\left(\mathrm{C}_{6} \mathrm{H}_{5}\right) \mathrm{OH}+\mathrm{HO}_{2} \\
26) & \left(\mathrm{C}_{6} \mathrm{H}_{5}\right)+\mathrm{OH}^{-}\left(+\mathrm{H}_{2} \mathrm{O}\right) \rightarrow\left(\mathrm{C}_{6} \mathrm{H}_{5}\right) \mathrm{HOH} \cdot+\mathrm{OH}^{-} \\
27) & \left(\mathrm{C}_{6} \mathrm{H}_{5}\right) \mathrm{HOH} \cdot+\left(\mathrm{C}_{6} \mathrm{H}_{5}\right) \mathrm{HOH} \cdot \rightarrow \mathrm{C}_{6} \mathrm{H}_{6}+\left(\mathrm{C}_{6} \mathrm{H}_{5}\right) \mathrm{OH}+\mathrm{H}_{2} \mathrm{O} \\
28) & \left(\mathrm{C}_{6} \mathrm{H}_{5}\right) \mathrm{HOH} \cdot+\left(\mathrm{C}_{6} \mathrm{H}_{5}\right) \mathrm{HOH} \cdot-\rightarrow\left(\mathrm{C}_{6} \mathrm{H}_{5}\right)-\left(\mathrm{C}_{6} \mathrm{H}_{5}\right)+2 \mathrm{H}_{2} \mathrm{O}
\end{array}
$$

Reactions of piphenylboron Radical $\left(\mathrm{C}_{6} \mathrm{H}_{5}\right)_{2} \mathrm{~B}$ :

$$
\left(\mathrm{C}_{6} \mathrm{H}_{5}\right)_{2} \mathrm{~B}^{\cdot}+\left(\mathrm{C}_{6} \mathrm{H}_{5}\right)_{2} \mathrm{~B}^{-} \rightarrow\left(\mathrm{C}_{6} \mathrm{H}_{5}\right)_{2} \mathrm{~B}-\mathrm{B}\left(\mathrm{C}_{6} \mathrm{H}_{5}\right)_{2}
$$

$$
\left(\mathrm{C}_{6} \mathrm{H}_{5}\right)_{2} \mathrm{~B} \cdot+\mathrm{O}_{2}\left(+\mathrm{H}_{2} \mathrm{O}\right) \rightarrow\left(\mathrm{C}_{6} \mathrm{H}_{5}\right)_{2} \mathrm{BOH}+\mathrm{HO}_{2}
$$

$$
\begin{aligned}
& \left(\mathrm{C}_{6} \mathrm{H}_{5}\right)_{2} \mathrm{~B} \cdot+\mathrm{OH}-\left(+\mathrm{H}_{2} \mathrm{O}\right)-->\left(\mathrm{C}_{6} \mathrm{H}_{5}\right)_{2} \mathrm{BHOH}^{-}+\mathrm{OH}^{-} \\
& \left(\mathrm{C}_{6} \mathrm{H}_{5}\right)_{2} \mathrm{BHOH} \cdot+\left(\mathrm{C}_{6} \mathrm{H}_{5}\right)_{2} \mathrm{BHOH} \cdot->\left(\mathrm{C}_{6} \mathrm{H}_{5}\right)_{2} \mathrm{BH}+\left(\mathrm{C}_{6} \mathrm{H}_{5}\right)_{\mathrm{B}} \mathrm{OH}_{2}+\mathrm{C}_{6} \mathrm{H}_{6}
\end{aligned}
$$$$
\left(\mathrm{C}_{6} \mathrm{H}_{5}\right)_{2} \mathrm{BHOH} \cdot+\left(\mathrm{C}_{6} \mathrm{H}_{5}\right)_{2} \mathrm{BHOH} \cdot-\rightarrow\left(\mathrm{C}_{6} \mathrm{H}_{5}\right)_{2} \mathrm{~B}-\mathrm{B}\left(\mathrm{C}_{6} \mathrm{H}_{5}\right)_{2}+2 \mathrm{H}_{2} \mathrm{O}
$$

In addition to reactions 24 and 29 above, the phenyl radical and the diphenylboron radicals could also react with each other: 


$$
\mathrm{C}_{6} \mathrm{H}_{5} \cdots+\left(\mathrm{C}_{6} \mathrm{H}_{5}\right) 2 \mathrm{~B} \cdot \rightarrow\left(\mathrm{C}_{6} \mathrm{H}_{5}\right)_{3} \mathrm{~B}
$$

This reaction as shown would produce triphenylboron which could undergo any of the postulated decomposition steps shown in reactions 8-12 above. The overall scheme presented above for copper-catalyzed tetraphenylborate decomposition in aerated solutions assumes that the presence of dissolved molecular oxygen is critical in oxidizing $\mathrm{Cu}$ (I) (see reaction 2), thus providing a channel for the catalysis mechanism involving the redox couple of $\mathrm{Cu}(\mathrm{II}) / \mathrm{Cu}(\mathrm{I})$.

Deaerated (Anoxic) Alkaline Solutions

If molecular oxygen is excluded from the overall scheme presented for the aerated solutions above, the following set of reactions could describe in general terms the copper catalyzed decomposition of $\mathrm{TPB}^{-}$ in deaerated solutions:

\section{Primary Reactions in Absence of Osygen}

1) $\quad\left(\mathrm{C}_{6} \mathrm{H}_{5}\right)_{3} \mathrm{~B}\left(\mathrm{C}_{6} \mathrm{H}_{5}\right)^{-}+\mathrm{Cu}^{2+} \rightarrow\left(\mathrm{C}_{6} \mathrm{H}_{5}\right)_{3} \mathrm{~B}\left(\mathrm{C}_{6} \mathrm{H}_{5}\right) \cdot+\mathrm{Cu}^{+}$

3) $\left(\mathrm{C}_{6} \mathrm{H}_{5}\right)_{3} \mathrm{~B}\left(\mathrm{C}_{6} \mathrm{H}_{5}\right)^{-}+\mathrm{Cu}^{+} \rightarrow\left(\mathrm{C}_{6} \mathrm{H}_{5}\right)_{3} \mathrm{~B}\left(\mathrm{C}_{6} \mathrm{H}_{5}\right) \cdot+\mathrm{Cu}(\mathrm{s})$

4) $\quad\left(\mathrm{C}_{6} \mathrm{H}_{5}\right)_{3} \mathrm{~B}\left(\mathrm{C}_{6} \mathrm{H}_{5}\right)+\mathrm{Cu}^{2+}+\mathrm{OH}^{-}-->\left(\mathrm{C}_{6} \mathrm{H}_{5}\right)_{3} \mathrm{~B}+\left(\mathrm{C}_{6} \mathrm{H}_{5}\right) \mathrm{OH}+\mathrm{Cu}^{+}$

5) $\left(\mathrm{C}_{6} \mathrm{H}_{5}\right)_{3} \mathrm{~B}\left(\mathrm{C}_{6} \mathrm{H}_{5}\right) \cdot+\mathrm{Cu}^{+}+\mathrm{OH}^{-} \rightarrow\left(\mathrm{C}_{6} \mathrm{H}_{5}\right)_{3} \mathrm{~B}+\left(\mathrm{C}_{6} \mathrm{H}_{5}\right) \mathrm{OH}+\mathrm{Cu}(\mathrm{s})$

6) $\quad\left(\mathrm{C}_{6} \mathrm{H}_{5}\right)_{3} \mathrm{~B}\left(\mathrm{C}_{6} \mathrm{H}_{5}\right) \cdot \rightarrow\left(\mathrm{C}_{6} \mathrm{H}_{5}\right)_{3} \mathrm{~B}+\left(\mathrm{C}_{6} \mathrm{H}_{5}\right) \cdot$

7) $\quad\left(\mathrm{C}_{6} \mathrm{H}_{5}\right)_{3} \mathrm{~B}\left(\mathrm{C}_{6} \mathrm{H}_{5}\right) \cdot-\rightarrow\left(\mathrm{C}_{6} \mathrm{H}_{5}\right)_{2} \mathrm{~B} \cdot+\left(\mathrm{C}_{6} \mathrm{H}_{5}\right)_{2}$

\section{Secondary Reactions in Absence of Oxygen}

Reactions of Triphenylboron $\left(\mathrm{C}_{6} \mathrm{H}_{5}\right)_{3} \mathrm{~B}$ :

-Alkaline-adduct/Hydrolysis

8) $\left(\mathrm{C}_{6} \mathrm{H}_{5}\right)_{3} \mathrm{~B}+\mathrm{OH}^{-} \quad \rightarrow\left(\mathrm{C}_{6} \mathrm{H}_{5}\right)_{3} \mathrm{BOH}^{-}$

9) $\left(\mathrm{C}_{6} \mathrm{H}_{5}\right)_{3} \mathrm{BOH}^{-}+\mathrm{H}_{2} \mathrm{O} \longrightarrow\left(\mathrm{C}_{6} \mathrm{H}_{5}\right)_{2} \mathrm{~B}(\mathrm{OH})_{2}^{-}+\mathrm{C}_{6} \mathrm{H}_{6}$

10) $\left(\mathrm{C}_{6} \mathrm{H}_{5}\right)_{2} \mathrm{~B}(\mathrm{OH})_{2}^{-}+\mathrm{H}_{2} \mathrm{O} \rightarrow\left(\mathrm{C}_{6} \mathrm{H}_{5}\right) \mathrm{B}(\mathrm{OH})_{3}^{-}+\mathrm{C}_{6} \mathrm{H}_{6}$

11) $\left(\mathrm{C}_{6} \mathrm{H}_{5}\right) \mathrm{B}(\mathrm{OH})_{3}^{-}+\mathrm{H}_{2} \mathrm{O} \rightarrow \mathrm{B}(\mathrm{OH})_{4}^{-}+\mathrm{C}_{6} \mathrm{H}_{6}$

SUM: $\quad\left(\mathrm{C}_{6} \mathrm{H}_{5}\right)_{3} \mathrm{~B}+\mathrm{OH}^{-}\left(+3 \mathrm{H}_{2} \mathrm{O}\right) \rightarrow \mathrm{B}(\mathrm{OH})_{4}^{-}+3 \mathrm{C}_{6} \mathrm{H}_{6}$

Note: It can be postulated that a phenyl transfer could occur between the original parent $\mathrm{TPB}^{-}$and the $\mathrm{B}(\mathrm{OH}) 4^{-}$end-product formed in reaction 11 above. This reaction would suggest a chain-propagation sequence as follows:

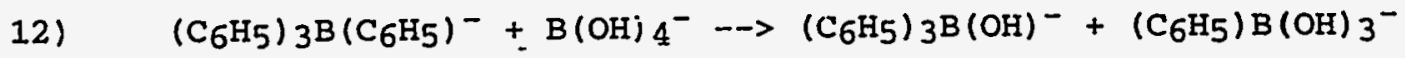

9) $\left(\mathrm{C}_{6} \mathrm{H}_{5}\right)_{3} \mathrm{BOH}^{-}+\mathrm{H}_{2} \mathrm{O} \longrightarrow\left(\mathrm{C}_{6} \mathrm{H}_{5}\right)_{2} \mathrm{~B}(\mathrm{OH})_{2}^{-}+\mathrm{C}_{6} \mathrm{H}_{6}$

10) $\left(\mathrm{C}_{6} \mathrm{H}_{5}\right)_{2} \mathrm{~B}(\mathrm{OH})_{2}^{-}+\mathrm{H}_{2} \mathrm{O}-\rightarrow\left(\mathrm{C}_{6} \mathrm{H}_{5}\right) \mathrm{B}(\mathrm{OH})_{3}^{-}+\mathrm{C}_{6} \mathrm{H}_{6}$

11) $\left(\mathrm{C}_{6} \mathrm{H}_{5}\right) \mathrm{B}(\mathrm{OH})_{3}^{-}+\mathrm{H}_{2} \mathrm{O} \rightarrow \mathrm{B}(\mathrm{OH})_{4}^{-}+\mathrm{C}_{6} \mathrm{H}_{6}$ 
Anoxic Reactions of Phenyl Radical $\left(\mathrm{C}_{6} \mathrm{H}_{5}\right)$ :
24)
$\left(\mathrm{C}_{6} \mathrm{H}_{5}\right)+\left(\mathrm{C}_{6} \mathrm{H}_{5}\right) \cdot \rightarrow\left(\mathrm{C}_{6} \mathrm{H}_{5}\right)-\left(\mathrm{C}_{6} \mathrm{H}_{5}\right)$
26)
$\left(\mathrm{C}_{6} \mathrm{H}_{5}\right)+\mathrm{OH}^{-}\left(+\mathrm{H}_{2} \mathrm{O}\right) \rightarrow\left(\mathrm{C}_{6} \mathrm{H}_{5}\right) \mathrm{HOH} \cdot+\mathrm{OH}^{-}$
27)
$\left(\mathrm{C}_{6} \mathrm{H}_{5}\right) \mathrm{HOH} \cdot+\left(\mathrm{C}_{6} \mathrm{H}_{5}\right) \mathrm{HOH} \cdot \rightarrow \mathrm{C}_{6} \mathrm{H}_{6}+\left(\mathrm{C}_{6} \mathrm{H}_{5}\right) \mathrm{OH}+\mathrm{H}_{2} \mathrm{O}$
28)
$\left(\mathrm{C}_{6} \mathrm{H}_{5}\right) \mathrm{HOH} \cdot+\left(\mathrm{C}_{6} \mathrm{H}_{5}\right) \mathrm{HOH} \cdot \rightarrow\left(\mathrm{C}_{6} \mathrm{H}_{5}\right)-\left(\mathrm{C}_{6} \mathrm{H}_{5}\right)+2 \mathrm{H}_{2} \mathrm{O}$

Anoxic Reactions of Diphenylboron Radical $\left(\mathrm{C}_{6} \mathrm{H}_{5}\right)_{2} \mathrm{~B}$ :

29) $\left(\mathrm{C}_{6} \mathrm{H}_{5}\right)_{2} \mathrm{~B} \cdot+\left(\mathrm{C}_{6} \mathrm{H}_{5}\right)_{2} \mathrm{~B} \cdot \rightarrow\left(\mathrm{C}_{6} \mathrm{H}_{5}\right)_{2} \mathrm{~B}-\mathrm{B}\left(\mathrm{C}_{6} \mathrm{H}_{5}\right)_{2}$

31) $\left(\mathrm{C}_{6} \mathrm{H}_{5}\right)_{2} \mathrm{~B}^{-}+\mathrm{OH}^{-}\left(+\mathrm{H}_{2} \mathrm{O}\right) \rightarrow\left(\mathrm{C}_{6} \mathrm{H}_{5}\right)_{2} \mathrm{BHOH} \cdot+\mathrm{OH}^{-}$

32) $\left(\mathrm{C}_{6} \mathrm{H}_{5}\right)_{2} \mathrm{BHOH} \cdot+\left(\mathrm{C}_{6} \mathrm{H}_{5}\right)_{2} \mathrm{BHOH} \cdot \rightarrow\left(\mathrm{C}_{6} \mathrm{H}_{5}\right)_{2} \mathrm{BH}+\left(\mathrm{C}_{6} \mathrm{H}_{5}\right) \mathrm{B}\left(\mathrm{OH}_{2}\right)_{2}+\mathrm{C}_{6} \mathrm{H}_{6}$

33) $\left(\mathrm{C}_{6} \mathrm{H}_{5}\right)_{2} \mathrm{BHOH} \cdot+\left(\mathrm{C}_{6} \mathrm{H}_{5}\right)_{2} \mathrm{BHOH} \cdot-->\left(\mathrm{C}_{6} \mathrm{H}_{5}\right)_{2} \mathrm{~B}-\mathrm{B}\left(\mathrm{C}_{6} \mathrm{H}_{5}\right)_{2}+2 \mathrm{H}_{2} \mathrm{O}$

Reaction of Phenyl Radical $\left(\mathrm{C}_{6} \mathrm{H}_{5}\right)$ with Diphenylboron Radical $\left(\mathrm{C}_{6} \mathrm{H}_{5}\right)_{2} \mathrm{~B}$ :

$$
\left(\mathrm{C}_{6} \mathrm{H}_{5}\right)_{2} \mathrm{~B} \cdot+\mathrm{C}_{6} \mathrm{H}_{5} \cdot \rightarrow\left(\mathrm{C}_{6} \mathrm{H}_{5}\right)_{3} \mathrm{~B}
$$

In the above section describing tetraphenylborate decomposition under anoxic conditions, the proposed mechanistic schemes, namely reactions 1 , and reactions 3-7, offer no suggested mechanism for reoxidation of the $\mathrm{Cu}(\mathrm{I})$ ion to complete the redox couple of $\mathrm{Cu}(\mathrm{I}) / \mathrm{Cu}$ (II). We note that it is unlikely that perhaps the oxygen-containing species phenol or phenylboric acid could act as $\mathrm{Cu}$ (I) oxidants based on a Iiterature account in which it is shown that phenylboric acid acts as a reductant towards $\mathrm{Cu}$ (II) to form $\mathrm{Cu}(\mathrm{I})$. [Ref. Q] However a reaction sequence is presented below in which the $\mathrm{Cu}$ (I) ion could catalytically decompose tetraphenylborate without involving $\mathrm{Cu}$ (II) after $\mathrm{Cu}(\mathrm{II})$ is initially reduced to $\mathrm{Cu}(\mathrm{I})$ (see reactions 36-40 presented below). This proposed catalysis could be initiated in the anoxic scheme by a coupling of the $\mathrm{Cu}(\mathrm{I})$ with the tetraphenylboron - radical, i.e. an alternate reaction to that of reaction 5 above, in which it is postulated that $\mathrm{Cu}(I)$ is reduced to metallic copper by the cetraphenylboron radical.

A broad comparison of the two different generalized schemes involving aerated catalytic decomposition of tetraphenylborate and anoxic catalytic decomposition of tetraphenylborate also suggest that benzene is possibly the most predominant end-product in the anoxic scheme (see anoxic scheme, reactions $8-12$ and reaction 34 (the product of which, ( $\left.66 \mathrm{H}_{5}\right) 3 \mathrm{~B}$, could proceed to decompose via reactions 8-12), and reactions 36-40 below). Further studies involving the decomposition of aqueous triphenylboron, i.e. dissolved air effects, $\mathrm{pH}$ effects, the effects of high levels of soluble salts, temperature effects (and perhaps even the effects of dissolved metal species that could potentially catalyze the triphenylboron decomposition), are needed to better understand the postulated reaction scheme in reactions $8-12$. 


\section{Catalytic Reaction Mechanism not Involving Metal-Redox Couple}

It was previously mentioned that the initial $\mathrm{Cu}$ (II) plus TPBreaction could be postulated to react via a simple electron transfertype process (see reaction 1 in the catalysis mechanism sections above) or alternatively via a Cu-B complex. The possibility of tetraphenylborate hydrolysis in a series of reactions that does not involve any copper redox chemistry (after the $\mathrm{Cu}(I) \mathrm{B}\left(\mathrm{C}_{6} \mathrm{H}_{5}\right)_{4}$ intermediate is formed) is shown below.

$$
\begin{aligned}
& \text {-35) } \mathrm{Cu}^{2+}+2\left(\mathrm{C}_{6} \mathrm{H}_{5}\right)_{3} \mathrm{~B}\left(\mathrm{C}_{6} \mathrm{H}_{5}\right)-->\mathrm{Cu}(\mathrm{I}) \mathrm{B}\left(\mathrm{C}_{6} \mathrm{H}_{5}\right)_{4}+\left(\mathrm{C}_{6} \mathrm{H}_{5}\right)_{4} \mathrm{~B}^{-} \\
& 36) \mathrm{Cu}(I) \mathrm{B}\left(\mathrm{C}_{6} \mathrm{H}_{5}\right)_{4} \Leftrightarrow \mathrm{Cu}(\mathrm{I})\left(\mathrm{C}_{6} \mathrm{H}_{5}\right)+\left(\mathrm{C}_{6} \mathrm{H}_{5}\right)_{3} \mathrm{~B} \\
& 37) \mathrm{Cu}(I)\left(\mathrm{C}_{6} \mathrm{H}_{5}\right)+\mathrm{OH}^{-} \Leftrightarrow\left(\mathrm{C}_{6} \mathrm{H}_{5}\right) \mathrm{Cu}(I) \mathrm{OH}^{-} \\
& 38) \quad\left(\mathrm{C}_{6} \mathrm{H}_{5}\right) \mathrm{Cu}(I) \mathrm{OH}^{-} \rightarrow \mathrm{C}_{6} \mathrm{H}_{6}+\mathrm{Cu}(I) \mathrm{O}^{-} \\
& 39) \mathrm{Cu}(I) \mathrm{O}^{-}+\mathrm{H}_{2} \mathrm{O} \rightarrow \mathrm{Cu}^{+}+2 \mathrm{OH}^{-} \\
& 40) \mathrm{Cu}^{+}+\left(\mathrm{C}_{6} \mathrm{H}_{5}\right)_{3} \mathrm{~B}\left(\mathrm{C}_{6} \mathrm{H}_{5}\right)^{-} \rightarrow \mathrm{Cu}(I) \mathrm{B}\left(\mathrm{C}_{6} \mathrm{H}_{5}\right)_{4}
\end{aligned}
$$

Literature accounts suggest that the initial reactions 35 and 36 are probable. [Ref. R, S] The $\mathrm{Cu}(\mathrm{I}) \mathrm{B}\left(\mathrm{C}_{6} \mathrm{H}_{5}\right)_{4}$ complex is reported to hydrolyze readily to benzene in contrast to a relatively more stable uncomplexed tetraphenylborate anion. The tetraphenylboron radical and triphenylboron produced in the above reactions 35 and 36 , respectively, could subsequently decompose by the previously mentioned schemes involving reactions 6 and 7 for $\left(\mathrm{C}_{6} \mathrm{H}_{5}\right)_{4} \mathrm{~B}$. and reactions $8-12$ for triphenyboron $\left(\left(\mathrm{C}_{6} \mathrm{H}_{5}\right)_{3} \mathrm{~B}\right)$.

\section{'References}

A) M. J. Barnes, "Decomposition of Tetraphenylborate, "Waste Management '91, 759-762 (1991).

B) Kirk-Othmer, "Concise Encyclopedia of Chemical Technology," p. 7, John Wiley \& Sons, New York, 1985.

C) H. H. Szmant, "Organic Building Blocks of the Chemical Industry," p. John Wiley \& Sons, New York, p. 497, 1989.

D) G. V. Buxton; C. L. Greenstock, W. P. Helman, and A. B. Ross, "Critical Review of Rate Constants for Reactions of Hydrated Electrons, Hydrogen Atoms, and Hydroxyl Radicals in Aqueous Solution," Reprint \#343, J. Phys. Chem. Ref. Data, 17(2), (1988).

E) Horii et al., "Oxidation Intermediates of Borohydride and Tetraphenylborate Ions in Aqueous Solutions obtained by Pulse Radiolysis," J. Chem. Soc., Chem. Commun., 915, (1986).

F) A. K. Gupta, R. J. Hanrahan, and D. D. Walker, "Radiolysis of Sodium and Potassium Tetraphenylborate in Aqueous Systems," $\mathrm{J}$. Phys. Chem., 95, 3590-3594 (1991). 
References (continued)

G) A. K. Gupta, R. J. Hanrahan, and D. D. Walker, "Use of Co-60 Gamma Irradiation to Simulate Decomposition of Tetraphenylborate Precipitates from High Level Radioactive Waste," Radiochim.Acta, $60,43-51$ (1993).

H) C. L. Crawford, M. R. Gholami, R. N. Bhave, and R. J. Hanrahan, "Pulse Radiolysis of Aqueous Solutions of Sodium Tetraphenylborate," Radiat. Phys. Chem., 44, 309-315 (1994).

I) V. A. Simon, "The Protolysis of the Tetraphenylboron Anion," Ph.D. Thesis, The University of Florida State, (1962).

J) M. H. Studier and E. J. Hart, "The Reduction of Benzene by Hydrated Electrons in Gamma-Ray Irradiated Alkaline Solutions", $J$. Am. Chem. Soc., 91; 4068-4071 (1969).

K) D. G. Marketos, A Marketou-Mantaka, and G. Stein, "Reaction of the Hydrated Electron with Benzene studied by Pulse Radiolysis", J. Phys. Chem., 78, 1987-1992 (1974).

L) B. D. Michael and E. J. Hart, "The Rate Constants of Hydrated Electron, Hydrogen Atom, and Hydroxyl Radical Reactions with Benzene, 1,3-Cyclohexadiene, 1,4-Cyclohexadiene, and Cyclohexene", J. Phys. Chem., 74, 2878-2884 (1970).

M) M. C. Sauer, Jr. and B. Ward, "The Reactions of Hydrogen Atoms with Benzene and Toluene Studied by Pulse Radiolysis: Reaction Rate Constants and Transient Spectra in the Gas Phase and Aqueous Soluțion", J. Phys. Chem., 71, 3971-3983 (1967).

N) E. J. Land and M. Ebert, "Pulse Radiolysis Studies of Aqueous Phenol.", Trans. Faraday Soc., 63, 1181 (1967).

O). H. C. Brown and V. H. Dodson, "Studies in stereochemistry. XXII. The Preparation and Reactions of Trimesitylborane. Evidence for the Localized Nature of the Odd Electron in Triarylborane Radical Ions and Related Free Radicals", J. Am. Chem. SOC., 79, 2302 (1957).

P) W. G. Peet and F. N. Tebbe, "Process for Making Alkali-Metal Tetra organylborates", U. S. Patent \# 4,510,327 to E. I. Dupont de Nemours and Co., (1985).

Q) A. D. Ainley and F. Challenger, "Studies of the Boron-Carbon Linkage, Part 1. The Oxidation and Nitration of Phenylboric Acid", J. Chem. Soc., 2171 (1930).

R) G. Wittig and P. Raff, Liebigs Ann. Chem., 573, p. 195 (1951).

S) G. Costa, A. Camus, N. Marsich, and L. Gatti, J. Organometal. Chem., 8, 339 (1967). 


\title{
Appendix Q. D. D. Walker "Excess NaTPB in Tank 48 Batch \#1 (U)", March 28, 1996.
}

\author{
INTER-OFEICE MEMORANDUM \\ Savannah River Site \\ 28-Mar-1996 02:05pm EST \\ To: See Below \\ From: Darrel Douglas Walker \\ Dept: SRI/IWT \\ TeI : 5-2612 \\ ( WALKER-DD-T5550) \\ Excess NaTpB in Tank 48 Batch \#1
}

There has been some discussion lately about the amount of excess sodium tetraphenylborate in Tank $48 \mathrm{H}$. I have maintained that the excess in the tank was about 16\%, whereas Raul Rutland has maintained that about 318 excess was added to the tank last September. Many others believe that we have used a 508 excess. After discussions with Paul yesterday, I agree that his value of 318 is the correct value. However. please note that the following two statements are both correct:

In September, a 318 excess of NaTPB was added over the theoretical amount required.

In November/December, all of the excess NaTPB decomposed. This excess was 16 wt 8 of the tetraphenylborate in the tank.

The difference is due to definitions of excess and is not due to any misunderstanding of how much NaTPB was added or how much potassium was in the tank. If you are interested in the details, please read on. Also, I have contacted Rob Swingle to discuss the values that he is using in the benzene material balance. He will make some minor changes to align his calculations with the values used by Rutland and Rick Fowler. However, one significant difference will remain. Swingle will continue to use a more accurate measure of the soluble tetraphenylborate that was sent to Tank 50 in the filtrate. The final tank volume and sodium concentration were slightly different than the pre-batch predictions, which resulted in a large difference in the soluble amount (note that the soluble amount is a

minor part of the totall.

The correct definition of excess for the NaTpB addition made in September is based on two amounts: (1) the theoretical amount of NaTPB needed to precipitate the $\mathrm{Cs}$ and $K$, and react with mercury, and (2) how much more than this amount was actually added. Rutland's calculation using amounts measured in gram-moles is:

$$
\& \text { Excess }=100 \times(\text { Total }- \text { Theoretical }) /(\text { Theoretical })
$$

The theoretical amount of NaTPB is obtained from the measured value for $\mathrm{Kt}$ with 88 additional for precipitation of $\mathrm{Cs}$ and reaction with mercury. In September, the $\mathrm{K}+$ concentration was 0.033 moiar frid the tank contained 456,000 gallons of waste. 2hus, the theoretical amount of NaTPB was. 61,600 gram-moles. Beyond the theoretical amount, additional NaTRB is added to (1) saturate the salt solution and (2) create solid NaTPB solids. To saturate the solution required $3600 \mathrm{~g}$-moles of NaTPB. The requirement for NaTPB solids is to add an additional 0.0075 molar NaTPB for the final tank volume. Note that this last component is independent of the amount of $\mathrm{Kt}$ to be precipitated and, when expressed as a percentage, will vary from 
Appendix R. D. D. Walker "Rate of Decomposition in Tank 48H (U)", April 3, 1996.

\section{DON'T SAY IT - WRITE IT}

TO: Todd Wright LOCATION 704-H DATE 4 4/3/96

FROM: D. D. Walker _PHONENO. $5-2612$ LOCATION T73-A

Rate of Decomposition in Tank $48 \mathrm{H}$

Attached is the graph you requested. The following are some comments about the "Expected" rate of increase of Cs-137 in the liquid phase.

Current Tank 49

The current rate of increase of Cs-137 in Tank 48 is 1.36 nCilg per day. This is based on data since December 1. It would appear from the graph that all the excess NaTPB was decomposed at approximately that time, initiating the increase in soluble Cs-137.

Tank 49 Storage expectations

The rate of degradation of precipitate due to radiolysis was studied in small-scale tests following the 1983 demonstration. Based on these experiments the ITP, Late Wash, and Acid Hydrolysis processes expected about $7.5 \%$ decomposition per year (for slurry containing $36 \mathrm{Ci}$ Cs-137 per gallon). When this result is adjusted to the current tank composition (2.5 $\mathrm{Ci} / g a l)$, the expected rate for $\mathrm{Cs}-137$ is $8 \mathrm{nCi} / \mathrm{g}$ per day. This is line shown for the "Expected" on the attached graph.

\section{Demonstration}

Following the 1983 demonstration, the Cs-137 concentration in the solution was measured over a period of three years. It increased linearly at a rate of about $22 \mathrm{nCi} / \mathrm{g}$ per day. If the results of the small scale tests are extrapolated to the composition following the 1983 demonstration, the expected rate of increase was $16 \mathrm{nCi} / \mathrm{g}$ per day.

\section{Summary}

The current mix of precipitates from 1983 and 1995 are decomposing at $a$ rate that is slower than expected. The slow rate could be due to

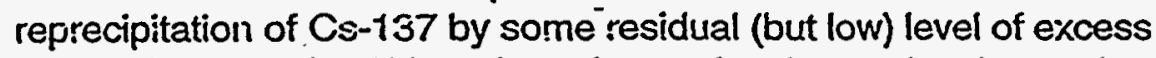
NaTPB in the tank. Although analyses of tank samples do not show any excess, the sensitivity of the arialysis cannot rule out a residual NaTPB 
content of up to 200 lbs. A second possibility is that the rate may accelerate with time. The experimental rates and post-1983 demo rate are based on time periods that are long compared to the 100 days since the Cs-137 began to increase in early December 1995.

CO. W. L. Tamosaitis

S. D. Fink

M. J. Barnes

R. A. Jacobs

B. G. Croley

J. D. Menna

P. L. Rutland

E. W. Holtzscheiter

Cs-137 Activity in Tank 48H Filtrate

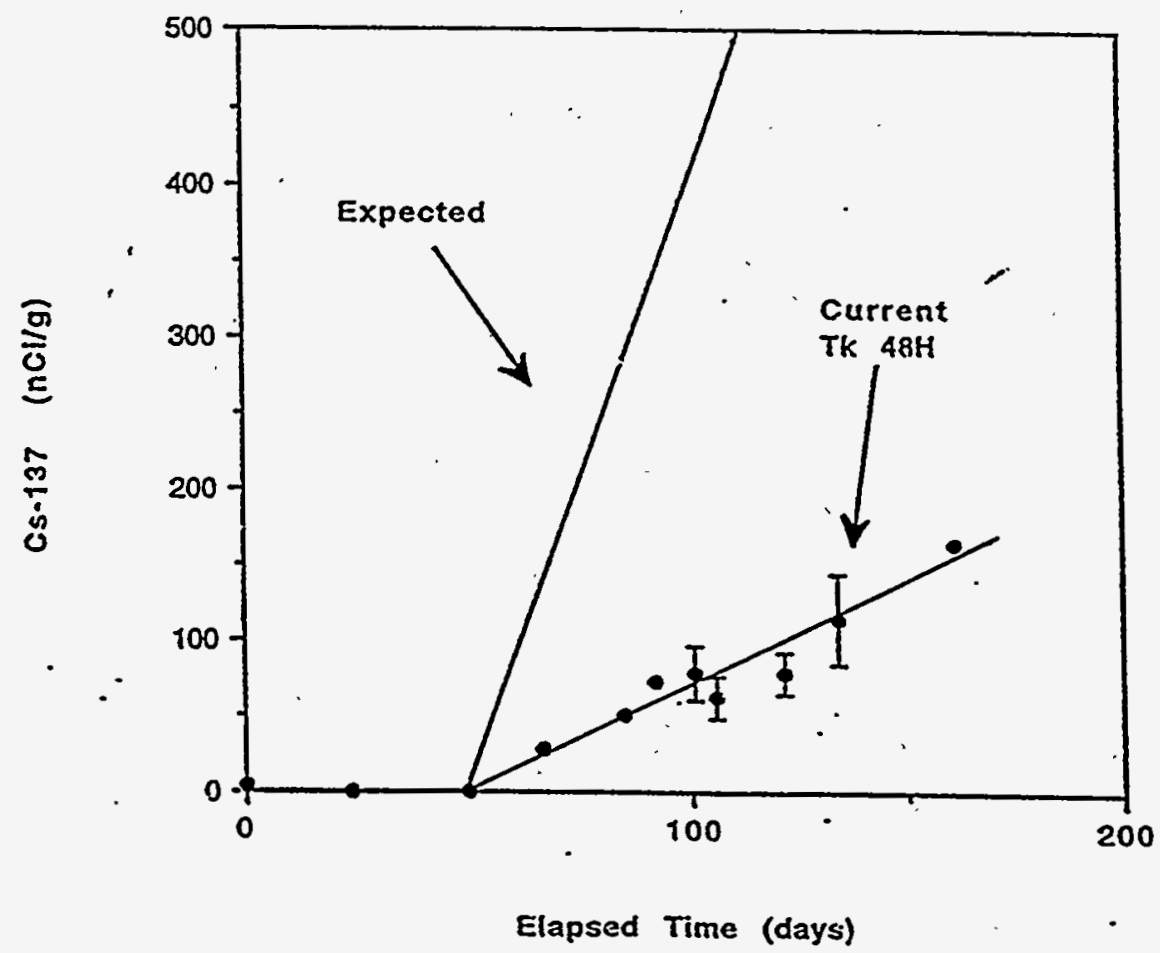


Appendix S. M. R. Poixier, "Preliminary Benzene Evolution

Rates During Saltstone Curing "(U),

SRT-WHM-96-0014, February 28, 1996.

Westinghouse Savannah River Company

Inter-Office Memorandum

SRT-WHM-96-0014

February 28, 1996

To: W. B. Van Pelt, 676-1T

From: M. R. Poirier, 676-T MRl

Preliminary Benzene Evolution Rates During Saltstone Curing

Summary

High Level Waste Engineering requested SRTC to determine the rate of benzene release during saltstone curing as part of the TCLP tests. SRTC prepared saltstone with the January 1996 Tank 50H sample and issued report SRT-WHM-96-0013 summarizing preliminary (7 day TCLP and benzene evolution and 14 day TCLP) results.

Benzene evolution rates as reported earlier for 4 and 7 day samples, and new data for 11 , and 14 day samples ranged from 0.012 to $0.172 \mu \mathrm{g} / \mathrm{h} \mathrm{hr}$, which is below the rate measured in the 1985 tests. Additional samples are being collected to measure benzene evolution rates over 28 days, and longer, and another report will be issued when that work is completed.

Background

Analyses of the liquid and vapor in Tank 50H have shown liquid benzene concentrations of $2-8 \mathrm{mg} / \mathrm{l}$ ard vapor benzene concentrations of $10-50 \mathrm{mg} / \mathrm{l}$. High Level Waste Engineering requested SRTC to determine the rate of benzene release-during saltstone curing, especially as - related to tetraphenylborate decomposition.

The amount of free benzene going to grout is much léss than the amount measured in Tank 50H due to inherent process losses.' Prior tests' sought to measure benzene evolution only from sodium tetraphenylborate. The current tests are measuring benzene evolution from potassium tetraphenyiborate and free benzene. Since potassium tetraphenylborate solubility is less than sodium tetraphenylborate solubility, the benzene evolution rates in the current tests will be lower than the raies in previous tests'.

Results.

A sample of Tank 50H salt solution was collected in January 1996 and used for these tests. Saltstcne samples were prepared containing 46 wt. \% salt solution, $5.4 \mathrm{wt} \%$ cement, $24.3 \mathrm{wt} . \%$ flyash, and $24.3 \mathrm{wt} \%$ slag. The saltstone was placed in a reaction kettle and the kettle sealed. Air was circulated through the reaction kettle at approximately $20 \mathrm{ml} / \mathrm{min}$ and passed through a charcoal filter as it exited to remove and collect any benzene which evolved. An additional sample was prepared using salt simulant rather than Tank $50 \mathrm{H}$ salt solution. 
W. B..Van Pelt :

The charcoal filters were changed after $4,7,11$, and 14 days, and submitted to ADS to determine the accumulation of benzene on the filter. Table 1 show's the results. The benzene evolution rates . ranged from 0.012 to $0.172 \mathrm{lg} / \mathrm{L} \mathrm{hr}$. Some scatter exists in the benzene evolution data. The reasons for the scatter are the difficulty in extracting the benzene from the charcoal filter and the small amount of benzene evolved during the test.

Table 1. Benzene Evolution Rates $3.4,5$

\begin{tabular}{|c|c|c|c|}
\hline Time (diays) & Salt Source* $^{*}$ & Benzene Collected & Benzene Evolution Rate \\
\hline $0-4$ & Simulant & $<0.1 \mu \mathrm{g}$ & $<0.026 u g / \mathrm{Lhr}$ \\
\hline $0-4$ & Tank 50H & $0.185 \mu \mathrm{g}$ & $0.048 \mu \mathrm{g} / \mathrm{Lhr}$ \\
\hline $0-4$ & Tank 50H & $0.130 \mu \mathrm{g}$ & $0.034 \mu \mathrm{g} / \mathrm{Lhr}$ \\
\hline $0-4$ & Tank 50H & $0.164 \mu \mathrm{g}$ & $0.041 \mu \mathrm{g} / \mathrm{Lhr}$ \\
\hline $4-7$ & Simulant : & $0.035 \mu \mathrm{g}$ & $0.012 \mu \mathrm{g} / \mathrm{Lhr}$ \\
\hline $4-7$ & Tank 50H & $0.061 \mu \mathrm{g}$. & $0.021 \mu \mathrm{g} / \mathrm{Lhr}$ \\
\hline $4-7$ & Tank 50H & $0.323 \mu \mathrm{g}$ & $0.110 \mu \mathrm{g} / \mathrm{Lhr}$ \\
\hline $4-7$ & Tank 50H & $0.487 \mu \mathrm{g}$ & $0.172 \mu \mathrm{g} / \mathrm{Lhr}$ \\
\hline $7-11$ & Simulant & $0.053 \mu \mathrm{g}$ & $0.013 \mu \mathrm{g} / \mathrm{Lhr}$ \\
\hline $7-11$ & Tank 50H & $0.256 \mu \mathrm{g}$ & $0.064 \mu \mathrm{g} / \mathrm{Lhr}$ \\
\hline $11-14$ & Simulant & $0.106 \mu \mathrm{g}$ & $0.037 \mathrm{Hg} / \mathrm{Lhr}$ \\
\hline $1-14$ & Tank 50H & $0.139 \mu \mathrm{g}$ & $0.049 \mu \mathrm{g} / \mathrm{Lhr}$ \\
\hline
\end{tabular}

* Benzene levels measured in Tank $50 \mathrm{H}$ were $2-8 \mathrm{mg} / \mathrm{L}$. The initial benzene in the grout was approximately $0.2 \mathrm{mg} / \mathrm{L}$ due to sample handling losses, which would be typical of losses in the 'Saltstone process.'

Figure 1 compares the benzene evolution rates in this test with the results from previous SRTC tests. ${ }^{1}$ The benzene evolution rates during the first 14 days of curing in the 1996 test are at or below the evolution rates measured in the previous test. In the previous test, the maximum benzene evolution rate occurred between 7 and 12 days after the curing started. ${ }^{1}$ Additional samples will be collected at 21 , and 28 days. These results will be reported when received.

\section{References}

1. S. B. Oblath, "Benzene Evolution During the Curing of Saltstone", DPST-86-645, September 2, 1986.

2. D. D. Walker, M. J. Bames, R. F. Swingle, and R. A. Peterson, "Recent Tetraphenylborate Decomposition Results",SRT-LWP-96-008, January 22, 1996

3. . J. E. Young, "Analysis Results; ADS 3-67987, -8, and -9", Inter-Office Memorandum, February.i6, 1996. (Attachment 1)

4. J.E. Young, "MRP Charcoal Tube Analysis", Inter-Office Memorandum, Febriary 13, 1996. (Attachment 2)

5. J. E. Young, “Orbo Tube Data”, Inter-Office Memorandum, February 26, 1996. (Attachment 3) 


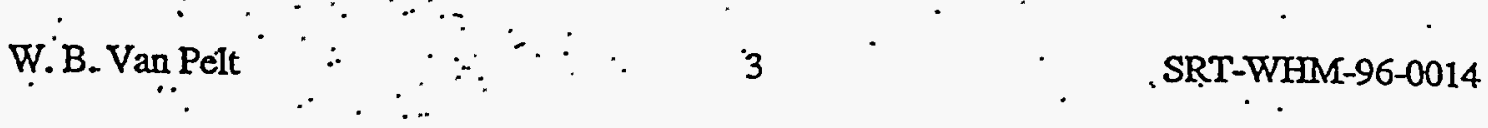

Figure 1. Benzene Evolution Rate During Saltstone Curing

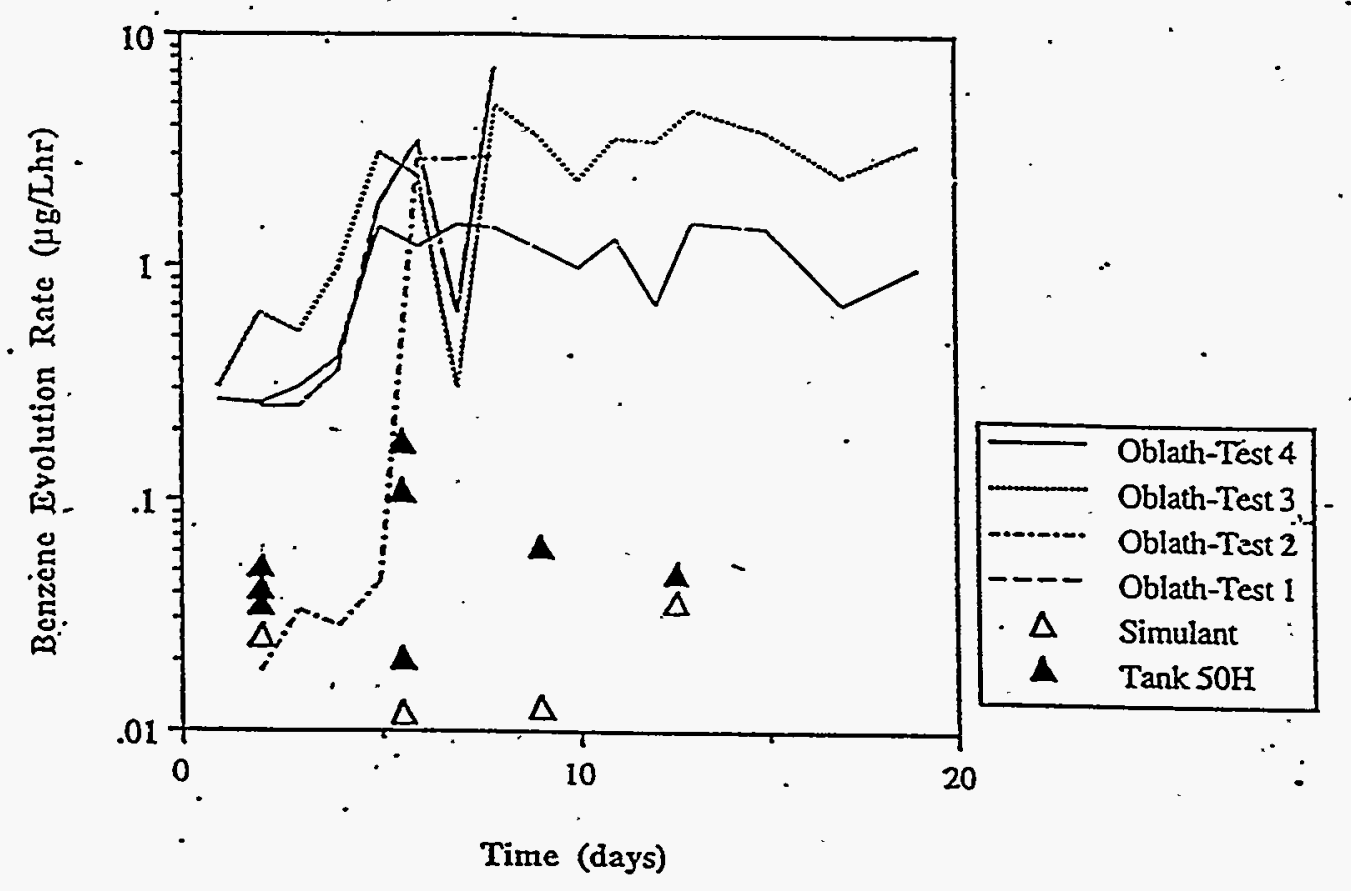

cc: W. L. Tamosaitis, 773-A

H. D. Harmon, 719-4A

S. D. Fink, 773-A

B. T. Butcher; 773-43A

B. G. Croley, 241-120H

J. R. Fowler, 704-Z

C. A. Langton, 773-43A

T. E. Britt, 730-2B .

T. D. Lookabill, 704Z

D. D. Walker, 773-A

M. K: Gupta, 730-2B

R. A. Peterson, 676-T

M. J. Barnes, 773-A

R. M. Satterfield, 719-4A

R. F. Swingle, 773-A

IWT File, 676-1T 
INTER-OFFICE MEMORANDUM

Savannah River Site

16-Feb-1996 09:21 Iam EST

To: Michael R Poinier (POIRIER-MR-Y5714@A1@SASRS5)

CC: Pamela K. Waller

CC: Jeffrey C. Griffin - (WALLER-PR-W2490 AT A1 AT SLSRPI) (GRIFFIN-JC-T8054 AT AI AT SLSRPI)

From: John E. Youing, ADS

Dept: Analytical Development $S$

Tel: (803) 725-3565

Analysis results; $\mathrm{ADS} 3-67987,-8$, and -9 [u] .

We have completed the analysis of your charcoal tube samples submitted on $2 / 15$.

The results are tabulated;

ADS\# Cust\# FileD ug benzene on tube

3-67987 MRP4 15el09. 0.0345

$\therefore$

3-67988 MRP5 $15 \mathrm{~d} 107 \quad 0.0613$

3-67989 MRP'́ $15 \mathrm{~d} 108 \quad 0.3230$

statistical method detection limit, prepared under ideal $0.15(1)$ conditions

(1) concentration at which $99 \%$ of analyses performed will generate à - detectable signal.

As you will note, the values are very close to the method detection limit. For best accuracy, and least influence from environmental contamination, at least 1 ug of benzene should be loaded onto the tube prior to analysis. It would be advised, if possible, to scale your experimients up accordingly. 
W. I. Tamosaitis

W. B. Van Pelt
WSRC-TR-96-0113

Attachment 2

SRT-WHM-96-0014

INTER-OFFICE MEMORANDUM

Savannah River Site

13-Feb-1996-11:40am EST

To: Michael R Poirier

CC: Pamela R. Waller

From: John E. Young, ADS

Dept: Analytical Development S

Tel : (803) 725-3565
(POIRIER-MR-Y5714 @A1@SASRS5)

(WALLER-PR-W2490 AT A1 AT SLSRP1).

(YOUNG-JE-T6035 AT AI AT SISRP1)

MRP charcoal tube analysis

Data is documented in WSRC-NB-94-62, p.159

\begin{tabular}{cccc} 
ADS\# & Cust ID & Benzene, ug on tube & TCE, ug on tube \\
\cline { 2 - 3 } $3-67535$ & MRP2 & 0.185 & 0.95 \\
$3-67536$ & MRP3 & 0.130 & 9.5 \\
$3-67537$ & MRP1 & $<0.1$ & 9.9
\end{tabular}

During the analysis of your samples, it was noted that a variety of compounds (other than benzene) were increasing throughout the ADS sequence number series. The compounds were mainly light freons and trichloroethene. Since trichloroethene is present in SRTC air from process water offgas, this data was coimputed and presented for your information.

Sample results were corrected for chemical recovery inefficiencies as measured from the chemical recovery of benzene and TCE on this same batch of charcoal tubes. 
W. B. Van Pelt

Attachment 3

INTER-OFFICE MEMORANDUM

Savaṇnah River Site

26-Feb-1996 10:59am EST

To: Michael R Poirier

(POIRIER-MR-Y5714 @A1@SASRS5 )

From: John E. Young, ADS

Dept: Analytical Development $S$

( (YOUNG-JE-T6035 AT A1 AT SLSRP1)

Tel : (803) 725-3565

ORBO tube data

ADS\# CustD Benzene, ug on tube

3-68240 MRP7 0.053

3-68241 MRP8 0.256

3-68242 MRP9 0.164

3-68258 MRP11 0.139

3-68259 MRP12 0.487

3-68260 MRP10 0.106

detection limit $\quad 0.150$

Please note the ordering difference between ADS\# sequence and MRP\# sequence in the last, batch. 
Appendix T. M. R. Poirier, "Benzene Evolution Rates During Curing of Saltstone Prepared with Tank 50 Salt Solution", SRT-WHM-96-0029.

Westinghouse Savannah River Company

Inter-Office Memorandum

SRT-WHM-96-0029

April 25, 1996

To: W. B. Van Pelt, 676-1T

From: M.R. Poirier, 676-T MRP

Benzene Evolution Rates During Curing of Saltstone Prepared with Tank 50 Salt Solution

Summary

High Level Waste Engineering requested SRTC to determine the rate of benzene release during saltstone curing. SRTC prepared saltstone with the January 1996 Tank $50 H$ sample, placed the salstone in a sealed reaction kettle; circulted air through the kettle, and passed the air through-a charcoal filter to collect benzene. The charcoal filters were analyzed to measure the benzene evolution rate.

Benzene evolution rates measured over 55 days ranged from 0.02 to $0.2 \mu \mathrm{g} / \mathrm{h} \mathrm{hr}$, which is below the rate measured in the 1985 tests. ${ }^{1}$ The maximum evolution rate occurred between four and seven days after the curing began.

Background.

Analyses of the liquid and vapor in Tank 50H have shown liquid benzene concentrations of 2-8 mg/ and vapor benzene concentrations of $10-50 \mathrm{mg} / \mathrm{L}^{2}$ High Level Waste Engineering - requested SRTC to determine the rate of benzene release during saltstone curing, especially as related to tetraphenylborate decomposition.

The amount of free benzene going to grout is:much léss than the amount measured in Tank $50 \mathrm{H}$ due to inherent process losses.' Prior tests ${ }^{2}$ sought to measure benzene evolution only from sodium tetraphenylborate. The current tests are measuring benzene evolution from potassium tetraphenylborate and free benzene. Since potassium tetraphenylborate solubility is less than sodium tetraphenyiborate solubility, the benzene evolution rates in the current tests will be lower than the rates in previous tests'.

Résults

A sample of Tank 50H sall solution was collected in Januaty 1996 and used for these tests. Saltstone samples were prepared containing 46 wt.\% sait solution, 5.4 wh\% cement, 24.3 wt\% flyash, and $24.3 \mathrm{wt} \%$ slag. The saltstone was placed in a reaction kettle and the kettle sealed. Air was circulated through the reaction kettle at approximately $20 \mathrm{ml} / \mathrm{min}$ and passed through a 
W. B. Van Pelt

2

SRT-WHIMI-96-0029

charcoal filter as it exited to remove and collect any benzene which evolved. An additional sample . was prepared using salt simulant rather than Tank 50H salt solution. .

- The charcoal filters were changed after $4,7,11,14,21,28,35$, and 55 days, and submitted to ADS to measure the accumulation of benzene on the filter. Table 1 shows the results. The benzene evolution rates ranged from 0.02 to $0.2 \mu \mathrm{g} / \mathrm{L} \mathrm{hr}$. Some scatter exists in the benzene evolution data. The reasons for the scatter are the difficulty in extracting the benzene from the charcoal filter and the small amount of benzene evolved during the test. -

Table 1. Benzene Evolution Rates $3.45,6.7,6.9$

\begin{tabular}{|c|c|c|c|c|}
\hline Time (days) & Salt Source* & Benzene Collected & Benzene Evolution Rate & $\underline{A D S} \#$ \\
\hline $0-4$ & Simulant . & $<0.1 \mu \mathrm{g}$ & $<0.026 \mu \mathrm{g} / \mathrm{Lhr}$ & $\frac{1407}{3-67537}$ \\
\hline $0-4$ & Tank 50H & $0.185 \mu \mathrm{g}$ & 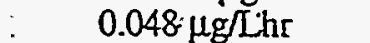 & $3-67535$ \\
\hline $0-4$ & Tank 50H & $0.130 \mu \mathrm{g}$ & $0.034 \mu \mathrm{g} / \mathrm{Lhr}$ & $3-67536$ \\
\hline $0-4$ & Tank 50H & $0.164 \mu \mathrm{g}$ & $0.041 \mu \mathrm{g} / \mathrm{Lhr}$ & $3-68242$ \\
\hline $4-7$ & Simulant & $0.035 \mu \mathrm{g}$ & $0.012 \mu \mathrm{g} / \mathrm{Lhr}$ & $3-67987$ \\
\hline $4-7$ & Tank 50H & $0.061 \mu g$ & $0.021 \mu \mathrm{g} / \mathrm{Lhr}$ & $3-67988$ \\
\hline $4-7$ & Tank 50H & $0.323 \mu \mathrm{g}$ & $0: 110 \mu \mathrm{g} / \mathrm{Lhr}$ & $3-67989$ \\
\hline $4-7$ & Tank 50H & $0.487 \mu \mathrm{g}$ & $0.172 \mu \mathrm{g} / \mathrm{Lhr}$ & 3-68259 \\
\hline $7-11$ & Simulant & $0.053 \mu \mathrm{g}$ & 0.013 بg/hr & $3-68240$ \\
\hline $7-11$ & Tank 50H & $0.256 \mu \mathrm{g}$ & $0.064 \mu \mathrm{\mu g} / \mathrm{Lhr}$ & $3-68241$ \\
\hline $7-14$ & Tank 50H & $0.513 \mu \mathrm{g}$ & $0.079 \mu \mathrm{g} / \mathrm{Lhr}$ & 8595 \\
\hline $11-14$ & Simulant & $0.106 \cdot \mu \mathrm{g}$ & $0.037 \mu \mathrm{g} / \mathrm{Lhr}$ & $3-68260$ \\
\hline $11-14$ & Tank 50H & $0.139 \mu \mathrm{g}$ & $0.049 \mu \mathrm{g} / \mathrm{Lhr}$ & 258 \\
\hline $14-21$ & Simulant & $0.127 \mu \mathrm{g}$ & $0.020 \mu \mathrm{g} / \mathrm{Lhr}$ & 60 \\
\hline $14-21$ & Tank 50H & $0.347 \mu g$ & $0.054 \mathrm{\mu g} / \mathrm{Lhr}$ & \\
\hline $14-.21$ & Tank 50H & $0.580 \mu \mathrm{g}$ & $0.084 \mathrm{\mu g} / \mathrm{Lhr}$ & 225 \\
\hline $21-28$ & Simulant & $0.122 \mu \mathrm{g}$ & $0.018 \mu \mathrm{g} / \mathrm{Lhr}$ & \\
\hline & Tank 50H & $0.322 \mu \mathrm{g}$ & $0.047 \mu g / \mathrm{Lhr}$ & \\
\hline $21-35$ & Tank 50H & $1.20 \mu \mathrm{g}$ & $0.089 \mu \mathrm{g} / \mathrm{Lhr}$ & $3-6$ \\
\hline & Tank 50H & $1.91 \mathrm{~kg}$ & $0.100 \mu \mathrm{g} / \mathrm{Lhr}$ & $3-71101$ \\
\hline
\end{tabular}

* Benzene levels measured in Tank $50 \mathrm{H}$ were $2-8 \mathrm{mg} / \mathrm{L}$. The initial benzene in the grout was approximately $0.2 \mathrm{mg} / \mathrm{L}$ due to sample handling losses, which would be typical of losses in the Saltstone process.'

Figure I compares the benzene evolution rates in this test with the results from previous SRTC tests.' The benzene evolution rates during 55 days of curing in the 1996 test are at or below the evolution rates measured in the previous test. In the previous test, the maximum benzene evolution .rate occurred between 7 and 12 days after the curing started. ${ }^{1}$ In this test, thie maximum evolution rate occurred between 4 and 7 days after the curing started.

\section{References}

1. S. B. Oblath, "Benzene Evolution During the Curing of Saitstone", DPST-86-645, September 2, 1986.

2. D. D. Walker, M. J. Bames, R. F. Swingle; and R. A. Peterson, "Recent Tetraphenylborate Decomposition Results"; SRT-LWP-96-008, January 22, 1996

3. J. E. Young, "Analysis Kesuits; ADS 3-67987:-8, and -9", Inter-Office Memorandum, February 16, 1996. (Attachment 1) 
W. B. Van.Pelt

3

4. J.E. Young, "MRP Charcoal Tube Analysis", Inter-Office Memorandum, February 13,

- 1996. (Attachment 2)

5. J.E. Young, “Orbo Tube Data”, Inter-Office Memorandum, February 26, 1996.

(Attachment 3)

6. J. E:Young, “Orbo Tube Data", Inter-Office Memorandum, March 1, 1996.

(Attachment 4).

7. . J. E. Young, "Orbo. Tube Analysis Results", Inter-Office Memorandum, March 11, 1996. (Attachment 6)

8. LIMS Report, Sample $\dot{\mathrm{D}}$ 300069886, March 27, 1996.

9. 'LIMS Report, Sample ID 300071101, April 24, 1996.

Figure 1. Benzene Evolution from Saltstone Prepared with Tank 50 Solution

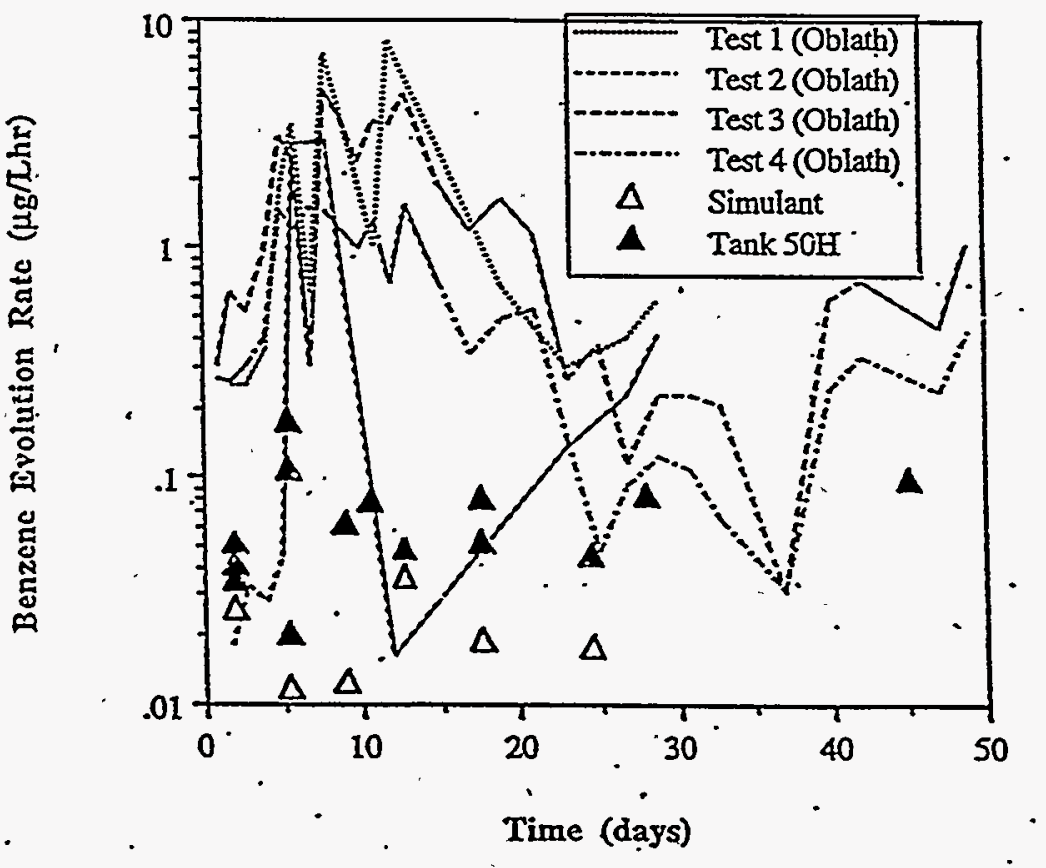

œ: W. L. Tamosaitis, 773-A

S. D.Fink, 773-A

H. D. Harmon, 719-4A

B. G. Croley, 241-120H

B. T. Butcher, 773-43A

C. A. Langton, 773-43A

J. R. Fowler, 704-Z

T. D. Lookabill, 704-Z

T. E. Britt, $730-2 B$

M. K. Gupta, 730-2B

D. D. Walker, 773-A

M. J. Bames, 773-A

R. A. Peterson, 676-T

R. M. Satterfield, 719-4A

S. R. Wilson, 704-28S

R. F. Swingle, 773-A

E. J. Frced, 704-Z

IWT File; 576-iT. 
W. B. Van Pelt

\section{Attachment 1}

INTER-OFFICE MEMORANDUM
Savannah River Site

16-Feb-1996 09:21am EST

To: Michael R Poirier

(POIRIER-MR-Y5714 @A1@SASRS5)

CC: Pamela R. Waller

CC: Jeffrey C. Griffin

(WẠLLER-PR-W2490 AT A1 AT SLSRPI)

(GRIFFIN-JC-T8054 AT AI AT SLSRP1)

From: John E. Young, ADS

Dept: Analytical Development $S$

(YOUNG-JE-T6035 AT AI AT SLSRP1)

Tel : (803) 725-3565 .

- Analysis results; ADS 3-67987,-8, and -9 [u]

We have completed the analysis of your charcoal tube samples submitted on

2/15.

The results are tabulated;

ADS\# Cust\# FileID ug benzene on tube

\begin{tabular}{ccc} 
3-67987 MRP4 & $15 \mathrm{el} 09$. & 0.0345 \\
\hline $3-67988$ MRP5 & $15 \mathrm{~d} 107$ & 0.0613 \\
\hline $3-67989$ MRP6 & $15 \mathrm{~d} 108$ & 0.3230
\end{tabular}

statistical method detection limit, prepared under ideal $\quad 0.15$ (1) conditions

(1) concentration at which $99 \%$ of analyses performed will generate a - detectable signal. $\because$

As you will note, the values are very close to the method detection limit. For best accuracy, and least influence from environmental contamination, at least 1 ug of benzene should be loaded onto the tube prior to analysis. It would be advised, if possible, to scale your experiments up accordingly. 
W. B. Van Pelt

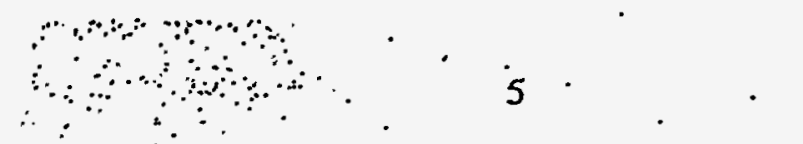

SRT-WHM-96-0029

Attachment 2

INTER-OFHCE 'MEMORANDDUM Savarinah River Site

13-Feb-1996 11:40am EST

To: Michael R Poirier

CC: Pánela R. Waller

(POIRIER-MR-Y5714@AI@SASRS5)

From: John E. Young, ADS

Dept: Analytical Development $S$

Tel : (303) 725-3565

MRP charcoal tube analysis

Data is documented in WSRC-NB-94-62, p.159

\begin{tabular}{|c|c|c|c|}
\hline ADS\# & Cust ID & Benzene, ug on tube & TCE, ug on tube \\
\hline $\begin{array}{l}3-67535 \\
3-67536 \\
3-67537\end{array}$ & $\begin{array}{l}\text { MRP2 } \\
\text { MRP3 } \\
\text { MRP1 }\end{array}$ & $\begin{array}{l}0.185 \\
0.130 \\
<0.1\end{array}$ & $\begin{array}{l}0.95 \\
9.5 \\
9.9\end{array}$ \\
\hline
\end{tabular}

During the analysis of your.samples, it was noted that a variety of compounds (other than benzene) 'were increasing throughout the ADS sequence number series. The compounds were mainly light freons and trichloroethene. Since trichloroethene is present in SRTC air from process water offgas, this data was computed and presented for your information.

Sample results were corrected for chemical recovery inefficiencies as measured from the chicmical recovery of benzene and TCE on this same batch of charcoal tubes. 
W. B. Van Pelt

$\therefore \quad \cdot \quad \cdot 6$

SRT-WHM-96-0029

\section{Attachment 3}

INTER-OFFICE MEMORANDUM Savannah River Site

26-F̈eb-1996 10:59am EST

To: Michaël R Poirier

(POIRIER-MR-YS714 @A1@SASRS5)

From: John E. Young, ADS

Dept: Analytical Development S

( YOUNG-JE-T6035 AT A1 AT SLSRP1)

Tel : (803) 725-3565

ORBO tube data

ADS\# Custm Benzene, ug on tube

$\begin{array}{lll}3-68240 & \text { MRP7 } & 0.053 \\ 3-68241 & \text { MRP8 } & 0.256 \\ 3-68242 & \text { MRP9 } & 0.164 \\ & & \\ 3-68258 & \text { MRP11 } & 0.139 \\ 3-68259 & \text { MRP12 } & 0.487 \\ \text { 3-68260 } & \text { MRP10 } & 0.106 \\ \text { detection limit } & 0.150\end{array}$

Please note the ordering difference between ADS\# sequence and MRP\# sequence in the last batch. 
$\because$

"W. B. Van Pelt $\quad$. . 7

SRT-WִWHM-9̣6-0029

\section{Attachment 4}

INTER-OFFICE MEMORANDUM

Savannah River Site

01-Mar-1996 11:12am EST.

To: Michael R Poirie:

(POIRIER-MR-Y5714.@A1@SASRS5)

From: John E. Young; ADS

Dept: Analytical Development S

(YOUNG-JE-T6035 AT A1 AT SLSRP1)

Tcl : (803) 725-3565 ...

orbo tube data

ADS\# CustiD\# Benzene, ug on tube

$\begin{array}{lll}3-68590 & \text { MRP13 } & 0.127 \text { (<PQL) } \\ 3-68594 & \text { MRP14 } & 0.347 \\ \text { 3-68595 } & \text { MRP15 } & 0.513\end{array}$

Practical quant limit 0.29 
W. I. Tamosaitis

$$
-T-8-
$$

WSRC-TR-96-0113

W. B: Van Pelt

\section{SRT-WHIM-96-0029}

\section{Attachment 5}

INTER-OFFICE MEMORANDUM

Savannah River Site

11-Mar-1996 08:50am EST

'To: Michael R Poirier

(POIRIER-MR-Y5714 @AI@SASRS5)

From: John E. Young, ADS

Dept: Analytical Development $S$

( YOUNG-JE-T6035 AT AI AT SLSRPI)

Tel : (803) 725-3565

ORBO tube analysis results

WSRC-NB-95-162 p.130

ADS\#3-69013; MRP17; - benzene $=0.322$ ug on tube

ADS\#3-69025; MRP18; benzene $=0.580$ ug on tube

ADS\#3-69026; MRP16; benzene $=0.122$ ug on tube $(<0.160)$

Statistically significant (1)

analyzed concentration benzene $=0.160$ ug on tube

level for this workup

(1) as determined by detection limit evaluation performed on $3 / 6 / 96$. 
Appendix U. M. R. Poirier, "TClP Benzene Results and Preliminary Benzene Generation Rates from Saltstone Prepared with the January 1996 Tank 50H Sample", SRT-WHM-96-0013, February 22, 1996.

February 22, 1996

To: B. T. Butcher, $773-43 \mathrm{~A}$

cc: W.L. Tamosaitis, 773-A.

W. B. Van Peit, 676-1T

J. R. Fowler, 704-Z

T.D. Lookabill, $704 Z$

T. E. Britt, $730-2 B$

M. K. Gupta, 730-2B

From: M. R. Poirier, 676-T MRP

TCLP Benzene Results and Preliminary Benzene Generation Rates from Saltstone Prepared with the January 1996 Tank 50H Sample

Summary

High Ievel Waste Engineering requested SRTC to determine the rare of benzene release during salistone curing and to determine whether the saltstone will pass the Toxic Characteriscic Leaching. Procedure (TCIP) test.

SRTC prepared saltstone with the January 1996 Tank SOH sample. The saltstone passed 7 and 14 day TCLP tests for benzene. A sample which was cured at $60^{\circ} \mathrm{C}$ for 14 days also passed the TCLP test for benzene, although the measured benzene concentration was $2-5$ imes higher than in the samples cured at room temperature. A 28 day TCLP test will be performed by a certified laboratory, and the results will be reported when recẹived.

Benzené generation rates measured after 4 days and 7 days ranged from 0.02 to $0.11 \mu g / L \mathrm{hr}$. Additional samples are being collected to measure benzene generation rates over 28 days, and another report will be issued when that work is completed.

Introduction

Analyses of the liquid and vapor in Tank 50H have shown liquid benzene concentrations of . 2-8 mol and vapor benzene concentrations of $10-50 \mathrm{mgh}$. High Level Waste Engineering requested SRTC to determine the rate oi berzene release during saltstone curing and to determine whether the saltstone prepared from the current contents of Tank 5OH will pass the TCLP test. 


\section{Results}

A sample of Tank 5OH salt solution was collected and used for these tests. Saltstone samples were prepared containing 46 wt.\% salt solution, 5.4 wt.\% ccment, 24.3 wt.\% flyash, and 24.3 wt.\% slag. The saltstone was placed in a reaction kettle and the kettle sealed. Air was circulated through the reaction kettle at approximately $20 \mathrm{ml} / \mathrm{min}$ and passed through a charcoal filter as it exited to remove and collect any benzone which evolved.

Two other Saitstone samples were prepared (by C. A Langton) with Tank 50H salt solution using the same saltstone mixture. One sample cured for 14 days, at ambient temperature in an open vessel, and the, other cured for 14 days in an oven at $60^{\circ} \mathrm{C}$.

After curing, the saltstone samples were collected, frozen in liquid nitrogen for six hours, and crushed. The samples $(2-2.5 \mathrm{~g})$ were placed in a zero-headspace extractor and extracted with acetic acid (TCLP results) or methanol ("Totals" results) for 18 hours.

Table 1 shows the resuits. ${ }^{2}$ : The benzene is well below the regulatory limits for Constituent Concentration in Waste Extract (TCLP) and Constituent Concentration in Waste ("Totals"). The benzene concentration in the TCLP extract ranged from $0.9-2.7 \mu \mathrm{g} / \mathrm{L}$, well below the regulatory limit of $500 \mu g / L$. The benzene in the "Totals" test ranged from $54-240 \mu \mathrm{g} / \mathrm{kg}$, well below the regulatory limit of $10,000 \mu \mathrm{g} / \mathrm{kg}$.

Table 1. Benzene TCLP Results

\begin{tabular}{lllll} 
Sample\# & TCLPResult & "Totals" Result & TCLPlimit & "Totals" limit \\
\hline 7 day ambient & $\frac{1.1 \pm 0.1 \mu \mathrm{g} / L}{54 \pm 13 \mu \mathrm{L} / \mathrm{kg}}$ & & $<500 \mu \mathrm{g} / \mathrm{L}$ & $<10,000 \mu \mathrm{g} / \mathrm{kg}$ \\
14 day ambient & $0.9 \pm 0.1 \mu \mathrm{g} / \mathrm{L}$ & $120 \pm 26 \mu \mathrm{g} / \mathrm{kg}$ & $<500 \mu \mathrm{L}$ & $<10,000 \mu \mathrm{g} / \mathrm{kg}$ \\
14 day $60^{\circ} \mathrm{C}$ & $2.7 \pm 0.1 \mu \mathrm{g} / \mathrm{L}$ & $240 \pm 5 \mu \mathrm{kg}$ & $<500 \mu \mathrm{g} /$ & $<10,000 \mu \mathrm{g} / \mathrm{kg}$
\end{tabular}

No significant difference in the TCLP benzene concentration was observed between the 7 day sample and the 14 day, ambient teinperature sample. When the curing temperature was increased to $60^{\circ} \mathrm{C}$, the TCLP benzene concentration increased by $2.5-3 \mathrm{X}$.

The "totals" benzene concentration measured in the 19 day, ambient sample was $\hat{2}-2.5 \mathrm{X}$ higher than in the 7 day sample. The "totals" benzene concentration in the 14 day, $60^{\circ} \mathrm{C}$ sample was $2 \mathrm{X}$ higher than in the 14 day ambient sample.

A Saltstone sample will be collected after 28 days, and submitted to a certified laboratory for a 28 day TCLP test. Those results will be reported when they are received.

The charcoal filters were changed after four days and seven days, and submitted to ADS to determine the accumulation of benzene on the filter. Table 2 shows the results. ${ }^{3,4}$ The benzene evolution rates ranged from 0.02 to $0.11 \mu \mathrm{g} / \mathrm{L} \mathrm{hr}$.

Table 2. Benzene Evolution Rates

\begin{tabular}{ll} 
Time (days) & Benzene Collected \\
\hline $0-7$ & $.185 \mu \mathrm{g}$ \\
$0-4$ & $.130 \mu \mathrm{g}$ \\
$4-7$ & $.061 \mu \mathrm{g}$ \\
$4-7$ & $.323 \mu \mathrm{g}$
\end{tabular}

- Benzene Evolution Rate $0.048 \mu \mathrm{g} / \mathrm{hr}$ $0.034 \mathrm{\mu g} / \mathrm{hr}$ $0.021 \mu \mathrm{g} / \mathrm{L} \mathrm{hr}$

$0.11 \mu \mathrm{g} / \mathrm{hr}$

Some scatter exists in the benzene evolution data. The reasons for the scatter are the difficulty in exiracting the benzene from the charcoal filter and the small amount of benzene evolved during the 
W. L. Tamosaitis

B. T. Butcher

$$
-\mathrm{u}-3-
$$

WSRC-TR-96-0113

test According to previous SRTC sest data, the maximum benzene evolution rate would be expocted between 7 and 12 days after the curing started ${ }^{5}$ Additional samples will be collected at $11,14,21$, and 28 days. These results will be reported when received.

\section{References}

1. D. D. Walker, M. J. Bames, R. F. Swingle, and R. A. Peterson, "Recent Tetraphenylborate Decomposition Restits", SRT-LWF-96-008, January 22, 1996

2. J. E. Young, "Total and TCLP Extractable VOA Analysis Results", SRT-ADS-96-0050, February 21, 1996. (Attachment 1)

3. 'J. E. Young, "Analysis Results; ADS 3-67987, -8, and -9", Inter-Office Memorandum, February 16, 1996. (Attachment 2)

4. J.E. Young, "MRP Charcoal Tube Analysis", Inter-Office Memorandum, February 13," 1996. (Altachment 3)

5. S. B. Oblath, "Benzene Evolution During the Curing of Saltstone", DPST-86-645, September 2, 1986. 
Attachment 1

INTER-OHFICE MEMORANDUM Savannah River Site

\section{1-Feb-1996 01:52pm EST}

To: See Below .

From: John E. Young, ADS

Dept: Analytical Development $S$

(YOUNG-JE-T6035 AT Al AT SLSRP1)

$\mathrm{Tel}:$ (803) 725-3565

Total and TCLP extractable VOA analysis results [u]

SRT-ADS-96-0060

Summary:

ADS has completed analyses in support of your program. The following data are presented in raw, unrounded values as measured from the sample preparation and analysis replicates. Statistical summary data is provided with each sample type, with the proper number of significant figures.

Regulatory classification:

Data is reported as Constituent Concentration in Waste (CCW) as "Total" and Constituent Concentration in Waste Extract (CCWE) as "TCLP", to provide nomenclature correlation with the EPA's Land Disposal Restriction regulations (LDR).

In general, TCLP values for benzene are used only to show that a solid waste is/is not a SCDHECIEPA regulated hazardous waste. For this purpose, a sample of the TCLP extract is tested for benzene at a regulatory limit of $0.5 \mathrm{mg} / \mathrm{L}$. This procedure (ICLP) was formerly referred to in the LDR as the the Constituent Concentration in the Waste Extract (CCWE).

The EPA's Land Disposal Regulations are applicable to determine if a regulated hazardous waste had been adequately treated for subsequent direct land disposal. The LDR regularory concentration for benzene is based on a "total" benzene measurement. The logic behind this regulatory classification is based on the fact that the reference technology, incineration, will destroy (rather than immobilize) the-organic constituents. The LDR limit for total benzene is expressed as the Constituent Concentration in the Waste (CCW), and is $10 \mathrm{mg} / \mathrm{kg}$.

The inorganic (metallic) constiments are regulated under the LDR as CCWE's because they are treated by immobilization, rather than destruction. Therefore, in the case of toxic metals, LDR compliance is based on the TCIP extract measurements.

Please note that these snalyses were pexformed by a laboratory that is not certified by the state of South Carolina for analyses required for specific permit analysis requirements. Generally, data that is required to be submitted to DHEC requires laboratory certification for the specific media. 
All reported data should be accompanied with this flag.

Experimental:

CCW - Totals: Total VOA's were determined by ultrasonication-assisted methanol extraction, as specified in ADS 2656, "Gas Chromatography/Mass Spectrometry for Volatile Orgarics - Contract Laboratory Program Method". Quantitation was performed using a custom developed selected ion monitoring mass spectrometric method. In this method, only the m/e of the ions of interest are monitored, which greatly increases sensitivity and signal to noise ratio.

The practical quantitation levels of the three compounds of interest were 25,600 , and $1500 u g / k g$ for benzene, 2-propanol, and n-butanol, respectiveiy (for this sample series preparative workup).

CCW - Total concentrations are listed in Table 1.

Table 1

analy'sis results, $\mathrm{CCW}$, constituent concentration in waste all results are in the units ug/kg (1)

\begin{tabular}{|c|c|c|}
\hline $\begin{array}{l}\text { ADS\# } \\
\text { ICust DD }\end{array}$ & 2-рторапоl & n-butanol \\
\hline $\begin{array}{l}3-68044 \quad 46.7 \\
\text { I Poirier-MRP3-A-total } 48.5\end{array}$ & ${ }_{1585}^{1636}$ & $\begin{array}{l}<1500 \\
<1500\end{array}$ \\
\hline $\begin{array}{l}3-68045 \quad 48.0 \\
\text { I Poirier-MRP3-B-total 72.8 }\end{array}$ & 1536835 & $\begin{array}{l}<1500 \\
<1500\end{array}$ \\
\hline \multicolumn{3}{|c|}{$\begin{array}{l}\text { MRP-3 summary; total benzene }=(54+1-13) \mathrm{ug} / \mathrm{kg} \\
\text { total } 2 \text {-propanol }=(1400+1-380) \mathrm{ug} / \mathrm{kg}\end{array}$} \\
\hline $\begin{array}{l}\text { 3-68046 Langton } \quad 135.3 \\
\text { l Langton-14D-STP-A-total }\end{array}$ & 1219 & $<1500$ \\
\hline $\begin{array}{lc}3-68047 & 105.9 \\
\text { ILangton-14D-STP-B-total }\end{array}$ & 707 & $<1500$ \\
\hline \multicolumn{3}{|c|}{$\begin{array}{l}\text { Langton } 14 \text { day room temp cure summary; } \\
\text { total benzene }=(120+/-26) \text { ug } / \mathrm{kg} \\
\text { total 2-propanol }=(960+/-450) \text { ug } / \mathrm{kg}\end{array}$} \\
\hline $\begin{array}{l}\text { 3-68048 } \\
\text { ILangton-14D-60D-A-total }\end{array}$ & 1569 & $<1500$ \\
\hline $\begin{array}{lc}3-68049 & 234.4 \\
\text { ILangton-1 } & \text { 4D-60D-B-total }\end{array}$ & 746 & $<1500$ \\
\hline \multicolumn{3}{|c|}{$\begin{array}{l}\text { Langton } 14 \text { day } 60 \text { degree cure summary; } \\
\text { total benzene }=(240+/-5) \text { ug } / \mathrm{kg} \\
\text { total } 2 \text {-propanol }=(1200+/-730) \text { ug } / \mathrm{kg}\end{array}$} \\
\hline
\end{tabular}


Notes:

(1) Land disposal restriction (LDR) regulatory concentrations are listed in the units of $\mathrm{mg} / \mathrm{kg}$, and should not be confused with the results listed here

CCWE - TCLP: Toxicity Characteristic Leaching Procodure (TCLP) preparative extractions were performed using a reduced scale zero headspace extractor (ZKHE). 2-2.5 gram samples of reduced particle size concrete were extracted for 18 hours in $0.1 N$ acetic acid. TCLP-extractable VOA's were measured using the same analysis method listed above for the total VOA's.

The practical quantitation levels of the three compounds of interest are $0.6,4$, and $38 \mathrm{ug} \pi$ for benzene, 2-propanol, and u-butanol, respectively (for this sample series preparative workup).

\section{Table 2}

analysis results, $\mathrm{CCWE}$, constituent concentration in waste extract, all results are in the units ug/L (1)

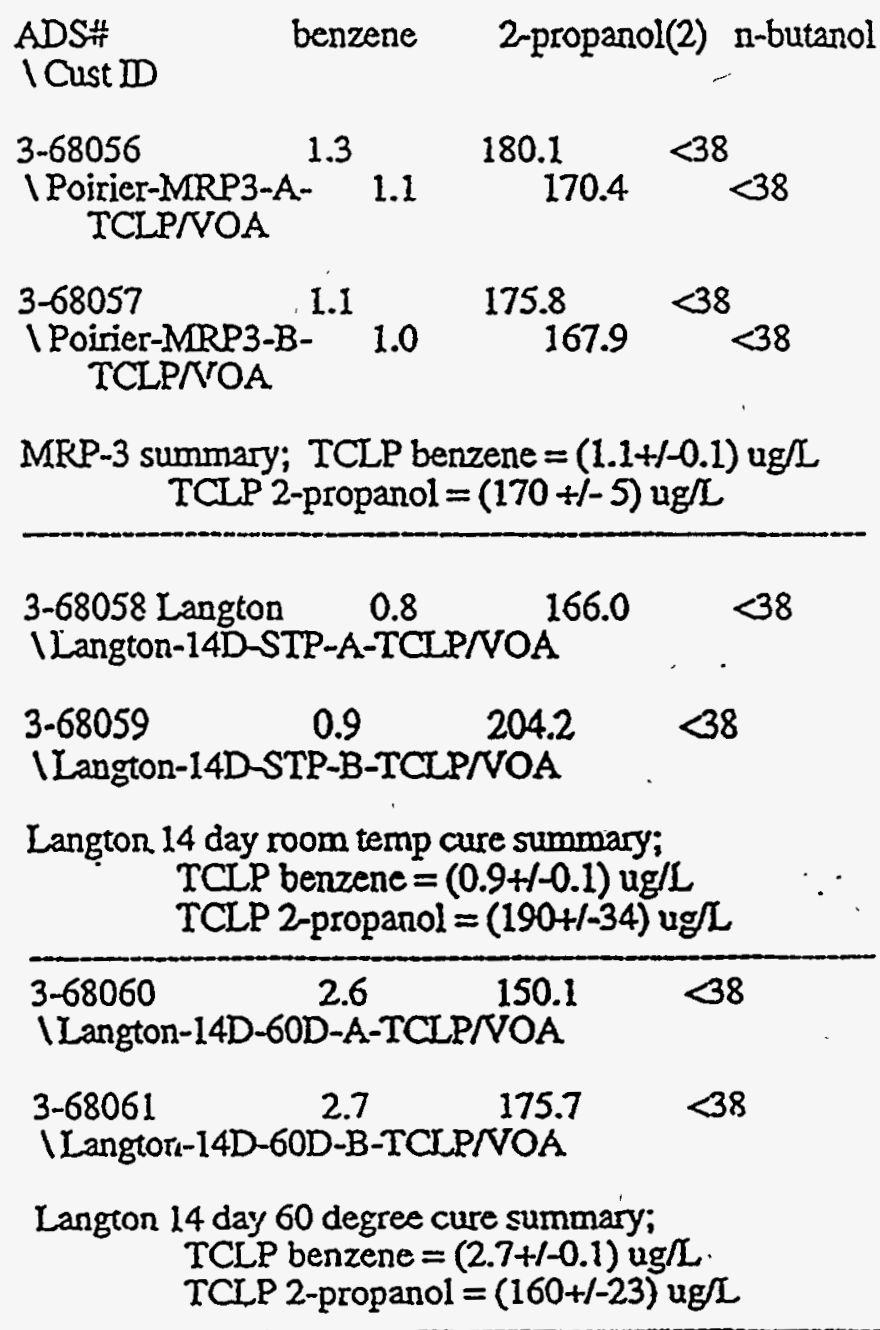


Notes:

(1) Land disposal restriction (LDR) regulatory concentrations are listed in the units of $\mathrm{mg} / \mathrm{L}$, and should not be confused with the results listed here.

(2) Follow-up preparative laboratory extraction blanks showed the extract to contain 2-propanol at 38 ug $\mathbb{L}$, and will positively bias analyses results. The observation is attributed to the popularity of isopropanol as a current solvent in commercial chemical products. 
Attachment 2

INTER-OPFICE MEMMORANDUM

Savannah River Site

16-Feb-1996 09:21 am EST

To: Michael R Poirier

(POIRIER-MR-YS714 @A1@SASRS5)

CC: Pamela $\mathrm{R}$. Waller

CC: Jeffrey C. Griffin!

(WAIIER-PR-W2490 AT AI AT SLSRP1)

(GRIFFIN-JC-T8054 AT AI AT SLSRP1)

From: John 2 . Young, ADS

Dept: Analytical Development $S$

(YOUNG-JE-T6035 AT Al AT SLSRP1)

Tel : (803) 725-3565

Analysis results; ADS 3-67987,-8, and -9 [u]

We have completed the analysis of your charcoal tube samples submitted on $2 / 15$.

The results are tabulated;

ADS\# Cust\# FileDD ug benzene on tube

3-67987 MRP4 15el09 0.0345

3-67988 MRP5 $15 \mathrm{~d} 107 \quad 0.0613$

3-67989 MRP6 $15 d 108 \quad 0.3230$

statistical method detection

limit, prepared under ideal 0.15 (1) conditions

(1) concentration at which $99 \%$ of analyses performed will generate a detectable signa!.

As you will note, the values are very close to the method detection limit For best accuracy, and least influence from ervironmental contamination, at least $1 \mathrm{ug}$ of benzene should be loaded onto the tube prior to analysis.

It would be advised, if possible, to scale your experiments up accordingly. 
B. T. Butcher

Attachment 3

INTER-OFFICE MEMORANDUM

Savannah River Site

13-Feb-1996 11:40am EST

To: Michael R Poirier

(POIRIER-MR-YS714 @A1@SASRS5)

CC: Pamela R. Waller

(WAILER-YR-W2490 AT AI AT SISRP1)

From: John E. Young, ADS

Dept: Analytical Devalopment $S$

(YOUNG-IE-T6035 AT A.l AT SLSRP1)

Tel : (803) 725-3565

MRP charcoal tube analysis

Data is documented in WSRC-NB-94-62, p.159

\begin{tabular}{llll} 
ADS\# & Cust ID & Benzene, ug on tube & TCE, ug on tube \\
\hdashline $3-67535$ & MRP2 & 0.185 & 0.95 \\
$3-67536$ & NRRP3 & 0.130 & 9.5 \\
$3-67537$ & MRP1 & $<0.1$ & 9.9
\end{tabular}

During the analysis of your samples, it was noted that a variety of compounds (other than benzene) were increasing throughout the ADS sequence number series. The compounds were mainly light freons and trichloroethene. Since trichloroethene is present in SRTC air from process water offgas, this data was computed and presented for your information.

Sample results were corrected for chemical recovery inefficiencies as measured from the chemical recovery of benzene and TCE on this same batch of charcoal tubes. 
Appendix V. C. A. Langton "Saltstone TCLP Results Versus Curing Time and Initial Benzene Concentration (U)", SRTC-WED-96-0163, February 27, 1996.

WESTINGHOUSE SAVANNAH RIVER .COMPANY

SAVANNAH RIVER TECHNOLOGY. CENTER

SRTC-WED-96-0163

February 27, 1996

To: $\quad$ B. T. Butcher, $773-43 \mathrm{~A}$

From: C. A. Langton, $773-43 A$

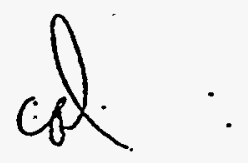

Saltstone TCLP Results Versus Curing Time and Initial Benzene Concentration (U)

Summary

Saltstone samples which were prepared with salt solution collected from Tank 50 in mid January, 1996 and cured for 14 and 28 days passed the TCLP test for benzene. The saltstone production runs from December, 1995 were also non hazardous. Saitstone made with early 1996 Tank 50 solution is expected to be non hazardous. Based on these results Saltstone production can be resumed. Results are summarized in Table 1.

\section{Results}

Saltstone samples collected from the Z-Area production runs on December 5 , : 12 , and 18 were. cured from 44,50 , and 57 days, respectively, before being subjected to the TCLP extraction test for benzene. These samples were made with salt solution containing relatively high concentrations of benzene, 6 to 8.5 $\mathrm{mg} / \mathrm{L}$, and tetraphenyl borate concentrations of $295+1-135 \mathrm{mg} / \mathrm{L}$. The TCLP results for benzene extracted from the December samples ranged from 12.4 to $15.4 \mu \mathrm{gil}=$. (SRTC-LWP-96-019) The TCLP limit for benzens is $500 \mu \mathrm{g} / \mathrm{L}$.

In order to determine whether the salt solution currently in Tank 50 will result in non hazardous saltstone, i.e., pass the TCLP test for benzene, laboratory samples were prepared at SRTC with solution collected in mid January, 1996. 
Results indicate that the solution contained $2.3+1-0.8 \mathrm{mg} / \mathrm{L}$ benzene and $295+l-$ $135 \mathrm{mg} / \mathrm{L}$ 'tetraphenyl borate. (The January sample had about $4 \mathrm{x}$ less benżene than did the December sample.) TCLP results for benzene extracted from these saltstone samples after 14 and 28 days curing at. ambient temperature - were $1+1-0.1 \mu \mathrm{g} / \mathrm{L}$. This is well below the TCLP limit. TCLP. results for Saltstone cured for 14 and 28 days at $60^{\circ} \mathrm{C}$ were $2.7+1-0.1$ and $4.7+1-0.2 \mu \mathrm{g} / \mathrm{L}$, respectively, which is also well below the limit for benzene.

The January Saltstone samples resulted in TCLP values about $5 x$ less than the December samples. This corresponds to less benzene in the Tank 50 Solution in january 1996 versus December 1995.

In addition the total benzene concentrations in the saltstone samples after 7 , 14 and 28 days curing were $54+1-13,120+1-26,90+1-8 \mu \mathrm{g} / \mathrm{kg}$, respectively. After 14 and 28 days curing at $60^{\circ} \mathrm{C}$ the total concentration of benzerie in the saltstone was $240+1-5,360+1-24 \mu \mathrm{g} / \mathrm{kg}$, respectively. Since the -total concentration of benzene in the samples is below the TCLP limit there is no question that these samples pass the regulatory requirements. Firially a comparison of the amount of benzene extracted versus the total benzene present in the samples indicates that saltstone retains 64 to $86 \%$ of the total benzene (14-36\% is extracted in the TCLP test.) The worst case for this comparison is the sample cured for 7 days at ambient temperature; $64 \%$ of the benzene was retained in the saltstone. (SRT-ADS-96-0060)

\section{Discussion}

Analytical 'results for benzene in liquiid and especially solid samples is very sensitive to sample handling. Saltstone samples prepared for TCLP extractions in SRTC were-frozen in liquid nitrogen to minimize benzene loss during crushing. The crushed material was transferred into the zero-head extractor in less than three minutes, again to minimize benzene losses i.e., maximize the amount available for extraction.

SRTC-ADS personnel follow protocols for analyses and documentation in

- accordance with the RCRAVCERCLA requirements. SRTC/IWT and Saltstone personnel use the ADS laboratory to complement results obtained from a SC DHEC certified laboratory. ADS has the capability of providing very quick response and special attention for samples which are not routine. To date SRTC-ADS results and certified vendor results have been consistent for all types of TCLP analyses requested. The ADS detection limit and quantitation limit for benzene are better than the RCRAVCERCLA requirement. An example of using these two analytical services in parallel is illustrated in the TCLP-Hg results in WSRC-RP-95-835. 


\section{Recommendations}

- Resume Saltstone production based on 14 day TCLP results.

- Follow up on proposed changes in the LDR regulations and their impact on Saltstone. 
Táble 1: Summary of TCLP Data for Saltstone Cured for 7 to 57 days. . . Tank 50 Analyses*

Curing Conditions TCLP Benzene

Tank50 Sample Benzene TPB . Saltstone Time Temp - Results Limit

Date Collected $\mathrm{mg} / \mathrm{L}$. $\mathrm{mg} / \mathrm{L} \cdot$. Preparation (days) $\cdot\left({ }^{\circ} \mathrm{C}\right)$

\begin{tabular}{|c|c|c|c|c|c|c|c|}
\hline December, 1995 & $5-8.5$ & $<160-431$ & $\begin{array}{l}\text { Z-Area } \\
\text { Production } \\
\text { Runs }\end{array}$ & $44-57$ & $23+/-1$ & $\begin{array}{c}12.1-15.4 \\
\text { SRT-ADS-96-0060 }\end{array}$ & 500 \\
\hline $\begin{array}{l}\text { January 15-31, } \\
1996\end{array}$ & $1.50-2.3$ & $\begin{array}{c}<160-431 \\
\cdots\end{array}$ & $\begin{array}{l}\text { SRTCITT } \\
\text { Laboratory } \\
\text { Samples }\end{array}$ & 14 & $23+/-1$ & $\begin{array}{c}0.9+/-0.1 \\
\text { SRT-ADS-96-0034 }\end{array}$ & 500 \\
\hline $\begin{array}{l}\text { January 15-31, } \\
1996\end{array}$ & $1.50-2.3$ & $<160-431$ & $\begin{array}{l}\text { SRTCIWT } \\
\text { Laboratory } \\
\text { Samples }\end{array}$ & 14 & $60+1-2$ & $\begin{array}{r}2.7+/-0.1= \\
=-\end{array}$ & 500 \\
\hline $\begin{array}{c}\text { January } 15-3 i, \\
1996\end{array}$ & $\begin{array}{l}1.50-2.3 \\
:\end{array}$ & $\begin{array}{r}<160-431 \\
\because\end{array}$ & $\begin{array}{l}\text { SRTCiTWT } \\
\text { Laboratory. } \\
\text { Samples }\end{array}$ & 28 & $23+1-1$ & $1.0+1 \_0.01$ & 500 \\
\hline $\begin{array}{c}\text { January } 15-31 \\
1996\end{array}$ & $1.50-2.3$ & $<160-431$ & $\begin{array}{l}\text { SRTCITT } \\
\text { Laboratory } \\
\text { Samples }\end{array}$ & $28^{\circ}$ & $60+1-$ & $4.7+1-0.2$ & 500 \\
\hline
\end{tabular}

* ITP Laboratory Results 


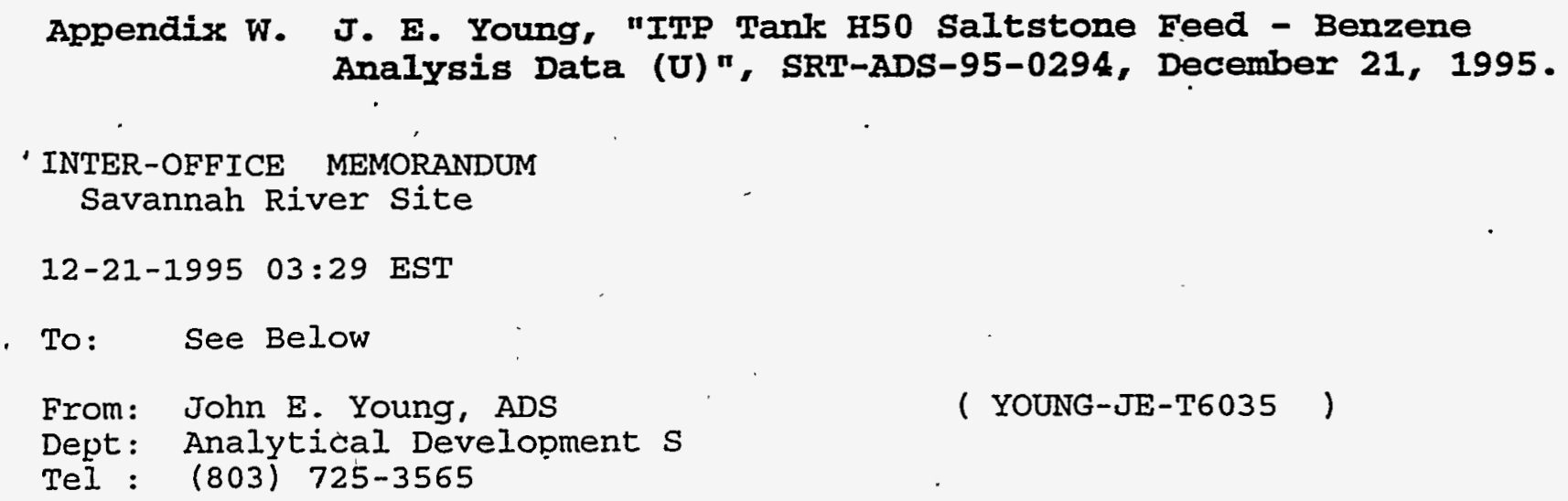

ITP Tank H50 Saltstone Feed - Benzene Analysis Data [u]

SRT-ADS-95-0294

ADS has completed analysis of your sample submission batch received on $11 / 20$ at approximately 10 PM.

Prior to sample analysis, instrument calibration verification was performed by the analysis of four replicate determination of benzene calibration standards obtained from two separate sources. All of the standard values were within QC startup specifications. QC data are listed below.

Blank verification was performed using boiled distilled water. No benzene (<10ppb) was detected in the blank water.

ADS laboratory tracking ID numbers have not yet been assigned, so the results are listed by ITP ID\#.

Customer ID Benzene, $\mathrm{mg} / \mathrm{I}$ (ppm) Report value

\begin{tabular}{|c|c|c|}
\hline ITP-219 & $\begin{array}{l}9.28 \mathrm{mg} / \mathrm{I} \\
8.63 \mathrm{mg} / \mathrm{I}\end{array}$ & $(9.0+/-0.6) \mathrm{mg} / \mathrm{l}$ \\
\hline ITP -220 & $\begin{array}{l}8.76 \mathrm{mg} / \mathrm{l} \\
9.06 \mathrm{mg} / \mathrm{l}\end{array}$ & $(8.9+/-0.3) \mathrm{mg} / \mathrm{l}$ \\
\hline z-saltstone & $\begin{array}{l}3.22 \mathrm{mg} / \mathrm{I} \\
3.21 \mathrm{mg} / \mathrm{l}\end{array}$ & $(3.2+/-0.01) \mathrm{mg} / 1$ \\
\hline
\end{tabular}

Incertainty is calculated by the range between duplicates $f 1.128$, per Standard Methods, 17th ed., 1-15.

Startup Calibration Verification QC Data

Standard ID Benzene, ug/I (ppb) \% of actual .

within CLE Iimits (I)

Ca]. Chk 100

95.1

Cal Chk 50

51.2 
Cal Chk 50

- Cal Chk 100

48.4

92.0

$<10 \cdot(0.2)$
$96.8 \%$

$92.0 \%$

NA yes

yes

yes

(1) CLP - Contract Laboratory Program, QC requirements for CERCLA site evaluation protocol.

Distribution:

To: A. Scott Plummer

CC: SAM D. FINK

CC: Bill Van pelt

CC: Keimpe Andringa

CC: Jeffrey C. Griffin

CC: Dana E. Lott

CC: CJ COLEMAN

CC; ADS Record File

CC: WOODIE I. MELTON

CC: Kathy $W$. Johns

CC: Timothy C. Balighman
( PLUMMER-AS-09639 @A1@SASRS5 )

( FINK-SD-T8302)

( VANPELT-WB-07016 @AI@SASRS2)

( ANDRINGA-K-T6141)

( GRIFFIN-JC-T8054")

( LOTT-DE-W7085 @A1@SASRS2 )

( COLEMAN-CJ-T5180)

( DIAMOND-SA-Y6955):-

( MELTON-WL-08975 @A1@SASRS2)

( JOHNS-KW-08091 @AI@SASRS2 )

( BAUGHMAN-TC-I5076 @AI@SASRS2) 


\section{Appendix X. M. A. Schmitz, "NaTPB Analysis" (U), Inter-Office memorandum, January 14, 1996.}

INTER-OFFICE MEMORANDUM Savannah River Site

01-14-1996 14:39 EST

To: See Below

From: Mark A. Schmitz

Dept: NMPD

( SCHMITZ-MA-06036 AT AI AT SASRSO)

Tel : 208-2666; Fax 8-1462

\section{NaTPB Analysis}

My laboratory notebook contains data on grab samples taken from all containers of NaTPB received between August 1982 and January 1983. There were a total of 272 containers and I believe everything used in the Demo was taken from those drums. (My memory tells me most of the containers were 40 gallon fiber drums or 55 galion metal drums and containing 100 to $2001 \mathrm{bs}$ of material.) The majority of the material was provided by Boulder Scientific Company, but Raylo and AFF were large contributors. My records have the following for each container:

My Number: 1-272

Supplier Name: Boulder Scientific, Raylo, AFF, or Noah (Preiser Scientific) Purity Requested: 95 or 99\%

Vendor Lot No.

Receipt Date at SRP

Lab Date Acceptance (Date TNX Lab pulled grab sample)

ADD Submittal Date

ADD Lab Submittal No.

Drum Weight

Weight Loss \%

Analytical purity-\%NaTPB (as measured by SRI)

Composite Group (explained below)

High Level Cave DF (explained below)

Manufacturer Analysis-\%NaTPB

The grab samples were assembled into composites identified as $A$ through $M$. Vendors were not mixed. Each composite was used in a precipitation and filtered with Lien-Mow Lee's High Level Cave cross flow filter. I do not have the DF results, only the date that the composites were submitted.

Keep in mind, the bulk of the material used in the Demo came from Boulder and Raylo, then AFF, then Naoh. All of the material was shipped in solid form to AFF, who put the NaTPB into solution. The 0.5 Molar solution was then transported by tanker truck to SRP for use in the Demo.

If you have questions, please contact me at 8-2666.

Distribution:

To: Lester L Kilpatrick 